\title{
Functional genomics in atherosclerosis : focus on cathepsin K
}

Citation for published version (APA):

Lutgens, S. P. M. (2007). Functional genomics in atherosclerosis : focus on cathepsin K. [Doctoral Thesis, Maastricht University]. Datawyse / Universitaire Pers Maastricht. https://doi.org/10.26481/dis.20071019sl

Document status and date:

Published: 01/01/2007

DOI:

10.26481/dis.20071019s|

Document Version:

Publisher's PDF, also known as Version of record

\section{Please check the document version of this publication:}

- A submitted manuscript is the version of the article upon submission and before peer-review. There can be important differences between the submitted version and the official published version of record.

People interested in the research are advised to contact the author for the final version of the publication, or visit the DOI to the publisher's website.

- The final author version and the galley proof are versions of the publication after peer review.

- The final published version features the final layout of the paper including the volume, issue and page numbers.

Link to publication

\footnotetext{
General rights rights.

- You may freely distribute the URL identifying the publication in the public portal. please follow below link for the End User Agreement:

www.umlib.nl/taverne-license

Take down policy

If you believe that this document breaches copyright please contact us at:

repository@maastrichtuniversity.nl

providing details and we will investigate your claim.
}

Copyright and moral rights for the publications made accessible in the public portal are retained by the authors and/or other copyright owners and it is a condition of accessing publications that users recognise and abide by the legal requirements associated with these

- Users may download and print one copy of any publication from the public portal for the purpose of private study or research.

- You may not further distribute the material or use it for any profit-making activity or commercial gain

If the publication is distributed under the terms of Article $25 \mathrm{fa}$ of the Dutch Copyright Act, indicated by the "Taverne" license above, 
Functional genomics in atherosclerosis:

focus on cathepsin $\mathrm{K}$ 
ISBN 978-90-5278-653-7

(C) Copyright SPM Lutgens, Maastricht 2007 


\title{
Functional genomics in atherosclerosis: focus on cathepsin $\mathrm{K}$
}

\author{
PROEFSCHRIFT \\ ter verkrijging van de graad van doctor aan de Universiteit Maastricht, \\ op gezag van de Rector Magnificus, prof. mr. G.P.M.F. Mols \\ volgens het besluit van het College van Decanen, \\ in het openbaar te verdedigen op vrijdag 19 oktober om 14.00 uur \\ door \\ Suzanne Paulina Maria Lutgens \\ geboren op 27 december 1979 te Sittard
}

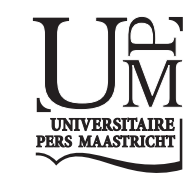




\section{PROMOTOR}

Prof. dr. M.J.A.P. Daemen

\section{COPROMOTORES}

Dr. K.B.J.M. Cleutjens

Dr. S. Heeneman

\section{BEOORDELINGSCOMMISSIE}

Prof. dr. M.P. van Dieijen-Visser (voorzitter)

Prof. dr. Th.J.C. van Berkel (Universiteit Leiden)

Prof. dr. A.C. Newby (Bristol Heart Institute, United Kingdom)

Prof. dr. J. Waltenberger

Dr. M.P.J. de Winther

Financial support by the Netherlands Heart Foundation for the publication of this thesis is gratefully acknowledged. The study described in this thesis was supported by a grant of the Netherlands Heart Foundation (NHF-2002B033). Also Organon NV, Sanquin, Pfizer BV, Clindia Benelux BV, BD Biosciences, and MSD BV are gratefully acknowledged for their financial support. 


\section{Contents}

Chapter 1 General introduction 7

Chapter 2 Cathepsin cysteine proteases in cardiovascular disease 15

Chapter 3 Disruption of the cathepsin K gene reduces atherosclerosis progression and induces plaque fibrosis but accelerates macrophage foam cell formation 43

Chapter 4 Gene profiling of cathepsin K deficiency in atherogenesis: profibrotic but lipogenic 67

Chapter 5 Pharmacologic inhibition of cathepsin K: extracellular matrix degrading effects do not coincide with lipogenic effects $\quad 87$

Chapter 6 Cathepsin $\mathrm{K}$ gene disruption does not affect murine aneurysm formation 101

Chapter 7 A new functional genomics approach to identify soluble mediators of atherosclerotic plaque stabilization 113

Chapter 8 General discussion 133

Summary 149

Samenvatting 152

Dankwoord 155

Curriculum Vitae 159 


\section{List of abbreviations}

\begin{tabular}{|c|c|}
\hline 2-DE & two-dimensional gel electrophoresis \\
\hline AAA & abdominal aortic aneurysm \\
\hline ADAM & a desintegrin and metalloproteinase \\
\hline APC & antigen presenting cell \\
\hline apo & apolipoprotein \\
\hline apoA-1 & apolipoprotein A-1 \\
\hline apoB-100 & apolipoprotein B-100 \\
\hline apoE & apolipoprotein E \\
\hline bFGF & basic fibroblast growth factor \\
\hline catK & cathepsin $\mathrm{K}$ \\
\hline CLIP & class II-associated invariant chain peptide \\
\hline CRP & C-reactive protein \\
\hline EC & endothelial cell \\
\hline ECM & extracellular matrix \\
\hline EPC & endothelial progenitor cell \\
\hline ER & endoplasmic reticulum \\
\hline FACS & fluorescence-activated cell sorting \\
\hline HDL & high density lipoprotein \\
\hline HUVEC & human umbilical venous endothelial cell \\
\hline ICE & interleukin- $1 \beta$ converting enzyme \\
\hline IFN- $\gamma$ & interferon $\gamma$ \\
\hline Ii & invariant chain \\
\hline IL-10 & interleukin 10 \\
\hline IL-1 $\beta$ & interleukin $1 \beta$ \\
\hline IL-6 & interleukin 6 \\
\hline LCM & L929 cell conditioned medium \\
\hline LCM & laser capture microdissection \\
\hline LDL & low density lipoprotein \\
\hline LTBP1 & latent TGF- $\beta$ binding protein-1 \\
\hline MHC & major histocompatibility complex \\
\hline MMP & matrix metalloproteinase \\
\hline МФ & macrophage \\
\hline MS & mass spectrometry \\
\hline NIRF & near infrared fluorescence \\
\hline PBMC & peripheral blood mononuclear cell \\
\hline PBS & phosphate-buffered saline \\
\hline PCR & polymerase chain reaction \\
\hline PMA & phorbol 12 -myristate 13 -acetate \\
\hline siRNA & silencing RNA \\
\hline SMC & smooth muscle cell \\
\hline SPARC & secreted protein, acidic and rich in cysteine \\
\hline SR & scavenger receptor \\
\hline TGF- $\beta$ & transforming growth factor $\beta$ \\
\hline TIMP & tissue inhibitor of MMP \\
\hline TNF- $\alpha$ & tumor necrosis factor $\alpha$ \\
\hline VEGF & vascular endothelial growth factor \\
\hline
\end{tabular}




\section{Chapter 1 \\ General introduction}




\section{ATHEROSCLEROSIS}

In western society, cardiovascular disease is the principal cause of death. In 2005, $31.8 \%$ of all causes of death could be attributed to cardiovascular diseases in the Netherlands (Centraal Bureau voor de Statistiek, Voorburg/Heerlen, The Netherlands). Clinically, these cardiovascular diseases are mainly manifested by ischemic heart diseases and stroke, for which, in the majority of cases, atherosclerotic plaque rupture and subsequent formation of an occluding thrombus on the surface of the atherosclerotic plaque can be held responsible. Healthy arteries consist of three different layers: the intima, formed by a small layer of extracellular matrix (ECM) and covered by an endothelial monolayer; the media, formed by elastic lamina and smooth muscle cells (SMC) interspersed between these elastic fibers; and the adventitia, consisting of connective tissue, fibroblasts and SMCs. During the initiation phase of atherosclerosis, hemodynamic forces at preference sites (branch points) act on the endothelial layer leading to increased permeability of the endothelium to lipoproteins, upregulation of leukocytes and endothelial adhesion molecules, and induction of leukocyte migration into the arterial wall. During fatty streak formation, adherent monocytes migrate into the subendothelial space and differentiate into macrophages. When low density lipoproteins (LDL) become trapped in the arterial wall, they can undergo oxidation and can be internalized by macrophages via scavenger receptors, such as CD36, leading to foam cell formation. As the lesion progresses, lymphocytes and macrophages are stimulated to secrete both pro-inflammatory cytokines, among which interleukin-6 (IL-6), interferon- $\gamma$ (IFN- $\gamma$ ), IL-1 and tumor necrosis factor $\alpha(\mathrm{TNF}-\alpha)$, and anti-inflammatory cytokines, among which IL-10 and transforming growth factor- $\beta$ (TGF- $\beta$ ). Migrated SMCs proliferate and secrete ECM proteins that form a fibrous cap. This fibrous cap covers a mixture of leukocytes, lipid and debris, leading to the formation of a necrotic core and accumulation of extracellular lipid. Inflammatory cytokines activate macrophages and induce them to undergo programmed cell death (apoptosis). Consequently, defective phagocytic clearance of apoptotic macrophages promotes secondary necrosis, inflammation and thrombosis. During the final stage of atherosclerosis, thinning of this fibrous cap results from ECM degradation by proteolytic enzymes, such as matrix metalloproteinases (MMPs) and cathepsins, secreted by macrophages. Weakening of this thin fibrous cap can lead to plaque rupture which exposes blood components to tissue factor. This leads to initiation of coagulation, adherence of platelets, and formation of a thrombus. Finally, the artery may occlude which is responsible for many of the clinical symptoms of atherosclerosis (reviewed in ${ }^{1-5}$ ). 
Atherosclerotic lesions can be morphologically classified ${ }^{6}$. In this morphological classification, atherosclerotic plaques are classified as an early or an advanced lesion. We further subdivided the advanced lesions into stable lesions and lesions containing a thrombus. The group of early lesions contains the following: 1. intimal thickening (the normal accumulation of SMCs in the intima in the absence of lipid or macrophage foam cells), 2. intimal xanthoma or 'fatty streak' (luminal accumulation of foam cells without a necrotic core or fibrous cap), and 3. pathological intimal thickening (SMCs in a proteoglycan-rich matrix with areas of extracellular lipid accumulation without necrosis). The group of stable lesions contains 1. fibrous cap atheroma (well-formed necrotic core with an overlying fibrous cap), 2. thin fibrous cap atheroma (a thin fibrous cap infiltrated by macrophages and lymphocytes with rare SMCs and an underlying necrotic core), and 3. fibrocalcific plaque (collagen-rich plaque with significant stenosis usually containing large areas of calcification with few inflammatory cells; a necrotic core may be present). The third group oflesions contains 1. ruptured lesions (disrupted fibrous cap and a thrombus that is in contact with the necrotic core), 2. lesions that show erosion (presence of a thrombus without signs of rupture), and 3. lesions showing intraplaque hemorrhage.

\section{ATHEROSCLEROSIS RESEARCH FROM SEVERAL PERSPECTIVES}

Since most of the clinical manifestations of atherosclerosis are initiated when a plaque becomes unstable and ruptures, it is important to gain more insight into the molecular mechanisms underlying the transition of a stable to a ruptured atherosclerotic plaque. During the last years our research lab made an attempt to unravel part of these mechanisms, which were studied using different approaches and techniques.

In 2001, Dhore used a biochemical approach to study differential expression of bone matrix regulatory proteins in human atherosclerotic plaques ${ }^{7}$. Using Western blot, immunohistochemistry, and in situ hybridization she found that several inhibitors of calcification were expressed throughout plaque development, while activators of calcification were solely expressed in advanced atherosclerotic lesions. In 2005, Donners also used proteomics to study differential expression in human atherosclerotic plaque progression ${ }^{8}$. She did not focus on one single process in atherogenesis, but made an attempt to study the underlying mechanisms of plaque rupture. She compared two-dimensional (2D) profiles of whole-mount human advanced stable lesions with plaques containing a thrombus. This analysis revealed the increased expression of one of six isoforms of $\alpha_{1}$-antitrypsin (AAT) in plaques containing a thrombus. 
In 2005, Lutgens applied a genomics approach to study atherosclerosis. She used microarray analysis to study murine gene expression in different stages of atherosclerosis. Pathway analysis revealed an important role for genes involved in inflammation and matrix degradation during atherosclerotic plaque progression. Furthermore, she showed that small inducible cytokines mediate plaque progression and stability. In 2001, Faber used another large scale gene expression tool, suppression subtractive hybridization ( $\mathrm{SSH}$ ), to study differential gene expression between whole-mount human stable and ruptured plaques ${ }^{10}$. Two libraries were generated, one containing 2,000 clones upregulated in stable plaques and one containing 3,000 clones upregulated in ruptured plaques. Subsequent macroarray analysis of 500 clones showed differential expression of 45 clones. Clone SSH6, upregulated in ruptured plaques, was further validated by Bijnens in $2003^{11}$. She cloned and characterized this novel mRNA/protein and named it vasculin. The final step in defining the role of selected genes is in vivo validation. Our lab has extensive experience in the use of interventions and/or genetic modified mice. In 2005, Donners assessed the role of the immuno-suppressive drug FK506 in collar-induced and spontaneous atherosclerosis in apoE-/- mice ${ }^{12}$. She found that low-dose FK506 reduced plaque development and progression and induced a more stable plaque phenotype. Lutgens validated the role of CD40-CD40L interactions in atherosclerosis. In 1999, she showed that deficiency of CD154 (CD40L) in apoE-/- mice induced a stable plaque phenotype with a reduction in T-lymphocyte/macrophage content ${ }^{13}$. In 2000, she further substantiated the role for CD40L in atherosclerosis by showing that anti-CD40L antibody induced a stable plaque phenotype in apoE-/- mice ${ }^{14}$. Furthermore, in 2002 Lutgens revealed that inhibition of TGF- $\beta$ using recombinant soluble TGF- $\beta$ receptor II (TGF- $\beta$ RII:Fc) in apoE-/- mice decreased fibrosis and increased inflammation ${ }^{15}$. Finally, in 2005 Schapira used apoE-/ - mice to study the role of integrin $\alpha 1 \beta 1$. Deficiency of integrin $\alpha 1$ or anti- $\alpha 1$ antibody treatment reduced atherosclerosis and induced a stable plaque phenotype ${ }^{16}$.

As described, our lab was highly successful in defining the in vivo function of several individual genes, such as CD40L, TGF- $\beta$ and integrin $\alpha 1$. In the present thesis, extensive in vivo and in vitro studies are described on another candidate molecule in atherogenesis, cathepsin K. Furthermore, we also used large scale gene expression studies to identify which genes are differentially expressed in several stages of atherosclerosis. However, when validating differential expression of individual genes as identified by large scale gene expression studies, a problem arises concerning the functionality of these differentially expressed genes. Since it is a daunting task to study the function of each differentially expressed gene individually in an in vivo model, an assay which facilitates early selection of only the functional genes would be a welcome approach. 
In conclusion, the before mentioned studies are a representative example of research as performed in the field of atherosclerosis. We and others have challenged many techniques to study the molecular mechanisms underlying atherosclerotic plaque transition: from large scale gene expression studies to identify possible candidates to validation of individual candidates and to the current need for functional assays.

\section{HYPOTHESIS AND OUTLINE}

Large scale gene expression studies may contribute to the elucidation of the molecular mechanisms underlying atherosclerotic plaque progression. A powerful tool to perform large scale expression studies is suppression subtractive hybridization (SSH). As described earlier in this chapter, we have used SSH to study differential gene expression between whole-mount human stable and ruptured plaques ${ }^{10}$. Based on that study, differentially expressed genes were categorized in three different categories: 1 . known genes that were previously linked to atherosclerosis, 2. known genes that were not previously linked to atherosclerosis, and 3. unknown genes/proteins involved in atherosclerosis with unknown functions. One of the candidate genes we found and subsequently validated is cathepsin K, which belongs to the second category.

Chapter 2 reviews the known functions of the cathepsin cysteine protease family, including cathepsin $\mathrm{K}$, in cardiovascular disease. Using SSH, cathepsin K was found to be highly upregulated in stable lesions compared with lesions containing a thrombus. Since cathepsin K exerts unique collagenolytic and elastolytic activi$\operatorname{ties}^{17-19}$, we hypothesized that cathepsin K contributes to atherosclerotic plaque progression and destabilization. The first experimental chapter, chapter 3, describes differential gene expression of cathepsin $\mathrm{K}$ in human atherosclerosis and the effect of genetic disruption of cathepsin $\mathrm{K}$ on lesion development in an apoE deficient atherosclerotic mouse model. Deficiency of cathepsin $\mathrm{K}$ and apoE reduced plaque progression and atherosclerotic plaque area and increased collagen content. However, it also increased macrophage size and aggravated foam cell formation. Therefore we used microarray and subsequent pathway analysis to further dissect the molecular mechanisms underlying this phenotype (chapter 4).

Since cathepsin K deficiency exerted both beneficial and detrimental effects in atherosclerosis, by reducing plaque progression and inducing a more stable plaque phenotype and by aggravating foam cell formation, the use of cathepsin $\mathrm{K}$ inhibitors for clinical purposes should be evaluated with this perspective. To further assess the role of cathepsin $\mathrm{K}$ inhibition in ECM degradation and lipid 
metabolism in human macrophages we cultured both murine and human macrophages and assayed these cells for protease activity, collagenolytic and elastinolytic activity, and assessed the effects of cathepsin $\mathrm{K}$ inhibition on lipid metabolism (chapter 5).

Deficiency of cathepsin $\mathrm{K}$ in apoE-/- mice also led to a decrease in the number of elastin breaks in the media underlying advanced atherosclerotic lesions, which may be attributed to the elastolytic properties of cathepsin $\mathrm{K}^{18,19}$. Based on these findings we hypothesized that deficiency of cathepsin K reduces aneurysm formation. To assess the role of cathepsin $\mathrm{K}$ deficiency in aneurysm formation, we used angiotensin II infused apoE deficient mice as a mouse model of aneurysm formation (chapter 6).

From the third category, unknown genes/proteins involved in atherosclerosis with unknown functions, we concluded that one of the disadvantages of large scale gene expression studies is the lack of functional assays early in the selection of candidates. To circumvent the selection of non-functional candidates, we hypothesized that it is possible to identify functional soluble mediators of inflammation, a key process in atherosclerosis. To test this hypothesis, we introduced a new high throughput functional screening approach. In this approach we combined differential gene expression with functional genomics to identify novel mediators of inflammation (chapter 7). In chapter 8 the findings of the experimental studies are discussed and future perspectives are given.

\section{REFERENCES}

1. Glass CK, Witztum JL. Atherosclerosis. the road ahead. Cell. Feb 23 2001;104(4):503-516.

2. Lusis AJ. Atherosclerosis. Nature. Sep 14 2000;407(6801):233-241.

3. Ross R. Atherosclerosis—an inflammatory disease. N Engl J Med. Jan 14 1999;340(2): 115-126.

4. Hansson GK. Inflammation, atherosclerosis, and coronary artery disease. N Engl J Med. Apr 21 2005;352(16):1685-1695.

5. Tabas I. Consequences and therapeutic implications of macrophage apoptosis in atherosclerosis: the importance of lesion stage and phagocytic efficiency. Arterioscler Thromb Vasc Biol. Nov 2005;25(11):2255-2264.

6. Virmani R, Kolodgie FD, Burke AP, Farb A, Schwartz SM. Lessons from sudden coronary death: a comprehensive morphological classification scheme for atherosclerotic lesions. Arterioscler Thromb Vasc Biol. May 2000;20(5):1262-1275.

7. Dhore CR, Cleutjens JP, Lutgens E, Cleutjens KB, Geusens PP, Kitslaar PJ, TordoirJH, Spronk HM, Vermeer C, Daemen MJ. Differential expression of bone matrix regulatory proteins in human atherosclerotic plaques. Arterioscler Thromb Vasc Biol. Dec 2001;21(12):1998-2003. 
8. Donners MM, Verluyten MJ, Bouwman FG, Mariman EC, Devreese B, Vanrobaeys F, van Beeumen J, van den Akker LH, Daemen MJ, Heeneman S. Proteomic analysis of differential protein expression in human atherosclerotic plaque progression. $J$ Pathol. May 2005;206(1):39-45.

9. Lutgens E, Faber B, Schapira K, Evelo CT, van Haaften R, Heeneman S, Cleutjens KB, Bijnens AP, Beckers L, Porter JG, Mackay CR, Rennert P, Bailly V, Jarpe M, Dolinski B, Koteliansky V, de Fougerolles T, Daemen MJ. Gene profiling in atherosclerosis reveals a key role for small inducible cytokines: validation using a novel monocyte chemoattractant protein monoclonal antibody. Circulation. Jun 28 2005;111(25):3443-3452.

10. Faber BC, Cleutjens KB, Niessen RL, Aarts PL, Boon W, Greenberg AS, Kitslaar PJ, Tordoir JH, Daemen MJ. Identification of genes potentially involved in rupture of human atherosclerotic plaques. Circ Res. Sep 14 2001;89(6):547-554.

11. Bijnens AP, Gils A, Jutten B, Faber BC, Heeneman S, Kitslaar PJ, Tordoir JH, de Vries CJ, Kroon AA, Daemen MJ, Cleutjens KB. Vasculin, a novel vascular protein differentially expressed in human atherogenesis. Blood. Oct 15 2003;102(8):2803-2810.

12. Donners MM, Bot I, De Windt LJ, van Berkel TJ, Daemen MJ, Biessen EA, Heeneman S. Low-dose FK506 blocks collar-induced atherosclerotic plaque development and stabilizes plaques in ApoE-/- mice. Am J Transplant. Jun 2005;5(6):1204-1215.

13. Lutgens E, Gorelik L, Daemen MJ, de Muinck ED, Grewal IS, Koteliansky VE, Flavell RA. Requirement for CD154 in the progression of atherosclerosis. Nat Med. Nov 1999;5(11):1313-1316.

14. Lutgens E, Cleutjens KB, Heeneman S, Koteliansky VE, Burkly LC, Daemen MJ. Both early and delayed anti-CD40L antibody treatment induces a stable plaque phenotype. Proc Natl Acad Sci U S A. Jun 20 2000;97(13):7464-7469.

15. Lutgens E, Gijbels M, Smook M, Heeringa P, Gotwals P, Koteliansky VE, Daemen MJ. Transforming growth factor-beta mediates balance between inflammation and fibrosis during plaque progression. Arterioscler Thromb Vasc Biol. Jun 1 2002;22(6):975-982.

16. Schapira K, Lutgens E, de Fougerolles A, Sprague A, Roemen A, Gardner H, Koteliansky V, Daemen M, Heeneman S. Genetic deletion or antibody blockade of alpha1beta1 integrin induces a stable plaque phenotype in ApoE-/- mice. Arterioscler Thromb Vasc Biol. Sep 2005;25(9):1917-1924.

17. Garnero P, Borel O, Byrjalsen I, Ferreras M, Drake FH, McQueney MS, Foged NT, Delmas PD, Delaisse JM. The collagenolytic activity of cathepsin K is unique among mammalian proteinases. J Biol Chem. Nov 27 1998;273(48):32347-32352.

18. Punturieri A, Filippov S, Allen E, Caras I, Murray R, Reddy V, Weiss SJ. Regulation of elastinolytic cysteine proteinase activity in normal and cathepsin K-deficient human macrophages. J Exp Med. Sep 18 2000;192(6):789-799.

19. Yasuda Y, Li Z, Greenbaum D, Bogyo M, Weber E, Bromme D. Cathepsin V, a novel and potent elastolytic activity expressed in activated macrophages. J Biol Chem. Aug 27 2004;279(35):36761-36770. 



\section{Chapter 2 \\ Cathepsin cysteine proteases in cardiovascular disease}

Suzanne P.M. Lutgens, Kitty B.J.M. Cleutjens, Mat J.A.P. Daemen,

Sylvia Heeneman

Department of Pathology, Cardiovascular Research Institute Maastricht (CARIM), Maastricht University, P. Debyelaan 25, Maastricht, The Netherlands.

Faseb J. 2007 May. 


\section{ABSTRACT}

Extracellular matrix (ECM) remodeling is one of the underlying mechanisms in cardiovascular diseases. Cathepsin cysteine proteases have a central role in ECM remodeling and have been implicated in the development and progression of cardiovascular diseases. Cathepsins also show differential expression in various stages of atherosclerosis, and in vivo knockout studies revealed that deficiency of cathepsin $\mathrm{K}$ or $\mathrm{S}$ reduces atherosclerosis. Furthermore, cathepsins are involved in lipid metabolism. Cathepsins have the capability to degrade low-density lipoprotein and reduce cholesterol efflux from macrophages, aggravating foam cell formation. Although expression studies also demonstrated differential expression of cathepsins in cardiovascular diseases like aneurysm formation, neointima formation, and neovascularization, in vivo studies to define the exact role of cathepsins in these processes are lacking. Evaluation of the feasibility of cathepsins as a diagnostic tool revealed that serum levels of cathepsins $\mathrm{L}$ and $\mathrm{S}$ seem to be promising as biomarkers in the diagnosis of atherosclerosis, whereas cathepsin $\mathrm{B}$ shows potential as an imaging tool. Furthermore, cathepsin K and S inhibitors showed effectiveness in (pre) clinical evaluation for the treatment of osteoporosis and osteoarthritis, suggesting that cathepsin inhibitors may also have therapeutic effects for the treatment of atherosclerosis. 


\section{INTRODUCTION}

Remodeling of the extracellular matrix (ECM) is an important feature of many physiological and pathological processes. The ECM consists of elastins, collagens and proteoglycans and is largely synthesized by smooth muscle cells (SMCs). It provides anchorage, support and structure to tissue. Proteolytic enzymes, such as matrix metalloproteinases (MMPs) and cathepsin cysteine proteases, can degrade the ECM and therefore contribute to (patho) physiological processes, like atherosclerosis, aneurysm formation, neointima formation, and neovascularization. In vitro and in vivo studies have been performed to establish the contribution of proteolytic enzymes to the etiology of cardiovascular disease. The contribution of several MMPs to ECM degradation in cardiovascular diseases has been highlighted in several excellent reviews ${ }^{1-3}$. MMPs are not the only proteins required for ECM degradation; other proteases like cathepsin cysteine proteases are needed as well. Cathepsins of the cysteine protease family are localized in lysosomes and endosomes, and degrade intracellular or endocytosed proteins. These cathepsins have been proven to play an important role in cardiovascular diseases $^{4,5}$. In this review we will focus on the role of the cysteine protease family of the cathepsins in cardiovascular disease.

\section{CATHEPSIN CYSTEINE PROTEASES IN A NUTSHELL}

Proteases are enzymes that catalyze the irreversible hydrolysis of amide bonds ${ }^{6}$. Different proteases catalyze this reaction with different strategies. These different properties are used to distinguish four major groups of proteases: cysteine, serine, aspartate, and metallo-proteases ${ }^{7}$. The cysteine proteases can be subgrouped into several families including the family of enzymes related to interleukin-1 $\beta$ converting enzyme (ICE), the calpain family, and the papain family ${ }^{7,8}$. The cysteine proteinases of the papain family are the most abundant of all cysteine proteases. The family consists of papain, related plant proteinases, and the lysosomal cathepsins B, C, F, H, K, L, O, S, V, W, and $\mathrm{X}^{8,9}$. Cathepsin N and T have also been described, but a detailed characterization is still lacking. ${ }^{8}$. Most cathepsins are endopeptidases ${ }^{8,10}$, although cathepsins $\mathrm{B}$ and $\mathrm{H}$ may also function as a dipeptidyl carboxypeptidase ${ }^{11}$ and as an aminopeptidase ${ }^{12}$, respectively. Cathepsin $\mathrm{C}$ is an aminodipeptidase $\mathrm{e}^{8,10}$ and cathepsin $\mathrm{X}$ is a carboxy-mono or -dipeptidase $\mathrm{e}^{13}$. The activation process of cathepsins has been thoroughly reviewed by Turk et al. ${ }^{9}$. In short, cathepsins are synthesized as preproenzymes. Procathepsin is formed after removal of the prepeptide during the passage to the endoplasmic reticulum. Subsequently, the active cathepsin can be produced after 
proteolytic removal of the propeptide in the acidic environments of late endosomes or lysosomes. This last process is accompanied by the action of several proteases, such as pepsin, neutrophil elastase, and various cysteine proteases. The propeptide is described to serve several functions such as stability, proper folding, targeting of cathepsins, and prevention of inappropriate protease activity ${ }^{9}$. Most cathepsins like cathepsins B, F, H, K, L, and V are optimally active in acidic environments and are only weakly active at neutral $\mathrm{pH}^{9}$. In contrast, cathepsin $\mathrm{S}$ activity is optimal at neutral $\mathrm{pH}^{9}$.

Cysteine protease inhibitors can be subgrouped in several superfamilies, of which the cystatins are the most important ${ }^{14}$. The cystatin superfamily can be divided into three groups. Type 1 cystatins are stefin A and B, also called cystatin A and B, which are localized mostly intracellular. Type II cystatins, among which cystatin C, act extracellularly. Type III cystatins comprise the kininogens, the circulating proteins ${ }^{14,15}$. The function of these cystatins is to protect against lysosomal proteins, such as cathepsins, which have accidentally escaped from lysosomes or which are occasionally released during, for example, apoptosis or phagocyte degranulation. Cystatin $\mathrm{C}$ shows the highest inhibiting properties to cathepsins $\mathrm{L}$ and $\mathrm{S}$, followed by cathepsins $\mathrm{B}$ and $\mathrm{H}^{16}$.

In humans, several cathepsin deficiencies have been described. A loss of function mutation in the cathepsin $\mathrm{C}$ gene leads to Papillon-Lefevre syndrome, an autosomal recessive disorder characterized by palmoplantar hyperkeratosis and severe early onset periodontitis ${ }^{17}$. Deficiency of cathepsin $\mathrm{K}$ leads to pycnodysostosis, an autosomal recessive osteochondrodysplasia characterized by osteosclerosis and short stature ${ }^{18}$. Cathepsin deficiencies have also been generated in mice. Although a role for cathepsin B was suggested in antigen presentation, the phenotype of cathepsin B deficient mice appeared normal compared with wild-type littermates and antigen presentation was not affected ${ }^{19}$. Deficiency of cathepsin F causes lysosomal storage defects (neuronal lipofuscinosis) and late-onset neurological disease in mic $\mathrm{e}^{20}$. An osteopetrotic phenotype with excessive trabeculation of the bone marrow space has been described for mice deficient in cathepsin $\mathrm{K}^{21}$. Mice lacking cathepsin L develop periodic hair loss, with alteration of hair follicle morphogenesis and cycling as well as hyperplasia and hyperkeratosis of the epidermis, which is attributed to hyperproliferation of hair follicle epithelial cells and basal keratinocytes. Although cathepsin S deficient mice have normal fertility and show no gross abnormalities or major developmental abnormalities in their lymphocytes, they demonstrate inhibition of invariant chain (Ii) degradation, resulting in slow peptide loading by $\mathrm{MHC}$ class II/Ii p10 ${ }^{22,23}$. Ondr et al. reported no abnormalities for cathepsin W deficient mice ${ }^{24}$. 


\section{CATHEPSIN CYSTEINE PROTEASES: MECHANISMS OF ACTION ON A CELL BIOLOGICAL LEVEL}

In this section we highlight some of the mechanisms by which cathepsins influence ECM turnover, inflammation, and apoptosis on a cell biological level. By influencing these processes cathepsin cysteine proteases may contribute to cardiovascular diseases including atherosclerosis, neointima formation, and aneurysm formation.

ECM degradation by cathepsin cysteine proteases contributes to a variety of physiological and pathological conditions, including cancer, bone remodeling, and cardiovascular disease ${ }^{4,5,7}$. Cathepsin cysteine proteases are folded into two relatively large globular domains surrounding a cleft that contains the active site residues. Cleavage is achieved by substrate entry into the cleft ${ }^{9}$. Individual cathepsins have specific substrate preferences. Cathepsin B and L have been described to degrade rat collagen type II, IX, and XI at acidic $\mathrm{pH}$ values ${ }^{25}$. Cathepsin L was somewhat more efficient than cathepsin B. Cathepsin K exerted strong elastolytic activity and was once suggested to be the most potent elastase at neutral $\mathrm{pH}^{26}$ and collagenase at acidic $\mathrm{pH}^{26,27}$. However, more recent findings indicate cathepsin $\mathrm{V}$ as a more potent elastase than cathepsin $\mathrm{K}^{28}$. Cathepsin $\mathrm{S}$ was also shown to be a strong elastase ${ }^{29}$.

Besides its role in ECM degradation, cathepsins are also involved in major histocompatibility complex (MHC) class II antigen presentation. MHC class II molecules are expressed on the surface of antigen-presenting cells (APCs); they bind exogenous proteins and present them to CD4+ T cells. MHC class II $\alpha \beta$ heterodimers assemble in the endoplasmic reticulum (ER) with the assistance of the invariant chain (Ii). The Ii cytoplasmic tail targets the MHC class II-Ii complex to the endosomal pathway and prevents early loading of antigenic proteins on MHC class II with class II-associated invariant chain peptide (CLIP). Maturation of the early endosome leads to activation of lysosomal enzymes, including cathepsins, which degrade Ii. The invariant chain Ii is sequentially degraded in IiP22, IiP10, and CLIP. After Ii degradation, the MHC class II peptide binding groove remains occupied by CLIP, preventing premature peptide loading. Removal of CLIP and loading of peptides is mediated by MHC-like molecule HLA-DM in humans and H-2M in mice (reviewed in refs. ${ }^{30,31}$ ). In professional APCs, cathepsin F (macrophages), L (cortical thymic epithelial cells), and S (B cells, dendritic cells and macrophages) have been described to degrade $\mathrm{MHC}$ class II-associated $\mathrm{Ii}^{23,32-35}$, while cathepsin B seems not to play a pivotal role in antigen presentation ${ }^{19}$. Cathepsin S, but not L, also efficiently degrades MHC class II-associated Ii in nonprofessional APCs, such as (intestinal) epithelial cells $\mathrm{s}^{36,37}$. 
Furthermore, cathepsin cysteine proteases are involved in apoptosis. Under physiological circumstances, cathepsins are located in the lysosomes. However, lysosomal permeabilization due to exogenous oxidants (reactive oxygen species) may induce lysosomal leakage leading to release of cathepsins into the cytoplasm $^{38}$. In vitro studies using cultured macrophages showed that both $7 \beta$-hydroxycholesterol and oxidized LDL (oxLDL) induced lysosomal destabilization, leading to leakage of cathepsins B and L to the cytoplasm, activation of caspases, and subsequent apoptosis. This suggests that cathepsins B and L may act as cleaving enzymes during the apoptotic process ${ }^{39,40}$. Furthermore, suppression of cathepsin B by serine protease inhibitor 2A (Spi2A, with cross-reactivity to cathepsin B) inhibits the lysosomal apoptosis pathway and protects cells from TNF- $\alpha$ induced apoptosis ${ }^{41}$. NF-kappaB can protect cells from death after TNF receptor stimulation by reducing cathepsin $\mathrm{B}$ activity in the cytosol, mediated by the up-regulation of Spi2A. Thus, NF-kappaB protects cells from apoptosis by inhibition of cathepsin B activity.

\section{CATHEPSINS IN ATHEROSCLEROSIS}

More than a decade ago it was shown that human macrophages secreted active cathepsins B, L, and S and showed elastolytic activity ${ }^{42}$. More recently, both mRNA and protein levels of cathepsin cysteine proteases B, L and S were found to be increased in murine atherosclerotic lesions. Cathepsin protein expression was localized in macrophages and/or in lipid rich areas ${ }^{43}$. Cathepsin $\mathrm{K}$ and $\mathrm{S}$ were the first cathepsins that were found to be expressed in human atherosclerotic lesions ${ }^{44}$.

Below we will extensively describe the role of cathepsins in atherosclerosis and therefore we have subdivided the paragraphs into segments describing the expression, knockout models and ECM remodeling, shear stress, and lipid metabolism and inflammation.

\section{Cathepsins in atherosclerosis: expression}

Expression patterns of cathepsins in atherosclerosis are summarized in table I. Cathepsin B mRNA and protein levels were found to be increased in atherosclerotic lesions of apoE-deficient mice, and cathepsin B immunoreactivity was highest in areas next to the lumen and in macrophages ${ }^{45}$. Cathepsin F was only weakly expressed in normal human arteries, but in human atherosclerotic lesions it was localized in macrophages devoid of intracellular lipid and in SMCs and ECs but not in T-lymphocytes ${ }^{46}$. Protein levels of cathepsin L were also increased in human atheroma. Cathepsin L was mainly localized in 
CATHEPSINS IN CARDIOVASCULAR DISEASE |

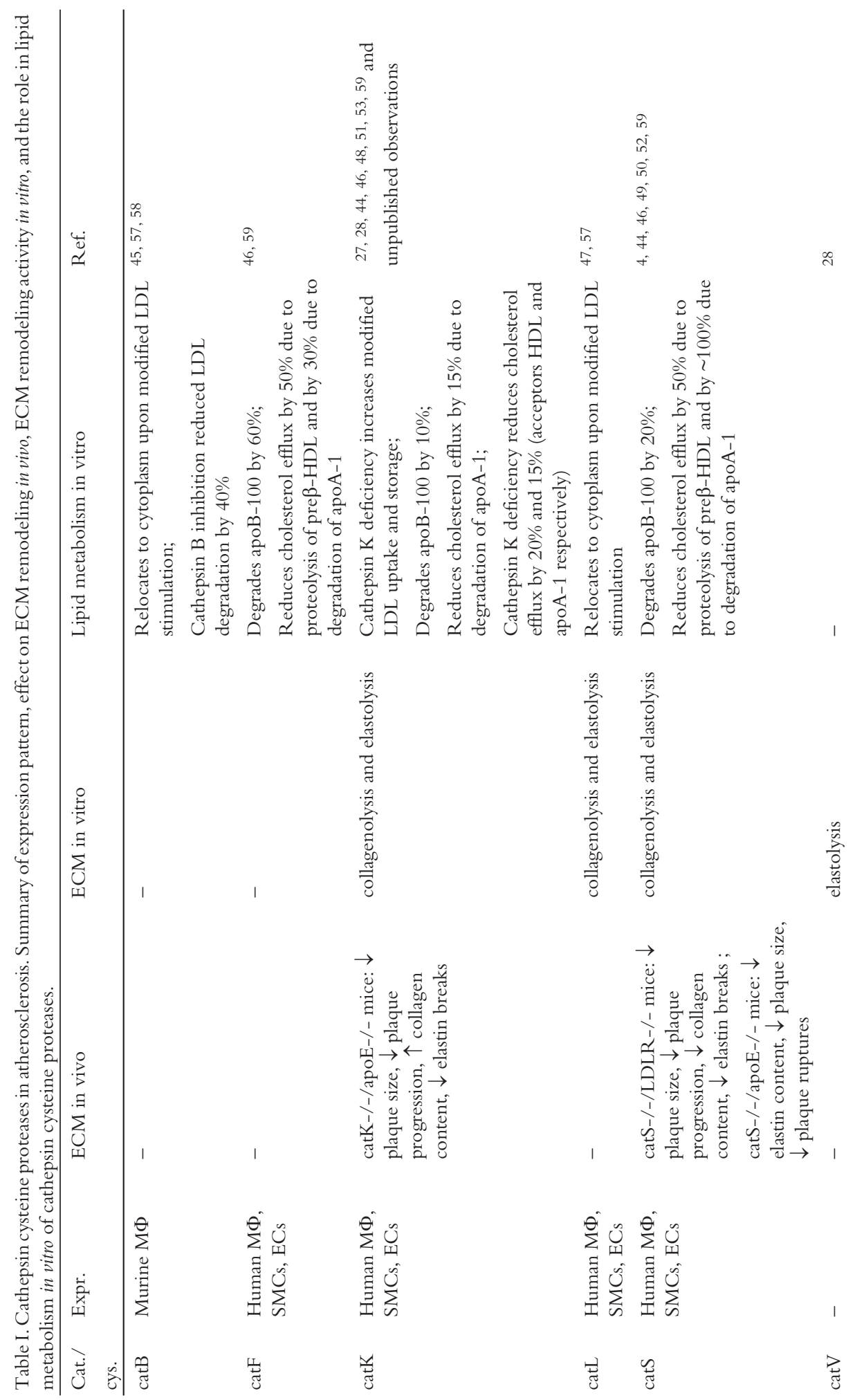


22 | ChAPTER 2

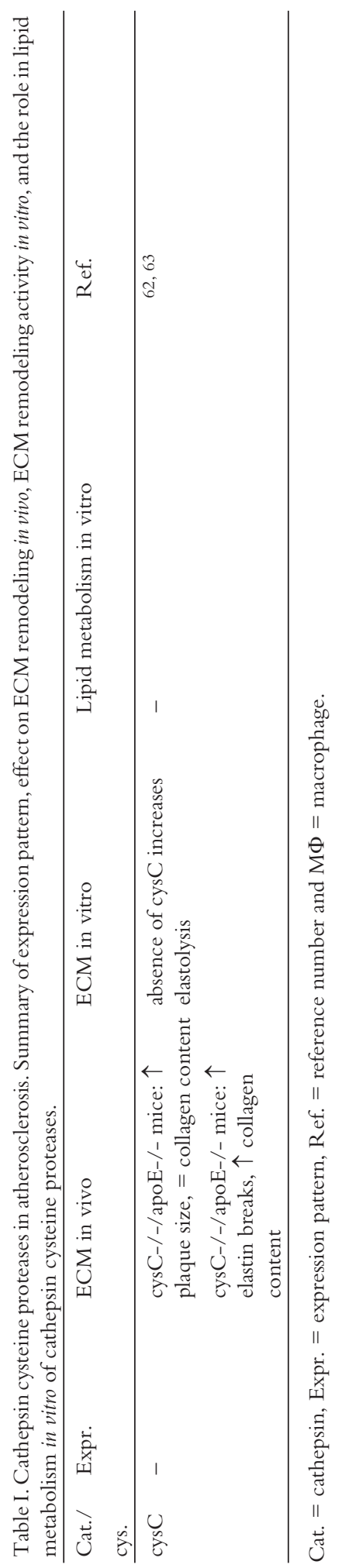


SMCs, ECs, and macrophages in advanced atherosclerotic lesions ${ }^{47}$. Cathepsin K expression in normal arteries is low. Early human atherosclerotic lesions showed cathepsin $\mathrm{K}$ expression in the intima and medial SMCs. In advanced atherosclerotic plaques, cathepsin $\mathrm{K}$ was localized mainly in macrophages and SMCs of the fibrous cap. Cathepsin $\mathrm{K}$ protein levels were increased in atherosclerotic lesions when compared with normal arteries, whereas cathepsin $\mathrm{K}$ mRNA levels were similar in both atherosclerotic and normal tissues ${ }^{44}$. We recently described that cathepsin K mRNA and protein levels were highest in advanced but stable human atherosclerotic plaques compared with early atherosclerotic lesions and lesions containing a thrombus. In these lesions, cathepsin K was localized in SMCs and macrophages, and also in $\mathrm{ECs}^{48}$ (chapter 3). The most extensively described cysteine protease in atherosclerosis is cathepsin S. Protein expression studies showed that normal human arteries sparsely expressed cathepsin S. Early human atherosclerotic lesions, or fatty streaks, showed cathepsin S expression in the intima and in medial SMCs. In advanced human atherosclerotic plaques, cathepsin $\mathrm{S}$ was localized in macrophages and SMCs of the fibrous cap ${ }^{44}$. ECs lining the lumen of the vessel itself and the plaque microvessels also expressed cathepsin $\mathrm{S}^{4}$. Furthermore, cathepsin S mRNA and protein levels were increased in human atheroma compared with normal arteries ${ }^{44}$. Recently, cathepsin $\mathrm{V}$ was also found to be expressed in human atheroma ${ }^{28}$.

\section{Cathepsins in atherosclerosis: knockout models and ECM remodeling}

The effects of cathepsin deficiency on ECM remodeling in in vivo mouse models are summarized in table I. Deficiency of cathepsin S in LDL receptor deficient mice resulted in a reduction in atherosclerotic plaque area (60\% reduction after 12 weeks atherogenic diet), a reduction in plaque stage development, and a reduction in the number of elastin breaks and elastase activity ${ }^{49}$. Furthermore, cathepsin $\mathrm{S}$ deficiency led to a reduction in SMC and collagen content, and fibrous cap thickness. Cathepsin S-deficient macrophage showed reduced transmigration through an EC monolayer and collagen type I and IV in vitro ${ }^{49}$. In another study using cathepsin S-deficient apoE-/- mice, no differences in the number of elastin breaks were found, although plaque elastin content was reduced by $49 \%{ }^{50}$. Cathepsin S deficiency reduced atherosclerotic plaque size by 46\% (after 12 weeks atherogenic diet) and reduced the number of plaque ruptures (defined as visible defects in the cap, accompanied by intrusion of erythrocytes into the region below it) by $73 \%$. In concordance with previous findings ${ }^{44}$, active cathepsin $\mathrm{S}$ was found in extracts of human atherosclerotic lesions, but not in normal arteries and cathepsin $\mathrm{S}$ expression in macrophages colocalized with areas 
of elastin fragmentation ${ }^{50}$. These data all point to a protective role of cathepsin S inhibition in atherogenesis by decreasing degradation of ECM components. Cathepsin K deficiency in apoE-/- mice resulted in a $42 \%$ reduction in atherosclerotic plaque area; although the total number of plaques remained unchanged, there was a relative increase in early lesions and a relative decrease of the number of advanced lesions when cathepsin K was absent. Furthermore, cathepsin $\mathrm{K}$ deficiency led to an increase in collagen content and macrophage size, a decrease in elastin breaks and macrophage content, but unchanged T-lymphocyte content and lipid core area. The increased macrophage size resulted from an increase in lipid uptake in macrophages, which was stored in lysosomes that had increased in $\operatorname{size}^{48}$ (chapter 3 ). Subsequent microarray and pathway analysis suggested that cathepsin K deficiency altered plaque phenotype not only by decreasing proteolytic activity, but also by stimulating TGF- $\beta$ signaling, and suggested a role for caveolin-1 and CD36 in the lipogenic phenotype of cathepsin K-deficient atherosclerotic lesions ${ }^{51}$ (chapter 4). These data suggest that cathepsin K deficiency may have a protective role in atherosclerosis by increasing fibrosis; however, cathepsin $\mathrm{K}$ deficiency also aggravates foam cell formation, at least in mice, which may affect plaque stability.

Table I summarizes the effects of cathepsins on ECM remodeling activities in vitro. It was shown that cathepsin $\mathrm{V}$ shows the highest elastolytic activity, followed by cathepsins K, S, F, L, and B. However, in cultured macrophages cathepsins K, S, and V contribute equally (20\%) to elastolytic activity, of which $20 \%$ takes place intracellularly and $40 \%$ extracellularly ${ }^{28}$. Extracts from human atheroma showed a twofold increase in elastolytic activity compared with normal arteries, which could be inhibited up to $40 \%$ by a cysteine protease inhibitor (E64). Cytokine-stimulated SMCs also showed elastolytic activity (in vitro), which could be inhibited for $>80 \%$ by a selective cathepsin $\mathrm{S}$ inhibitor (LHVS) or a cysteine protease inhibitor $(\mathrm{E} 64)^{44}$. Other studies demonstrated that cathepsin S inhibition in (unstimulated) SMCs by either LHVS, E64, or the cysteine protease inhibitor cystatin $\mathrm{C}$ reduced invasion through an elastin gel by about $90 \%$, while invasion through a collagen type I gel was reduced by only $30 \%$. No effect on adhesion and migration was found, indicating that cathepsin $\mathrm{S}$ could exert its effect in atherosclerotic lesions via elastolysis ${ }^{52}$. Cathepsin $\mathrm{S}$ also exerted collagenolytic activities although less potent than elastolytic activities. The elastolytic and collagenolytic activity (type I) of cathepsin L in SMCs and ECs has already been mentioned to increase after bFGF stimulation ${ }^{47}$. Cathepsin $\mathrm{K}$ not only contributes to elastinolysis, although cathepsin L and $\mathrm{S}$ may take over when cathepsin $\mathrm{K}$ is absent ${ }^{53}$, but also plays an important role in the degradation of collagen type $\mathrm{I}$, and therefore its collagenolytic activity is unique among proteases $^{27}$. 


\section{Cathepsins: shear stress sensitive proteases}

During the initiation phase of atherosclerosis, hemodynamic forces at branch points act on the endothelial layer (shear stress) leading to increased permeability of the endothelium to lipoproteins, expression of endothelial adhesion molecules, and induction of leukocyte migration into the arterial wall. Oscillatory shear stress corresponds to atheroprone areas, while laminar shear stress corresponds to atheroprotected areas ${ }^{54}$. It was recently suggested that secreted cathepsin $\mathrm{L}$ is a shear-dependent matrix protease $\mathrm{e}^{55}$. Inhibition of cathepsin $\mathrm{L}$ by a cysteine protease inhibitor or cathepsin L silencing RNA (siRNA) treatment inhibited oscillatory shear stress-induced gelatinase and elastase activity by mouse aortic ECs, but not laminar shear stress-induced activity ${ }^{55}$. This suggests that cathepsin L is a shear-sensitive protease with potential importance in vascular remodeling and atherosclerosis. The same researchers also showed that cathepsin $\mathrm{K}$ is shear stress regulated, since cathepsin K siRNA reduced oscillatory shear stress-induced gelatinase and elastase activity by mouse aortic $\mathrm{ECs}^{56}$. Thus, it can be suggested that both cathepsin $\mathrm{K}$ and L activity is increased by oscillatory shear stress, which leads to increased ECM remodeling and atherosclerosis.

\section{Cathepsins in atherosclerosis: lipid metabolism and inflammation}

The role of cathepsins in lipid metabolism is summarized in table I. If lipids are oxidized, the resulting oxysterols, hydroxyperoxides, and their toxic carbonylic fragments may affect lysosomal enzymes and membranes. Uptake of modified (oxidized) LDL damages the lysosomal membrane and, as a result, the acidic components will flow into the cytoso ${ }^{57}$. Modified LDL relocates cathepsins B and $\mathrm{L}$ from the lysosome into the cytosol, probably as a result of disruption of the lysosomal membrane. It also reduces overall cathepsin L activity, but induces the relative cytoplasmic activity. Lysosomal cathepsins that are translocated to the cytoplasm may act as cleavage enzymes during apoptosis ${ }^{39}$. These harmful effects of modified LDL on lysosomal membrane damage and cathepsin L relocation and inactivation can be partly prevented by high density lipoprotein (HDL) and/or vitamin $\mathrm{E}^{57}$.

DiI-labeled modified (oxidized) LDL uptake studies showed an increased uptake of modified LDL in cathepsin K-deficient apoE-/- bone marrow (BM)-derived macrophages $^{48}$ (chapter 3). Subsequent pathway analysis revealed that the increased lipid uptake is mediated by both CD36 and caveolins ${ }^{51}$ (chapter 4). In addition, cathepsin K-deficient apoE-/- BM-derived macrophages showed an increase in cholesterol ester storage compared with apoE-/- BM-derived macrophages, which was stored in large lysosomal compartments ${ }^{48}$ (chapter 3). These data indicate that deficiency of cathepsin K aggravates foam cell formation. 
Cathepsins may also play a role in (modified) LDL degradation. Inhibition of cathepsin B inhibited naturally occurring modified LDL degradation in human aortic SMC lysates by 41\% (pH 4.0 and $\mathrm{pH} 5.5$ ). Decreased lysosomal degradation may lead to LDL accumulation in SMCs and subsequent foam cell forma tion $^{58}$. In vitro studies showed that recombinant cathepsin F extensively degraded apoB-100 (60\% degradation at $\mathrm{pH}$ 6.0), while cathepsins $\mathrm{K}$ and $\mathrm{S}$ showed less extensive degradation (10\% and $20 \%$ respectively at $\mathrm{pH} 6.0)^{46}$. Increasing $\mathrm{pH}$ led to a reduction in the degrading capacity of cathepsins $\mathrm{F}$ and $\mathrm{K}$ but affects cathepsin S to a much lesser extent. Degradation (proteolytic modification) of apoB-100 by cathepsin F, but not cathepsins $\mathrm{K}$ and $\mathrm{S}$, led to aggregation and fusion of LDL particles and increased the ability of LDL to bind proteoglycans, subsequently leading to the accumulation of extracellular lipid droplets. These data suggest that cathepsins B, F, K, and S contribute to extracellular lipid accumulation in the arterial wall, a key feature of atherosclerosis.

Literature provides ample evidence that cathepsins are also involved in cholesterol efflux. Lindstedt et al. showed that cathepsins $\mathrm{F}$ and $\mathrm{S}$ reduced the ability of cholesterol efflux from macrophages by $50 \%$ in vitro due to proteolysis of pre $\beta-\mathrm{HDL}^{59}$. Furthermore, cathepsin S totally (100\%) degraded lipid-free apolipoprotein A-1 (apoA-1) leading to complete loss of the ability of apoA-1 to stimulate cholesterol efflux. Cathepsins $\mathrm{F}$ and $\mathrm{K}$ also partially degraded apoA-1 leading to a reduction of cholesterol efflux of $30 \%$ and $15 \%$ respectively ${ }^{59}$. These data suggest that reduction of cholesterol efflux by cathepsins F, K, and S mediated degradation of cholesterol acceptors may contribute to the preservation of foam cells in the atherosclerotic lesion. In a recent study from our laboratory, however, deficiency of cathepsin $\mathrm{K}$ in apoE-/- bone marrow derived macrophages reduced both HDL and D37F (a specific apoA-1 mimetic peptide) mediated cholesterol efflux by $20 \%$ and $15 \%$, respectively, compared with apoE-/- bone marrow derived macrophages (S. Lutgens, unpublished observations). Although our results contradict the results of Lindstedt et al., these findings can be explained. Lindstedt et al. studied the extracellular capacity of cathepsin K to reduce cholesterol efflux by degradation of pre $\beta-\mathrm{HDL}$ and apoA- $1^{59}$. However, by using cathepsin K-deficient apoE-/- bone marrow-derived macrophages, we studied the intracellular effect of cathepsin K deficiency on cholesterol efflux without prior degradation of the cholesterol acceptor by cathepsins. Thus, extracellular cathepsin $\mathrm{K}$ reduces cholesterol efflux by decreasing the amount of cholesterol acceptors, while intracellular deficiency of cathepsin $\mathrm{K}$ reduces the reverse cholesterol transporting capacity independent of cholesterol acceptor degradation.

The role of cathepsin cysteine proteases in lipid uptake, storage, and efflux has been partly elucidated. However, the most important question of whether the 
role of cathepsins in lipid metabolism is atherosclerosis-stimulating or -protective remains unanswered. Relocation of cathepsins $\mathrm{B}$ and $\mathrm{L}$ from the lysosome into the cytosol, where they may act as cleavage enzymes in apoptosis, may eventually contribute to the formation of the necrotic core and can be considered as an atherosclerosis-stimulating role for cathepsins B and L. On the other hand, inhibition of cathepsin B reduced lysosomal degradation of modified LDL, thereby inducing foam cell formation, which can be considered as an atherosclerosis-protective role for cathepsin B. A similar case can be made for the role of cathepsin $\mathrm{K}$ in cholesterol efflux. Lindstedt et al. suggested a role for cathepsin $\mathrm{K}$ in reducing cholesterol efflux (atherosclerosis-stimulating role for cathepsin K), while we suggested that cathepsin K deficiency reduced cholesterol efflux (an atherosclerosis protective role for cathepsin $\mathrm{K}$ ).

Evidence for a role for cathepsins in the inflammation process in atherosclerosis is sparse. Sukhova et al. showed that cathepsin S deficiency in atherosclerotic apoE-deficient mice led to a reduction in macrophage and lipid content, in the number of T-cells, and in IFN- $\gamma$ content ${ }^{49}$. We have already mentioned that cathepsins F, L, and S can degrade MHC class II-associated Ii. However, data defining the role of cathepsin cysteine proteases in antigen processing and presentation related to atherosclerosis are lacking. Besides a direct role for cathepsins in inflammation, they can also play an indirect role via reducing TGF- $\beta$ expression levels. Inhibition of TGF- $\beta$ in apoE-/- mice resulted in an inflammatory plaque phenotype with an increased inflammatory cell content $t^{60}$. We recently showed that deficiency of cathepsin $\mathrm{K}$ induced an increased expression of genes involved in TGF- $\beta$ signaling in atherosclerotic lesions of apoE-/- mice, suggesting that cathepsin K deficiency may decrease inflammation by inducing TGF- $\beta$ activity ${ }^{51}$.

\section{ROLE OF NATURAL CATHEPSIN INHIBITORS IN ATHEROSCLEROSIS}

The effects of cathepsins in atherosclerotic lesions are balanced by cystatin C. Cystatin C protein levels decreased in human atherosclerotic plaques ${ }^{61}$. Elastinolytic activity of IFN- $\gamma$ stimulated vascular SMCs was inhibited by cystatin C. TGF- $\beta 1$ stimulated SMC cystatin $C$ secretion and subsequently blocked SMC elastase activity ${ }^{61}$. Two groups studied the effects of cystatin $\mathrm{C}$ deficiency on atherosclerosis in apoE-deficient mice, but found contradictory effects ${ }^{62,63}$ (see table I). One group studied the effect of cystatin $\mathrm{C}$ deficiency in female apoE-deficient mice fed a high-fat diet $(21 \%$ cocoa fat, $0.15 \%$ cholesterol, and $0 \%$ sodium cholate) for 25 weeks. They observed an increase in plaque size at the aortic root, whereas no effect on collagen content was observed. Lipid content tended to be larger and total macrophage content increased in the absence of 
Table II. Cathepsin and cystatin mRNA and protein expression level in restenosis and neointima formation.

\begin{tabular}{lll}
\hline Cat./cys. & Cathepsin expression in in vivo model & Ref. \\
\hline catK & Rat balloon injury (carotid artery) $\uparrow$ & 66 \\
catS & Rat balloon injury (carotid artery) $\uparrow$ & 66 \\
catS & Rabbit balloon injury (iliofemoral artery) $\uparrow$ & 65 \\
cysC & Rat balloon injury (carotid artery) $=$ & 66 \\
cysC & Rabbit balloon injury (iliofemoral artery) $\uparrow$ & 65 \\
\hline
\end{tabular}

Cat. $=$ cathepsin, cys. $=$ cystatin, Ref. $=$ reference number.

cystatin $\mathrm{C}^{62}$. In the aortic arches of cystatin C deficient male apoE-/- mice fed a "Western" type diet (20.1\% saturated fat, 1.37\% cholesterol, and $0 \%$ sodium cholate) for 12 weeks, elastic lamina degradation, SMC, and collagen content increased, indicating that disruption of the elastic lamina may facilitate SMC migration. Lesion size did not differ between these cysC-/-/apoE-/- and apoE-/- mice. Levels of cathepsin B, L, and S in aortic extracts were increased in the absence of cystatin C. Cytokine or growth factor stimulated SMCs also showed increased production of these cathepsins when cystatin C was absent. Both aortic extracts and (stimulated) SMCs showed higher elastolytic activity in the absence of cystatin C. Lipid content was reduced, while macrophage content and $\mathrm{T}$ cell content were unchange ${ }^{63}$. Although data from both studies are contradictory in some aspects, it seems that deficiency of cystatin C facilitates the atherosclerotic process either by increasing plaque size or by increasing elastolytic activity, and thus ECM degradation.

\section{CATHEPSINS IN RESTENOSIS AND NEOINTIMA FORMATION}

As mentioned, cathepsins contribute to ECM degradation, suggesting a possible role for cathepsins in restenosis and neointima formation. After percutaneous coronary intervention, luminal size may decrease as a result of constrictive remodeling. Placement of a stent may induce neointima formation and contribute to restenosis ${ }^{64}$. In a balloon injury model of restenosis in hypercholesterolemic rabbits, cathepsin S mRNA and protein expression was increased. Protein expression was increased in SMCs and macrophages. Cystatin C mRNA and protein expression were only minimally up-regulated ${ }^{65}$. A carotid balloon injury model of restenosis in rats on a normal diet also showed increased mRNA and protein levels of cathepsin S, but also cathepsin K, whereas cystatin C mRNA and protein were not increased ${ }^{66}$. These studies imply that there is a relative larger increase in cathepsin activity than cystatin activity. In vitro studies demonstrated that tissue extracts from whole-mount balloon injured carotid 
Table III. Cathepsin and cystatin mRNA and protein expression level in aortic abdominal aneurysm (AAA) formation.

\begin{tabular}{llll}
\hline Cat./cys. & $\begin{array}{l}\text { Cathepsin expression in } \\
\text { in vivo model }\end{array}$ & $\begin{array}{l}\text { In vitro up }(\uparrow) \text { or } \\
\text { down }(\downarrow) \text { regulated by }\end{array}$ & Ref. \\
\hline catK & Human: expression $\uparrow$ & - & 61 \\
catL & Human: expression $\uparrow$ & $\uparrow$ by bFGF, IFN- $\gamma$, TNF- $\alpha$ & 47 \\
catS & Human: expression $\uparrow$ & $\uparrow$ by IFN- $\gamma$ & 61 \\
cysC & - Human: expression $\downarrow$ & $\uparrow$ by TGF- $\beta 1$ & 61,63 \\
& - cysC-/-apoE-/- & & \\
& mice: aortic arch circumference & & \\
& and length $\uparrow$ & & \\
\hline
\end{tabular}

Cat. $=$ cathepsin, cys. $=$ cystatin, Ref. $=$ reference number.

arteries showed an increase in elastolytic and a minor increase in collagenolytic activity $^{66}$. Furthermore, it was demonstrated that cathepsin S degrades laminin, fibronectin, and collagen type I and that SMC migration through an in vitro basement membrane matrix could be inhibited by a selective cathepsin $S$ inhibitor ${ }^{65}$.

As summarized in table II, the increased expression level of cathepsins $\mathrm{K}$ and $\mathrm{S}$ during neointima formation and the increased ECM degrading potential of cathepsin S suggest that these proteases are involved in neointima formation. Degradation of the ECM may facilitate the migration and invasion of SMCs and macrophages, thereby contributing to the arterial remodeling as observed in neointima formation and restenosis. However, until now in vivo intervention studies using inhibitors or genetically modified mice to define the exact role of these proteases in neointima formation have been lacking, nor had expression patterns of cathepsin cysteine proteases been studied in human neointima formation.

\section{CATHEPSINS IN ANEURYSM FORMATION}

By their contribution to ECM remodeling and inflammation, cathepsins may play an important role in aneurysm formation. Abdominal aortic aneurysm (AAA) formation is characterized by ECM degradation and chronic inflammation of the aortic wall, accounting for high morbidity and mortality rates ${ }^{67,68}$. Risk factors include male sex, history of atherosclerotic vascular disease, lower high density lipoprotein (HDL) values, and higher LDL levels ${ }^{69}$. Compared with normal arteries, human aortic aneurysms show increased protein levels of cathepsins $\mathrm{K}$ and $\mathrm{S}$, whereas cystatin $\mathrm{C}$ protein levels were decreased ${ }^{61}$ (see table III). These data imply that the increase in cathepsin activity exceeds the increase in cystatin activity. Cathepsins B, C, and L also showed increased activity in the 
aneurysm wall and thrombus of human aortic aneurysms when compared with normal arteries ${ }^{70-72}$. Other in vitro studies showed that unstimulated vascular SMCs do not express cathepsin $\mathrm{S}$ and show hardly any elastolytic activity, whereas SMCs stimulated with IFN- $\gamma$ secrete active cathepsin $\mathrm{S}$ and show elastolytic activity. This elastolytic activity could be inhibited by cystatin $\mathrm{C}^{44}$. TGF- $\beta 1$, a known inducer of protease inhibitors, was demonstrated to stimulate SMC cystatin $\mathrm{C}$ secretion and subsequently block SMC elastase activity in vitro ${ }^{61}$. Protein levels of cathepsin L were also increased in human AAA and atheroma ${ }^{47}$. In vitro stimulation with the proinflammatory cytokines interleukin $1 \beta$, interferon $\gamma$, and tumor necrosis factor $\alpha$ (IL-1 $\beta$, IFN- $\gamma$, TNF- $\alpha$ ) and the growth factors basic fibroblast growth factor and vascular endothelial growth factor (bFGF, VEGF) increased cathepsin L mRNA and protein expression in SMCs (induced by bFGF, IFN- $\gamma$, TNF- $\alpha$ ), endothelial cells (ECs) (similar induction as SMCs), and macrophages (induced by IFN- $\gamma$ ). Stimulation of both SMCs and ECs with bFGF increased their elastolytic and collagenolytic (type I) activity. The same was true for macrophages stimulated with IFN- $\gamma^{47}$. Furthermore, Sukhova et al. examined the effect of cystatin $\mathrm{C}$ deficiency in an atherosclerotic apoE-deficient mouse model on aneurysm formation ${ }^{63}$. They found an increase in both aortic circumference and length when cystatin $\mathrm{C}$ was absent.

The increased expression patterns of several cathepsins, including cathepsins K, L, and S, suggest involvement of these proteins in aneurysm formation. Cathepsin activity might be enhanced by inflammation, since cathepsin L and S protease activity increases after stimulation with inflammatory cytokines. Until now, in vivo intervention studies using inhibitors or genetically modified mice to define the role of cysteine protease cathepsins in aneurysm formation have been lacking.

\section{CATHEPSINS IN NEOVASCULARIZATION}

Neovascularization is defined as the formation of new blood vessels, mediated by progenitor and/or ECs. Subsequently, tube formation will take place, eventually resulting in a stabilized new blood vessel. Cathepsin B and S have been described to contribute to neovascularization by stimulating the formation of capillary-like tubular structures ${ }^{73}$ or by stimulating angiogenic islet formation and cell proliferation $^{74}$. The effect of these proteases on vessel formation has been studied extensively in tumors, but not in cardiovascular diseases.

ECs stimulated with bFGF developed capillary-like tubule structures, while cystatin $\mathrm{C}$ and a selective cathepsin S inhibitor (LHVS) reduced this tube formation by $80 \%$ and $50 \%$, respectively ${ }^{75}$. Although cathepsin S deficiency did not affect proliferation or adhesion of mouse ECs, cathepsin S-deficient ECs showed 
reduced elastolytic and type IV collagenolytic activity and a reduced capacity to invade matrigel or collagen type I gel membranes. Wounded skin shows increased expression of cathepsin $\mathrm{S}$ in macrophages, T-lymphocytes, and microvascular ECs. At the site of wound healing, cathepsin S-deficient mice showed an $80 \%$ reduction in microvessels despite normal levels of the angiogenic factors bFGF and VEGF ${ }^{75}$. These data suggest that cathepsin S plays an important role in ECM degradation, thereby facilitating microvessel formation in physiological neovascularization (wound healing).

Attraction of endothelial progenitor cells (EPCs) to the ischemic tissue is also thought to play a role in neovascularization ${ }^{76,77}$. Cathepsins $\mathrm{H}, \mathrm{L}$, and $\mathrm{O}$ were recently found to be highly expressed in EPCs compared with mature $\mathrm{ECs}^{78}$. Cathepsin L activity was higher in EPCs than in mature ECs (human umbilical venous endothelial cells or HUVECs). Gelatin and collagen (type IV) degradation activity assays in EPC extracts and culture supernatants suggested that cathepsin L was required for ECM degradation, and thus for the invasive capacity of EPCs in vitro. Mice receiving EPCs pretreated with a cathepsin L inhibitor showed impaired recovery after limb ischemia, decreased capillary density, and decreased incorporation of EPCs into vascular structures. The same was evident when mice received cathepsin L-deficient bone marrow-derived cells, indicating that cathepsin L plays a crucial role in integrating EPCs into ischemic tissue. Irradiation of mice resulted in abolishment of cathepsin $\mathrm{L}$ activity, indicating that cathepsin L activity was mediated by irradiation-sensitive cells that probably originated from the bone marrow. Finally, infusion of cathepsin L-transfected mature ECs (HUVECs) increased the recovery of limb perfusion after ischemia ${ }^{78}$. In addition, cathepsin $\mathrm{G}$, although not a cysteine protease, may play a role in neovascularization. EPCs may secrete cathepsin G to eventually promote early CXCR2-dependent EPC arrest on denuded SMCs or adherent platelets ${ }^{79}$.

Although the role of neovascularization in atherosclerosis is not completely unraveled, neovascularization is particularly prominent in complicated lesions. Furthermore, neovascularization has recently been identified as a marker of plaque vulnerability ${ }^{77,80-82}$. Together, these data indicate that cathepsins are involved in neovascularization, but data defining the role of cathepsin cysteine proteases in neovascularization related to atherosclerosis are lacking.

\section{CATHEPSINS IN RELATION TO MMPS}

In literature there is little evidence about the differential role of MMPs and cathepsins in cardiovascular disease. Reddy et al. showed that human monocyte-derived macrophages synthesize both elastinolytic MMPs (MMP-7 
and -9) and cathepsins B, L, and S. However, only the cathepsins were detected extracellularly as processed, active enzymes. Inhibition of cathepsins L and S, but not MMPs, almost completely blocked macrophage-mediated elastinolytic activity, indicating that cathepsins are the most potent elastases secreted by human macrophages $^{42}$. The relative contribution of MMPs and cathepsins in bone remodeling is studied more extensively. Cathepsin K-deficient mice showed an osteopetrotic phenotype with excessive trabeculation of the bone marrow space $^{21}$, indicating that cathepsin $\mathrm{K}$ plays a major role in osteoclastic bone resorption. However, cathepsin K-deficient mice continued to grow, suggesting that other proteases, such as MMPs, compensated for the loss of cathepsin K activity ${ }^{83}$. It was suggested that osteoclasts lower the $\mathrm{pH}$ in the resorption area, after which the bone matrix was first digested by cysteine proteases. Digestion by MMPs followed at higher $\mathrm{pH}$ levels ${ }^{84}$. Site-specificity existed in relation to digestion of the bone matrix by osteoclasts, since osteoclastic resorption of calvarial bone (intramembranous bone) was dependent on both cysteine proteases and MMP activity, whereas long bone (endochondral bone) resorption was only dependent on cysteine protease activity ${ }^{85}$. Others suggested that resorption of scapular bone (intramembranous bone) was more dependent on MMPs than cysteine proteases whereas resorption of long bone (endochondral bone) was more dependent on cysteine proteases than $\mathrm{MMPs}^{86}$. Recently, it was shown that calvarial osteoclasts use other cysteine proteases in addition to cathepsin $\mathrm{K}$ and that long bone osteoclasts use MMPs in the absence of cathepsin $\mathrm{K}^{87}$. Deficiency of other cathepsins, including cathepsins B and L, do not show osteoclast-related effects in bones. In absence of cathepsin L activity, osteoclasts do not use MMPs for the resorption of calvarial bone matrix, suggesting that cathepsin L plays a role in osteoclast-mediated bone matrix resorption by activating $\mathrm{MMPs}^{87}$.

Both MMPs (MMP-1, -2, -3, -7, -9, -11, -12, and -13) and TIMPs (TIMP-1 and -2) have been extensively studied in atherosclerosis using both overexpression and knockout studies ${ }^{1-3}$. For example, Johnson et al. studied atherosclerotic plaque stability in apoE-deficient mice lacking MMP-3, -7, -9, or -12 and found that members of the MMP family had differential effects on atherogenesis, some having a protective role (MMP-3 and -9) and others having a stimulating role (MMP-12), while deficiency of MMP-7 showed no apparent effect on atherosclerotic plaque stability $(\mathrm{MMP}-7)^{88}$. The same group showed that adenoviral infection of TIMP-2, but not TIMP-1, resulted in reduction of lesion area and macrophage content and in an increase in SMC and elastin content ${ }^{89}$. For the cathepsin cysteine protease family, only cathepsins K and S knockout studies have been described. While recent studies in bone remodeling indicate that deficiency of cathepsin $\mathrm{K}$ is compensated for by MMP activity and that cathepsins and MMPs show site specificity, more in vivo studies are needed to compare the rela- 
tive contribution and the differential role of MMPs and cathepsins in cardiovascular diseases.

\section{CATHEPSINS AND CYSTATINS AS A DIAGNOSTIC TOOL IN VASCULAR PATHOLOGY}

Several studies have evaluated the use of serum cathepsin levels as a diagnostic tool for AAAs. Using a DNA expression array, cathepsin $\mathrm{H}$ (30-fold up-regulated) was found to be up-regulated in human AAAs compared with normal aorta ${ }^{90}$. Further evaluation of a role for cathepsin $\mathrm{H}$ in the etiology of AAA, using genetic linkage analysis, did not confirm a linkage for cathepsin $\mathrm{H}$ with $\mathrm{AAA}^{91}$. A comparison of serum levels of patients with AAA versus normal aorta revealed decreased levels of serum cystatin $\mathrm{C}^{61}$, but no difference in serum cathepsins B and L levels was found ${ }^{92}$. These data suggest that measurement of serum cystatin C levels may be helpful in the diagnosis of AAA, but this requires further exploration.

Recently, the feasibility of the use of cathepsins as a tool in the diagnostic imaging of atherosclerosis was explored. In vivo imaging of cathepsin B using a cathepsin $\mathrm{B}$ imaging probe showed colocalization with cathepsin B immunoreactivity in atherosclerotic plaques ${ }^{45}$. Several other studies have suggested that cathepsins might be a useful diagnostic tool for atherosclerosis. Cathepsin L serum levels were found to be increased in patients with $>10 \%$ stenosis in at least one of the coronary arteries when compared with patients without stenosis. This increase persisted after adjustment for the confounders sex, smoking, age, and glucose levels ${ }^{47}$. Serum cathepsin S levels were also increased in patients with atherosclerotic stenosis in at least one of the coronary arteries when compared with patients without stenosis ${ }^{93}$. Serum cystatin C levels were unchanged between these groups. The increase in serum cathepsin $\mathrm{S}$ is further specified by the finding that cathepsin S may serve as a marker for adiposity, a risk factor for atherosclerosis $^{94}$. In a recent study, higher serum cystatin C levels were found to be associated with all-cause mortality, cardiovascular events and incident congestive heart failure among ambulatory persons with coronary heart disease, which could not be captured completely by changes in kidney function ${ }^{95}$. Using proteome scanning technology to identify new biomarkers for atherosclerosis, cathepsins B, L, S, and X (in order of confidence) were found to be up-regulated in THP-1 macrophages stimulated with modified (oxidized) LDL compared with THP-1 macrophages stimulated with native LDL, while cathepsin $\mathrm{H}$ was down-regulated. However, only cathepsin L was validated and confirmed to be up-regulated ${ }^{96}$. Although the data are still rather preliminary, this indicates that 

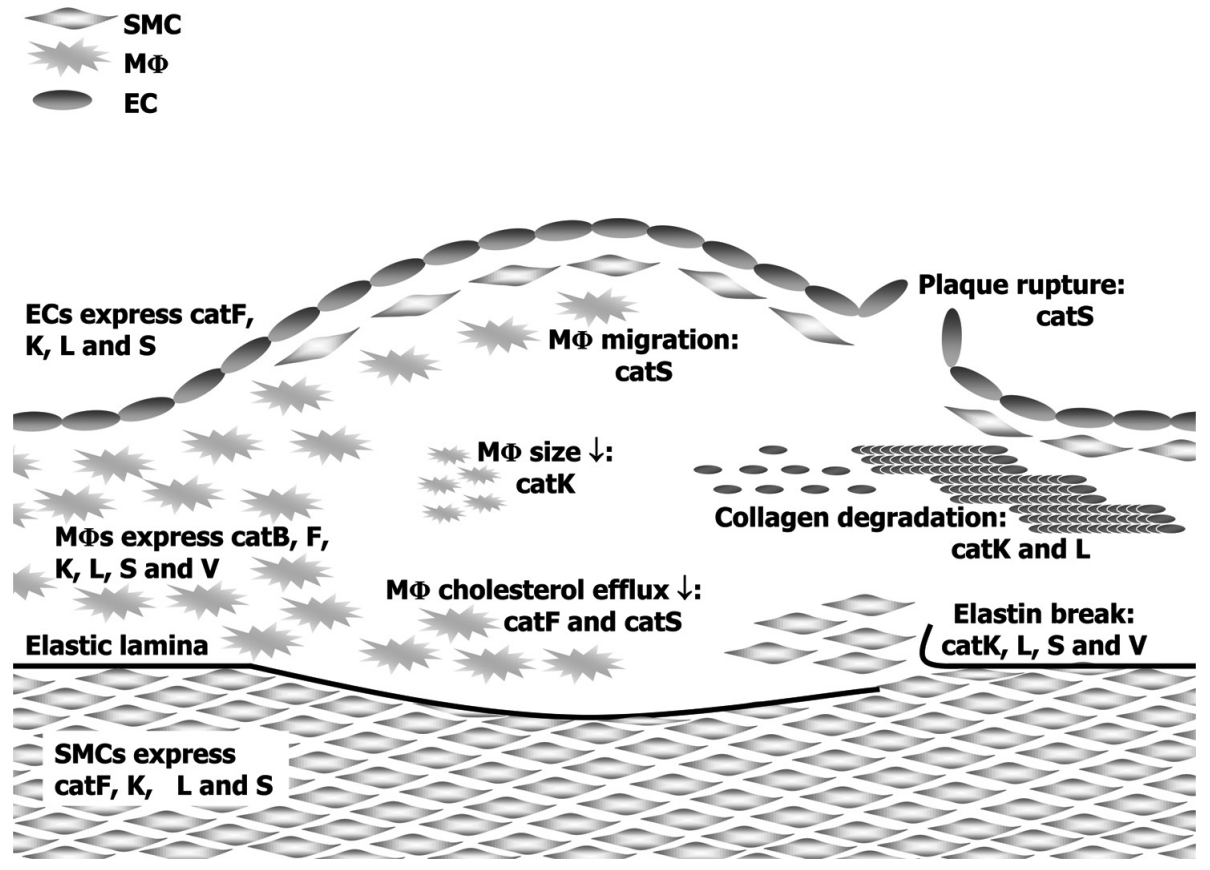

Figure 1. Overview of cathepsin expression and activity in the atherosclerotic plaque. Cathepsins are expressed in endothelial cells (EC), smooth muscle cells (SMC), and macrophages (MФ). The ECM, containing elastin and collagen, is degraded by cathepsins L, K, S, and V. Cathepsin S may even induce plaque rupture. Cathepsins $\mathrm{F}$ and $\mathrm{S}$ contribute to macrophage foam cell formation by reducing cholesterol efflux, which is counteracted by cathepsin $\mathrm{K}$ as a result of increasing lipid uptake.

several cathepsins may serve as useful biomarkers or imaging tools in the diagnosis of atherosclerosis.

\section{THERAPEUTIC POTENTIAL OF CATHEPSINS K AND S}

Over the past decade several pharmaceutical companies have become interested in cysteine protease inhibitor development. Cathepsin $\mathrm{K}$ and $\mathrm{S}$ are considered to be valuable therapeutic targets. To date, two cathepsin K-inhibiting compounds have been enrolled in clinical trials to study their effect on osteoporosis and/or osteoarthritis $^{97,98}$. A phase II study of the cathepsin K inhibitor AAE581 for the treatment of osteoporosis was reported in 2003. Preliminary results showed that the compound was well tolerated, inhibited bone resorption, and improved bone formation. The chemical structure of the compound was not disclosed. In 2002, a phase I trial of SB-462795 (relacatib) for the treatment of postmenopausal osteo- 
porosis and osteoarthritis was reported. Recently, it was shown that relacatib inhibited bone resorption in monkeys ${ }^{99,100}$. Until now, however, no data were available on the effect of AAE581, SB-462795 (relacatib), or other cathepsin K inhibitors in animal or human atherosclerosis. Currently, phase I and II clinical trials are being performed to evaluate the effectiveness of cathepsin S inhibitors for the treatment of psoriasis and osteoarthritis.

\section{SUMMARY}

Cathepsin cysteine proteases have been described to play a role in several cardiovascular diseases, including restenosis and neointima formation, aneurysm formation, and atherosclerosis. Many studies have investigated the role of cathepsin cysteine proteases in atherosclerosis (Figure 1). Cathepsins B, F, K, L, S, and V are mainly expressed in macrophages, but also in SMCs and ECs. In vivo knockout studies revealed that cathepsins $\mathrm{K}$ and $\mathrm{S}$ are important in ECM degradation, since deficiency of these cathepsins reduces plaque size, atherosclerotic plaque progression, and the number of elastin breaks. Deficiency of cystatin $\mathrm{C}$ shows opposite effects on atherosclerotic plaque size and elastin breaks. Cathepsins also play an essential role in lipid metabolism. Especially cathepsin F, but also cathepsins B, K, and $\mathrm{S}$, are important in the degradation of lipid. The role of cathepsins in cholesterol efflux seems to depend on the localization of cathepsins. Extracellular cathepsins degrade cholesterol acceptors, thereby reducing cholesterol efflux and increasing foam cell formation. Intracellular deficiency of cathepsin $\mathrm{K}$ also reduces cholesterol efflux independent of cholesterol acceptor degradation. This latter observation suggests a protective role for cathepsin $\mathrm{K}$ in foam cell formation, which is further substantiated by the increase in lipid uptake and storage by macrophages when cathepsin $\mathrm{K}$ is absent.

Although to date no in vivo studies are available for the role of cathepsins in neointima and aneurysm formation, changes in expression levels of cathepsins $\mathrm{K}$, $\mathrm{L}, \mathrm{S}$, and the natural inhibitor of cathepsins, cystatin $\mathrm{C}$, in diseased arteries strongly suggest a role for these proteins in both neointima and aneurysm formation. Degradation of the ECM by cathepsin cysteine proteases may facilitate the migration and invasion of SMCs and macrophages, thereby contributing to neointima formation. The inflammatory status as seen in aneurysms may contribute to cathepsin activity, thereby increasing ECM degradation and possibly contributing to the formation of aneurysms. Furthermore, both cathepsins $\mathrm{L}$ and $\mathrm{S}$ have been described to play a role in neovascularization by degradation of the ECM. However, in vivo data exploring the role of cathepsins in relation to neovascularization in cardiovascular disease are still lacking. 
Recent findings also indicate a possible role for cathepsins as a diagnostic tool both as imaging device and as biomarker. The current quest for cathepsins as diagnostic tool seems a reasonable goal in atherosclerosis research. Furthermore, inhibitors of cathepsins $\mathrm{K}$ and $\mathrm{S}$ have been evaluated in (pre) clinical evaluation for the use as a therapy. Especially cathepsin $\mathrm{K}$ inhibitors show promising results in treating osteoporosis and osteoarthritis. However, until now no data were available on the effect of these inhibitors in atherosclerosis.

\section{REFERENCES}

1. Newby AC. Dual role of matrix metalloproteinases (matrixins) in intimal thickening and atherosclerotic plaque rupture. Physiol Rev. Jan 2005;85(1):1-31.

2. Keeling WB, Armstrong PA, Stone PA, Bandyk DF, Shames ML. An overview of matrix metalloproteinases in the pathogenesis and treatment of abdominal aortic aneurysms. Vasc Endovascular Surg. Nov-Dec 2005;39(6):457-464.

3. Lijnen HR. Metalloproteinases in development and progression of vascular disease. Pathophysiol Haemost Thromb. Sep-2004 Dec 2003;33(5-6):275-281.

4. Liu J, Sukhova GK, Sun JS, Xu WH, Libby P, Shi GP. Lysosomal cysteine proteases in atherosclerosis. Arterioscler Thromb Vasc Biol. Aug 2004;24(8):1359-1366.

5. Sukhova GK, Shi GP. Do cathepsins play a role in abdominal aortic aneurysm pathogenesis? Ann N Y Acad Sci. Nov 2006;1085:161-169.

6. Neurath $\mathrm{H}$, Walsh KA. Role of proteolytic enzymes in biological regulation (a review). Proc Natl Acad Sci U S A. Nov 1976;73(11):3825-3832.

7. Chapman HA, Riese RJ, Shi GP. Emerging roles for cysteine proteases in human biology. Annu Rev Physiol. 1997;59:63-88.

8. Turk B, Turk V, Turk D. Structural and functional aspects of papain-like cysteine proteinases and their protein inhibitors. Biol Chem. Mar-Apr 1997;378(3-4):141-150.

9. Turk B, Turk D, Turk V. Lysosomal cysteine proteases: more than scavengers. Biochim Biophys Acta. Mar 7 2000;1477(1-2):98-111.

10. Turk V, Turk B, Turk D. Lysosomal cysteine proteases: facts and opportunities. Embo J. Sep 3 2001;20(17):4629-4633.

11. Aronson NN, Jr., Barrett AJ. The specificity of cathepsin B. Hydrolysis of glucagon at the C-terminus by a peptidyldipeptidase mechanism. Biochem J. Jun 1 1978;171(3):759-765.

12. Koga H, Mori N, Yamada H, Nishimura Y, Tokuda K, Kato K, Imoto T. Endo- and aminopeptidase activities of rat cathepsin H. Chem Pharm Bull (Tokyo). Apr 1992;40(4): 965-970.

13. Klemencic I, Carmona AK, Cezari MH, Juliano MA, Juliano L, Guncar G, Turk D, Krizaj I, Turk V, Turk B. Biochemical characterization of human cathepsin X revealed that the enzyme is an exopeptidase, acting as carboxymonopeptidase or carboxydipeptidase. Eur J Biochem. Sep 2000;267(17):5404-5412.

14. Dubin G. Proteinaceous cysteine protease inhibitors. Cell Mol Life Sci. Mar 2005;62(6): 653-669.

15. Turk V, Bode W. The cystatins: protein inhibitors of cysteine proteinases. FEBS Lett. Jul 22 1991;285(2):213-219. 
16. Hall A, Ekiel I, Mason RW, Kasprzykowski F, Grubb A, Abrahamson M. Structural basis for different inhibitory specificities of human cystatins C and D. Biochemistry. Mar 24 1998;37(12):4071-4079.

17. Hart TC, Hart PS, Bowden DW, Michalec MD, Callison SA, Walker SJ, Zhang Y, Firatli E. Mutations of the cathepsin $\mathrm{C}$ gene are responsible for Papillon-Lefevre syndrome. J Med Genet. Dec 1999;36(12):881-887.

18. Gelb BD, Shi GP, Chapman HA, Desnick RJ. Pycnodysostosis, a lysosomal disease caused by cathepsin K deficiency. Science. Aug 30 1996;273(5279):1236-1238.

19. Deussing J, Roth W, Saftig P, Peters C, Ploegh HL, Villadangos JA. Cathepsins B and D are dispensable for major histocompatibility complex class II-mediated antigen presentation. Proc Natl Acad Sci U S A. Apr 14 1998;95(8):4516-4521.

20. Tang CH, Lee JW, Galvez MG, Robillard L, Mole SE, Chapman HA. Murine cathepsin F deficiency causes neuronal lipofuscinosis and late-onset neurological disease. Mol Cell Biol. Mar 2006;26(6):2309-2316.

21. Saftig P, Hunziker E, Wehmeyer O, Jones S, Boyde A, Rommerskirch W, Moritz JD, Schu P, von Figura K. Impaired osteoclastic bone resorption leads to osteopetrosis in cathepsin-K-deficient mice. Proc Natl Acad Sci U S A. Nov 10 1998;95(23):1345313458.

22. Nakagawa TY, Brissette WH, Lira PD, Griffiths RJ, Petrushova N, Stock J, McNeish JD, Eastman SE, Howard ED, Clarke SR, Rosloniec EF, Elliott EA, Rudensky AY. Impaired invariant chain degradation and antigen presentation and diminished collagen-induced arthritis in cathepsin S null mice. Immunity. Feb 1999;10(2):207-217.

23. Shi GP, Villadangos JA, Dranoff G, Small C, Gu L, Haley KJ, Riese R, Ploegh HL, Chapman HA. Cathepsin S required for normal MHC class II peptide loading and germinal center development. Immunity. Feb 1999;10(2):197-206.

24. Ondr JK, Pham CT. Characterization of murine cathepsin W and its role in cell-mediated cytotoxicity. J Biol Chem. Jun 25 2004;279(26):27525-27533.

25. Maciewicz RA, Wotton SF, Etherington DJ, Duance VC. Susceptibility of the cartilage collagens types II, IX and XI to degradation by the cysteine proteinases, cathepsins B and L. FEBS Lett. Aug 20 1990;269(1):189-193.

26. Bromme D, Okamoto K, Wang BB, Biroc S. Human cathepsin O2, a matrix protein-degrading cysteine protease expressed in osteoclasts. Functional expression of human cathepsin $\mathrm{O} 2$ in Spodoptera frugiperda and characterization of the enzyme.J Biol Chem. Jan 26 1996;271(4):2126-2132.

27. Garnero P, Borel O, Byrjalsen I, Ferreras M, Drake FH, McQueney MS, Foged NT, Delmas PD, Delaisse JM. The collagenolytic activity of cathepsin K is unique among mammalian proteinases. J Biol Chem. Nov 27 1998;273(48):32347-32352.

28. Yasuda Y, Li Z, Greenbaum D, Bogyo M, Weber E, Bromme D. Cathepsin V, a novel and potent elastolytic activity expressed in activated macrophages. J Biol Chem. Aug 27 2004;279(35):36761-36770.

29. Shi GP, Munger JS, Meara JP, Rich DH, Chapman HA. Molecular cloning and expression of human alveolar macrophage cathepsin S, an elastinolytic cysteine protease. J Biol Chem. Apr 15 1992;267(11):7258-7262.

30. Honey K, Rudensky AY. Lysosomal cysteine proteases regulate antigen presentation. Nat Rev Immunol. Jun 2003;3(6):472-482.

31. Hsing LC, Rudensky AY. The lysosomal cysteine proteases in MHC class II antigen presentation. Immunol Rev. Oct 2005;207:229-241. 
32. Shi GP, Bryant RA, Riese R, Verhelst S, Driessen C, Li Z, Bromme D, Ploegh HL, Chapman HA. Role for cathepsin $\mathrm{F}$ in invariant chain processing and major histocompatibility complex class II peptide loading by macrophages. J Exp Med. Apr 3 2000;191(7):1177-1186.

33. Hsieh CS, deRoos P, Honey K, Beers C, Rudensky AY. A role for cathepsin L and cathepsin $\mathrm{S}$ in peptide generation for MHC class II presentation. J Immunol. Mar 15 2002;168(6):2618-2625.

34. Riese RJ, Mitchell RN, Villadangos JA, Shi GP, Palmer JT, Karp ER, De Sanctis GT, Ploegh HL, Chapman HA. Cathepsin S activity regulates antigen presentation and immunity. J Clin Invest. Jun 1 1998;101(11):2351-2363.

35. Beers C, Honey K, Fink S, Forbush K, Rudensky A. Differential regulation of cathepsin $\mathrm{S}$ and cathepsin $\mathrm{L}$ in interferon gamma-treated macrophages. J Exp Med. Jan 20 2003;197(2):169-179.

36. Bania J, Gatti E, Lelouard H, David A, Cappello F, Weber E, Camosseto V, Pierre P. Human cathepsin S, but not cathepsin L, degrades efficiently MHC class II-associated invariant chain in nonprofessional APCs. Proc Natl Acad Sci U S A. May 27 2003;100(11):6664-6669.

37. Beers C, Burich A, Kleijmeer MJ, Griffith JM, Wong P, Rudensky AY. Cathepsin S controls MHC class II-mediated antigen presentation by epithelial cells in vivo. $J$ Immunol. Feb 1 2005;174(3):1205-1212.

38. Chwieralski CE, Welte T, Buhling F. Cathepsin-regulated apoptosis. Apoptosis. Feb 2006;11(2):143-149.

39. Li W, Yuan XM. Increased expression and translocation of lysosomal cathepsins contribute to macrophage apoptosis in atherogenesis. Ann NY Acad Sci. Dec 2004;1030:427-433.

40. Li W, Dalen H, Eaton JW, Yuan XM. Apoptotic death of inflammatory cells in human atheroma. Arterioscler Thromb Vasc Biol. Jul 2001;21(7):1124-1130.

41. Liu N, Raja SM, Zazzeroni F, Metkar SS, Shah R, Zhang M, Wang Y, Bromme D, Russin WA, Lee JC, Peter ME, Froelich CJ, Franzoso G, Ashton-Rickardt PG. NF-kappaB protects from the lysosomal pathway of cell death. Embo J. Oct 1 2003;22(19):5313-5322.

42. Reddy VY, Zhang QY, Weiss SJ. Pericellular mobilization of the tissue-destructive cysteine proteinases, cathepsins B, L, and S, by human monocyte-derived macrophages. Proc Natl Acad Sci U S A. Apr 25 1995;92(9):3849-3853.

43. Jormsjo S, Wuttge DM, Sirsjo A, Whatling C, Hamsten A, Stemme S, Eriksson P. Differential expression of cysteine and aspartic proteases during progression of atherosclerosis in apolipoprotein E-deficient mice. Am J Pathol. Sep 2002;161(3):939-945.

44. Sukhova GK, Shi GP, Simon DI, Chapman HA, Libby P. Expression of the elastolytic cathepsins $\mathrm{S}$ and $\mathrm{K}$ in human atheroma and regulation of their production in smooth muscle cells. J Clin Invest. Aug 1 1998;102(3):576-583.

45. Chen J, Tung CH, Mahmood U, Ntziachristos V, Gyurko R, Fishman MC, Huang PL, Weissleder R. In vivo imaging of proteolytic activity in atherosclerosis. Circulation. Jun 11 2002;105(23):2766-2771.

46. Oorni K, Sneck M, Bromme D, Pentikainen MO, Lindstedt KA, Mayranpaa M, Aitio $\mathrm{H}$, Kovanen PT. Cysteine protease cathepsin $\mathrm{F}$ is expressed in human atherosclerotic lesions, is secreted by cultured macrophages, and modifies low density lipoprotein particles in vitro. J Biol Chem. Aug 13 2004;279(33):34776-34784. 
47. Liu J, Sukhova GK, YangJT, Sun J, Ma L, Ren A, Xu WH, Fu H, Dolganov GM, Hu C, Libby P, Shi GP. Cathepsin L expression and regulation in human abdominal aortic aneurysm, atherosclerosis, and vascular cells. Atherosclerosis. Feb 2006;184(2):302-311.

48. Lutgens E, Lutgens SP, Faber BC, Heeneman S, Gijbels MM, de Winther MP, Frederik P, van der Made I, Daugherty A, Sijbers AM, Fisher A, Long CJ, Saftig P, Black D, Daemen MJ, Cleutjens KB. Disruption of the cathepsin K gene reduces atherosclerosis progression and induces plaque fibrosis but accelerates macrophage foam cell formation. Circulation. Jan 3 2006;113(1):98-107.

49. Sukhova GK, Zhang Y, Pan JH, Wada Y, Yamamoto T, Naito M, Kodama T, Tsimikas S, Witztum JL, Lu ML, Sakara Y, Chin MT, Libby P, Shi GP. Deficiency of cathepsin S reduces atherosclerosis in LDL receptor-deficient mice. $J$ Clin Invest. Mar 2003;111(6):897-906.

50. Rodgers KJ, Watkins DJ, Miller AL, Chan PY, Karanam S, Brissette WH, Long CJ, Jackson CL. Destabilizing role of cathepsin $\mathrm{S}$ in murine atherosclerotic plaques. Arterioscler Thromb Vasc Biol. Apr 2006;26(4):851-856.

51. Lutgens S, Kisters N, Lutgens E, van Haaften R, Evelo C, de Winther M, Saftig P, Daemen M, Heeneman S, Cleutjens K. Gene profiling of cathepsin K deficiency in atherogenesis: profibrotic but lipogenic. J Pathol. Sep 142006.

52. Cheng XW, Kuzuya M, Nakamura K, Di Q, Liu Z, Sasaki T, Kanda S, Jin H, Shi GP, Murohara T, Yokota M, Iguchi A. Localization of cysteine protease, cathepsin S, to the surface of vascular smooth muscle cells by association with integrin alphanubeta3. Am J Pathol. Feb 2006;168(2):685-694.

53. Punturieri A, Filippov S, Allen E, Caras I, Murray R, Reddy V, Weiss SJ. Regulation of elastinolytic cysteine proteinase activity in normal and cathepsin K-deficient human macrophages. J Exp Med. Sep 18 2000;192(6):789-799.

54. Zarins CK, Giddens DP, Bharadvaj BK, Sottiurai VS, Mabon RF, Glagov S. Carotid bifurcation atherosclerosis. Quantitative correlation of plaque localization with flow velocity profiles and wall shear stress. Circ Res. Oct 1983;53(4):502-514.

55. Platt MO, Ankeny RF, Jo H. Laminar Shear Stress Inhibits Cathepsin L Activity in Endothelial Cells. Arterioscler Thromb Vasc Biol. May 182006.

56. Platt MO, Ankeny RF, Shi GP, Weiss D, Taylor WR, Vega JD, Jo H. Expression of cathepsin $\mathrm{K}$ is regulated by shear stress in cultured endothelial cells and is increased in endothelium in human atherosclerosis. Am J Physiol Heart Circ Physiol. Nov 102006.

57. Li W, Yuan XM, Olsson AG, Brunk UT. Uptake of oxidized LDL by macrophages results in partial lysosomal enzyme inactivation and relocation. Arterioscler Thromb Vasc Biol. Feb 1998;18(2):177-184.

58. Tertov VV, Orekhov AN. Metabolism of native and naturally occurring multiple modified low density lipoprotein in smooth muscle cells of human aortic intima. Exp Mol Pathol. 1997;64(3):127-145.

59. Lindstedt L, Lee M, Oorni K, Bromme D, Kovanen PT. Cathepsins F and S block HDL3-induced cholesterol efflux from macrophage foam cells. Biochem Biophys Res Commun. Dec 26 2003;312(4):1019-1024.

60. Lutgens E, Gijbels M, Smook M, Heeringa P, Gotwals P, Koteliansky VE, Daemen MJ. Transforming growth factor-beta mediates balance between inflammation and fibrosis during plaque progression. Arterioscler Thromb Vasc Biol. Jun 1 2002;22(6):975-982. 
61. Shi GP, Sukhova GK, Grubb A, Ducharme A, Rhode LH, Lee RT, Ridker PM, Libby $\mathrm{P}$, Chapman HA. Cystatin C deficiency in human atherosclerosis and aortic aneurysms. J Clin Invest. Nov 1999;104(9):1191-1197.

62. Bengtsson E, To F, Hakansson K, Grubb A, Branen L, Nilsson J, Jovinge S. Lack of the cysteine protease inhibitor cystatin $\mathrm{C}$ promotes atherosclerosis in apolipoprotein E-deficient mice. Arterioscler Thromb Vasc Biol. Oct 2005;25(10):2151-2156.

63. Sukhova GK, Wang B, Libby P, Pan JH, Zhang Y, Grubb A, Fang K, Chapman HA, Shi GP. Cystatin C deficiency increases elastic lamina degradation and aortic dilatation in apolipoprotein E-null mice. Circ Res. Feb 18 2005;96(3):368-375.

64. Schwartz RS, Henry TD. Pathophysiology of coronary artery restenosis. Rev Cardiovasc Med. 2002;3 Suppl 5:S4-9.

65. Burns-Kurtis CL, Olzinski AR, Needle S, Fox JH, Capper EA, Kelly FM, McQueney MS, Romanic AM. Cathepsin S expression is up-regulated following balloon angioplasty in the hypercholesterolemic rabbit. Cardiovasc Res. Jun 1 2004;62(3): 610-620.

66. Cheng XW, Kuzuya M, Sasaki T, Arakawa K, Kanda S, Sumi D, Koike T, Maeda K, Tamaya-Mori N, Shi GP, Saito N, Iguchi A. Increased expression of elastolytic cysteine proteases, cathepsins $\mathrm{S}$ and $\mathrm{K}$, in the neointima of balloon-injured rat carotid arteries. $\mathrm{Am}$ J Pathol. Jan 2004;164(1):243-251.

67. Kadoglou NP, Liapis CD. Matrix metalloproteinases: contribution to pathogenesis, diagnosis, surveillance and treatment of abdominal aortic aneurysms. Curr Med Res Opin. Apr 2004;20(4):419-432.

68. Shimizu K, Mitchell RN, Libby P. Inflammation and cellular immune responses in abdominal aortic aneurysms. Arterioscler Thromb Vasc Biol. May 2006;26(5):987-994.

69. Alcorn HG, Wolfson SK, Jr., Sutton-Tyrrell K, Kuller LH, O’Leary D. Risk factors for abdominal aortic aneurysms in older adults enrolled in The Cardiovascular Health Study. Arterioscler Thromb Vasc Biol. Aug 1996;16(8):963-970.

70. Gacko M, Chyczewski L, Chrostek L. Distribution, activity and concentration of cathepsin B and cystatin C in the wall of aortic aneurysm. PolJ Pathol. 1999;50(2):83-86.

71. Gacko M, Glowinski S. Cathepsin D and cathepsin L activities in aortic aneurysm wall and parietal thrombus. Clin Chem Lab Med. Jun 1998;36(7):449-452.

72. Gacko M, Glowinski S. Activities of proteases in parietal thrombus of aortic aneurysm. Clin Chim Acta. Mar 23 1998;271(2):171-177.

73. Premzl A, Turk V, Kos J. Intracellular proteolytic activity of cathepsin B is associated with capillary-like tube formation by endothelial cells in vitro. J Cell Biochem. Apr 15 2006;97(6):1230-1240.

74. Wang B, Sun J, Kitamoto S, Yang M, Grubb A, Chapman HA, Kalluri R, Shi GP. Cathepsin $\mathrm{S}$ controls angiogenesis and tumor growth via matrix-derived angiogenic factors. J Biol Chem. Mar 3 2006;281(9):6020-6029.

75. Shi GP, Sukhova GK, Kuzuya M, Ye Q, Du J, Zhang Y, Pan JH, Lu ML, Cheng XW, Iguchi A, Perrey S, Lee AM, Chapman HA, Libby P. Deficiency of the cysteine protease cathepsin S impairs microvessel growth. Circ Res. Mar 21 2003;92(5):493-500.

76. Asahara T, Murohara T, Sullivan A, Silver M, van der Zee R, Li T, Witzenbichler B, Schatteman G, Isner JM. Isolation of putative progenitor endothelial cells for angiogenesis. Science. Feb 14 1997;275(5302):964-967.

77. Khurana R, Simons M, Martin JF, Zachary IC. Role of angiogenesis in cardiovascular disease: a critical appraisal. Circulation. Sep 20 2005;112(12):1813-1824. 
78. Urbich C, Heeschen C, Aicher A, Sasaki K, Bruhl T, Farhadi MR, Vajkoczy P, Hofmann WK, Peters C, Pennacchio LA, Abolmaali ND, Chavakis E, Reinheckel T, Zeiher AM, Dimmeler S. Cathepsin L is required for endothelial progenitor cell-induced neovascularization. Nat Med. Feb 2005;11(2):206-213.

79. Hristov M, Zernecke A, Bidzhekov K, Liehn EA, Shagdarsuren E, Ludwig A, Weber C. Importance of CXC chemokine receptor 2 in the homing of human peripheral blood endothelial progenitor cells to sites of arterial injury. Circ Res. Mar 2 2007;100(4): 590-597.

80. Herrmann J, Lerman LO, Mukhopadhyay D, Napoli C, Lerman A. Angiogenesis in Atherogenesis. Arterioscler Thromb Vasc Biol. Jun 222006.

81. Moreno PR, Purushothaman KR, Sirol M, Levy AP, Fuster V. Neovascularization in human atherosclerosis. Circulation. May 9 2006;113(18):2245-2252.

82. Purushothaman KR, Sanz J, Zias E, Fuster V, Moreno PR. Atherosclerosis neovascularization and imaging. Curr Mol Med. Aug 2006;6(5):549-556.

83. Okaji M, Sakai H, Sakai E, Shibata M, Hashimoto F, Kobayashi Y, Yoshida N, Okamoto $\mathrm{K}$, Yamamoto K, Kato Y. The regulation of bone resorption in tooth formation and eruption processes in mouse alveolar crest devoid of cathepsin k. J Pharmacol Sci. Apr 2003;91(4):285-294.

84. Everts V, Delaisse JM, Korper W, Beertsen W. Cysteine proteinases and matrix metalloproteinases play distinct roles in the subosteoclastic resorption zone.J Bone Miner Res. Sep 1998;13(9):1420-1430.

85. Everts V, Korper W, Jansen DC, Steinfort J, Lammerse I, Heera S, Docherty AJ, Beertsen W. Functional heterogeneity of osteoclasts: matrix metalloproteinases participate in osteoclastic resorption of calvarial bone but not in resorption of long bone. Faseb J. Jul 1999;13(10):1219-1230.

86. Shorey S, Heersche JN, Manolson MF. The relative contribution of cysteine proteinases and matrix metalloproteinases to the resorption process in osteoclasts derived from long bone and scapula. Bone. Oct 2004;35(4):909-917.

87. Everts V, Korper W, Hoeben KA, Jansen ID, Bromme D, Cleutjens KB, Heeneman S, Peters C, Reinheckel T, Saftig P, Beertsen W. Osteoclastic bone degradation and the role of different cysteine proteinases and matrix metalloproteinases: differences between calvaria and long bone. J Bone Miner Res. Sep 2006;21(9):1399-1408.

88. Johnson JL, George SJ, Newby AC, Jackson CL. Divergent effects of matrix metalloproteinases $3,7,9$, and 12 on atherosclerotic plaque stability in mouse brachiocephalic arteries. Proc Natl Acad Sci U S A. Oct 25 2005;102(43):15575-15580.

89. Johnson JL, Baker AH, Oka K, Chan L, Newby AC, Jackson CL, George SJ. Suppression of atherosclerotic plaque progression and instability by tissue inhibitor of metalloproteinase-2: involvement of macrophage migration and apoptosis. Circulation. May 23 2006;113(20):2435-2444.

90. Tung WS, Lee JK, Thompson RW. Simultaneous analysis of 1176 gene products in normal human aorta and abdominal aortic aneurysms using a membrane-based complementary DNA expression array. J Vasc Surg. Jul 2001;34(1):143-150.

91. van Vlijmen-van Keulen CJ, Vahl AC, Hennekam RC, Rauwerda JA, Pals G. Genetic linkage of candidate genes in families with abdominal aortic aneurysms? Eur J Vasc Endovasc Surg. Aug 2003;26(2):205-210. 
92. Gacko M, Ostapowicz R, Chrostek L, Worowska A, Kordecki K. Activity of enzymes with different subcellular localization in the blood plasma of patients with aortic aneurysm. Med Sci Monit. Apr 2005;11(4):CR211-213.

93. Liu J, Ma L, Yang J, Ren A, Sun Z, Yan G, Sun J, Fu H, Xu W, Hu C, Shi GP. Increased serum cathepsin $\mathrm{S}$ in patients with atherosclerosis and diabetes. Atherosclerosis. Jun 2006;186(2):411-419.

94. Taleb S, Lacasa D, Bastard JP, Poitou C, Cancello R, Pelloux V, Viguerie N, Benis A, Zucker JD, Bouillot JL, Coussieu C, Basdevant A, Langin D, Clement K. Cathepsin S, a novel biomarker of adiposity: relevance to atherogenesis. Faseb J. Sep 2005;19(11): 1540-1542.

95. Ix JH, Shlipak MG, Chertow GM, Whooley MA. Association of cystatin C with mortality, cardiovascular events, and incident heart failure among persons with coronary heart disease: data from the Heart and Soul Study. Circulation. Jan 16 2007;115(2): 173-179.

96. Fach EM, Garulacan LA, Gao J, Xiao Q, Storm SM, Dubaquie YP, Hefta SA, Opiteck GJ. In vitro biomarker discovery for atherosclerosis by proteomics. Mol Cell Proteomics. Dec 2004;3(12):1200-1210.

97. Abbenante G, Fairlie DP. Protease inhibitors in the clinic. Med Chem. Jan 2005;1(1): 71-104.

98. Yasuda Y, Kaleta J, Bromme D. The role of cathepsins in osteoporosis and arthritis: rationale for the design of new therapeutics. Adv Drug Deliv Rev. May 25 2005;57(7): 973-993.

99. Kumar S, Dare L, Vasko-Moser JA, James IE, Blake SM, Rickard DJ, Hwang SM, Tomaszek T, Yamashita DS, Marquis RW, Oh H, JeongJU, Veber DF, Gowen M, Lark MW, Stroup G. A highly potent inhibitor of cathepsin K (relacatib) reduces biomarkers of bone resorption both in vitro and in an acute model of elevated bone turnover in vivo in monkeys. Bone. Jan 2007;40(1):122-131.

100. Yamashita DS, Marquis RW, Xie R, Nidamarthy SD, Oh HJ, Jeong JU, Erhard KF, Ward KW, Roethke TJ, Smith BR, Cheng HY, Geng X, Lin F, Offen PH, Wang B, Nevins N, Head MS, Haltiwanger RC, Narducci Sarjeant AA, Liable-Sands LM, Zhao B, Smith WW, Janson CA, Gao E, Tomaszek T, McQueney M, James IE, Gress CJ, Zembryki DL, Lark MW, Veber DF. Structure activity relationships of 5-, 6-, and 7-methyl-substituted azepan-3-one cathepsin K inhibitors. J Med Chem. Mar 9 2006;49(5):1597-1612 . 


\section{Chapter 3 \\ Disruption of the cathepsin $\mathrm{K}$ gene reduces atherosclerosis progression and induces plaque fibrosis but accelerates macrophage foam cell formation}

Suzanne P.M. Lutgens ${ }^{1} \star$, Esther Lutgens ${ }^{1} \star$, Birgit C.G. Faber ${ }^{1}$, Sylvia Heeneman ${ }^{1}$, Marion M.J. Gijbels ${ }^{1,2}$, Menno P.J de Winther ${ }^{2}$, Peter Frederik ${ }^{3}$, Inge van der Made ${ }^{2}$, Alan Daugherty ${ }^{4}$, Anneke M. Sijbers ${ }^{5}$, Angela Fisher ${ }^{5}$, Clive J. Long ${ }^{5}$, Paul Saftig ${ }^{6}$, Darcey Black ${ }^{5}$, Mat J.A.P. Daemen ${ }^{1}$, Kitty B.J.M. Cleutjens ${ }^{1} \star$ Both authors have contributed equally

Departments of Pathology ${ }^{1}$, Molecular Genetics ${ }^{2}$ and Electron Microscopy ${ }^{3}$, Cardiovascular Research Institute Maastricht (CARIM), University of Maastricht, Maastricht, the Netherlands; University of Kentucky ${ }^{4}$, Lexington; Organon Scotland ${ }^{5}$, Newhouse, Scotland; Biochemical Institute ${ }^{6}$, University of Kiel, Germany. 


\section{ABSTRACT}

Cathepsin K (catK), a lysosomal cysteine protease, was identified in a gene-profiling experiment that compared human early plaques, advanced stable plaques, and advanced atherosclerotic plaques containing a thrombus, where it was highly upregulated in advanced stable plaques.

To assess the function of cathepsin $\mathrm{K}$ in atherosclerosis, catK-/-/apoE-/- mice were generated. At 26 weeks of age, plaque area in the catK-/-/apoE-/- mice was reduced $(41.8 \%)$ owing to a decrease in the number of advanced lesions as well as a decrease in individual advanced plaque area. This suggests an important role for cathepsin $\mathrm{K}$ in atherosclerosis progression.

Advanced plaques of catK-/-/apoE-/- mice showed an increase in collagen content. Medial elastin fibers were less prone to rupture than those of apoE-/mice. Although the relative macrophage content did not differ, individual macrophage size increased. In vitro studies of bone marrow derived macrophages confirmed this observation. Scavenger receptor mediated uptake (particularly by CD36) of modified LDL increased in absence of cathepsin K, resulting in an increased macrophage size because of increased cellular storage of cholesterol esters, thereby enlarging the lysosomes.

A deficiency of cathepsin $\mathrm{K}$ reduces plaque progression and induces plaque fibrosis but aggravates macrophage foam cell formation in atherosclerosis. 


\section{INTRODUCTION}

Proteases have been linked to the cascade of pathological alterations involved in atherosclerosis. The lysosomal cysteine proteases, or cathepsins ${ }^{1}$, recently received much interest in the vascular field ${ }^{2}$. Large scale gene expression studies indicated differential expression of cathepsin B, L, S and $\mathrm{H}$ mRNAs in atherosclerotic human and mouse $\operatorname{arteries}^{3-6}$. Cathepsin S, D, F, K, L, and V proteins $^{7-10}$ were present in human atheromata. Interestingly, cysteine proteases account for $40 \%$ of the total elastase activity of human atheroma extracts ${ }^{7}$.

Genetic disruption of the cathepsin S gene reduced plaque progression in LDL receptor deficient mice ${ }^{11}$ and inhibited angiogenesis ${ }^{12}$. Cathepsin $\mathrm{L}$ is required for endothelial progenitor cell induced neovascularization ${ }^{13}$. In addition, a decrease in cystatin $\mathrm{C}$ levels, the most abundant extracellular inhibitor of cysteine proteases $^{14}$, was frequently observed in patients with severe vascular disease ${ }^{15}$. Apolipoprotein (apo) E-/- mice deficient in cystatin C developed atherosclerotic plaques that were rich in collagen and smooth muscle cells (SMCs) and developed progressive aortic dilatation ${ }^{16}$. These data indicate an important role in plaque progression.

In a recent suppressive subtractive hybridization analysis of whole-mount human atherosclerotic plaques that compared stable atherosclerotic plaques and plaques containing thrombus, we identified upregulation of cathepsin $\mathrm{K}$ (catK) in advanced stable plaques ${ }^{17}$. Cathepsin $\mathrm{K}$ is composed of a 15 -residue $\mathrm{N}$-terminal signal peptide, a 99-residue propeptide, and a mature protein of 215 amino acids. Cathepsin $\mathrm{K}$ is the most potent mammalian elastase yet described and harbors unique collagenolytic activity ${ }^{18,19}$. Cathepsin $\mathrm{K}$ was originally identified in an osteoclast cDNA library, but it has since been found to be expressed in many tissues such as arteries, breast, ovary, stomach, and lung ${ }^{7,18,20-22}$.

In the present study, we show that cathepsin $\mathrm{K}$ mRNA and protein expression is highly upregulated in advanced human atherosclerotic lesions. We further investigated the role of cathepsin $\mathrm{K}$ in atherosclerosis by studying mice deficient in apoE (apoE-/-) and cathepsin K (catK-/-/apoE-/- mice). Here we show that a deficiency of cathepsin $\mathrm{K}$ not only reduces plaque progression and induces fibrosis but also affects macrophage foam cell formation.

\section{METHODS}

\section{Tissue sampling}

Atherosclerotic plaques were obtained from patients undergoing vascular surgery (Department of General Surgery, Academic Hospital Maastricht, the Nether- 
lands) or at autopsy (Department of Pathology, Academic Hospital Maastricht, the Netherlands). Vascular specimens were processed as described ${ }^{17}$ and classified according Virmani et al. ${ }^{23}$.

\section{Dot blot analysis}

Five dot-blots containing cathepsin K cDNA ( 20 ng per spot) were hybridized at high stringency with ${ }^{32} \mathrm{P}$-labeled (High Prime, Boehringer Mannheim) SMART cDNA derived from pooled ( $\mathrm{n}=3$ per group) whole-mount human vascular plaques ${ }^{17}$. Hybridization signals from (1) nondiseased arteries, (2) early atherosclerotic lesions, (3) advanced stable plaques, (4) lesions containing thrombus, and (5) veins were quantified by PhosphorImager analysis (Quantity One, Bio-Rad) and normalized for the signals of RNA polymerase II and human genomic DNA.

\section{Reverse transcription-polymerase chain reaction}

RNA was isolated from individual samples of veins $(n=5)$, nondiseased arteries $(n=4)$, early atherosclerotic plaques $(n=5)$, advanced lesions $(n=10)$, and lesions with thrombi $(n=10)$ and reverse transcriptase-polymerase chain reaction (RT-PCR) was performed for cathepsin K and glyceraldehyde 3-phosphate dehydrogenase.

\section{Western blot analysis}

Blots were incubated with mouse monoclonal anti-cathepsin $\mathrm{K}$ antibody (5 $\mu \mathrm{g} / \mathrm{ml}$, Calbiochem) or phosphate-buffered saline, and horseradish peroxidase-coupled rabbit anti-mouse antibody (1:1000, Dako). Specific antibody binding was visualized by enhanced chemiluminescence (Amersham Pharmacia Biotech).

\section{Animals}

7ApoE-/- mice on a C57BL6 background were obtained from Iffa Credo (Lyon, France) and backcrossed 5 to 7 times to catK-/- mice (C57BL6 background; P. Saftig). During the experimental period, mice were fed a normal chow diet. At the age of 26 weeks, male catK-/-/apoE-/ - $(n=7)$, apoE-/- $(n=8)$ and catK-/$(\mathrm{n}=8)$ mice were humanely killed after an 8 -hour fast. Blood was obtained, and after in situ perfusion-fixation, the complete arterial tree was excised and fixed as described previously ${ }^{24}$. The aortic arch including its main branch points (brachiocephalic trunk, right and left common carotid arteries, and left subclavian artery) were embedded longitudinally and cut into $\approx 40$ sections. A series of twenty $4-\mu \mathrm{m}$ sections, which represented the central area of the arch with an 
intact morphology of the complete arch including branch points, was analyzed as described previously ${ }^{24}$.

\section{Lipid profile}

For assessment of lipid profiles, standard enzymatic techniques, automated on a Cobas Fara centrifugal analyzer (Hoffmann-La Roche), were used (kit Nos. 0736635, 543004, and 0148270, Hoffmann-La Roche; and kit No. 337-40A/337-10B; Sigma Chemical Co).

Evaluation of possible systemic effects

More than 20 organs were excised from 4 mice per group and analyzed by microscopy of $4-\mu \mathrm{m}$ sections stained with hematoxylin and eosin. Fluorescence-activated cell sorting (FACS) analysis of lymph nodes, blood, and spleen was performed as described previously ${ }^{25}$.

\section{Histology and morphometry of mouse plaques}

For histological analysis and morphometry, 4 sections (20 $\mu \mathrm{m}$ apart) were stained with hematoxylin and eosin, and 4 consecutive sections (also $20 \mu \mathrm{m}$ apart) were stained with Lawson solution to stain the elastic laminas. Sirius red staining was performed to detect collagen. Morphometric parameters were determined as described previously ${ }^{24,26}$. Atherosclerotic lesions were analyzed and classified according to Virmani et al. $^{23}$. Because the data among the initial plaque stages (intimal thickening and intimal xanthomas) and among the advanced atherosclerotic lesions (thin and thick fibrous cap atheromas and fibrocalcified plaques) were similar, data are presented for these 2 groups: initial lesions and advanced lesions.

\section{Immunohistochemistry}

(Double) immunohistochemistry and was performed as described before ${ }^{24,25}$ with the following antibodies: anti-cathepsin $\mathrm{K}$ antibody (mouse monoclonal, 50 $\mu \mathrm{g} / \mathrm{ml}$; Calbiochem), $\alpha$-smooth muscle actin monoclonal antibody (1:500, Sigma) as a marker for vascular SMCs and myo-fibroblasts; MAC3 rat monoclonal antibody (1:30, Pharmingen) to detect macrophages; CD3 polyclonal antibody (A0452, 1:200; Dako) to detect T lymphocytes; and CD36 ${ }^{27}$ and scavenger receptor (SR)-A antibodies (chicken and rabbit-polyclonals, kind gifts of Prof de Beer and Prof A. Daugherty, University of Kentucky, Lexington) to determine SR immunoreactivity. 


\section{Bone density measurements}

Trabecular mineral density $\left(\mathrm{mg} / \mathrm{cm}^{3}\right)$, total bone area $\left(\mathrm{mm}^{2}\right)$, cortical mineral density $\left(\mathrm{mg} / \mathrm{cm}^{3}\right)$ and cortical thickness $(\mathrm{mm})$ of the left femur were assessed in cross section by peripheral quantitative computed tomography (model XCT-960A Norland Stratec) with a voxel size of $0.08 \mathrm{~mm}$ and a threshold of 0.464 .

\section{$B M$ derived macrophages}

Bone marrow (BM) was flushed from the femurs and tibias of 20- to 25-week-old apoE-/- and catK-/-/apoE-/- mice and cultured for 8 days RPMI medium containing L-glutamine, HEPES, 10\% fetal calf serum and $100 \mathrm{IU} / \mathrm{ml}$ penicillin/streptomycin with the addition of 15\% L929 cell-conditioned medium (LCM) to induce differentiation into macrophages ${ }^{27}$.

\section{Migration assay}

To determine transmigration of BM derived macrophages, BD Biocoat Matrigel invasion chambers (BD Biosciences), serving as a reconstituted basement membrane in vitro, were used. The transmigration assay was carried out at $37^{\circ} \mathrm{C}$ for 24 hours (with monocyte chemoattractant protein) followed by toluidine blue staining. Ten microscopic fields were randomly chosen to count transmigrated cells.

\section{Trypan blue exclusion test}

To determine the viability of both apoE-/- and catK-/-/apoE-/- BM derived macrophages, a trypan blue exclusion test was performed. After incubation with or without oxidized (ox)LDL for 24 hours, vital and nonvital (trypan blue colored) cells were counted in 10 microscopic fields per sample.

\section{LDL extraction and oxidation and uptake of oxLDL}

Low density lipoprotein (LDL) was extracted from fresh human plasma by graded ultracentrifugation. The LDL was oxidized by overnight incubation at $37^{\circ} \mathrm{C}$ with $\mathrm{CuSO}_{4}$. OxLDL was labeled with the fluorescent lipid 1,1'-dioctadecyl3,3,3',3'-tetramethylindocarbocyanine perchlorate (DiI; Molecular Probes). BM derived macrophages were incubated with $25 \mu \mathrm{g} / \mathrm{ml}$ DiI labeled oxLDL for 0.5 , 1 , or 3 hours. The SR inhibitor poly(I)lysine $(20 \mu \mathrm{g} / \mathrm{ml})$ was added 5 minutes before the DiI labeled oxLDL incubation. OxLDL uptake was determined by FACS (BD Biosciences). 


\section{High-Performance Thin-Layer Chromatography}

To determine the composition of lipid storage by BM derived macrophages, high performance thin layer chromatography (HPTLC) was performed. Cells were incubated with $25 \mu \mathrm{g} / \mathrm{ml}$ oxLDL for 24 or 48 hours. Cellular lipid accumulation per mg protein was analyzed by HPTLC. Cholesterol acetate in chloroform (20 $\mu \mathrm{g} / \mathrm{ml})$ was used as an external standard.

\section{Quantitative Real-Time PCR for SR-A and CD36}

RNAs from aortic arches of 26-week-old catK-/-/apoE-/- mice $(\mathrm{n}=11)$ and apoE-/- mice ( $\mathrm{n}=11$ ), were used for real-time PCR analysis. cDNA was diluted to a concentration of $2 \mathrm{ng} / \mu \mathrm{l}$. The Bio-Rad MyIQ single-color real-time PCR detection system with Optic system software version 1.0 was used for real-time PCR. For each PCR, $10 \mathrm{ng}$ cDNA, 2x universal PCR master mix, $300 \mathrm{nM}$ forward primer, $300 \mathrm{nM}$ backward primer, and $200 \mathrm{nM}$ Taqman probe were added to a final volume of $25 \mu \mathrm{l}$. PCR amplification of the housekeeping gene cyclophilin and of SR-A and CD36 was performed according to standard procedures $\left(1\right.$ cycle at $50^{\circ} \mathrm{C}$ for 2 minutes, 1 cycle at $95^{\circ} \mathrm{C}$ for 10 minutes, followed by 50 cycles of $95^{\circ} \mathrm{C}$ for 15 seconds and $60^{\circ} \mathrm{C}$ for 1 minute). A standard curve was generated for all experiments, and all assays were performed in duplicate. Relative RNA copy numbers were calculated from standard curves that were obtained by serial dilution of quantified template cDNA. The expression of each target gene was normalized to the expression of the housekeeping gene cyclophilin.

\section{Electron microscopy}

For analysis of lysosomal compartments, BM derived macrophages were incubated with $25 \mu \mathrm{g} / \mathrm{ml}$ oxLDL for 24 hours at $37^{\circ} \mathrm{C}\left(5 \% \mathrm{CO}_{2}\right)$, fixed in $2.5 \%$ glutaraldehyde, embedded in $10 \%$ gelatin blocks, postfixed in $1 \% \mathrm{OsO}_{4}$ solution, dehydrated, and embedded in epoxy resin. Ultrathin sections were mounted on Formvar (1595 E, Merck)-coated 75 mesh copper grids and counterstained with uranyl acetate and lead citrate before analysis in a Philips CM100 transmission electron microscope. Ten electron microscopic fields for each condition were measured. Individual lysosomal area was determined using ImageJ software (http://rsb.info.nih.gov/ij/).

\section{Statistical analysis}

All data are expressed as mean \pm SEM. Means between groups were compared by the use of the nonparametric Mann-Whitney U test. Data were considered statistically significant at $\mathrm{P}<0.05$. 

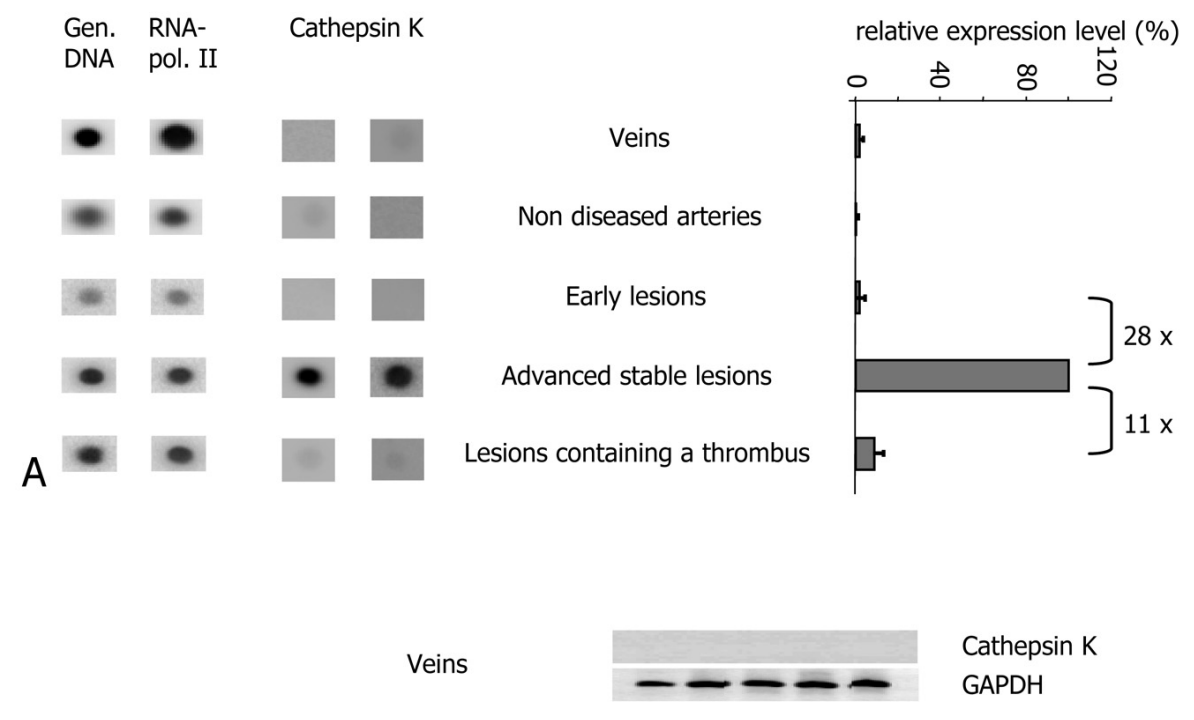

Non diseased arteries

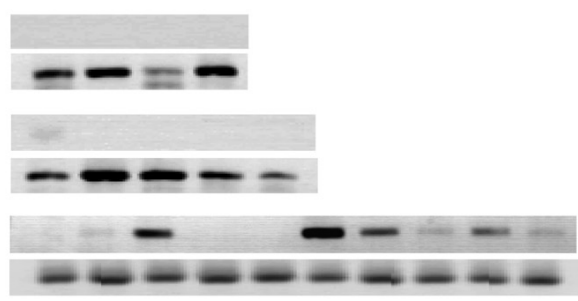

B

\section{Lesions containing a thrombus}

Figure 1. Cathepsin K mRNA expression in different stages of plaque development A. Two sets of 5 identical dot blots containing cathepsin K cDNA were hybridized to pools of ${ }^{32} \mathrm{P}-$ labeled cDNA derived from human veins, nondiseased arteries, early lesions, advanced stable lesions, and lesions with thrombus. Expression levels were normalized to the hybridization signals for genomic (Gen.) DNA and RNA polymerase (pol.) II. B. RT-PCR analysis of mRNA isolated from veins, nondiseased arteries, early lesions, advanced stable lesions, and lesions containing a thrombus. GAPDH indicates glyceraldehydes 3-phosphate dehydrogenase.

\section{RESULTS}

Cathepsin $K m R N A$ expression during human atherogenesis

Cathepsin $\mathrm{K}$ mRNA is expressed at a low level in human veins, nondiseased arteries, and early atherosclerotic lesions (Figure 1A). Expression was upregulated by 28 -fold in advanced but stable lesions when compared with early lesions and by 11 -fold when compared with lesions containing a thrombus. In addition, RT-PCR analysis of individual samples revealed no detectable cathepsin $\mathrm{K}$ 


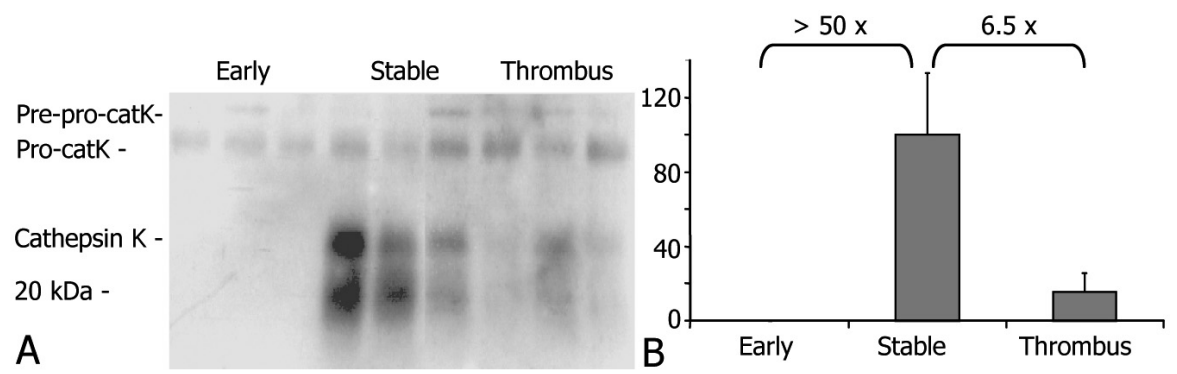

Figure 2. Western blot analysis of cathepsin $\mathrm{K}$ expression in human atherosclerotic lesions.

A. Lanes 1 through 3, early lesions; lanes 4 through 6 , advanced but stable atherosclerotic lesions; lanes 7 through 9, lesions containing a thrombus. B. Quantification of mature cathepsin K content, as judged by densitometric scanning.
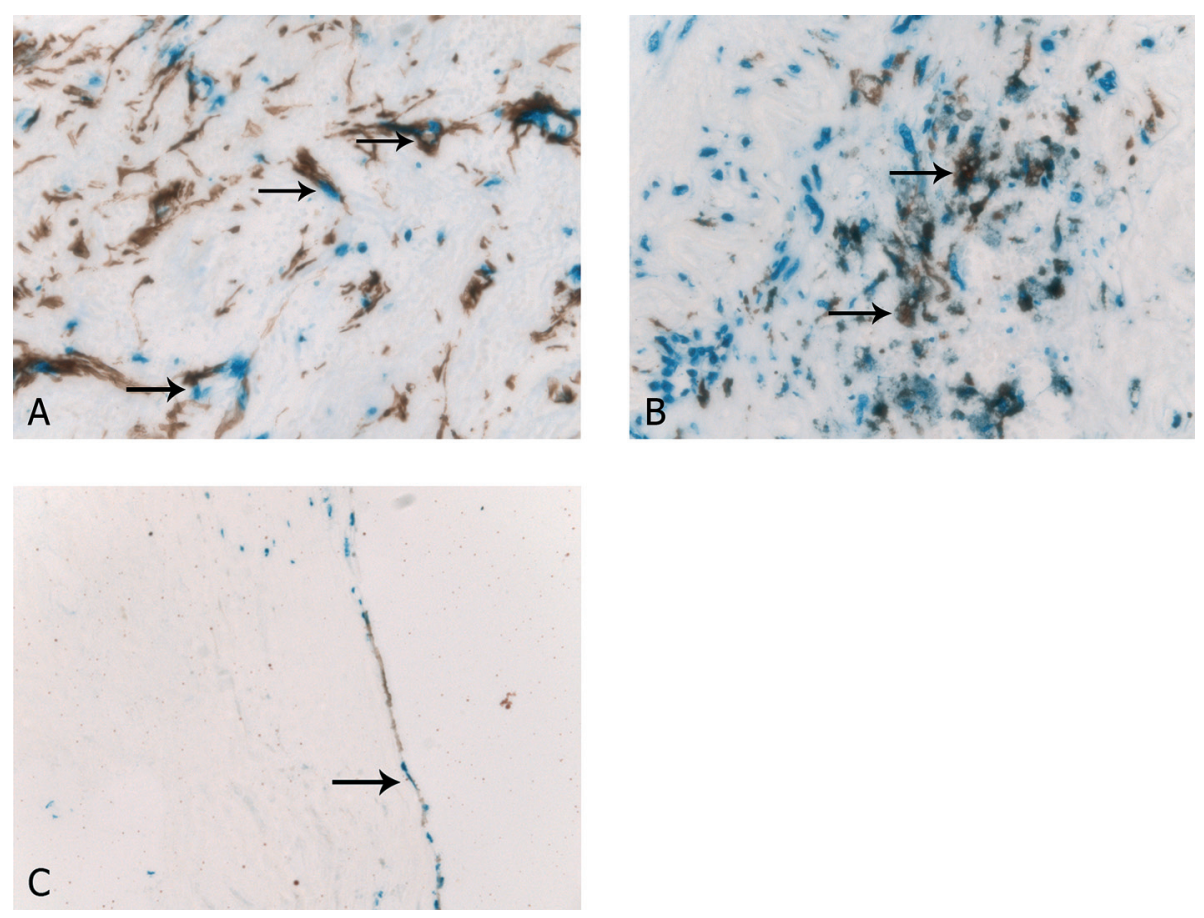

Figure 3. Cell type-specific cathepsin K expression.

Double immunohistochemistry for cathepsin K (blue) and (A) $\alpha$-smooth muscle actin (ASMA; brown), (B) CD68 (brown), and (C) CD34 (brown), revealing expression of cathepsin K in plaque SMCs, macrophages, and endothelial cells (arrows). 

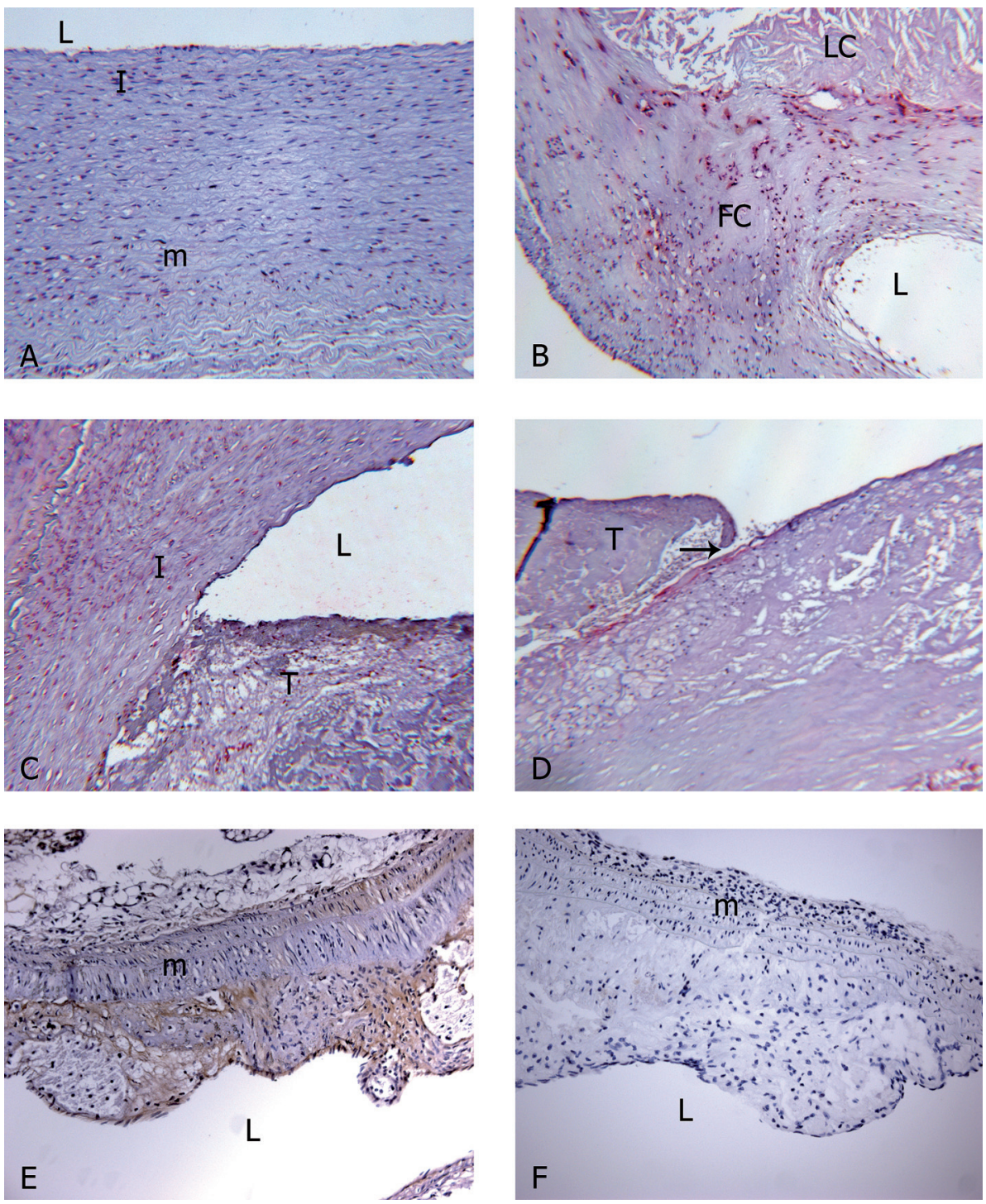

Figure 4. Localization of cathepsin K expression.

Photomicrographs show cathepsin $\mathrm{K}$ expression in various stages of human atherogenesis: (A) intimal xanthoma, (B) a stable plaque, (C) a lesion containing a thrombus, and (D) at the actual site of plaque rupture. $\mathrm{E}$ shows cathepsin $\mathrm{K}$ expression in an advanced lesion from an apoE-/- mouse, whereas $\mathrm{F}$ shows the absence of cathepsin $\mathrm{K}$ staining in a catK-/-/apoE-/- murine advanced plaque (x 100). Cathepsin $\mathrm{K}$ immunoreactivity is depicted in red (A-D) or in brown ( $\mathrm{E}$ and $\mathrm{F}$ ). $\mathrm{M}$ indicates media; I,intima; L,lumen; LC,lipid core; T,thrombus; and FC, foam cell. The arrow (D) points toward the actual site of plaque rupture. 
expression in veins and nondiseased arteries, whereas $20 \%$ of early lesions, $70 \%$ of advanced lesions and $30 \%$ of lesions containing a thrombus tested positive (Figure 1B).

\section{Cathepsin K protein expression}

In lysates from individual early lesions, advanced stable lesions, and advanced lesions containing a thrombus ( $\mathrm{n}=3$ per group), at least 3 cathepsin $\mathrm{K}$ protein products were distinguished: the pre-proenzyme of $40 \mathrm{kDa}$, a proenzyme of 37 $\mathrm{kDa}$, and the mature enzyme with a molecular weight of $27 \mathrm{kDa}$ (Figure 2A). Expression of mature cathepsin $\mathrm{K}$ was upregulated by $>50$-fold in stable lesions when compared with early lesions and by 6.5-fold when compared with lesions containing a thrombus (Figure $2 \mathrm{~B}$ ). In addition, we observed a $>50$-fold increase in the expression level of an $\approx 20-\mathrm{kDa}$ immunoreactive band, presumably representing a cathepsin $\mathrm{K}$ degradation product, in stable lesions when compared with early lesions and a 4.5-fold increase when compared with lesions with a thrombus.

In atherosclerotic plaques, cathepsin $\mathrm{K}$ was expressed in SMCs, macrophages and endothelial cells (Figure 3A through 3C). In human veins, nondiseased arteries, and early atherosclerotic lesions (Figure 4A), cathepsin K expression was low. However, strong immuno-reactivity was present in stable lesions (Figure 4B). The fibrous cap, shoulder region, and rim of the lipid core particularly showed high levels of cathepsin $\mathrm{K}$ protein immunoreactivity. Lesions containing a thrombus revealed intermediate levels of immunoreactivity, with a pattern similar to that observed in advanced stable lesions (Figure 4C). Cathepsin K protein was also expressed at the actual site of plaque rupture (Figure 4D). Advanced lesions in apoE-/- mice showed high levels of cathepsin K expression in the cytoplasm of vascular endothelial cells, neointimal and medial SMCs, and macrophages. As expected, catK-/-/apoE-/- mice showed no expression of cathepsin K (Figure 4E and 4F).

\section{In vivo validation}

Survival rates of catK-/-/apoE-/- mice, apoE-/- mice and catK-/- mice were $100 \%$ in all 3 groups. Body weights were similar. Autopsy ( $>20$ organs) revealed no macroscopic or microscopic abnormalities in sections stained with hematoxylin and eosin, except for the increased trabecularization oflong bones in catK-/- and catK-/-/apoE-/- mice (Figure 5) when compared with apoE-/mice, as previously described ${ }^{28}$. The observed increase in bone trabecularization was further substantiated by bone density measurements, showing a 2-fold increase in trabecular bone density in catK-/- and catK-/-/apoE-/- mice when compared with apoE-/- mice (Table I). 

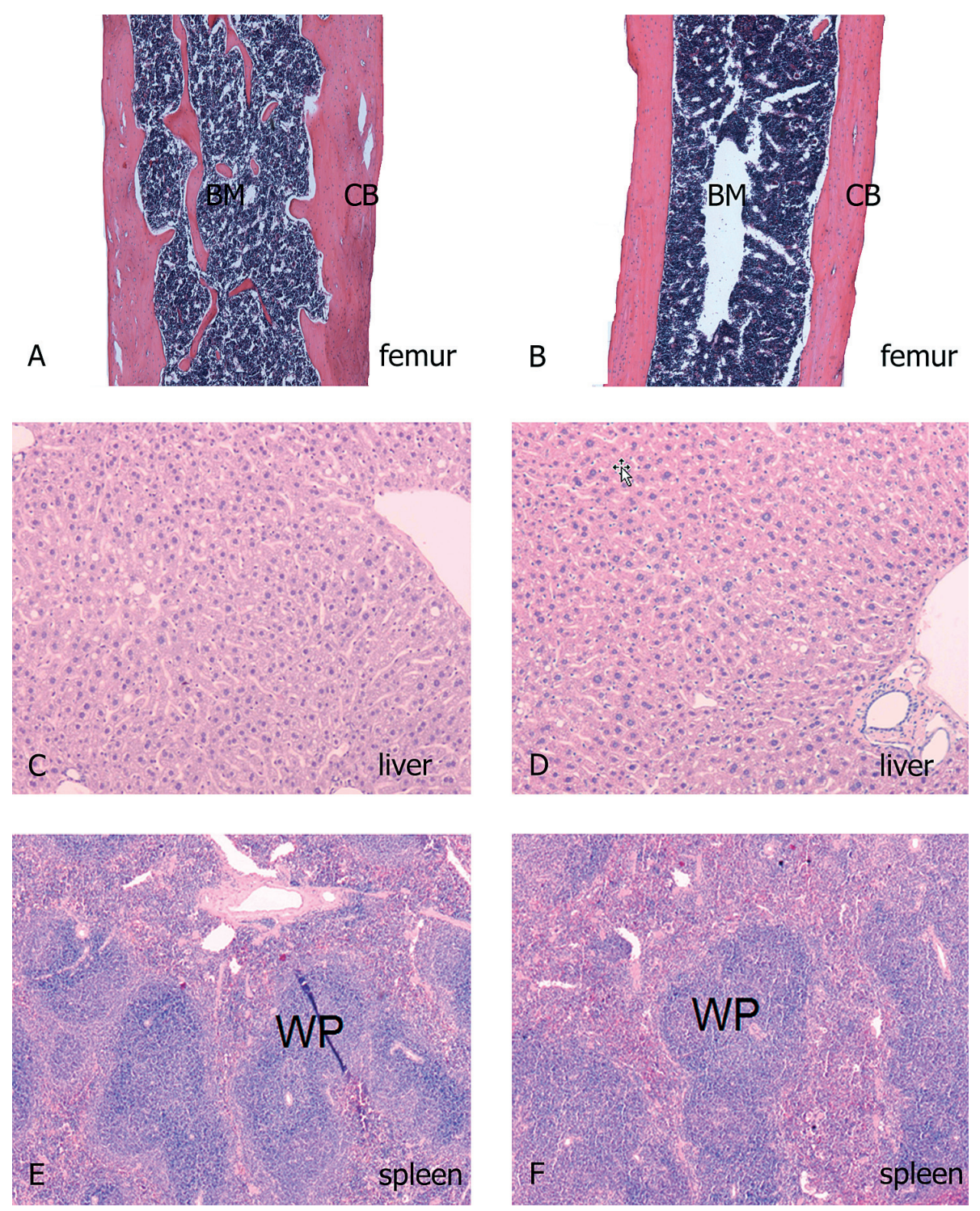

Figure 5. Autopsy revealed no macroscopic or microscopic abnormalities.

Hematoxylin and eosin staining of the left femur $(\mathrm{A}$ and $\mathrm{B})$, liver $(\mathrm{C}$ and $\mathrm{D})$ and spleen $(\mathrm{E}$ and $\mathrm{F})$ of catK-/-/apoE-/- (A, C, and E) and apoE-/- mice (B, D, and F). CB indicates cortical bone; BM, bone marrow; WP, white pulpa. 
Table I. Bone density.

\begin{tabular}{llll}
\hline & catK-/-/apoE-/- & catK-/- & apoE-/- \\
\hline Trabecular mineral density $\left(\mathrm{mg} / \mathrm{cm}^{3}\right)$ & $242 \pm 15^{\star}$ & $227 \pm 24.5 \star$ & $115 \pm 18^{\star}$ \\
Total bone area $\left(\mathrm{mm}^{2}\right)$ & $1.8 \pm 0.1$ & $1.9 \pm 0.1$ & $1.8 \pm 0.1$ \\
Cortical mineral density $\left(\mathrm{mg} / \mathrm{cm}^{3}\right)$ & $1086 \pm 7$ & $1098 \pm 10$ & $963 \pm 28$ \\
Cortical thickness $(\mathrm{mm})$ & $0.3 \pm 0.03$ & $0.3 \pm 0.02$ & $0.2 \pm 0.05$ \\
\hline
\end{tabular}

Values are represented as mean \pm SEM. $\star \mathrm{P}<0.05$ for the difference between apoE-/- mice and both catK-/-/apoE-/- and catK-/- mice. Trabecular mineral density of catK-/-/apoE-/- and catK-/- mice were similar.

Table II. Plasma cholesterol and triglyceride levels.

\begin{tabular}{llll}
\hline & $\begin{array}{l}\text { catK-/-/apoE-/- } \\
(\mathrm{n}=7)\end{array}$ & $\begin{array}{l}\text { apoE-/- } \\
(\mathrm{n}=8)\end{array}$ & $\begin{array}{l}\text { catK-/- } \\
(\mathrm{n}=8)\end{array}$ \\
\hline Total cholesterol, $\mathrm{mg} / \mathrm{dl}$ & $858 \pm 97 \star$ & $719 \pm 155^{\star}$ & $16 \pm 4^{\star}$ \\
HDL cholesterol, $\mathrm{mg} / \mathrm{dl}$ & $3.9 \pm 2.3 \star$ & $11.2 \pm 2.7 \star$ & $54.9 \pm 5.8^{\star}$ \\
LDL cholesterol, $\mathrm{mg} / \mathrm{dl}$ & $800 \pm 93^{\star}$ & $677 \pm 139 \star$ & $19 \pm 4^{\star}$ \\
Total triglyceride, $\mathrm{mg} / \mathrm{dl}$ & $245 \pm 35^{\star}$ & $184 \pm 70 \star$ & $53 \pm 4^{\star}$ \\
Free triglyceride, $\mathrm{mg} / \mathrm{dl}$ & $22 \pm 3.0$ & $21.8 \pm 2.6$ & $20.1 \pm 0.9$ \\
\hline
\end{tabular}

Values are represented as mean \pm SEM. ${ }^{\star} \mathrm{P}<0.05$ for the difference between catK-/- mice and both catK-/-/apoE -/- and apoE -/- mice. Lipid levels of catK-/-/apoE-/- and apoE -/- mice were similar, but catK-/-/apoE-/- showed a trend toward higher total cholesterol $(\mathrm{P}=0.12)$, LDL cholesterol $(\mathrm{P}=0.15)$, and triglyceride levels $(\mathrm{P}=0.27)$, and lower HDL cholesterol levels $(\mathrm{P}=0.58)$.

FACS analysis revealed no differences in the amount of CD3-positive cells ( $T$ cells), in the activation status of $\mathrm{T}$ cells between the groups (CD4 to CD8 ratio, CD25+ T cells), and the amount of GR-1-positive cells (macrophages) in lymph nodes, blood, and spleen, confirming the absence of extensive systemic effects of cathepsin $\mathrm{K}$ deficiency on $\mathrm{T}$-cell number and activation or macrophage number (data not shown).

Although there was a trend toward higher total cholesterol, LDL, and triglyceride levels and lower HDL levels in catK-/-/apoE-/- mice compared with apoE-/mice, these changes were not significant (Table II).

\section{Plaque burden}

CatK-/-/apoE-/- mice showed a $41.8 \%$ reduction of total plaque area $(580.996$ $\pm 119.010 \mu \mathrm{m}^{2} / \mathrm{arch}$ in $\mathrm{catK}-/$-/apoE-/- mice versus $998.544 \pm 81.665$ $\mu \mathrm{m}^{2} /$ arch in apoE-/- mice, $\left.\mathrm{P}<0.05\right)$, whereas the total number of plaques per aortic arch did not differ $(6.3 \pm 0.6$ in catK-/-/apoE-/- mice versus $6.2 \pm 0.8$ in apoE- $/-$ mice, $\mathrm{P}<0.05)$. The decrease in total plaque area was due to a decrease in the number of advanced atherosclerotic plaques (catK-/-/apoE-/-: $2.6 \pm 0.5$ versus apoE-/-: $4.4 \pm 0.4 ; \mathrm{P}<0.05$; Figures $6 \mathrm{~A}, 7 \mathrm{~A}$ and $7 \mathrm{~B})$. In addition, 

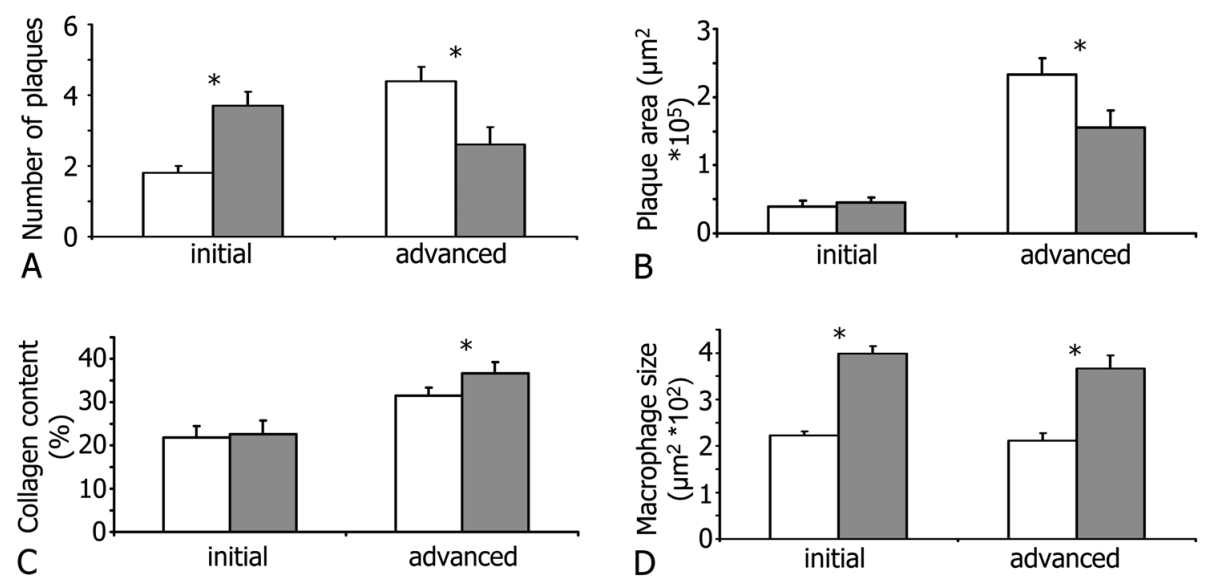

apoE-/-

catK-/-/apoE-/-

Figure 6. Quantification of plaque characteristics of catK-/-/apoE-/- and apoE-/- mice.

Number of plaques per aortic arch (A), individual plaque area (B), collagen content $(\mathrm{C})$, and individual macrophage size (D) of initial and advanced lesions of catK-/-/apoE-/- and apoE-/- mice are shown. Values are represented as mean \pm SEM.

advanced plaques of catK-/-/apoE-/- mice were significantly smaller (Figure $6 \mathrm{~B}$ ), whereas the number of initial plaques was increased (Figure 6A). This finding indicates an important role for cathepsin $\mathrm{K}$ in atherosclerotic plaque progression.

\section{Plaque composition}

In addition to the decrease in plaque progression and plaque area, significant differences in plaque composition between catK-/-/apoE-/- and apoE-/- mice were observed. As expected, a deficiency of cathepsin $\mathrm{K}$ had a profound effect on plaque extracellular matrix content. Collagen content increased significantly in advanced plaques of catK-/-/apoE-/- mice $(36.7 \pm 2.5 \%$ versus $31.5 \pm 1.9 \%$; $\mathrm{P}<0.05$; Figures $6 \mathrm{C}, 7 \mathrm{C}$ and $7 \mathrm{D})$. The number of elastin breaks in the media underlying the atherosclerotic plaque was decreased in the advanced lesions of catK-/-/apoE-/- mice (initial lesions: catK-/-/apoE-/-: $1.0 \pm 0.2$ versus apoE-/-: $1.0 \pm 0.6 ; \mathrm{P}>0.05$; advanced lesions: $\mathrm{catK}-/-/$ apoE-/ $1.0 \pm 0.2$ versus apoE-/-: $1.8 \pm 0.3 ; \mathrm{P}<0.05$; Figure $7 \mathrm{E}$ and $7 \mathrm{~F})$. The relative plaque macrophage content showed a borderline significant decrease (Table III; initial lesions, $\mathrm{P}=0.067$; advanced lesions, $\mathrm{P}=0.092$ ) in plaques of catK-//apoE-/- mice. Interestingly, individual macrophage foam cells in the plaques were increased in 

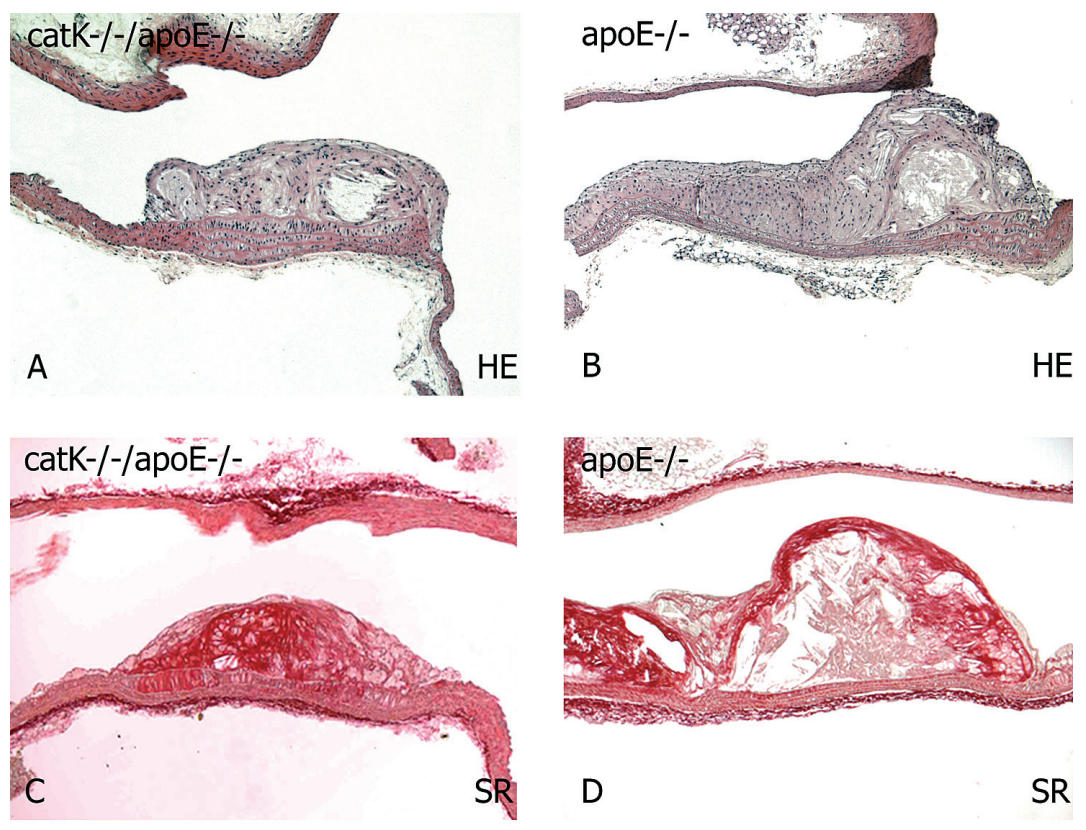

B

HE
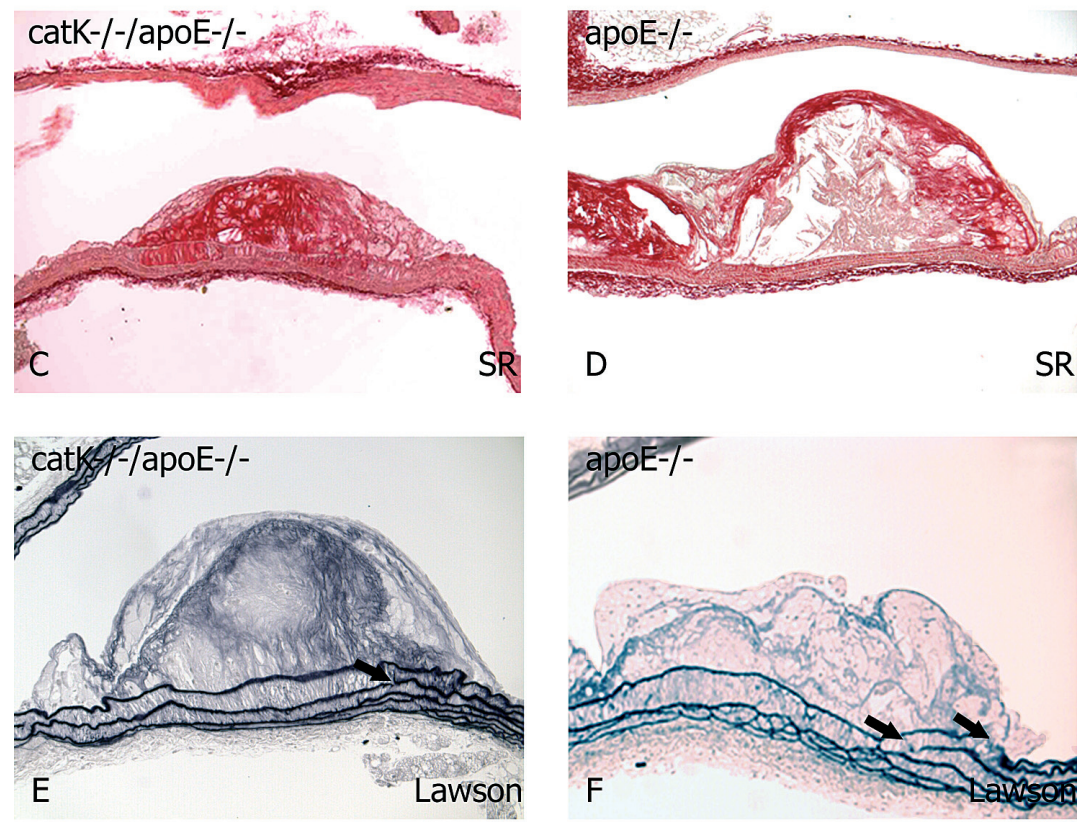

D SR
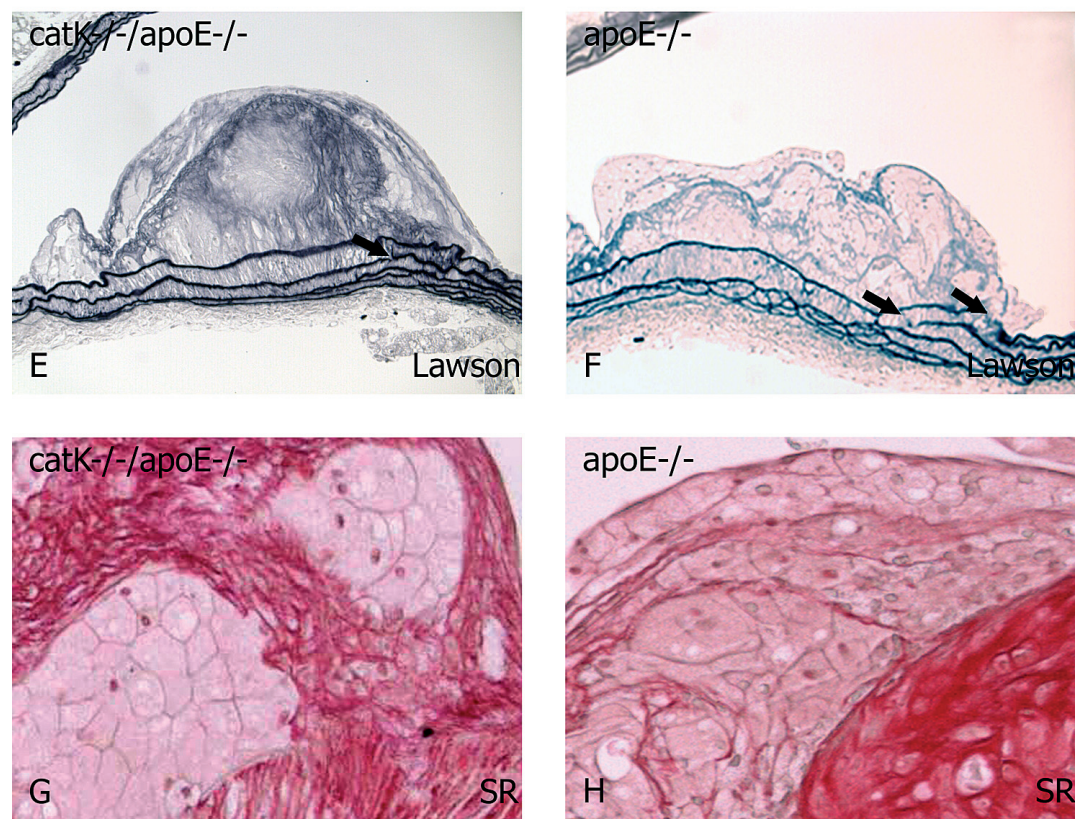

Figure 7. Histological characteristics of atherosclerotic plaques of catK-/-/apoE-/- and apoE-/- mice.

Hematoxylin and eosin (A and B) staining (x 100) reveals a decreased advanced plaque area in catK-/-/apoE-/- mice. Sirius red (C and D) staining (x 100) shows increased collagen content in plaques from catK-/-/apoE-/- mice. Lawson staining ( $\mathrm{E}$ and $\mathrm{F}$ ) shows extensive disruption of medial elastin fibers in apoE-/- mice (arrows), which hardly occurs in catK-/-/apoE-/- mice. SR staining ( $\mathrm{G}$ and $\mathrm{H}$; $\mathrm{x} 400$ ) shows larger plaque macrophage foam cells (arrows) in lesions from catK-/-/apoE-/- mice. 

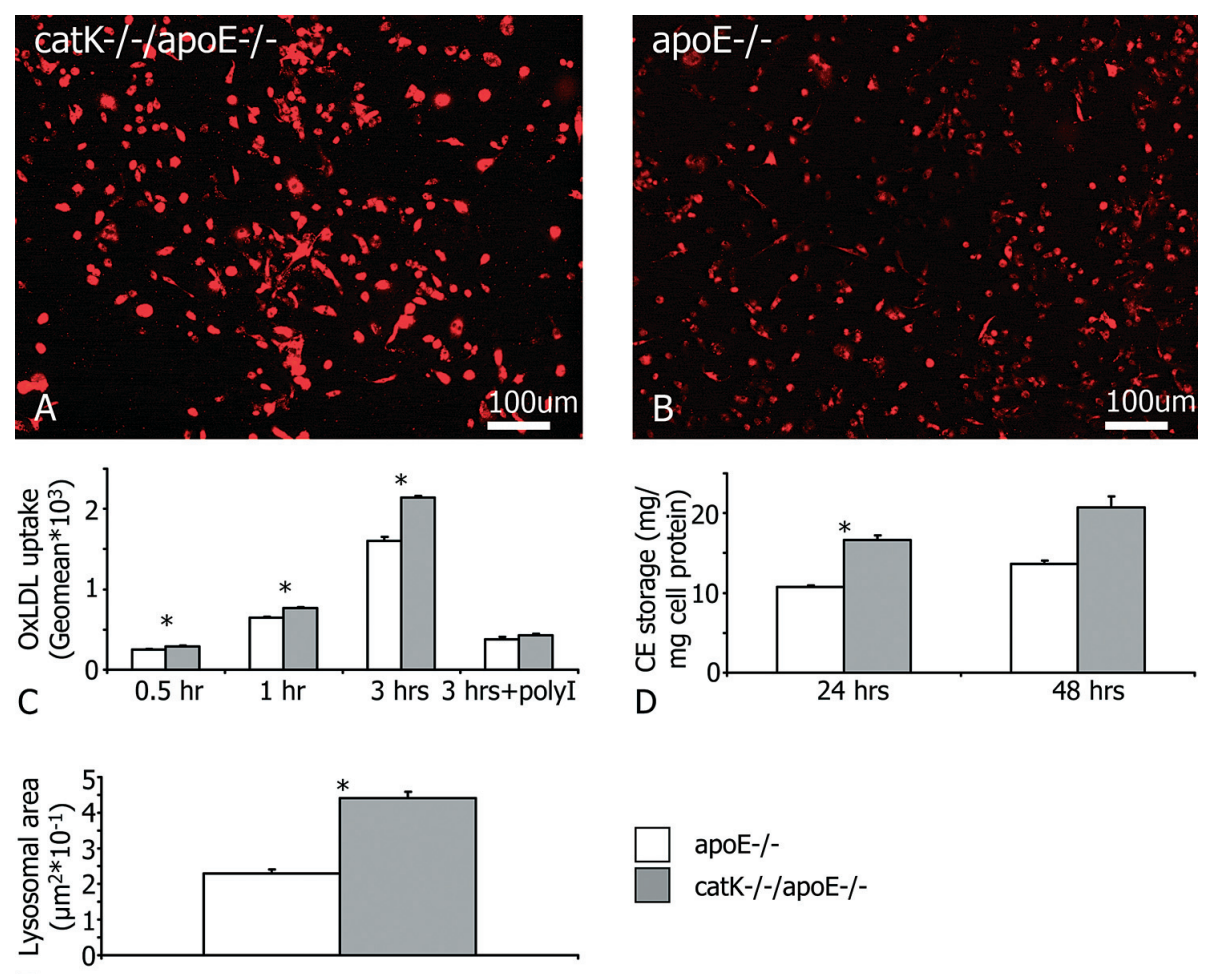

E
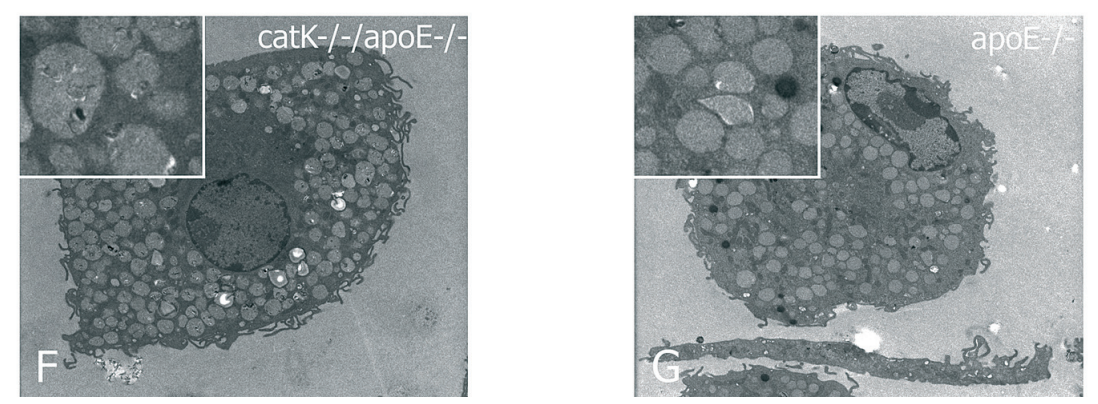

Figure 8. Uptake of DiI labeled oxLDL $(25 \mu \mathrm{g} / \mathrm{ml})$ by BM derived macrophages.

$A$ and B. Increased DiI labeled oxLDL uptake after a 3 hours incubation in catK-/-/apoE-/macrophages compared with apoE-/- BM derived macrophages. C. Increased DiI-oxLDL uptake in catK-/-/apoE-/- versus apoE-/- BM derived macrophages after $0.5,1$, and 3 hours of incubation $(\mathrm{P}=0.0286)$. Addition of poly $(\mathrm{I})$ lysine $(20 \mu \mathrm{g} / \mathrm{ml})$ reduced oxLDL uptake by 76 to $80 \%$ in both groups. D. catK-/-/apoE-/- macrophages that were incubated for 24 hours $(n=6)$ with oxLDL showed a $32 \%$ increase in cholesterol ester (CE) levels compared with apoE-/- macrophages $(\mathrm{P}=0.004)$. Incubation for 48 hours $(n=3)$ showed the same trend but did not reach statistical significance $(P=0.050)$. E, F and G. Lysosomal area has increased in macrophages from catK-/-/apoE-/- mice. Note the increased lysosomal area in catK-/-/apoE-/- mice in the electron photomicrographs. 
Table III. Cell types and characteristics.

\begin{tabular}{lll}
\hline & apoE-/- & catK-/-/apoE-/- \\
\hline T-lymphocyte content (\%), initial lesions & $0.2 \pm 0.2$ & $1.5 \pm 0.5$ \\
T-lymphocyte content (\%), advanced lesions & $1.0 \pm 0.5$ & $1.0 \pm 0.3$ \\
Macrophage content (\%), initial lesions & $72.8 \pm 5.2$ & $54.5 \pm 6.5$ \\
Macrophage content (\%) advanced lesions & $48.1 \pm 2.5$ & $46.1 \pm 5.6$ \\
Lipid core area (\%), advanced lesions & $26.5 \pm 2.4$ & $27.2 \pm 1.9$ \\
\hline
\end{tabular}

Values are represented as mean \pm SEM.
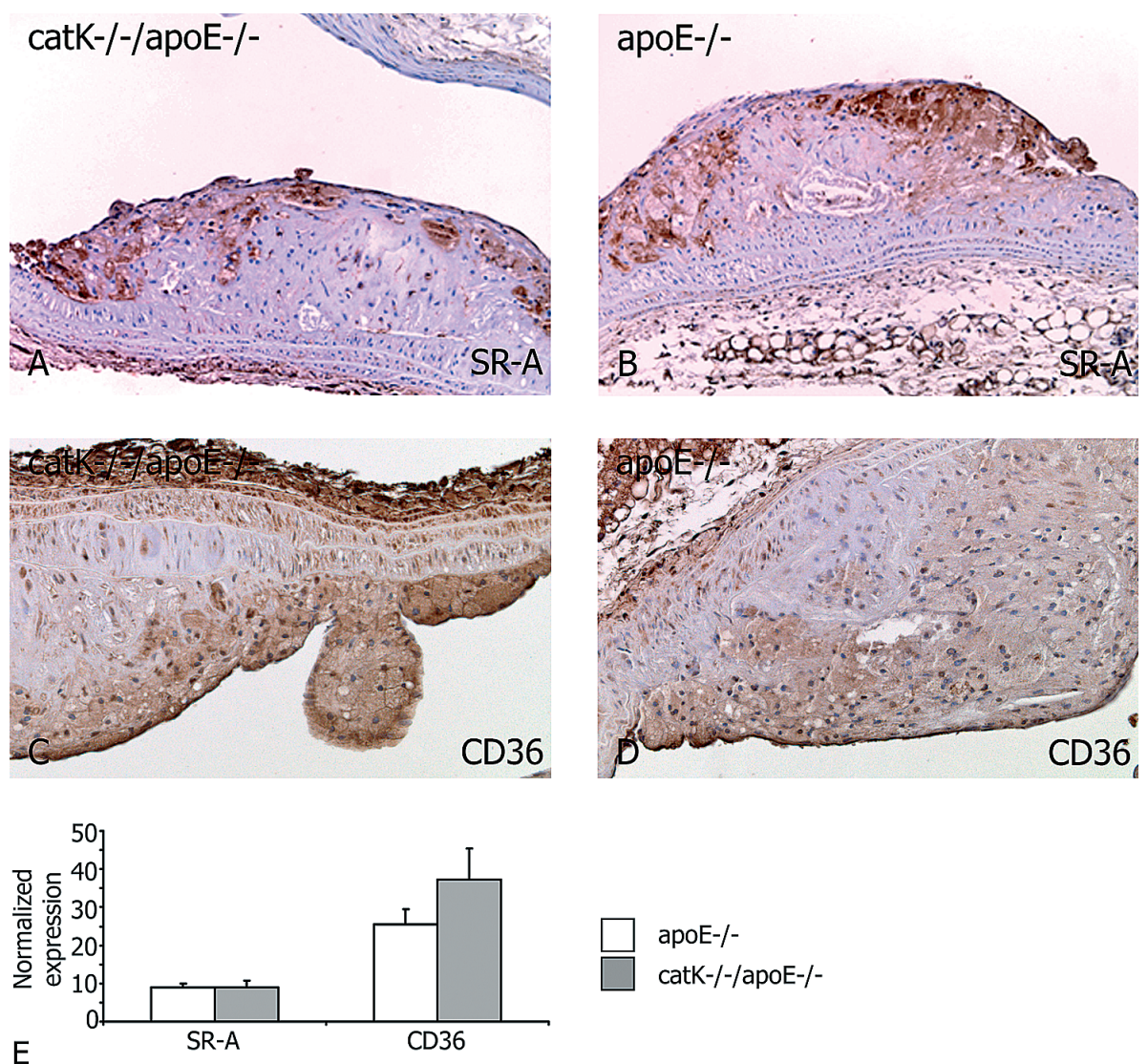

$\square$ apoE-/-
$\square$ catK-/-/apoE-/-

Figure 9. SR-A and CD36 expression in the absence of cathepsin K

$\mathrm{A}, \mathrm{B}$, and $\mathrm{E}$. No difference in SR-A expression in atherosclerotic plaques from catK-/-/apoE-/- versus apoE-/- mice. C, D, and E. Increased mRNA and protein expression from CD36 in plaques of catK-/-/apoE-/- mice vs apoE-/- mice. 
size (initial lesions: catK-/-/apoE-/-: $398.2 \pm 16.2 \mu \mathrm{m}^{2} /$ foam cell versus apoE-/-: $221.7 \pm 8.7 \mu \mathrm{m}^{2} /$ foam cell; advanced lesions: catK-/-/apoE-/-: 365.6 $\pm 29.4 \mu \mathrm{m}^{2} /$ foam cell versus apoE-/-: $212.7 \pm 15.1 \mu \mathrm{m}^{2} /$ foam cell; $\mathrm{P}<0.05$; determined in all lesions of all mice included), suggesting a role for cathepsin $\mathrm{K}$ in foam cell formation (Figures 6D, 7G, and 7H).

T-lymphocyte content and lipid core area showed no significant differences in both initial and advanced lesions between catK-/-/apoE-/- and apoE-/- mice (see Table III).

\section{Migration assay}

Transmigration of BM derived macrophages was tested in a Matrigel matrix assay. In both groups, large numbers of cells transmigrated (88 to 90\%), without differences noted between apoE-/- and catK-/-/apoE-/- BM derived macrophages $(\mathrm{P}>0.05)$. The trypan blue exclusion test showed no difference in cell death after 24 hours oxLDL incubation between both groups $(\mathrm{P}>0.05)$.

\section{Mechanisms of foam cell formation: in vitro studies}

Because disruption of the cathepsin $\mathrm{K}$ gene resulted in an increase of macrophage size in atherosclerotic lesions of catK-/-/apoE-/- mice, macrophage size, lysosomal area, oxLDL uptake, and subsequent storage of cholesterol esters were quantified in BM derived macrophage foam cells in culture.

As our in vivo atherosclerosis data have already shown, macrophage area (as determined by DiI-oxLDL-positive staining) in vitro increased significantly $(300 \%)$ in the absence of cathepsin $\mathrm{K}$ after 24 hrs of incubation with oxLDL (Figure 8A and 8B). Furthermore, FACS analysis revealed increased uptake of DiI labeled oxLDL in BM derived macrophages in the absence of cathepsin $\mathrm{K}$ after $0.5,1$, and 3 hours $(\mathrm{P}=0.0286$ at all three time points; Figure $8 \mathrm{C})$. Poly(I)lysine, a SR inhibitor, reduced oxLDL uptake by 76 to $80 \%$ at 3.0 hours in both groups (Figure 8C), indicating that the increased oxLDL uptake was SR mediated. To investigate which SRs were responsible for the enhanced foam cell formation in catK-/-/apoE-/- mice, immunohistochemistry and real-time PCR analysis for SR-A and CD36 were performed. Interestingly, both mRNA expression and immunoreactivity for SR-A did not differ between plaque macrophages of catK-/-/apoE-/- and apoE-/- mice (Figure 9). However, CD36 mRNA and protein expression was significantly increased in plaques lacking cathepsin K (Figure 9), indicating that CD36 is one of the SRs responsible for the increased foam cell formation in absence of cathepsin $\mathrm{K}$.

HPTLC revealed that catK-/-/apoE-/- BM derived macrophages incubated for 24 hours with oxLDL showed a 53.7\% $(\mathrm{P}=0.004)$ increase in cholesterol ester 
levels compared with apoE-/- BM derived macrophages (Figure 8D). No significant differences were seen in free cholesterol levels (data not shown).

Electron microscopy revealed an increase in lysosomal area in macrophages $(\mathrm{n}=10)$ in the absence of cathepsin $\mathrm{K}$ (mean lysosomal size of $\mathrm{n}>1000$ lysosomes in catK-/-/apoE-/- mice: $0.44 \pm 0.02 \mu \mathrm{m}^{2}$ versus in apoE-/-: $0.23 \pm 0.01 \mu \mathrm{m}^{2}$ after 24 hours incubation with oxLDL; Figure 8E, F and G).

These data illustrate the increased SR mediated uptake of oxLDL, predominantly by CD36, in catK-/-/apoE-/- BM derived macrophages, which results in increased storage of cholesterol esters in large lysosomal compartments.

\section{DISCUSSION}

In the present study, we have shown that cathepsin $\mathrm{K}$ mRNA and protein are predominantly expressed in advanced atherosclerosis and that cathepsin $\mathrm{K}$ is involved in plaque progression. The elevated levels of cathepsin $\mathrm{K}$ mRNA and protein in stable human lesions are in agreement with the observation of Sukhova et $\mathrm{al}^{7}$ who reported high levels of cathepsin $\mathrm{K}$ in human atheromata. Moreover, other closely related family members of the cathepsin family such as S, D, F, L, and $\mathrm{V}$, were also found in human and mouse atherosclerotic plaques ${ }^{3,7,9,10}$ as well as in restenotic lesions of rabbits and rats $^{29,30}$. Interestingly, when compared with advanced stable plaques, cathepsin K mRNA and protein levels were decreased in plaques containing a thrombus. We hypothesize that this decrease in cathepsin $\mathrm{K}$ levels is due to the fact that plaque rupture, ie, an event associated with high collagenolytic activity, has already taken place in lesions containing an organized thrombus. Consequently, cathepsin K levels decrease. Plaques containing a thrombus are in an 'active wound-healing' phase, which also requires deposition of collagen rather than extensive collagen breakdown. Because cathepsin K levels in plaques containing a thrombus are still higher compared with initial atherosclerotic lesions, we think that cathepsin $\mathrm{K}$ is also involved in the healing process after plaque rupture.

In advanced atherosclerotic lesions of apoE-/- mice, a deficiency of cathepsin K resulted in a highly fibrotic plaque phenotype. This phenomenon was not observed in cathepsin S-/-/LDL-R-/- mice ${ }^{31}$. Although most cathepsin family members show elastolytic and some collagenolytic activity, cathepsin $\mathrm{K}$ is the most potent collagenase, capable of cleaving triple-helical collagens at multiple sites $^{32-34}$. The unique collagenolytic property of cathepsin $\mathrm{K}$ may explain the fibrotic phenotype observed in catK-/-/apoE-/- mice. The fibrotic phenotype was also observed in a model of bleomycin-induced lung fibrosis, in which cathepsin K-/- mice exhibited significantly more fibrosis than did wild-type 
mice $^{22}$. Moreover, a deficiency of cathepsin $\mathrm{K}$ reduced the number of elastin breaks in the media underlying the plaque, indicating that aneurysm formation might be prevented in the absence of cathepsin K. No true plaque ruptures or intraplaque hemorrhages were observed in any of the groups.

The deficiency of cathepsin $\mathrm{K}$ in apoE-/- mice not only affected the extracellular matrix component of atherosclerotic plaques but also had a profound effect on macrophage foam cell formation. A deficiency of cathepsin $\mathrm{K}$ increased the SR mediated uptake of oxLDL and increased storage of cholesterol esters in macrophages. Moreover, electron microscopic analysis of macrophage foam cells revealed an increased lysosomal size in the absence of cathepsin K. These phenomena resulted in the large macrophage foam cells that were present in plaques of catK-/-/apoE-/- mice and in our cell culture studies. Cathepsins D and $\mathrm{F}$ are known inducers of foam cell formation that modify LDL, which increases macrophage LDL uptake and facilitates the binding of modified LDL to proteoglycans. ${ }^{9}$. However, the exact mechanism by which cathepsin $\mathrm{K}$ induces foam cell formation still needs to be investigated, although our data point toward a SR mediated process with a role for CD36 in particular. Interestingly, reports on the role of CD36 in atherosclerosis are somewhat ambivalent, with some claiming a proatherogenic role for CD36 in plaque formation ${ }^{35,36}$ whereas others do not ${ }^{36}$. However, regulation of the uptake of oxLDL of plaque macrophages is a complex process with many players $^{37}$, of which the cathepsin K-SR axis might be an important one.

Cathepsins are also involved in the modulation of cholesterol efflux. At neutral $\mathrm{pH}$, cathepsin $\mathrm{F}$ but not $\mathrm{K}$ is able to partially degrade lipid-free apoA-I and partially inhibit cholesterol efflux, whereas cathepsin $\mathrm{S}$ is capable of completely inhibiting cholesterol efflux ${ }^{38}$. However, at pH 5-6, cathepsin $\mathrm{K}$ inhibits cholesterol efflux as well by inhibiting apoA-I induced efflux. Therefore, it might be expected that deficiency of cathepsin $\mathrm{K}$ would increase cholesterol efflux. However, because cathepsin $\mathrm{K}$ is only indirectly involved in the inhibition of cholesterol efflux ${ }^{38}$, this increase in cholesterol efflux may not be sufficient to compensate for the increase in foam cell formation in catK-/-/apoE-/- mice. The present study shows a dual effect for cathepsin $\mathrm{K}$ in atherogenesis: absence of cathepsin $\mathrm{K}$ induces extracellular matrix deposition and accelerates foam cell formation. From an atherosclerosis treatment perspective, these effects seem somewhat contradictory but can be explained. Cathepsins are predominantly synthesized and targeted to the acidic compartments of the cell, lysosomes and endosomes. In these compartments, $\mathrm{pH}$ is optimal for their activity, and it is here that cathepsins degrade unwanted intracellular or endocytosed proteins such as modified LDL. However, although cathepsins have a very narrow $\mathrm{pH}$ optimum ( $\mathrm{pH} 4$ to 6), they have also demonstrated activity in media of cultured 
macrophages, endothelial cells and $\mathrm{SMCs}^{11,15,39,40}$. When macrophages make contact with the extracellular matrix, a localized acidic environment is formed that allows cathepsins to degrade the extracellular matrix ${ }^{40}$. In atherosclerotic plaques, the microenvironment is somewhat acidic owing to inflammation and hypoxia ${ }^{41}$, which facilitate the actions of cathepsins. A deficiency of cathepsin $\mathrm{K}$ thus limits the degradation of modified LDL and at the same time, prevents degradation of the extracellular matrix, thereby inducing atherosclerotic plaques with large macrophage foam cells and profound plaque fibrosis.

Our findings on the in vivo function of cathepsin $\mathrm{K}$ in apoE-deficient mice and its expression profile in human atherosclerotic lesions identify cathepsin $\mathrm{K}$ as a potential therapeutic target. Assuming similar effects in humans, inhibition of cathepsin $\mathrm{K}$ activity could lead to decreased plaque progression and increased plaque stability. In addition, inhibition of cathepsin $\mathrm{K}$ activity might be beneficial in the treatment of osteoporosis, as cathepsin K deficiency, both in humans and in mice, resulted in a significant increase in trabecular bone density. However, the role of cathepsin $\mathrm{K}$ on foam cell formation and serum lipid levels should be taken into account. Deficiency of cathepsin K aggravates foam cell formation that may affect plaque stability. Moreover, catK-/-/apoE-/- mice showed a trend toward increased serum cholesterol, LDL cholesterol, and triglyceride levels and decreased HDL levels. Therefore, combination therapy using a cathepsin $\mathrm{K}$ inhibitor and a lipid-lowering drug such as a HMG-CoA reductase inhibitor may be preferable.

\section{REFERENCES}

1. Turk V, Turk B, Turk D. Lysosomal cysteine proteases: facts and opportunities. Embo J. Sep 3 2001;20(17):4629-4633.

2. Liu J, Sukhova GK, Sun JS, Xu WH, Libby P, Shi GP. Lysosomal cysteine proteases in atherosclerosis. Arterioscler Thromb Vasc Biol. Aug 2004;24(8):1359-1366.

3. Jormsjo S, Wuttge DM, Sirsjo A, Whatling C, Hamsten A, Stemme S, Eriksson P. Differential expression of cysteine and aspartic proteases during progression of atherosclerosis in apolipoprotein E-deficient mice. Am.J.Pathol. 9/2002 2002;161(3):939-945.

4. Hiltunen MO, Tuomisto TT, Niemi M, Brasen JH, Rissanen TT, Toronen P, Vajanto I, Yla-Herttuala S. Changes in gene expression in atherosclerotic plaques analyzed using DNA array. Atherosclerosis. Nov 2002;165(1):23-32.

5. Tung WS, Lee JK, Thompson RW. Simultaneous analysis of 1176 gene products in normal human aorta and abdominal aortic aneurysms using a membrane-based complementary DNA expression array. J.Vasc.Surg. 7/2001 2001;34(1):143-150.

6. Chen J, Tung CH, Mahmood U, Ntziachristos V, Gyurko R, Fishman MC, Huang PL, Weissleder R. In vivo imaging of proteolytic activity in atherosclerosis. Circulation. 6/11/2002 2002;105(23):2766-2771. 
7. Sukhova GK, Shi GP, Simon DI, Chapman HA, Libby P. Expression of the elastolytic cathepsins $\mathrm{S}$ and $\mathrm{K}$ in human atheroma and regulation of their production in smooth muscle cells. J.Clin.Invest. 8/1/1998 1998;102(3):576-583.

8. Hakala JK, Oksjoki R, Laine P, Du H, Grabowski GA, Kovanen PT, Pentikainen MO. Lysosomal enzymes are released from cultured human macrophages, hydrolyze LDL in vitro, and are present extracellularly in human atherosclerotic lesions. Arterioscler Thromb Vasc Biol. Aug 1 2003;23(8):1430-1436.

9. Oorni K, Sneck M, Bromme D, Pentikainen MO, Lindstedt KA, Mayranpaa M, Aitio $\mathrm{H}$, Kovanen PT. Cysteine protease cathepsin F is expressed in human atherosclerotic lesions, is secreted by cultured macrophages, and modifies low density lipoprotein particles in vitro. J Biol Chem. Aug 13 2004;279(33):34776-34784.

10. Yasuda Y, Li Z, Greenbaum D, Bogyo M, Weber E, Bromme D. Cathepsin V, a novel and potent elastolytic activity expressed in activated macrophages. J Biol Chem. Aug 27 2004;279(35):36761-36770.

11. Sukhova GK, Y Z, J P, Libby P. Targeted disruption of Cathepsin S reduces atherosclerosis in low density lipoprotein receptor deficient mice. Circulation; 2001.

12. Shi GP, Sukhova GK, Kuzuya M, Ye Q, Du J, Zhang Y, Pan JH, Lu ML, Cheng XW, Iguchi A, Perrey S, Lee AM, Chapman HA, Libby P. Deficiency of the cysteine protease cathepsin S impairs microvessel growth. Circ Res. Mar 21 2003;92(5):493-500.

13. Urbich C, Heeschen C, Aicher A, Sasaki K, Bruhl T, Farhadi MR, Vajkoczy P, Hofmann WK, Peters C, Pennacchio LA, Abolmaali ND, Chavakis E, Reinheckel T, Zeiher AM, Dimmeler S. Cathepsin L is required for endothelial progenitor cell-induced neovascularization. Nat Med. Feb 2005;11(2):206-213.

14. Barrett AJ, Davies ME, Grubb A. The place of human gamma-trace (cystatin C) amongst the cysteine proteinase inhibitors. Biochem Biophys Res Commun. Apr 30 1984;120(2): 631-636.

15. Shi GP, Sukhova GK, Grubb A, Ducharme A, Rhode LH, Lee RT, Ridker PM, Libby $\mathrm{P}$, Chapman HA. Cystatin $\mathrm{C}$ deficiency in human atherosclerosis and aortic aneurysms. J.Clin.Invest. 11/1999 1999;104(9):1191-1197.

16. Sukhova GK, Wang B, Libby P, Pan JH, Zhang Y, Grubb A, Fang K, Chapman HA, Shi GP. Cystatin C deficiency increases elastic lamina degradation and aortic dilatation in apolipoprotein E-null mice. Circ Res. Feb 18 2005;96(3):368-375.

17. Faber BC, Cleutjens KB, Niessen RL, Aarts PL, Boon W, Greenberg AS, Kitslaar PJ, Tordoir JH, Daemen MJ. Identification of genes potentially involved in rupture of human atherosclerotic plaques. Circ.Res. 9/14/2001 2001;89(6):547-554.

18. Bromme D, Okamoto K, Wang BB, Biroc S. Human cathepsin O2, a matrix protein-degrading cysteine protease expressed in osteoclasts. Functional expression of human cathepsin O2 in Spodoptera frugiperda and characterization of the enzyme.J Biol Chem. Jan 26 1996;271(4):2126-2132.

19. Lecaille F, Choe Y, Brandt W, Li Z, Craik CS, Bromme D. Selective inhibition of the collagenolytic activity of human cathepsin $\mathrm{K}$ by altering its $\mathrm{S} 2$ subsite specificity. Biochemistry. Jul 2 2002;41(26):8447-8454.

20. Shi GP, Chapman HA, Bhairi SM, DeLeeuw C, Reddy VY, Weiss SJ. Molecular cloning of human cathepsin $\mathrm{O}$, a novel endoproteinase and homologue of rabbit OC2. FEBS Lett. Jan 3 1995;357(2):129-134. 
21. Buhling F, Peitz U, Kruger S, Kuster D, Vieth M, Gebert I, Roessner A, Weber E, Malfertheiner P, Wex T. Cathepsins K, L, B, X and W are differentially expressed in normal and chronically inflamed gastric mucosa. Biol Chem. May 2004;385(5):439-445.

22. Buhling F, Rocken C, Brasch F, Hartig R, Yasuda Y, Saftig P, Bromme D, Welte T. Pivotal role of cathepsin K in lung fibrosis. Am J Pathol. Jun 2004;164(6):2203-2216.

23. Virmani R, Kolodgie FD, Burke AP, Farb A, Schwartz SM. Lessons from sudden coronary death: a comprehensive morphological classification scheme for atherosclerotic lesions. Arterioscler. Thromb.Vasc.Biol. 5/2000 2000;20(5):1262-1275.

24. Lutgens E, Gorelik L, Daemen MJ, de Muinck ED, Grewal IS, Koteliansky VE, Flavell RA. Requirement for CD154 in the progression of atherosclerosis. Nat.Med. 11/1999 1999;5(11):1313-1316.

25. Lutgens E, Gijbels M, Smook M, Heeringa P, Gotwals P, Koteliansky VE, Daemen MJ. Transforming growth factor-beta mediates balance between inflammation and fibrosis during plaque progression. Atterioscler. Thromb. Vasc. Biol. 6/1/2002 2002;22(6):975-982.

26. Lutgens E, Daemen MJ. Transforming growth factor-beta: a local or systemic mediator of plaque stability? Circ. Res. 11/9/2001 2001;89(10):853-855.

27. Kanters E, Pasparakis M, Gijbels MJ, Vergouwe MN, Partouns-Hendriks I, Fijneman RJ, Clausen BE, Forster I, Kockx MM, Rajewsky K, Kraal G, Hofker MH, de Winther MP. Inhibition of NF-kappaB activation in macrophages increases atherosclerosis in LDL receptor-deficient mice. J Clin Invest. Oct 2003;112(8):1176-1185.

28. Saftig P, Hunziker E, Wehmeyer O, Jones S, Boyde A, Rommerskirch W, Moritz JD, Schu P, von Figura K. Impaired osteoclastic bone resorption leads to osteopetrosis in cathepsin-K-deficient mice. Proc Natl Acad Sci U S A. Nov 10 1998;95(23):1345313458.

29. Burns-Kurtis CL, Olzinski AR, Needle S, Fox JH, Capper EA, Kelly FM, McQueney MS, Romanic AM. Cathepsin S expression is up-regulated following balloon angioplasty in the hypercholesterolemic rabbit. Cardiovasc Res. Jun 1 2004;62(3): 610-620.

30. Cheng XW, Kuzuya M, Sasaki T, Arakawa K, Kanda S, Sumi D, Koike T, Maeda K, Tamaya-Mori N, Shi GP, Saito N, Iguchi A. Increased expression of elastolytic cysteine proteases, cathepsins $\mathrm{S}$ and $\mathrm{K}$, in the neointima of balloon-injured rat carotid arteries. Am J Pathol. Jan 2004;164(1):243-251.

31. Sukhova GK, Zhang Y, Pan JH, Wada Y, Yamamoto T, Naito M, Kodama T, Tsimikas S, Witztum JL, Lu ML, Sakara Y, Chin MT, Libby P, Shi GP. Deficiency of cathepsin S reduces atherosclerosis in LDL receptor- deficient mice. J.Clin.Invest. 3/2003 2003;111(6):897-906.

32. Garnero P, Borel O, Byrjalsen I, Ferreras M, Drake FH, McQueney MS, Foged NT, Delmas PD, Delaisse JM. The collagenolytic activity of cathepsin K is unique among mammalian proteinases. J Biol Chem. Nov 27 1998;273(48):32347-32352.

33. Kafienah W, Bromme D, Buttle DJ, Croucher LJ, Hollander AP. Human cathepsin K cleaves native type I and II collagens at the N-terminal end of the triple helix. Biochem J. May 1 1998;331 (Pt 3):727-732.

34. Li Z, Yasuda Y, Li W, Bogyo M, Katz N, Gordon RE, Fields GB, Bromme D. Regulation of collagenase activities of human cathepsins by glycosaminoglycans. J Biol Chem. Feb 13 2004;279(7):5470-5479. 
35. Febbraio M, Guy E, Silverstein RL. Stem cell transplantation reveals that absence of macrophage CD36 is protective against atherosclerosis. Arterioscler Thromb Vasc Biol. Dec 2004;24(12):2333-2338.

36. Moore KJ, Kunjathoor VV, Koehn SL, Manning JJ, Tseng AA, Silver JM, McKee M, Freeman MW. Loss of receptor-mediated lipid uptake via scavenger receptor A or CD36 pathways does not ameliorate atherosclerosis in hyperlipidemic mice. J Clin Invest. Aug 2005;115(8):2192-2201.

37. Witztum JL. You are right too! J Clin Invest. Aug 2005;115(8):2072-2075.

38. Lindstedt L, Lee M, Oorni K, Bromme D, Kovanen PT. Cathepsins F and S block HDL3-induced cholesterol efflux from macrophage foam cells. Biochem Biophys Res Commun. Dec 26 2003;312(4):1019-1024.

39. Reddy VY, Zhang QY, Weiss SJ. Pericellular mobilization of the tissue-destructive cysteine proteinases, cathepsins B, L, and S, by human monocyte-derived macrophages. Proc Natl Acad Sci U S A. Apr 25 1995;92(9):3849-3853.

40. Punturieri A, Filippov S, Allen E, Caras I, Murray R, Reddy V, Weiss SJ. Regulation of elastinolytic cysteine proteinase activity in normal and cathepsin K-deficient human macrophages. J Exp Med. Sep 18 2000;192(6):789-799.

41. Naghavi M, John R, Naguib S, Siadaty MS, Grasu R, Kurian KC, van Winkle WB, Soller B, Litovsky S, Madjid M, Willerson JT, Casscells W. pH Heterogeneity of human and rabbit atherosclerotic plaques; a new insight into detection of vulnerable plaque. Atherosclerosis. Sep 2002;164(1):27-35. 


\section{Chapter 4 Gene profiling of cathepsin $\mathrm{K}$ deficiency in atherogenesis: profibrotic but lipogenic}

Suzanne P.M. Lutgens ${ }^{1}$, Natasja Kisters ${ }^{1}$, Esther Lutgens ${ }^{1}$, Rachel I.M. van Haaften ${ }^{2}$, Chris T.A. Evelo ${ }^{2}$, Menno P.J. de Winther ${ }^{3}$, Paul Saftig ${ }^{4}$, Mat J.A.P. Daemen ${ }^{1}$, Sylvia Heeneman ${ }^{1}$, Kitty B.J.M. Cleutjens ${ }^{1}$

Departments of Pathology ${ }^{1}$, Bioinformatics ${ }^{2}$ and Molecular Genetics ${ }^{3}$ Cardiovascular Research Institute Maastricht (CARIM), University of Maastricht, Maastricht, The Netherlands; Biochemical Institute ${ }^{4}$, University of Kiel, Germany. 


\section{ABSTRACT}

Recently, we showed that cathepsin K deficiency reduces atherosclerotic plaque progression, induces plaque fibrosis, but aggravates macrophage foam cell formation in the apoE-/- mouse.

To obtain more insight into the molecular mechanisms by which cathepsin $\mathrm{K}$ disruption evoked the observed phenotypic changes, we used microarray analysis for gene expression profiling of aortic arches of catK-/-/apoE-/- and apoE-/mice on a mouse oligo microarray. Out of 20,280 reporters, 444 reporters were significantly differentially expressed ( $\mathrm{P}$-value of $<0.05$, fold change of $\geq 1.4$ or $\leq$ -1.4 , and intensity value of $>2.5$ times background in at least one channel). Ingenuity Pathway Analysis and GenMAPP revealed upregulation of genes involved in lipid uptake, trafficking, and intracellular storage, including caveolin-1, -2, -3 and CD36, and profibrotic genes involved in transforming growth factor $\beta$ (TGF- $\beta$ ) signaling, including TGF- $\beta 2$, latent TGF- $\beta$ binding protein-1 (LTBP1), and secreted protein, acidic and rich in cysteine (SPARC), in catK-/-/apoE-/- mice. Differential gene expression was confirmed at the mRNA and protein level. In vitro modified low density lipoprotein (LDL) uptake assays, using bone marrow derived macrophages preincubated with caveolae and scavenger receptor inhibitors, confirmed the importance of caveolins and CD36 in increasing modified LDL uptake in the absence of cathepsin $\mathrm{K}$.

In conclusion, we suggest that cathepsin K deficiency alters plaque phenotype not only by decreasing proteolytic activity, but also by stimulating TGF- $\beta$ signaling. Besides this profibrotic effect, cathepsin K deficiency has a lipogenic effect owing to increased lipid uptake mediated by CD36 and caveolins. 


\section{INTRODUCTION}

Cathepsin K was first described in 1995 as a papain-like cysteine protease and has a distinct extracellular matrix degrading potential; its elastase activity exceeds that of all other elastases, and cathepsin K harbors a unique collagenolytic activity ${ }^{1-4}$. Cathepsin K was originally identified to play a role in bone resorption, but is expressed in many other tissues, including arteries, breast, ovary, stomach, and lung ${ }^{2,5-9}$. Sukhova et al. showed expression of both cathepsins $\mathrm{S}$ and $\mathrm{K}$ in human atheroma. Furthermore, cathepsin $\mathrm{S}$ was shown to be involved in atherosclerosis, as cathepsin S deficiency reduced plaque size in low density lipoprotein (LDL) receptor deficient mice $\mathrm{e}^{10,11}$.

Recently, we reported upregulation of cathepsin K expression in advanced stable human atherosclerotic plaques in comparison with early lesions and lesions containing a thrombus ${ }^{12}$. In catK-/-/apoE-/- atherosclerotic lesions we showed reduction of atherosclerotic plaque progression, induction of plaque fibrosis, but aggravation of macrophage foam cell formation in comparison with apoE- $/-^{12}$. To unravel further the molecular mechanisms underlying the observed

phenotypic changes evoked by cathepsin K deficiency, we performed gene expression profiling of plaque containing aortic arches of catK-/-/apoE-/- mice and apoE-/- mice on a mouse oligo microarray.

Microarray analysis was performed in duplicate using dye swap hybridization and data were validated by real-time polymerase chain reaction (PCR), immunohistochemistry, and western blot analysis. Pathway validation revealed an important role for caveolins and CD36 in increasing modified LDL uptake in the absence of cathepsin K. This study suggests that the use of cathepsin $\mathrm{K}$ as a possible therapeutic target for atherosclerosis has to be evaluated with care since cathepsin $\mathrm{K}$ inhibition might lead to a profibrotic, but also to a more lipogenic plaque phenotype.

\section{METHODS}

\section{Mice and experimental protocols}

ApoE-/ - mice on a C57BL6 background were obtained from Iffa Credo (Lyon, France) and were backcrossed 7-9 times to catK-/- mice on a C57BL6 background. Animal experiments were approved by the regulatory authority of the University of Maastricht and were performed in compliance with the Dutch government guidelines. Normal chow diet and water were provided ad libitum. At the age of 26 weeks, catK-/-/apoE-/- and apoE-/- mice were sacrificed after an 8 hour fast. The complete arterial tree was excised. Tissues of mice were used 
for RNA extraction (catK-/-/apoE-/- $[\mathrm{n}=11]$, apoE-/- $[\mathrm{n}=11]$ ), histological analysis (catK-/-/apoE-/- $[\mathrm{n}=7]$, apoE-/- $[\mathrm{n}=8]$ ) or protein extraction (catK-/-/apoE-/- $[\mathrm{n}=5]$, apoE-/- $[\mathrm{n}=4]$ ). For RNA and protein extraction, aortic arches including their main branchpoints were cleaned from fatty tissue, excised, rinsed in ice-cold phosphate-buffered saline, snap frozen in liquid nitrogen, and stored at $-80^{\circ} \mathrm{C}$ until further use. For histological analysis, aortic arches, including their main branch points, were processed as described previously $^{13,14}$.

\section{RNA isolation}

Aortic arches were disrupted in lysis buffer using a beadmill, and total RNA was isolated using the RNeasy kit (Qiagen). For microarray analysis, atherosclerotic plaque containing aortic arches of both catK-/-/apoE-/- and apoE-/- mice were pooled ( $\mathrm{n}=3$ for both groups).

\section{Microarray analysis}

cRNA labeling, microarray hybridization, scanning and data extraction were performed by ServiceXS (Leiden, The Netherlands) using the Mouse Development Oligo Microarray kit (G4120A; Agilent Technologies). This array contains 20,280 (60-mer) probes. Samples were cy3 or cy5 labeled using Agilent fluorescent linear amplification kit (G2554A; Agilent Technologies). In short, a primer which contains poly dT and a T7 polymerase promoter sequence was annealed to $2 \mu \mathrm{g}$ total RNA. cRNA was synthesized using T7 RNA polymerase, which simultaneously incorporated cy3- or cy5-labeled CTP. cRNA was processed using the in situ hybridization kit (5184-3568; Agilent Technologies). Briefly, $0.5 \mu \mathrm{g}$ cRNA was applied to the hybridization chamber and incubated at $60^{\circ} \mathrm{C}$ in a hybridization oven for 17 hours. Subsequently, arrays were washed and dried using a nitrogen-filled air gun. Hybridization was performed in duplicate using a dye swap.

(Statistical) analysis of microarray data

Array image acquisition and feature extraction were performed using the Agilent G2565AA Microarray Scanner and Feature Extraction software version 5.1. Raw intensity values for cy 3 and cy 5 were normalized to each other based on the mean intensity of all reporters. Feature extraction results were entered into Spotfire ${ }^{\circledR}$ DecisionSite 7.3 for Functional Genomics.

In Spotfire ${ }^{\circledR}$ DecisionSite, a t-test of $z$-scores normalized values for both experiments was performed. Subsequently, Unigene ID numbers, fold changes, t-test p-values and intensity values were imported into the Ingenuity Pathway Analysis software (Ingenuity Systems 2000-2005). SwissProt ID numbers or, if those were 
not available, Unigene ID numbers, fold changes, t-test p-values and intensity values were imported to GenMAPP (Gene Map Annotator and Pathway Profiler) version 2.0 (Gladstone Institutes 2000-2004, www.GenMAPP.org using gene ontology database (www.geneontology.org): Mm-Std_20040824. gdb and local mapps: Mm-contributed_20041216). Genes were only considered significantly differentially expressed when they had a P-value of $<0.05$, a fold change of at least 1.4, and an intensity value of at least 2.5 times background in at least one channel.

\section{Validation procedures}

\section{Real-Time PCR}

Random primers were used for the preparation of cDNA from template RNA. $\mathrm{dNTP}(5 \mu \mathrm{l} ; 10 \mathrm{mM}), 2.5 \mu \mathrm{l}$ random primer $(20 \mu \mathrm{g} / \mathrm{ml}$, Promega $), 5.0 \mu \mathrm{l} 5 \mathrm{x}$ first strand buffer (Invitrogen), and $11 \mu \mathrm{l}$ template RNA were added, followed by incubation at $72^{\circ} \mathrm{C}$ for 6 minutes and $37^{\circ} \mathrm{C}$ for 5 minutes. Then, $2.5 \mu \mathrm{DTT}(100$ $\mathrm{mM}$, Invitrogen), $0.5 \mu \mathrm{l}$ RNAsin (40U/ $\mu \mathrm{l}$, Promega), and $0.5 \mu 1 \mathrm{MMLV}$ reverse transcriptase $(200 \mathrm{U} / \mu \mathrm{l}$, Invitrogen) were added to a final volume of $25 \mu \mathrm{l}$, followed by 1 cycle of $37^{\circ} \mathrm{C}$ for 60 minutes and $95^{\circ} \mathrm{C}$ for 5 minutes. cDNA was diluted to a concentration of $2 \mathrm{ng} / \mu \mathrm{l}$. Real-time PCR was performed as described previously ${ }^{12}$ (For primers and probes, see Table I).

\section{Human tissue sampling}

Atherosclerotic plaques from the internal carotid artery were obtained from patients undergoing vascular surgery (Department of General Surgery, Academic Hospital Maastricht) or at autopsy (Department of Pathology, Academic Hospital Maastricht) and were collected in compliance with institutional ethical guidelines in accordance with the Helsinki Declaration of 1975, as revised in 1983. Vascular specimens were processed as previously described ${ }^{15}$ and were classified according Virmani et al. ${ }^{16}$.

\section{Immunohistochemistry}

(Double) immunohistochemistry was performed as described previously ${ }^{13,14}$ with the following antibodies: caveolin-1 polyclonal antibody (1:800, Santa Cruz), SPARC polyclonal antibody (osteonectin) (1:50, gift from Dr L Fisher, University Institute of Pathological Anatomy, Copenhagen, Denmark), $\alpha$-smooth muscle actin monoclonal antibody (1:500, Sigma) as a marker for vascular SMCs and myofibroblasts, MAC3 rat monoclonal antibody (1:30, Pharmingen) to detect macrophages, factor VIII von Willebrand (1:500, Dako) as a marker for endothelial cells, and control mouse IgG (Dako) as a negative control. Caveolin-1 
72 | CHAPTER 4

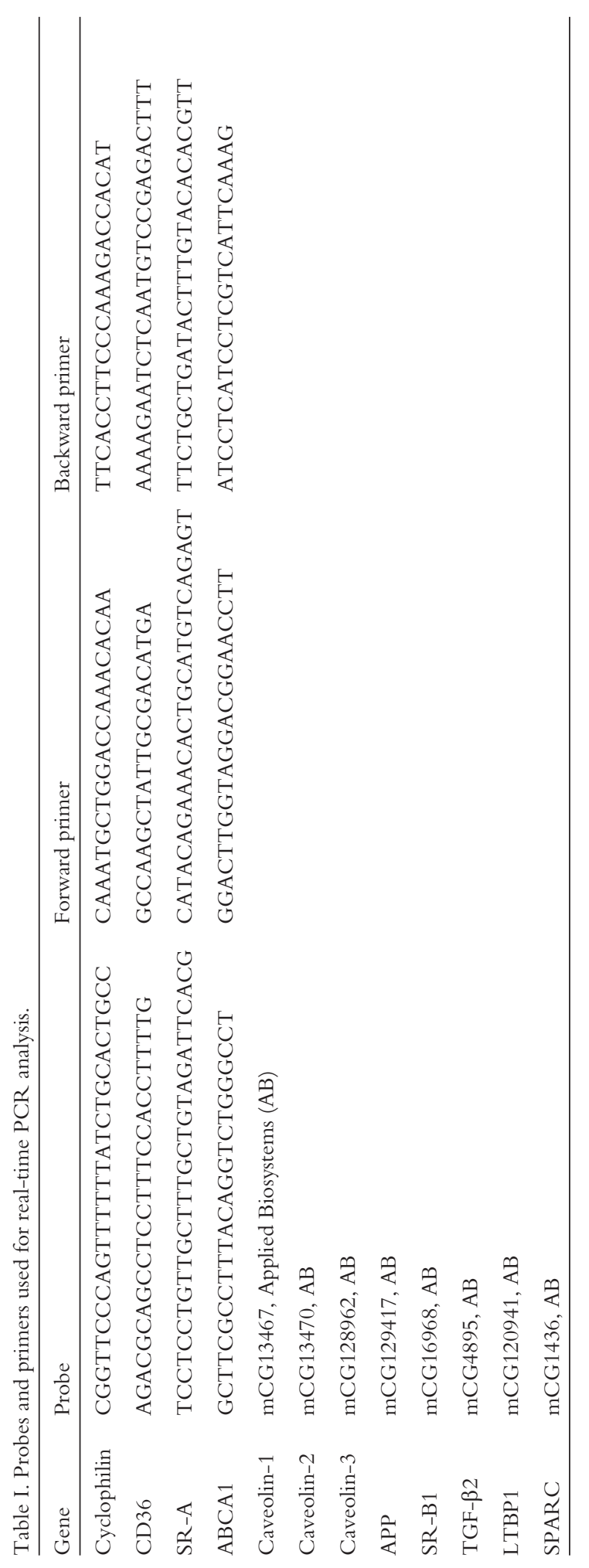


and secreted protein, acidic and rich in protein (SPARC) staining of the atherosclerotic plaque in the left subclavian artery branch were measured using image analysis software (Leica Qwin) as the percentage of positive stained area to total plaque area. Incubation with control mouse $\mathrm{IgG}$ or deletion of the primary antibody did not show any staining.

\section{Western blot}

Bone marrow (BM) derived macrophages were obtained according to standard procedures $^{17}$. Blots were incubated with caveolin-1 polyclonal antibody (1:800, Santa Cruz) or phosphate-buffered saline, followed by incubation with horseradish peroxidase-coupled anti-rabbit antibody (1:1500, Dako). Specific antibody binding was visualized with WestPico (Pierce, Perbio Science).

\section{In vitro intervention assay using $B M$ derived macrophages}

LDL was extracted, oxidized, and labeled as described previously ${ }^{12}$. BM derived macrophages were incubated with 25 or $50 \mu \mathrm{g} / \mathrm{ml}$ DiI labeled oxLDL for 3 hours. Inhibitors were added 30 minutes before DiI labeled oxLDL incubation. Methylbetacyclodextrin (2 mM and $10 \mathrm{mM}$, Sigma) was used to disrupt caveolae, the smo antibody (monoclonal anti-CD36, $10 \mu \mathrm{g} / \mathrm{ml}$, Ancell) as an inhibiting antibody of CD36, fucoidan $(10 \mu \mathrm{g} / \mathrm{ml}$, Sigma) to inhibit scavenger receptor (SR)-A, and SR BI/II polyclonal antibody to inhibit SR-BI/II (1:100, Novus Biologicals). OxLDL uptake was determined by fluorescence-activated cell sorting (FACS; BD Biosciences).

\section{Statistical analysis}

All statistical analyses, except the array analysis in Spotfire ${ }^{\circledR}$, were performed using GraphPad Prism (GraphPad Software Inc.). All data were analyzed by the nonparametric Mann-Whitney $U$ test. Data are presented as mean \pm SEM and were considered statistically significant at $\mathrm{P}<0.05$.

\section{RESULTS}

\section{Microarray analysis}

After normalization of microarray data and t-test analysis in Spotfire ${ }^{\circledR}$ DecisionSite, 558 of 20,280 reporters were found to be differentially regulated $(\mathrm{P}<0.05)$, while 444 reporters had a $\mathrm{P}$-value of $<0.05$, a fold change of $\geq 1.4$ or $\leq$ -1.4 , and an intensity value of $>2.5$ times background in at least one channel. 


\section{CHAPTER 4}

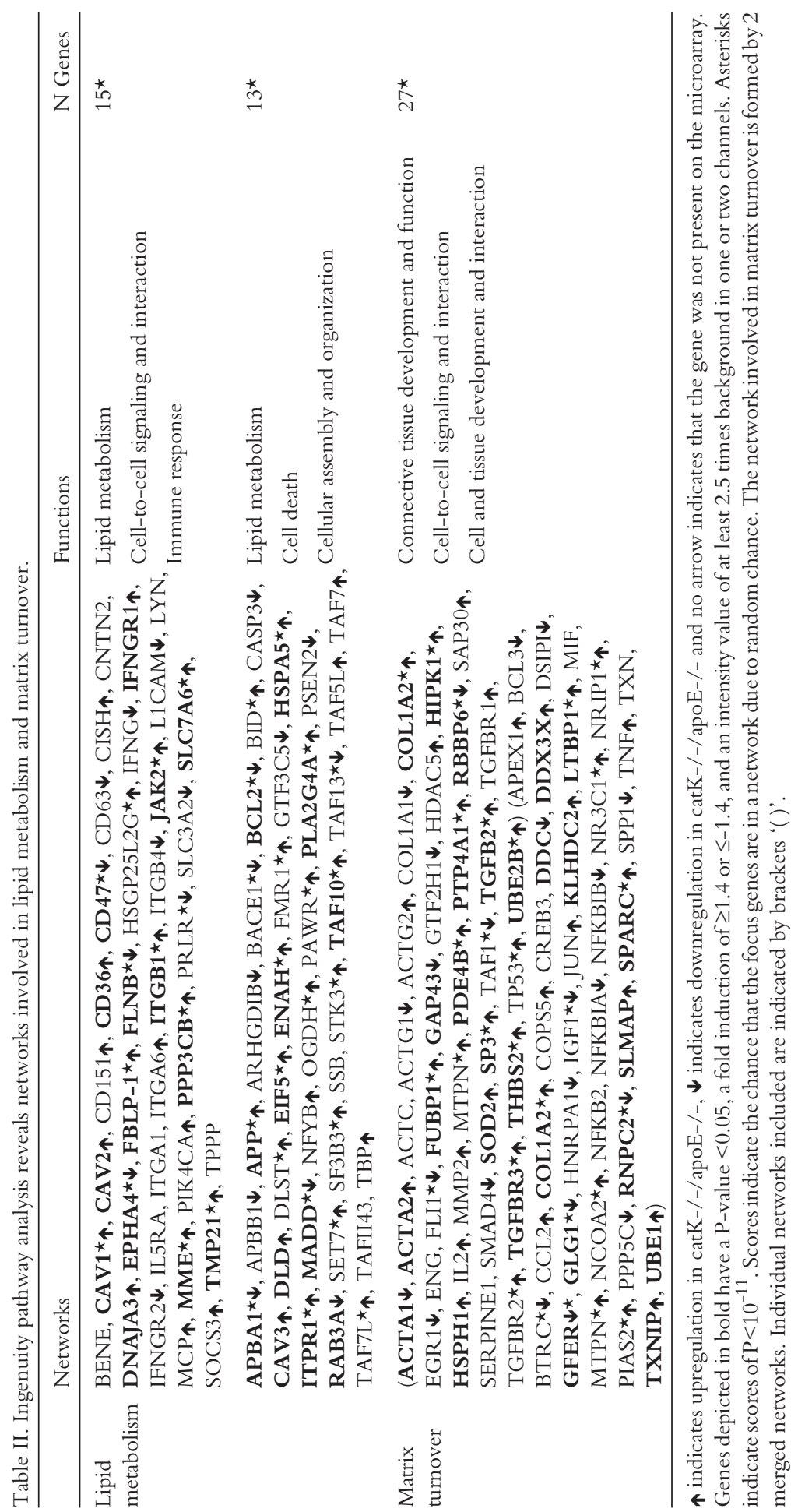


Table III. GenMAPP reveals several processes and components involved in caveolae, actin cytoskeleton and TGF- $\beta$ signaling. GenMAPP not only confirmed pathways already found in Ingenuity Pathway Analysis (lipid metabolism and matrix turnover), but also revealed an additional pathway involved (actin cytoskeleton).

\begin{tabular}{|c|c|c|}
\hline Process / Component & Genes & Z-score \\
\hline Caveolae & $\mathrm{CAV} \uparrow, \mathrm{CAV} 2 \uparrow, \mathrm{CAV} 3 \uparrow$ & 5.90 \\
\hline Actin cytoskeleton & 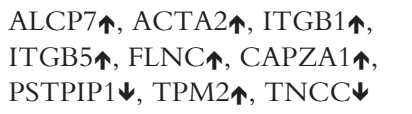 & 4.61 \\
\hline TGF- $\beta$ signaling & 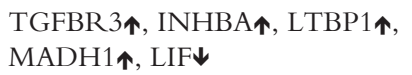 & 1.46 \\
\hline
\end{tabular}

Only differentially expressed genes are included. $\uparrow$ indicates upregulation in catK-/-/apoE-/-, $\downarrow$ indicates downregulation in catK-/-/apoE-/-. All genes depicted have a P-value $<0.05$, a fold induction of $\geq 1.4$ or $\leq-1.4$, and an intensity value of at least 2.5 times background in one or two channels.

\section{Pathway analysis and functional clustering}

To identify molecular and cellular pathways by which cathepsin $\mathrm{K}$ disruption evoked the observed increased fibrosis and increased lipid storage in vivo, we performed pathway analysis using both Ingenuity Pathway Analysis and GenMAPP. Table II lists the most important differentially expressed networks detected by Ingenuity Pathway Analysis.

Of special interest were two networks containing genes involved in lipid metabolism (Table II). A total of 15/35 (43\%) and 13/35 (37\%) genes included in these networks were significantly up- or downregulated, with the majority $(75 \%)$ of genes being significantly upregulated in aortic arches derived from catK-/-/apoE-/- mice. Another network of interest was the merged network involved in matrix turnover (Table II). A total of 27/68 (40\%) genes included were significantly up- or downregulated. Again, the majority (75\%) was significantly upregulated in aortic arches derived from catK-/-/apoE-/- mice.

To perform a complete pathway profiling, SwissProt ID or, if not available, Unigene ID numbers of all genes meeting the above mentioned differential expression criteria (a combined criterion consisting of fold inductions, P-values, and intensities) were also forwarded to GenMAPP. The most significant pathways found in GenMAPP were pathways involving caveolae (Gene Ontology (GO) based), TGF- $\beta$ signaling (local MAPP), and actin cytoskeleton (GO). Table III lists the most important networks of GenMAPP. Figure 1 shows a flowchart depicting both Ingenuity Pathway and GenMAPP analysis. 


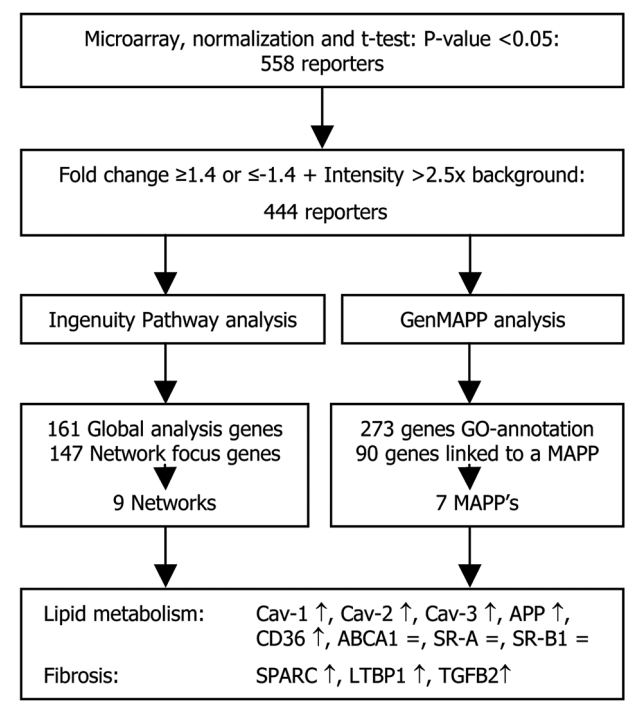

Figure 1. Flowchart depicting an overview of Ingenuity Pathway Analysis and GenMAPP. Global analysis genes indicate a biologically related interaction between genes, and Network focus genes (genes eligible for networks) indicate a direct interaction between molecules. GO, Gene Ontology annotations; GenMAPP, Gene Map Annotator and Pathway Profiler.

Table IV. Fold changes identified by microarray analysis were confirmed on RNA level using real-time PCR.

\begin{tabular}{lll}
\hline Gene & Fold change microarray & Fold change real-time PCR \\
\hline Matrix turnover & & \\
LTBP1 & $4.3^{\star}$ & $2.9 \pm 0.7^{\star}$ \\
TGFB2 & $2.6^{\star}$ & $3.0 \pm 0.5^{\star}$ \\
SPARC & $2.2^{\star}$ & $2.5 \pm 0.7^{\star}$ \\
Lipid metabolism & & \\
Cav-1 & $6.0^{\star}$ & $2.4 \pm 0.2^{\star}$ \\
Cav-2 & $4.3^{\star}$ & $1.6 \pm 0.1^{\star}$ \\
Cav-3 & $2.2^{\star}$ & $1.8 \pm 0.3^{\star}$ \\
CD36 & $1.9^{\star}$ & $1.5 \pm 0.1$ \\
APP & $2.9^{\star}$ & $1.4 \pm 0.02^{\star}$ \\
SR-A & $=$ & $=$ \\
SR-B1 & $=$ & $=$ \\
ABCA1 & $=$ & $=$
\end{tabular}

Asterisks indicate $\mathrm{P}<0.05$ and data are presented as mean \pm SEM. Cav indicates caveolin; ' =' indicates no altered expression. 

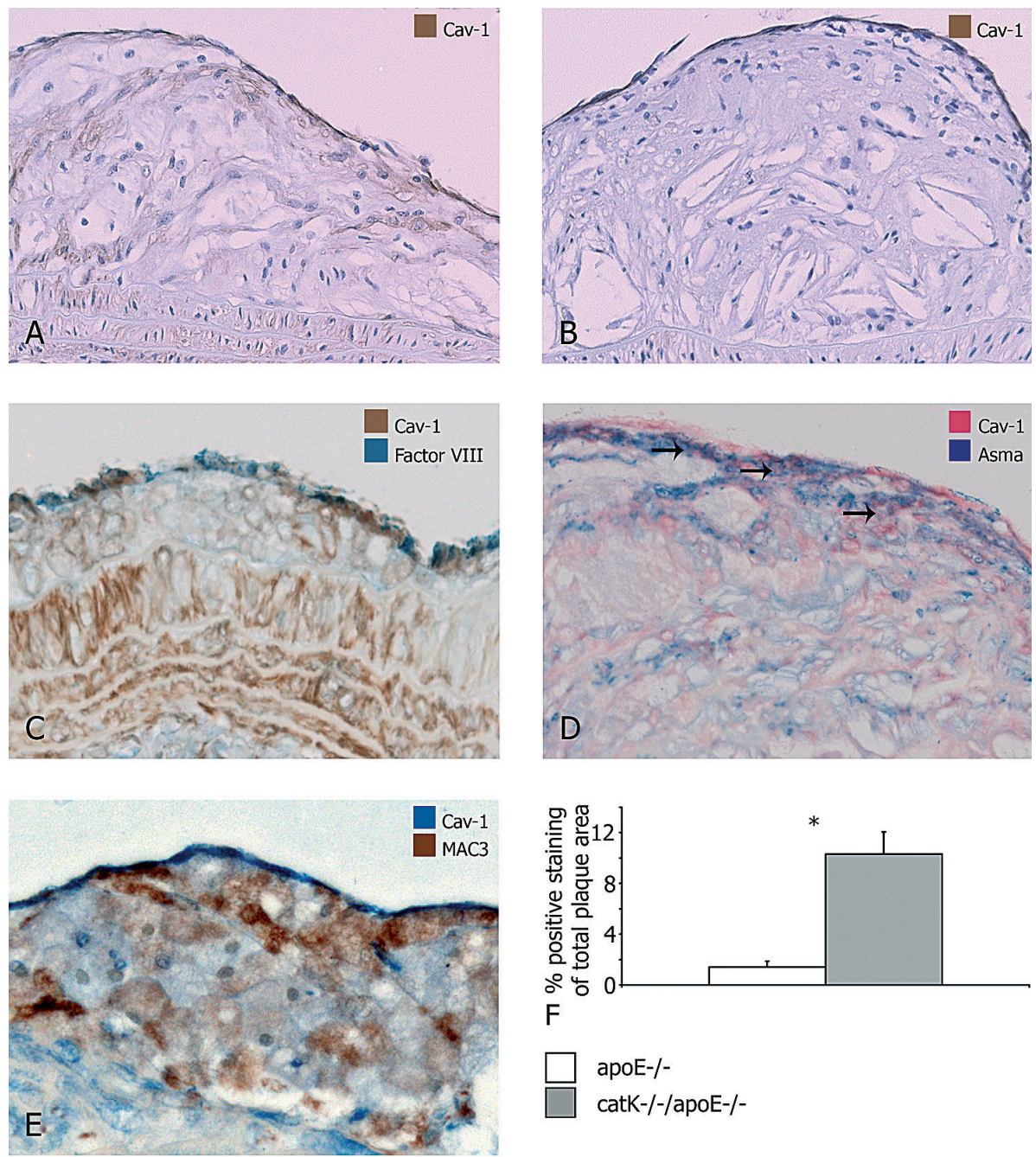

Figure 2. Representative immunohistochemical staining showing that caveolin-1 (brown) was localized, especially in plaque macrophages and endothelial cells, in catK-/-/apoE-/- mice (A) in comparison with apoE-/- mice (B). Double immunohistochemistry showed that caveolin-1 was localized in endothelial cells (C) caveolin-1 in brown and factor VIII in blue), only sporadically in SMCs (D) caveolin-1 in red, $\alpha$-smooth muscle actin in blue, indicated with black arrows), and in macrophages (E) caveolin-1 in blue, MAC3 in brown). Atherosclerotic plaques of catK-/-/apoE-/- mice showed increased caveolin-1 protein levels in comparison with apoE-/- $(\mathrm{F})$. Asterisks indicate $\mathrm{P}<0.05$, and data are presented as mean \pm SEM. 
Validation of microarray expression profiles at $m R N A$ level Upregulation in catK-/-/apoE-/- aortic arches was confirmed by real-time PCR for caveolin-1, caveolin-2, and caveolin-3, APP, TGF- $\beta 2$, latent TGF- $\beta$ binding protein-1 (LTBP1), and SPARC (Table IV). As reported earlier the increased expression of CD36 was confirmed to be borderline significant (1.9 fold, $\mathrm{P}=0.05$ ) in real-time PCR ${ }^{12}$. Expression of SR-A, SR-B1 and ABCA1 was not altered in both microarray and real-time PCR analysis.

\section{Validation of microarray expression levels at protein level}

Atherosclerotic plaques of catK-/-/apoE-/- mice showed increased caveolin-1 (Figure 2) and SPARC (Figure 3) protein levels in comparison with apoE-/mice. In both genotypes, caveolin-1 was localized in endothelial cells (Figure 2C) and sporadically in SMCs (Figure 2D). However, in catK-/-/apoE-/- mice caveolin-1 was also localized in plaque macrophages (Figure 2E). Positive caveolin-1 stained area to total plaque area was $10.3 \pm 4.7 \%$ of total plaque area in catK-/-/apoE-/- versus $1.4 \pm 1.3 \%$ in apoE-/-, $\mathrm{P}<0.05$ (Figure 2F). Immunohistochemical staining for SPARC showed positivity of chondroid-like cells in both lesion types (Figure 3C). In addition, in catK-/-/apoE-/- lesions SPARC protein was also localized in plaque macrophages (Figure 3D), while incidentally also some endothelial cells showed SPARC protein expression. Positive SPARC stained area to total plaque area was $14.5 \pm 7.6 \%$ in catK-/-/apoE-/- versus $2.0 \pm 1.0 \%$ in apoE-/-, $\mathrm{P}<0.05$ (Figure 3E). We reported previously that CD36 protein levels are increased in catK-/-/apoE-/aortic lesions in comparison with apoE- $/{ }^{12}$. Furthermore, lysates from aortic arches and BM derived macrophages showed increased levels of caveolin-1 in catK-/-/apoE-/- in comparison with apoE-/-. Densitometry analysis showed a significant increase in caveolin-1 protein expression in lysates from catK-/-/apoE-/- aortic arches compared with apoE-/- $(\mathrm{P}<0.05$; Figure 4). Immunohistochemistry also revealed high levels of caveolin-1 protein in human atherosclerotic plaques (Figure 5). Caveolin-1 protein expression was especially localized in endothelial cells and macrophages of early lesions and stable advanced lesions, when compared with lesions containing a thrombus.

\section{In vitro pathway validation}

Absolute uptake of DiI-labeled oxLDL uptake without inhibitors was increased in catK-/-/apoE-/- BM derived macrophages as described previously ${ }^{12}$ and indicated in Figure 6A. Absolute inhibition of DiI-labeled oxLDL uptake by addition of an inhibitor was related to absolute inhibition of DiI-labeled oxLDL uptake without inhibitor using the following formula: ([Geomean without inhibitor Geomean with inhibitor] / Geomean without inhibitor) x $100 \%$. Figure 6B 

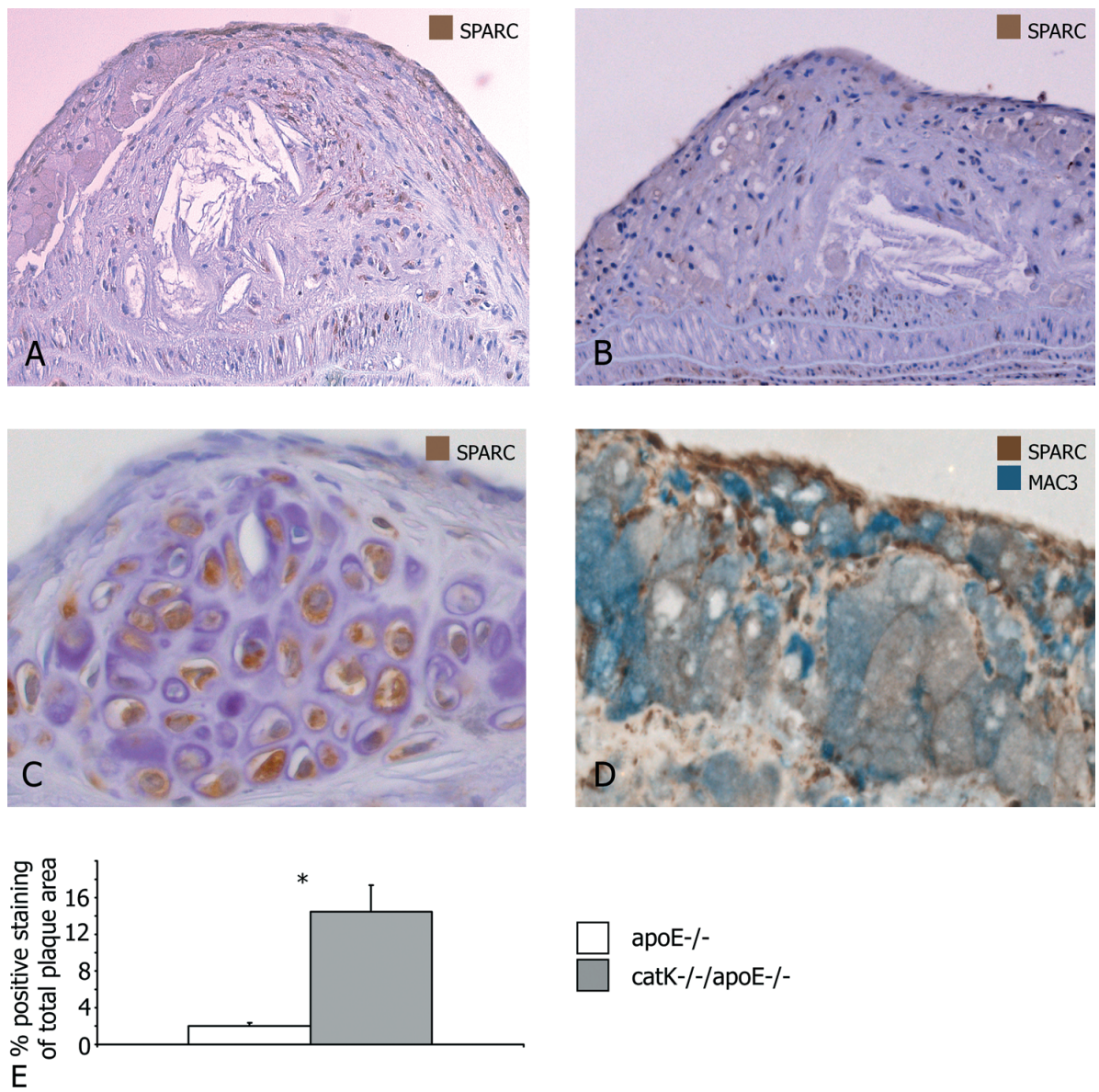

apoE-/-

catK-/-/apoE-/-

Figure 3. Representative immunohistochemical staining showing that SPARC (brown) was especially localized in plaque macrophages and endothelial cells in catK-/-/apoE-/- (A) compared with apoE-/(B). SPARC staining showed positivity in chondroid-like cells in both lesion types (C). Double immunohistochemistry showed that SPARC was localized in plaque macrophages especially (D) SPARC in brown, MAC3 in blue). Atherosclerotic plaques of catK-/-/apoE-/- mice showed increased SPARC protein levels in comparison with apoE-/- (E). Asterisks indicate $\mathrm{P}<0.05$, and data are presented as mean \pm SEM.

shows that disruption of caveolae by methylbetacyclodextrin and inhibition of CD36 by the inhibiting antibody smo lead to increased inhibition of modified LDL uptake in catK-/-/apoE-/- BM derived macrophages in comparison with apoE-/-. Inhibition of SR-A and SR-B by fucoidan and SR-BI/II inhibiting antibody respectively did not lead to a significant inhibition of modified LDL uptake. 


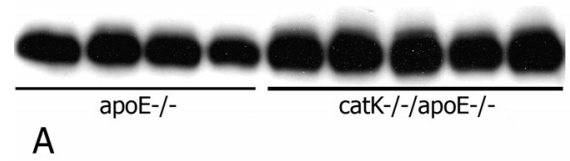

apoE-/-

catK-/-/apoE-/-

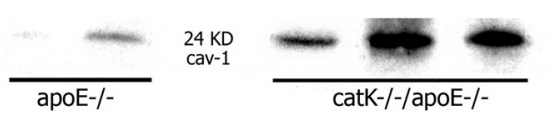

C

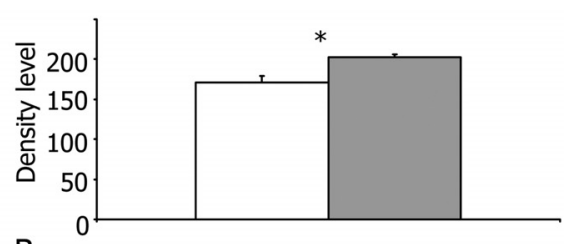

B

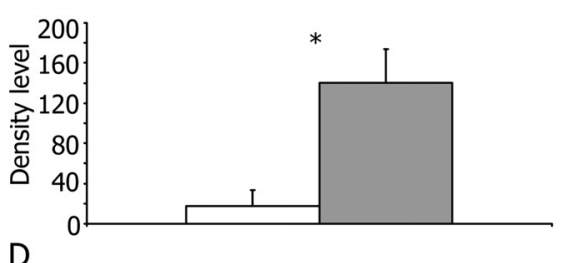

Figure 4. Western blot and densitometry analysis showing increased expression of caveolin-1 in catK-/-/apoE-/- compared with apoE-/- aortic arches (A and B) and BM derived macrophages ( $\mathrm{C}$ and D). Asterisks indicate $\mathrm{P}<0.05$. and data are presented as mean \pm SEM.
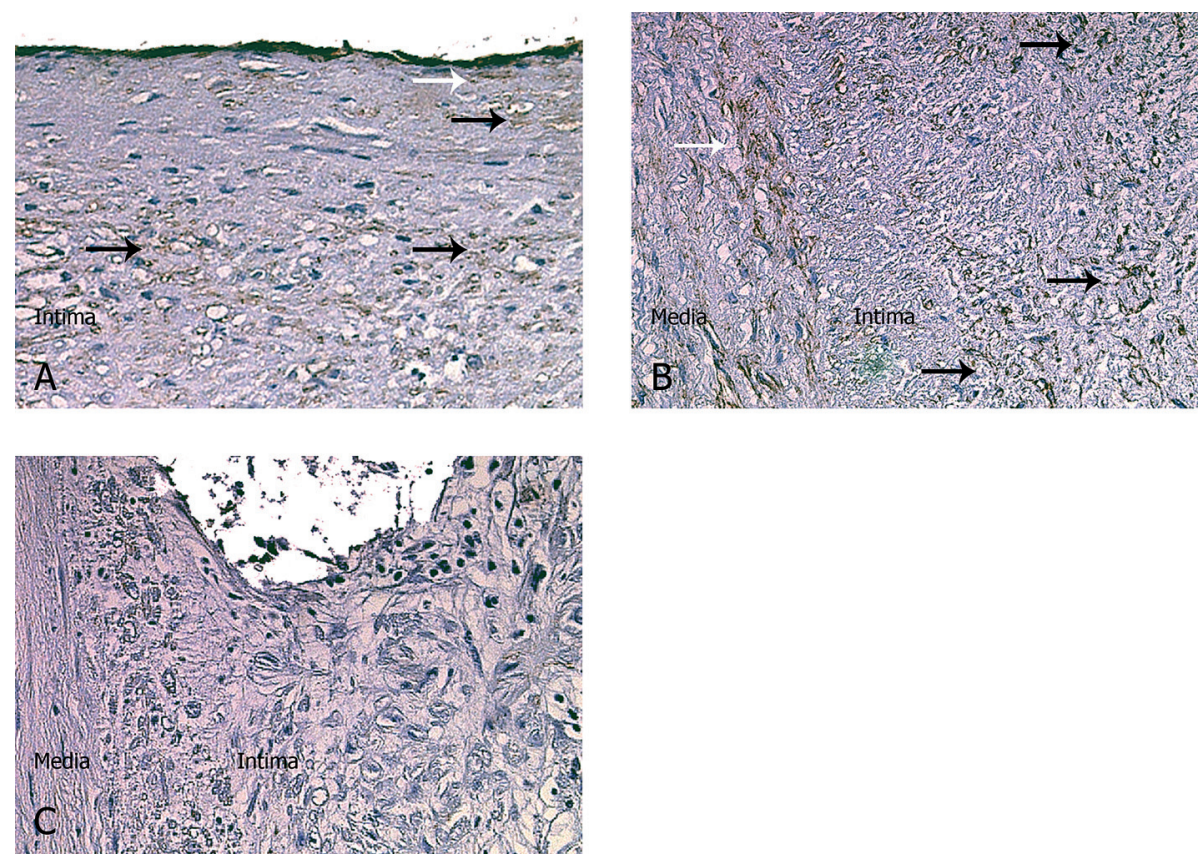

Figure 5. Representative immunohistochemical staining of human atherosclerotic lesions. Caveolin-1 staining (brown) is localized in smooth muscle cells (white arrows) and macrophages (black arrows) in early lesions (A) and stable advanced lesions (B), and to a lesser extent in lesions containing a thrombus (C). 

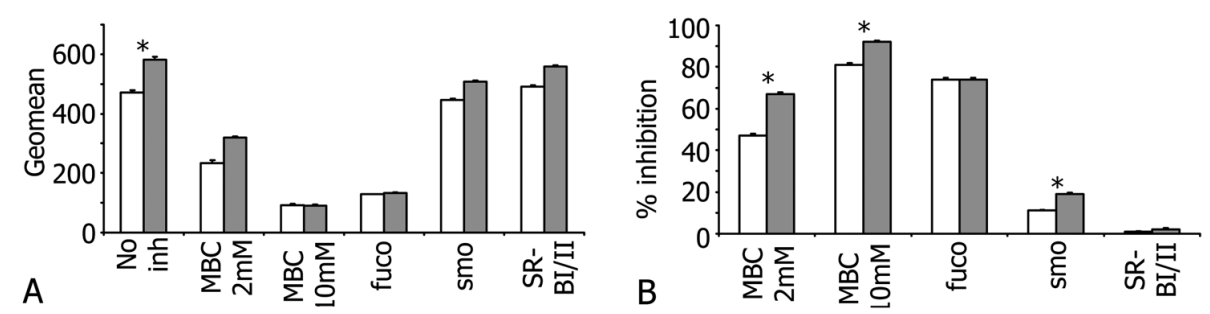

apoE-/-

catK-/-/apoE-/-

Figure 6. In vitro inhibitor assay. Absolute uptake of DiI-labeled oxLDL uptake without inhibitors is increased in catK-/-/apoE-/- BM derived macrophages (A). To relate the absolute inhibition of DiI-labeled oxLDL uptake by addition of an inhibitor to DiI-labeled oxLDL uptake without inhibitor, relative percentages of inhibition were calculated using the following formula: ([Geomean without inhibitor - Geomean with inhibitor] / Geomean without inhibitor) x $100 \%$. B. Disruption of caveolae by methylbetacyclodextrin (MBC) leads to increased inhibition of DiI labeled oxLDL in catK-/-/apoE-/- in comparison with apoE-/- BM derived macrophages, and inhibition of SR CD36 by the CD36 blocking antibody smo also leads to increased inhibition of DiI labeled oxLDL in catK-/-/apoE-/- in comparison with apoE-/- BM derived macrophages. Inhibition of SR-A and SR-BI/II by fucoidan (fuco) and SR-BI/II inhibiting Ab, respectively, did not differ between the two genotypes. Asterisks indicate $\mathrm{P}<0.05$ and data are presented as mean \pm SEM.

\section{DISCUSSION}

In the present study, microarray analysis comparing aortic arches of catK-/-/apoE-/- with those of apoE-/- mice revealed upregulation of several genes and pathways, including (1) lipid metabolism and caveolae, (2) actin cytoskeleton, and (3) matrix turnover and more specifically TGF- $\beta$ signaling. The role of TGF- $\beta$ is well known and has been described on many occasions ${ }^{13,18,19}$. However, our finding that cathepsin K deficiency also increased lipid uptake and storage by macrophages and aggravated subsequent foam cell formation was unexpected $^{12}$. Foam cell formation plays an important role in plaque destabilization and given the current quest for cathepsin $\mathrm{K}$ inhibitors as a therapeutic modality for atherosclerosis, the role of cathepsin $\mathrm{K}$ in foam cell formation needs further exploration. Therefore we mainly focused on the functional mechanisms by which cathepsin $\mathrm{K}$ deficiency leads to changes in lipid uptake and storage.

Our study suggests a role for cathepsin $\mathrm{K}$ in lipid metabolism, since mediators such as caveolin-1, $-2,-3$ and CD36 were significantly upregulated in cathepsin $\mathrm{K}$ deficient atherosclerotic lesions. Caveolins have been shown to play a role in atherosclerosis, especially in cholesterol metabolism ${ }^{20-26}$. However, the overall effect is still unknown since both proatherogenic and antiatherogenic properties 
are attributed to caveolins ${ }^{8,27,28}$. In aortic arch atherosclerotic lesions of catK-/-/apoE-/- mice, we found that both caveolins and CD36 were upregulated, but other SRs, like SR-A and SR-B1, were not differentially regulated. This suggests that cathepsin K deficiency leads to increased lipid uptake through a mechanism involving both caveolae and CD36, but not SR-A and SR-B1. We reported earlier that cathepsin $\mathrm{K}$ deficiency leads to increased uptake and storage of modified LDL by BM derived macrophages ${ }^{12}$. Here, we confirm the role of caveolins and CD36 in increasing lipid uptake when cathepsin $\mathrm{K}$ is deficient, since disruption of caveolae and inhibition of CD36 leads to increased inhibition of modified LDL uptake by catK-/-/apoE-/- in comparison with apoE-/- BM derived macrophages. SR-A, although playing an important role in lipid uptake, does not seem to have an additional contribution to increasing lipid uptake in cathepsin K deficient lesions, nor does SR-BI/II. The potential role for CD36 in lipid uptake has been described earlier, but CD36 has not been previously associated with cathepsin K. Alternatively, our observations of increased intracellular lipid storage could not only be the result of an increased lipid influx but also the result of a decrease in lipid efflux. However, our data did not reveal altered expression of the main efflux associated genes, including several ABCA and ABCG transporters. This finding is supported by Lindstedt et al. who showed that cathepsins $\mathrm{F}$ and $\mathrm{S}$ have an important role in cholesterol efflux and suggested only a minor role for cathepsin $\mathrm{K}^{29}$. mRNA levels of the efflux associated gene SR-B1 are also not altered in catK-/-/apoE-/- aortic arch atherosclerotic lesions. The role of caveolin-1 in affecting this SR-B1 mediated cholesterol efflux is uncertain $^{30-32}$.

We demonstrated that caveolin-1 is not only present in murine atherosclerotic plaques but also in human atherogenesis. Recently, Schwencke et al. already showed that the proliferation of vascular SMCs in human atheromata is associated with a decrease in caveolin-1 expression ${ }^{33}$.

Furthermore, we found upregulation of several genes involved in the actin cytoskeleton. Caveolar endocytosis mediated by the actin cytoskeleton has been described in the literature ${ }^{15,34-36}$. Several of the upregulated genes in this study are related to caveolar endocytosis. Integrin beta-1 activates the internalization of caveola $e^{34,37}$, while the actin-binding protein filamin is a ligand for caveolin- $1^{38}$, and microtubules are needed for transport of caveolar vesicles ${ }^{39}$. This suggests that the increased lipid storage, as described earlier ${ }^{12}$, may be the result of increased lipid transport mediated by the actin cytoskeleton.

We and others previously showed that disruption of TGF- $\beta$ signaling led to a decrease in fibrosis in atherosclerotic lesions ${ }^{13,18}$. Interestingly, Buhling et al. found an increase in extracellular matrix deposition in lungs when cathepsin $\mathrm{K}$ was disrupted $^{7,8}$. Data from our own lab also showed that disruption of cathepsin $\mathrm{K}$ in 


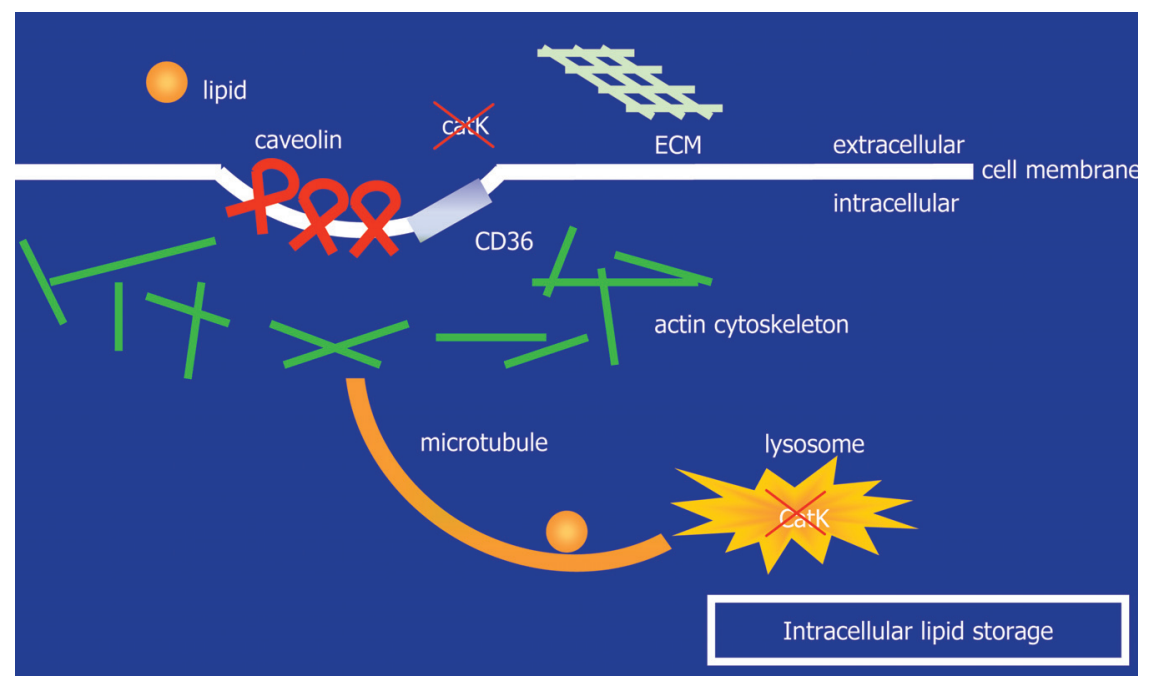

Figure 7. Putative mechanism by which cathepsin K (catK) deficiency leads to a pro-fibrotic, but also lipogenic plaque phenotype. In the cathepsin $\mathrm{K}$ deficient macrophage, lipid uptake is increased. This increased lipid uptake is mediated by both CD36 and caveolins. Then, lipid is transported, possibly via the actin cytoskeleton, to the interior of the cell and stored in lysosomes

apoE-/- mice resulted in an increase in collagen content in atherosclerotic plaques $^{12}$. This increase in collagen content was not reflected by an increase in vascular SMC content (initial lesions: $0.8 \pm 0.3 \%$ of total plaque area in catK-/-/apoE-/- versus $0.7 \pm 0.2 \%$ and advanced lesions: $0.7 \pm 0.2 \%$ in catK-/-/apoE-/- versus $0.8 \pm 0.2 \%$ in apoE-/-, P>0.05). The upregulation of genes involved in matrix turnover and TGF- $\beta$ signaling suggests that cathepsin $\mathrm{K}$ deficiency increases plaque fibrosis not only by decreasing proteolytic activity but also by stimulating genes involved in matrix turnover and TGF- $\beta$ signaling.

One question that remains to be answered here is the mechanism by which cathepsin $\mathrm{K}$ deficiency leads to the induction of gene transcription and translation of the differentially expressed genes as found in this study. Until now, caveolin-1 has been described as being involved in regulation, activation, and expression of cathepsin $\mathrm{B}^{40}$. However, no such relation between cathepsin $\mathrm{K}$ and caveolin-1, and more generally between cathepsin $\mathrm{K}$ and lipid metabolism, has been described.

In view of the role of the lysosomal cysteine protease cathepsin $\mathrm{K}$ in foam cell formation, we hypothesize that the increased lipid uptake and storage in enlarged lysosomes in the cathepsin $\mathrm{K}$ deficient macrophage is the net result of increased CD36 and caveolin-1 protein levels, which facilitate lipid uptake into the cell. After transportation across the cell membrane into the cell, lipid is transcytosed through the interior of the cell by the actin cytoskeleton and its associated 
proteins. Finally, lipid is stored, owing to the absence of the lysosomal cysteine protease cathepsin $\mathrm{K}$, in the enlarged lysosomes, eventually resulting in a macrophage foam cell that contains more lipids compared with the 'normal' apoE-/- macrophages (summarized in Figure 7).

In conclusion, we suggest that cathepsin $\mathrm{K}$ deficiency not only induces a profibrotic atherosclerotic plaque phenotype but also results in a lipogenic plaque phenotype. Assuming similar effects for the human plaque phenotype, the use of cathepsin $\mathrm{K}$ as a possible therapeutic target should be evaluated with care.

\section{REFERENCES}

1. Garnero P, Borel O, Byrjalsen I, Ferreras M, Drake FH, McQueney MS, Foged NT, Delmas PD, Delaisse JM. The collagenolytic activity of cathepsin K is unique among mammalian proteinases. J Biol Chem. Nov 27 1998;273(48):32347-32352.

2. Gelb BD, Moissoglu K, ZhangJ, Martignetti JA, Bromme D, Desnick RJ. Cathepsin K: isolation and characterization of the murine cDNA and genomic sequence, the homologue of the human pycnodysostosis gene. Biochem Mol Med. Dec 1996;59(2): 200-206.

3. Chapman HA, Riese RJ, Shi GP. Emerging roles for cysteine proteases in human biology. Annu Rev Physiol. 1997;59:63-88.

4. Bromme D, Okamoto K. Human cathepsin O2, a novel cysteine protease highly expressed in osteoclastomas and ovary molecular cloning, sequencing and tissue distribution. Biol Chem Hoppe Seyler. Jun 1995;376(6):379-384.

5. Inaoka T, Bilbe G, Ishibashi O, Tezuka K, Kumegawa M, Kokubo T. Molecular cloning of human cDNA for cathepsin K: novel cysteine proteinase predominantly expressed in bone. Biochem Biophys Res Commun. Jan 5 1995;206(1):89-96.

6. Shi GP, Chapman HA, Bhairi SM, DeLeeuw C, Reddy VY, Weiss SJ. Molecular cloning of human cathepsin $\mathrm{O}$, a novel endoproteinase and homologue of rabbit OC2. FEBS Lett. Jan 3 1995;357(2):129-134.

7. Buhling F, Peitz U, Kruger S, Kuster D, Vieth M, Gebert I, Roessner A, Weber E, Malfertheiner P, Wex T. Cathepsins K, L, B, X and W are differentially expressed in normal and chronically inflamed gastric mucosa. Biol Chem. May 2004;385(5):439-445.

8. Buhling F, Rocken C, Brasch F, Hartig R, Yasuda Y, Saftig P, Bromme D, Welte T. Pivotal role of cathepsin K in lung fibrosis. Am J Pathol. Jun 2004;164(6):2203-2216.

9. Littlewood-Evans AJ, Bilbe G, Bowler WB, Farley D, Wlodarski B, Kokubo T, Inaoka T, Sloane J, Evans DB, Gallagher JA. The osteoclast-associated protease cathepsin K is expressed in human breast carcinoma. Cancer Res. Dec 1 1997;57(23):5386-5390.

10. Sukhova GK, Shi GP, Simon DI, Chapman HA, Libby P. Expression of the elastolytic cathepsins $\mathrm{S}$ and $\mathrm{K}$ in human atheroma and regulation of their production in smooth muscle cells. J Clin Invest. Aug 1 1998;102(3):576-583.

11. Sukhova GK, Zhang Y, Pan JH, Wada Y, Yamamoto T, Naito M, Kodama T, Tsimikas S, Witztum JL, Lu ML, Sakara Y, Chin MT, Libby P, Shi GP. Deficiency of cathepsin S reduces atherosclerosis in $\mathrm{LDL}$ receptor-deficient mice. J Clin Invest. Mar 2003;111(6):897-906. 
12. Lutgens E, Lutgens SP, Faber BC, Heeneman S, Gijbels MM, de Winther MP, Frederik P, van der Made I, Daugherty A, Sijbers AM, Fisher A, Long CJ, Saftig P, Black D, Daemen MJ, Cleutjens KB. Disruption of the cathepsin K gene reduces atherosclerosis progression and induces plaque fibrosis but accelerates macrophage foam cell formation. Circulation. Jan 3 2006;113(1):98-107.

13. Lutgens E, Gijbels M, Smook M, Heeringa P, Gotwals P, Koteliansky VE, Daemen MJ. Transforming growth factor-beta mediates balance between inflammation and fibrosis during plaque progression. Arterioscler Thromb Vasc Biol. Jun 1 2002;22(6):975-982.

14. Lutgens E, Gorelik L, Daemen MJ, de Muinck ED, Grewal IS, Koteliansky VE, Flavell RA. Requirement for CD154 in the progression of atherosclerosis. Nat Med. Nov 1999;5(11):1313-1316.

15. Faber BC, Cleutjens KB, Niessen RL, Aarts PL, Boon W, Greenberg AS, Kitslaar PJ, Tordoir JH, Daemen MJ. Identification of genes potentially involved in rupture of human atherosclerotic plaques. Circ Res. Sep 14 2001;89(6):547-554.

16. Virmani R, Kolodgie FD, Burke AP, Farb A, Schwartz SM. Lessons from sudden coronary death: a comprehensive morphological classification scheme for atherosclerotic lesions. Arterioscler Thromb Vasc Biol. May 2000;20(5):1262-1275.

17. Kanters E, Pasparakis M, Gijbels MJ, Vergouwe MN, Partouns-Hendriks I, Fijneman RJ, Clausen BE, Forster I, Kockx MM, Rajewsky K, Kraal G, Hofker MH, de Winther MP. Inhibition of NF-kappaB activation in macrophages increases atherosclerosis in LDL receptor-deficient mice. J Clin Invest. Oct 2003;112(8):1176-1185.

18. Mallat Z, Gojova A, Marchiol-Fournigault C, Esposito B, Kamate C, Merval R, Fradelizi D, Tedgui A. Inhibition of transforming growth factor-beta signaling accelerates atherosclerosis and induces an unstable plaque phenotype in mice. Circ Res. Nov 9 2001;89(10):930-934.

19. Robertson AK, Rudling M, Zhou X, Gorelik L, Flavell RA, Hansson GK. Disruption of TGF-beta signaling in T cells accelerates atherosclerosis. J Clin Invest. Nov 2003;112(9): 1342-1350.

20. Schroeder F, Gallegos AM, Atshaves BP, Storey SM, McIntosh AL, Petrescu AD, Huang H, Starodub O, Chao H, Yang H, Frolov A, Kier AB. Recent advances in membrane microdomains: rafts, caveolae, and intracellular cholesterol trafficking. Exp Biol Med (Maywood). Nov 2001;226(10):873-890.

21. Gargalovic P, Dory L. Caveolins and macrophage lipid metabolism. J Lipid Res. Jan 2003;44(1):11-21.

22. Fielding CJ, Fielding PE. Intracellular cholesterol transport. J Lipid Res. Aug 1997;38(8):1503-1521.

23. van Deurs B, Roepstorff K, Hommelgaard AM, Sandvig K. Caveolae: anchored, multifunctional platforms in the lipid ocean. Trends Cell Biol. Feb 2003;13(2):92-100.

24. Razani B, Woodman SE, Lisanti MP. Caveolae: from cell biology to animal physiology. Pharmacol Rev. Sep 2002;54(3):431-467.

25. Schnitzer JE. Caveolae: from basic trafficking mechanisms to targeting transcytosis for tissue-specific drug and gene delivery in vivo. Adv Drug Deliv Rev. Jul 28 2001;49(3): 265-280.

26. Simionescu M, Gafencu A, Antohe F. Transcytosis of plasma macromolecules in endothelial cells: a cell biological survey. Microsc Res Tech. Jun 1 2002;57(5):269-288. 
27. Frank PG, Lee H, Park DS, Tandon NN, Scherer PE, Lisanti MP. Genetic ablation of caveolin-1 confers protection against atherosclerosis. Arterioscler Thromb Vasc Biol. Jan 2004;24(1):98-105.

28. Frank PG, Lisanti MP. Caveolin-1 and caveolae in atherosclerosis: differential roles in fatty streak formation and neointimal hyperplasia. Curr Opin Lipidol. Oct 2004;15(5): 523-529.

29. Lindstedt L, Lee M, Oorni K, Bromme D, Kovanen PT. Cathepsins F and S block HDL3-induced cholesterol efflux from macrophage foam cells. Biochem Biophys Res Commun. Dec 26 2003;312(4):1019-1024.

30. Frank PG, Marcel YL, Connelly MA, Lublin DM, Franklin V, Williams DL, Lisanti MP. Stabilization of caveolin-1 by cellular cholesterol and scavenger receptor class B type I. Biochemistry. Oct 1 2002;41(39):11931-11940.

31. Wang L, Connelly MA, Ostermeyer AG, Chen HH, Williams DL, Brown DA. Caveolin-1 does not affect SR-BI-mediated cholesterol efflux or selective uptake of cholesteryl ester in two cell lines. J Lipid Res. Apr 2003;44(4):807-815.

32. Matveev S, Uittenbogaard A, van Der Westhuyzen D, Smart EJ. Caveolin-1 negatively regulates SR-BI mediated selective uptake of high-density lipoprotein-derived cholesteryl ester. Eur J Biochem. Nov 2001;268(21):5609-5616.

33. Schwencke C, Schmeisser A, Walter C, Wachter R, Pannach S, Weck B, Braun-Dullaeus RC, Kasper M, Strasser RH. Decreased caveolin-1 in atheroma: loss of antiproliferative control of vascular smooth muscle cells in atherosclerosis. Cardiovasc Res. Oct 1 2005;68(1):128-135.

34. Navarro A, Anand-Apte B, Parat MO. A role for caveolae in cell migration. Faseb J. Dec 2004;18(15):1801-1811.

35. Parton RG, Joggerst B, Simons K. Regulated internalization of caveolae. J Cell Biol. Dec 1994;127(5):1199-1215.

36. Pol A, Lu A, Pons M, Peiro S, Enrich C. Epidermal growth factor-mediated caveolin recruitment to early endosomes and MAPK activation. Role of cholesterol and actin cytoskeleton. J Biol Chem. Sep 29 2000;275(39):30566-30572.

37. Upla P, Marjomaki V, Kankaanpaa P, Ivaska J, Hyypia T, Van Der Goot FG, Heino J. Clustering induces a lateral redistribution of alpha 2 beta 1 integrin from membrane rafts to caveolae and subsequent protein kinase C-dependent internalization. Mol Biol Cell. Feb 2004;15(2):625-636.

38. Stahlhut M, van Deurs B. Identification of filamin as a novel ligand for caveolin-1: evidence for the organization of caveolin-1-associated membrane domains by the actin cytoskeleton. Mol Biol Cell. Jan 2000;11(1):325-337.

39. Mundy DI, Machleidt T, Ying YS, Anderson RG, Bloom GS. Dual control of caveolar membrane traffic by microtubules and the actin cytoskeleton. J Cell Sci. Nov 15 2002;115(Pt 22):4327-4339.

40. Cavallo-Medved D, Mai J, Dosescu J, Sameni M, Sloane BF. Caveolin-1 mediates the expression and localization of cathepsin $\mathrm{B}$, pro-urokinase plasminogen activator and their cell-surface receptors in human colorectal carcinoma cells. J Cell Sci. Apr 1 2005;118(Pt 7):1493-1503. 


\section{Chapter 5 \\ Pharmacologic inhibition of cathepsin K: extracellular matrix degrading effects do not coincide with lipogenic effects}

Suzanne P.M. Lutgens ${ }^{1}$, Mat J. Rousch ${ }^{1}$, Barry Jutten ${ }^{1}$, Dianne J. Delsing ${ }^{2}$, Clive J. Long ${ }^{3}$, Angela Fisher ${ }^{3}$, Darcey Black ${ }^{3}$, Paul Saftig ${ }^{4}$, Mat J.A.P. Daemen ${ }^{1}$, Sylvia Heeneman ${ }^{1}$, Kitty B.J.M. Cleutjens ${ }^{1}$

Department of Pathology ${ }^{1}$, Cardiovascular Research Institute Maastricht (CARIM), University of Maastricht, Maastricht, The Netherlands; Department of Molecular Design and Informatics $^{2}$, NV Organon, Oss, The Netherlands; Organon Scotland ${ }^{3}$, Newhouse, Scotland; Biochemical Institute ${ }^{4}$, University of Kiel, Germany.

In preparation 


\section{ABSTRACT}

In chapter 3, we showed that cathepsin $\mathrm{K}$ deficiency reduced atherosclerotic plaque progression, induced plaque fibrosis, but aggravated macrophage foam cell formation in apoE-/- mice. In in vitro cultured bone marrow derived macrophages, genetic cathepsin $\mathrm{K}$ deficiency also displayed lipogenic effects (chapters 3 and 4). In the present study we investigated the effect of pharmacologic inhibition of cathepsin $\mathrm{K}$ activity on both extracellular matrix turnover and lipid metabolism.

Using recombinant murine and human cathepsin $\mathrm{K}$ as well as murine apoE-/bone marrow derived macrophages and human monocyte derived macrophages, we assessed the effect of the cathepsin K inhibitor Org 29762 on the degradation of a cathepsin K specific substrate, collagenase and elastase activity, and lipid uptake and cholesterol efflux. Org 29762 showed a dose-dependent inhibition of cathepsin $\mathrm{K}$ specific substrate degradation by both recombinant murine cathepsin $\mathrm{K}$ and murine macrophages, and by both recombinant human cathepsin $\mathrm{K}$ and human macrophages. Furthermore, incubation with Org 29762 inhibited collagen type I and IV and elastin degradation by both murine and human recombinant cathepsin K and murine macrophages, but had no effect on lipid uptake.

Although further in vivo validation is required, these results showed that the profibrotic and lipogenic effects of cathepsin $\mathrm{K}$ inhibition are differentially regulated and that it is possible to specifically target the profibrotic function, without affecting the lipogenic function of cathepsin K. 


\section{INTRODUCTION}

Cathepsin $\mathrm{K}$, a lysosomal cysteine protease was isolated from an osteoclast cDNA library and expression was first considered to be confined to osteoclasts ${ }^{1-3}$. Over the years, cathepsin $\mathrm{K}$ expression was also observed in many other tissues including human atherosclerotic lesions ${ }^{4-8}$. In humans, deficiency of cathepsin $\mathrm{K}$ causes pycnodysostosis, an autosomal recessive osteochondrodysplasia characterized by osteosclerosis and short stature'. Cathepsins are synthesized as pre-proenzymes. After removal of the pre-peptide during the passage to the endoplasmic reticulum, pro-cathepsin is formed. Subsequently, the active cathepsin can be produced after proteolytic removal of the pro-peptide in the acidic environments of late endosomes and lysosomes ${ }^{10}$. Both nucleotide and amino acid sequences are highly conserved between murine and human cathepsin $\mathrm{K}^{11,12}$. Amino acid sequence alignment revealed $85 \%$ identity and 93\% similarity between murine and human amino acid sequences ${ }^{11}$.

Since cathepsin $\mathrm{K}$ exerts unique collagenolytic activities ${ }^{13}$ and is found to be expressed in macrophages ${ }^{7}$, a role for cathepsin $\mathrm{K}$ in atherosclerosis was suggested. Cathepsin K was first studied in atherosclerosis by Sukhova et al., demonstrating that human non-diseased arteries showed low cathepsin K expression, while advanced atherosclerotic plaques showed cathepsin $\mathrm{K}$ expression in the fibrous cap and in regions of foam cell formation in the shoulders of the lesions ${ }^{8}$. Furthermore, extracts of human atheroma showed increased cathepsin K protein expression compared with non-diseased arteries ${ }^{8}$. Recently, we further substantiated the role for cathepsin $\mathrm{K}$ in atherosclerosis ${ }^{14}$ (chapter 3 ). We showed that cathepsin $\mathrm{K}$ is highly upregulated in advanced stable lesions when compared with early lesions and lesions containing a thrombus. Disruption of cathepsin K in apoE-/mice resulted in an increase in collagen content and a decrease in the number of advanced lesions and plaque area. Furthermore, an increase in macrophage size was observed, which was due to an increase in modified LDL uptake and an increase in cholesterol ester storage in enlarged lysosomes ${ }^{14}$. Microarray analysis and pathway profiling revealed a role for both CD36 and caveolins in increasing lipid uptake, thereby aggravating foam cell formation ${ }^{15}$ (chapter 4 ).

Cathepsin $\mathrm{K}$ inhibitors may have therapeutic potential in treating both osteoporosis and atherosclerosis. This assumes similar effects of cathepsin $\mathrm{K}$ in the murine and human lipid metabolism and similar effects of genetic deficiency and pharmacologic inhibition. In the present study we use recombinant murine and human cathepsin K, murine apoE-/- bone marrow derived macrophages and human monocyte derived macrophages (further designated as murine and human macrophages, respectively) to evaluate the effect of the cathepsin K inhibitor Org 
29762 on the degradation of a cathepsin K specific substrate, extracellular matrix turnover, and lipid metabolism.

\section{METHODS}

\section{Materials}

Human pro-cathepsin K, active human cathepsin S (hcatS) and active mouse cathepsin K (mcatK) were kindly provided by Organon Research Scotland (Newhouse, United Kingdom). To activate cathepsin K, human recombinant pro-cathepsin K was dialyzed for 16 hours using a Slide-A-Lyzer cassette (Pierce) with a $10 \mathrm{~K}$ MW cut-off against $50 \mathrm{mM}$ sodium acetate $\mathrm{pH} 4.0,20 \mathrm{mM}$ L-cysteine and $0.3 \mathrm{M} \mathrm{NaCl}$. After overnight incubation at $4^{\circ} \mathrm{C}$, recombinant cathepsin $\mathrm{K}$ was incubated at room temperature for 3 hours. Subsequently, protein concentration was determined and active recombinant cathepsin $\mathrm{K}$ protein (hcatK) was stored in the presence of $10 \%$ glycerol at $-80^{\circ} \mathrm{C}$. The cathepsin $\mathrm{K}$ inhibitor Org 29762 was provided by Organon Research Scotland and was dissolved in 100\% DMSO. The inhibitor stock solution was subsequently diluted in assay buffer or tissue culture medium, with a concentration of $0.01 \%$ DMSO. Assay buffer or tissue culture medium containing comparable concentrations DMSO served as negative controls.

\section{Cells}

To obtain apoE-/- and catK-/-/apoE-/- macrophages, bone marrow (BM) was flushed from femurs and tibiae of apoE-/- and catK-/-/apoE-/- mice at the age 20-25 weeks and cultured for 8 days in RPMI medium containing L-glutamine, HEPES, 10\% FCS and $100 \mathrm{IU} / \mathrm{ml}$ penicillin/streptomycin with the addition of 15\% L929 cell conditioned medium (LCM) to differentiate into macrophages ${ }^{16}$. THP-1 cells (human monocyte cell line, ATCC TIB-202) were cultured in phenol red free RPMI 1640 medium supplemented with 25mM HEPES and L-glutamine (Gibco), supplemented with 10\% fetal clone III (Hyclone) and 100 $\mathrm{IU} / \mathrm{ml}$ penicillin/streptomycin (Gibco). During in vitro assays THP-1 cells were grown in X-Vivo 15 medium (Cambrex) supplemented with 10\% fetal clone III and $100 \mathrm{IU} / \mathrm{ml}$ penicillin/streptomycin. For macrophage differentiation phorbol 12-myristate 13-acetate (PMA) was added (final concentration $120 \mathrm{ng} / \mathrm{ml}$ ) to the medium. On day 3 medium was refreshed and cells were assayed on day 4 . For isolation of human monocytes, 'buffy coat' cell preparations from the buffy coat derived from $500 \mathrm{ml}$ whole blood were obtained from the Centre de Transfusion Sanguine, Liège, Belgium. Peripheral blood mononuclear cells (PBMC) were collected after purification using a Leucosep tube (Greiner) as instructed by 
the manufacturer. The cell top layer (PBMCs) below the serum was collected and washed three times with $2 \mathrm{mM}$ EDTA in PBS. Subsequently, cells were once more purified using Percoll (Sigma) as instructed by the manufacturer. The cell top layer (monocytes) was collected and washed once in medium. Cells were grown at a density of $0.5^{\star} 10^{6}$ monocytes per $\mathrm{ml}$ in RPMI supplemented with $10 \%$ FCS and $25 \mathrm{ng} / \mathrm{ml}$ M-CSF (R\&D Systems) to differentiate monocytes into macrophages. On day 5 medium was replaced and cells were assayed during day 6 to 9 .

\section{Cathepsin K assay}

The enzymatic activity of hcatK, hcatS, and mcatK $(3 \mathrm{nM})$ and cellular extracts $(5$ $\mu \mathrm{g} / \mathrm{ml}$ ) was determined essentially as described before ${ }^{17,18}$. In short, cell pellets were resuspended in PBS containing $2.5 \mathrm{mM}$ dithiothreitol (DTT) and sonicated for $3 \times 20$ s. The suspension was centrifuged at $1,000 \mathrm{~g}$ for $10 \mathrm{~min}$ at $4^{\circ} \mathrm{C}$, and the resulting supernatant was utilized as the cellular extract. Assays were performed at room temperature in $200 \mu \mathrm{l} 50 \mathrm{mM}$ 2-(N-morpholino)ethanesulfonic acid (MES) buffer, pH 5.5, containing $2.5 \mathrm{mM}$ ethylene-diamine tetraacetic acid (EDTA), $2.5 \mathrm{mM}$ DTT, 10\% DMSO and $5 \mu \mathrm{M}$ Cathepsin K Substrate I (Calbiochem, Cat. No. 219390). Substrate hydrolysis was monitored over a period of $60 \mathrm{~min}$ at room temperature and rhodamine fluorescence was detected by excitation at $485 \mathrm{~nm}$ and emission at $530 \mathrm{~nm}$ with a cut-off value of $515 \mathrm{~nm}$.

\section{Collagenase and elastase assay}

Assays were performed at room temperature in $200 \mu \mathrm{l}$ reaction buffer containing 75-100 $\mu \mathrm{g} / \mathrm{ml}$ DQ collagen I (D-12060, EnzChek, Molecular Probes), DQ collagen IV (D-12052, EnzChek, Molecular Probes) or DQ elastin (E-12056, EnzChek, Molecular Probes) and $100 \mathrm{nM}$ recombinant protein (mcatK or hcatK) or $50 \mu \mathrm{g} / \mathrm{ml}$ cellular extract of murine or human macrophages. Substrate hydrolysis was monitored at $\mathrm{T}=0,1,2,3$, and 4 hours and fluorescence was detected by excitation at $485 \mathrm{~nm}$ and emission at $530 \mathrm{~nm}$ with a cut-off value of $515 \mathrm{~nm}$.

\section{Modified LDL uptake}

Oxidized LDL was purchased (Intracel) and labeled as described before ${ }^{14}$. Cells were incubated with $25 \mu \mathrm{g} / \mathrm{ml}$ DiI labeled oxLDL for 3 hours. Inhibitors were added 1 hour before DiI labeled oxLDL incubation. DiI labeled oxLDL uptake was determined by FACS (BD Biosciences, San Jose, California, USA).

\section{Cholesterol efflux assay}

Cholesterol $\left[1,2-{ }^{3} \mathrm{H}(\mathrm{N})\right]$ (Perkin Elmer) was incorporated into acetylated LDL (acLDL, Intracel). On day 1, BM derived macrophages were incubated with $\left[{ }^{3} \mathrm{H}\right]$ 
cholesterol labeled acLDL (final concentration $2.5 \mu \mathrm{Ci} / \mathrm{ml}\left[{ }^{3} \mathrm{H}\right]$ cholesterol and $50 \mu \mathrm{g} / \mathrm{ml}$ acLDL). On day 3 cholesterol acceptors were added. Org 29762 was added $1 \mathrm{hr}$ before addition of cholesterol acceptors. HDL was used at a final concentration of 10 or $20 \mu \mathrm{g} / \mathrm{ml}$ and considered responsible for ATP binding cassette transporter (ABC) G1 and scavenger receptor (SR)-B1 mediated cholesterol efflux ${ }^{19}$. D37F, a specific apoA-1 mimetic peptide, was used at a final concentration of $7.5 \mu \mathrm{g} / \mathrm{ml}$ and considered responsible for ABCA1 mediated cholesterol efflux ${ }^{19}$. D37K, an a-specific control peptide with a mutation in the active site, served as a negative assay control. On day 4 both medium and cell lysate were counted on a beta counter. The percentage of cholesterol efflux was defined by the following formula: media value / (media value + cell lysate value) $\star 100$.

\section{Proteolysis of modified LDL by cathepsin $K$ and $S$}

Oxidized LDL $(0.5 \mathrm{mg} / \mathrm{ml})$ was incubated with $50 \mathrm{nM}$ hcatK, hcatS or mcatK in a buffer consisting of $150 \mathrm{mM} \mathrm{NaCl}, 5 \mathrm{mM}$ EDTA and $20 \mathrm{mM}$ Pipes $^{20,21}$. pH was adjusted to 5.5 (hcatK and mcatK) or 7.0 (hcatS). Proteolysis was determined after 5 and $30 \mathrm{~min}$ incubation at room temperature by gel electrophoresis and subsequent Coommassie staining (BioRad).

\section{Statistical analysis}

All statistical analyses were performed using SPSS 13.0 and GraphPad Prism (GraphPad Software Inc.). Data were analyzed by the nonparametric Mann-Whitney $U$ test when comparing 2 groups or Kruskal-Wallis when comparing more than 2 groups. Data are presented as mean \pm SEM and were considered statistically significant at $\mathrm{P}<0.05$.

\section{RESULTS}

Org 29762 is a potent inhibitor of both human and mouse cathepsin K Using recombinant human and murine cathepsin $\mathrm{K}$ as well as murine and human macrophages, we assessed the effect of Org 29762 on the degradation of a cathepsin K specific substrate. Org 29762 showed a dose-dependent inhibition of cathepsin $\mathrm{K}$ specific substrate degradation by recombinant murine cathepsin $\mathrm{K}$ (Figure 1A) and recombinant human cathepsin K (Figure 1B). As expected, recombinant human cathepsin $\mathrm{S}$, which served as a negative control, did not show cathepsin K specific substrate degradation. Furthermore, Org 29762 dose-dependently inhibited cathepsin K specific substrate degradation by murine (Figure 1A) and human (Figure 1B) macrophages. Negative controls, without inhibitor but containing comparable DMSO concentrations, showed no inhibi- 


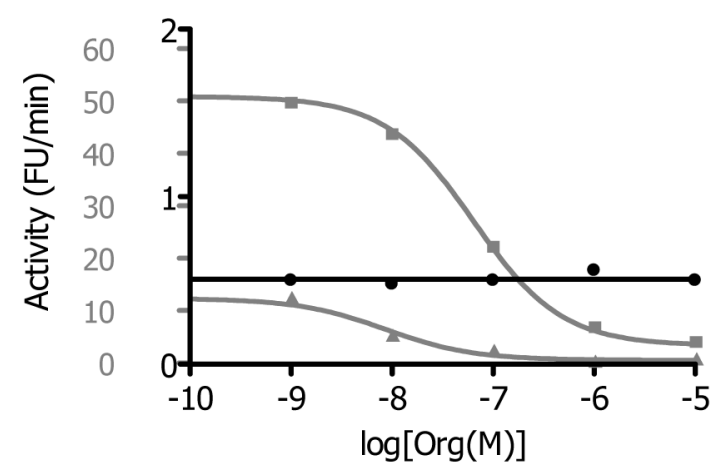

- catK-/- murine $\mathrm{m} \Phi$

- mcatk

- murine $\mathrm{m \Phi}$

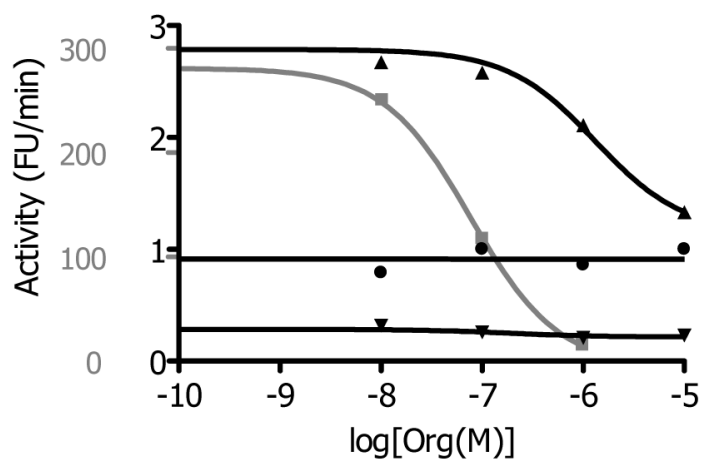

- hcatS

- human $\mathrm{m} \Phi$

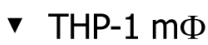

- hcatK

Figure 1. Cathepsin K specific substrate degradation assay.

A. Org 29762 showed dose-dependent inhibition of cathepsin K specific substrate degradation by recombinant murine cathepsin $\mathrm{K}$ (concentration required for $50 \%$ inhibition $\left(\mathrm{IC}_{50}\right): 8.62 \star 10^{-8} \mathrm{M}$ ) and by murine macrophages $\left(\mathrm{IC}_{50}: 2.79 \star 10^{-8} \mathrm{M}\right)$. B. Org 29762 showed dose-dependent inhibition of cathepsin $\mathrm{K}$ specific substrate degradation by recombinant human cathepsin $\mathrm{K}\left(\mathrm{IC}_{50}: 7.74 \star 10^{-8} \mathrm{M}\right)$ and human (monocyte derived) macrophages $\left(\mathrm{IC}_{50}: 1.29 \star 10^{-6} \mathrm{M}\right)$.

tion of cathepsin $\mathrm{K}$ specific substrate degradation. As expected, the cellular extracts of catK-/- murine macrophages did not show significant cathepsin $\mathrm{K}$ specific substrate degradation. Also PMA differentiated THP-1 cells did not show cathepsin $\mathrm{K}$ activity.

In conclusion, Org 29762 inhibited both murine and human cathepsin K activity. 

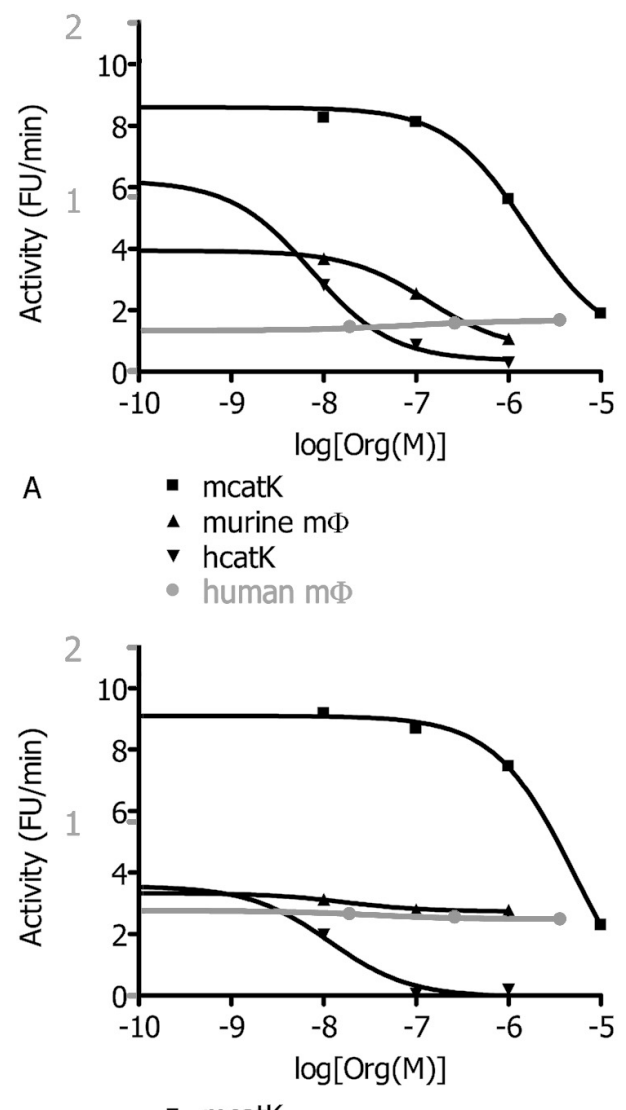

B

- mcatk

- murine mథ

v hcatk

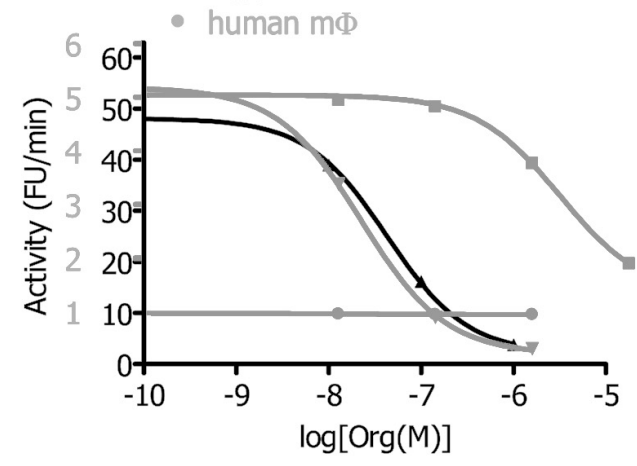

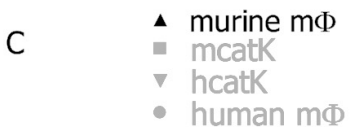

Figure 2. Collagen I, IV and elastin degradation assay.

Org 29762 was able to significantly inhibit A. collagen I (IC50: $1.79 \star 10^{-6}$ (murine) and $7.39 \star 10^{-9}$ (human)), B. collagen IV (IC $\mathrm{IC}_{50}: 2.50^{\star} 10^{-6}(\mathrm{~m})$ and $\left.1.17 \star 10^{-8}(\mathrm{~h})\right)$, and C. elastin $\left(\mathrm{IC}_{50}: 2.12^{\star} 10^{-6}(\mathrm{~m})\right.$ and $\left.1.70 \star 10^{-8}(\mathrm{~h})\right)$ degradation by recombinant murine and human cathepsin $\mathrm{K}$. 

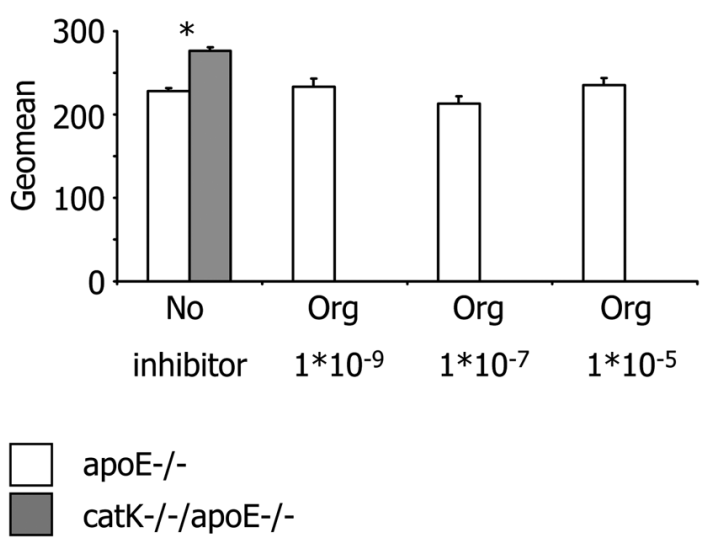

Figure 3. DiloxLDL uptake is increased in catK-/-/apoE-/- macrophages compared with apoE-/macrophages. Addition of Org 29762 to apoE-/- macrophages does not affect lipid uptake. Data are presented as mean \pm SEM. (Org = Org 29762 inhibitor).

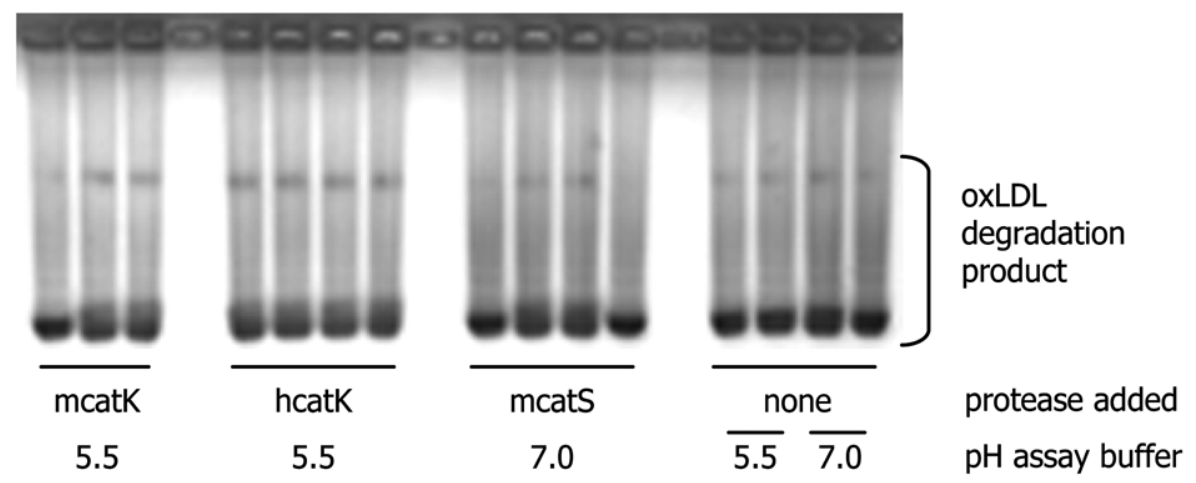

Figure 4. Incubation of oxLDL (30 min) with murine recombinant cathepsin K (mcatK; pH 5.5), human recombinant cathepsin $\mathrm{K}$ (hcatK; $\mathrm{pH} 5.5$ ), and human recombinant cathepsin S (hcatS; $\mathrm{pH} 7.0$ ) did not result in oxLDL degradation (negative controls: oxLDL without addition of recombinant cathepsin; pH 5.5 and 7.0).

Org 29762 significantly inhibited collagenolytic and elastinolytic activity of recombinant murine and human cathepsin $K$ and murine macrophages.

Since cathepsin $\mathrm{K}$ is known for its collagenolytic and elastinolytic activity ${ }^{13,22}$, we tested the inhibitory potential of Org 29762 on degradation of collagen I and IV and elastin by murine and human recombinant cathepsin $\mathrm{K}$ and the cellular extracts of murine and human macrophages. As shown in figure 2 murine and human recombinant cathepsin $\mathrm{K}$ and murine macrophages showed collagenase I and IV and elastase activity, while human monocyte derived macrophages showed no significant collagenolytic or elastolytic activity. Furthermore, Org 


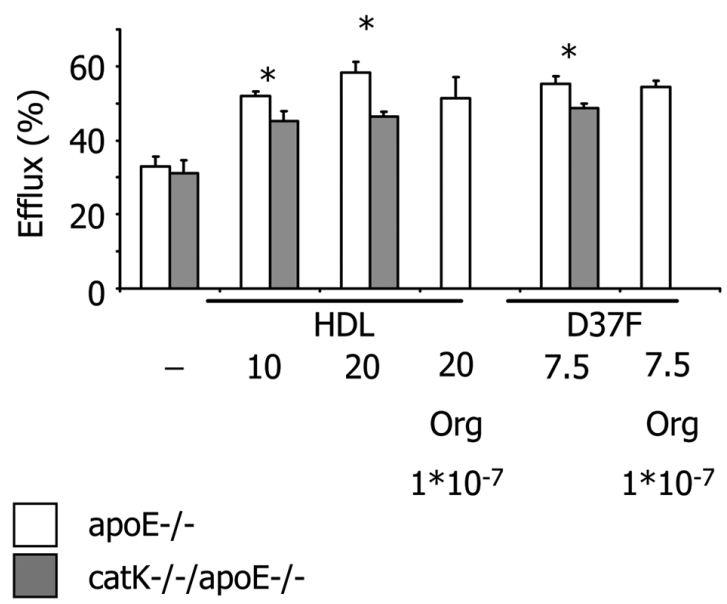

Figure 5. Genetic disruption of cathepsin K significantly decreases HDL (10 or $20 \mu \mathrm{g} / \mathrm{ml}$ ) and apoA-1 (D37F; $7.5 \mu \mathrm{g} / \mathrm{ml}$ ) mediated cholesterol efflux. Org 29762 (concentration: $1{ }^{\star} 10^{-7} \mathrm{M}$ ) did not influence HDL or apoA-1 mediated cholesterol efflux. The percentage of cholesterol efflux is defined by the following formula: media value / (media value + cell lysate value) $\star 100 \%$. Data are presented as mean \pm SEM.

29762 was able to significantly inhibit collagen I (Figure 2A), collagen IV (Figure $2 \mathrm{~B}$ ), and elastin (Figure 2C) degradation by recombinant murine and human cathepsin K. Note that inhibition of both collagen and elastin degradation was much stronger for recombinant human cathepsin $\mathrm{K}$ than for recombinant murine cathepsin K. Org 29762 was also able to significantly inhibit collagen I and elastin degradation by murine macrophages (Figure 2A and C).

Org 29762 did not increase DiIoxLDL uptake in murine macrophages Since we reported earlier that cathepsin K deficiency in apoE-/- bone marrow derived macrophages resulted in increased DiIoxLDL uptake ${ }^{15}$ (chapter 3 and 4), we also examined the effect of cathepsin $\mathrm{K}$ inhibition on DiloxLDL uptake. As shown in figure 3, lipid uptake in apoE-/-/catK-/- bone marrow derived macrophages increased significantly compared with apoE-/- macrophages. However, Org 29762 did not influence DiIoxLDL uptake by murine or human macrophages.

Since cathepsin K has strong proteolytic capacity, we assessed whether cathepsin $\mathrm{K}$ has an effect on oxLDL integrity. Since neither human nor mouse recombinant cathepsin K resulted in any oxLDL degradation (Figure 4), the observed increase in DiI labeled oxLDL uptake is not simply the result of a reduction in oxLDL degradation due to deficiency of cathepsin K. 
Table I Overview of effect of cathepsin K inhibition by Org 29762 on cathepsin K specific substrate degradation, collagenase type I and IV activity and elastase activity, DiIoxLDL uptake, and cholesterol efflux.

\begin{tabular}{|c|c|c|c|c|c|c|}
\hline Substrate & $\begin{array}{l}\text { cathepsin K } \\
\text { specific } \\
\text { substrate } \\
\text { degradation }\end{array}$ & $\begin{array}{l}\text { Collagenase } \\
\text { type I activity }\end{array}$ & $\begin{array}{l}\text { Collagenase } \\
\text { type IV activity }\end{array}$ & $\begin{array}{l}\text { Elastase } \\
\text { activity }\end{array}$ & $\begin{array}{l}\text { DiloxLDL } \\
\text { uptake }\end{array}$ & $\begin{array}{l}\text { Cholesterol } \\
\text { efflux }\end{array}$ \\
\hline mcatK & $\downarrow$ & $\downarrow$ & $\downarrow$ & $\downarrow$ & & \\
\hline murine $\mathrm{M} \Phi$ & $\downarrow$ & $\downarrow$ & $\downarrow$ & $\downarrow$ & $=$ & $=$ \\
\hline hcatK & $\downarrow$ & $\downarrow$ & $\downarrow$ & $\downarrow$ & & \\
\hline human $М \Phi$ & $\downarrow$ & & & & $=$ & \\
\hline
\end{tabular}

Shaded cell means not applicable (MФ indicates macrophage).

Genetic deficiency but not pharmacologic inhibition of cathepsin $K$ in murine macrophages results in reduced cholesterol efflux

As reported earlier, deficiency of cathepsin $\mathrm{K}$ in apoE-/- BM derived macrophages aggravated foam cell formation as a result of increased lipid uptake and cholesterol ester storage ${ }^{15}$. However, data on cholesterol efflux were still lacking. Therefore a cholesterol efflux assay was performed showing that genetic deficiency of cathepsin K significantly reduced both HDL (ABCG1 and SR-B1) and apoA-1 (ABCA1) mediated cholesterol efflux of murine macrophages (Figure 5). However, Org 29762 did not affect HDL or apoA-1 mediated cholesterol efflux.

\section{DISCUSSION}

As summarized in table I, murine and human recombinant cathepsin $\mathrm{K}$, as well as murine and human macrophage cell lysates showed cathepsin $\mathrm{K}$ specific substrate degradation capacity, which could be inhibited by Org 29762. Furthermore, both murine and human recombinant cathepsin $\mathrm{K}$ and murine macrophage cell lysate showed collagen I and IV and elastin degrading activity, which could all be inhibited by Org 29762. Human macrophages showed no significant collagen I and IV and elastin degrading activity. To our knowledge, we are the first to describe collagen IV degrading activity for murine macrophages and murine and human recombinant cathepsin $\mathrm{K}$.

In contrast to the inhibitory effect on ECM degradation, Org 29762 did not affect oxLDL uptake and cholesterol efflux by murine and/or human macrophages. Lindstedt et al. showed that cathepsin K partially degraded apoA-1 leading to a reduction of cholesterol efflux of $15 \%{ }^{21}$. This suggests that reduction of choles- 
terol efflux by cathepsin $\mathrm{K}$ mediated degradation of cholesterol acceptors may contribute to the preservation of foam cells in the atherosclerotic lesion. However, in this study we showed that genetic deletion of cathepsin $\mathrm{K}$ resulted in a decrease in both ABCG1 and SR-B1 (HDL) and ABCA1 (apoA-1) mediated cholesterol efflux by respectively $20 \%$ and $15 \%$. Although our results seem rather contradictory to the results of Lindstedt et al., these findings can be explained. Lindstedt et al. studied the extracellular capacity of cathepsin K to reduce cholesterol efflux by degradation of pre $\beta-H D L$ and apoA-1. However, by using cathepsin $\mathrm{K}$ deficient murine macrophages, we studied the intracellular effect of cathepsin K deficiency on cholesterol efflux, without prior degradation of extracellular cholesterol acceptors by cathepsins, resulting in a reduction of both HDL and apoA-1 mediated cholesterol efflux upon cathepsin K deficiency. Thus, extracellular cathepsin $\mathrm{K}$ reduced cholesterol efflux by decreasing the amount of cholesterol acceptors, while intracellular deficiency of cathepsin $\mathrm{K}$ reduced the reverse cholesterol transporting capacity independent of cholesterol acceptor degradation.

Given the results of our earlier experiments, in which cathepsin K deficiency resulted in a profibrotic but also lipogenic plaque phenotype, we previously stated that the use of cathepsin K inhibitors should be evaluated with care. Our current results indicate that pharmacological inhibition using Org29762 specifically targets ECM turnover, without affecting the lipogenic function of cathepsin K, opening new therapeutic options for pharmacological interventions affecting cathepsin $\mathrm{K}$ activity.

The observed uncoupling of the effects of the cathepsin K inhibitor Org 29762 on ECM turnover and lipid metabolism raises questions about the (molecular) mechanism(s) by which Org 29762 can differentiate between both effects. We hypothesize that the cathepsin K inhibitor Org 29762 directly influences the proteolytic active site, resulting in decreased ECM degradation, without affecting (in)direct effects of cathepsin $\mathrm{K}$ deficiency on the lipid metabolism ${ }^{15}$.

In conclusion, although further in vitro and in vivo validation studies are required, our data show that the profibrotic and lipogenic effects of cathepsin $\mathrm{K}$ inhibition using Org 29762 are differentially regulated and that it is possible to specifically target the profibrotic function, without affecting the lipogenic function of cathespsin $\mathrm{K}$.

\section{REFERENCES}

1. Tezuka K, Tezuka Y, Maejima A, Sato T, Nemoto K, Kamioka H, Hakeda Y, Kumegawa M. Molecular cloning of a possible cysteine proteinase predominantly expressed in osteoclasts. J Biol Chem. Jan 14 1994;269(2):1106-1109. 
2. Inaoka T, Bilbe G, Ishibashi O, Tezuka K, Kumegawa M, Kokubo T. Molecular cloning of human cDNA for cathepsin K: novel cysteine proteinase predominantly expressed in bone. Biochem Biophys Res Commun. Jan 5 1995;206(1):89-96.

3. Rantakokko J, Aro HT, Savontaus M, Vuorio E. Mouse cathepsin K: cDNA cloning and predominant expression of the gene in osteoclasts, and in some hypertrophying chondrocytes during mouse development. FEBS Lett. Sep 16 1996;393(2-3):307-313.

4. Bromme D, Okamoto K, Wang BB, Biroc S. Human cathepsin O2, a matrix protein-degrading cysteine protease expressed in osteoclasts. Functional expression of human cathepsin O2 in Spodoptera frugiperda and characterization of the enzyme.J Biol Chem. Jan 26 1996;271(4):2126-2132.

5. Buhling F, Peitz U, Kruger S, Kuster D, Vieth M, Gebert I, Roessner A, Weber E, Malfertheiner P, Wex T. Cathepsins K, L, B, X and W are differentially expressed in normal and chronically inflamed gastric mucosa. Biol Chem. May 2004;385(5):439-445.

6. Buhling F, Rocken C, Brasch F, Hartig R, Yasuda Y, Saftig P, Bromme D, Welte T. Pivotal role of cathepsin K in lung fibrosis. Am J Pathol. Jun 2004;164(6):2203-2216.

7. Shi GP, Chapman HA, Bhairi SM, DeLeeuw C, Reddy VY, Weiss SJ. Molecular cloning of human cathepsin $\mathrm{O}$, a novel endoproteinase and homologue of rabbit OC2. FEBS Lett. Jan 3 1995;357(2):129-134.

8. Sukhova GK, Shi GP, Simon DI, Chapman HA, Libby P. Expression of the elastolytic cathepsins $\mathrm{S}$ and $\mathrm{K}$ in human atheroma and regulation of their production in smooth muscle cells. J Clin Invest. Aug 1 1998;102(3):576-583.

9. Gelb BD, Shi GP, Chapman HA, Desnick RJ. Pycnodysostosis, a lysosomal disease caused by cathepsin K deficiency. Science. Aug 30 1996;273(5279):1236-1238.

10. Turk B, Turk D, Turk V. Lysosomal cysteine proteases: more than scavengers. Biochim Biophys Acta. Mar 7 2000;1477(1-2):98-111.

11. Gelb BD, Moissoglu K, ZhangJ, Martignetti JA, Bromme D, Desnick RJ. Cathepsin K: isolation and characterization of the murine cDNA and genomic sequence, the homologue of the human pycnodysostosis gene. Biochem Mol Med. Dec 1996;59(2): 200-206.

12. Rantakokko J, Kiviranta R, Eerola R, Aro HT, Vuorio E. Complete genomic structure of the mouse cathepsin K gene (Ctsk) and its localization next to the Arnt gene on mouse chromosome 3. Matrix Biol. Apr 1999;18(2):155-161.

13. Garnero P, Borel O, Byrjalsen I, Ferreras M, Drake FH, McQueney MS, Foged NT, Delmas PD, Delaisse JM. The collagenolytic activity of cathepsin K is unique among mammalian proteinases. J Biol Chem. Nov 27 1998;273(48):32347-32352.

14. Lutgens E, Lutgens SP, Faber BC, Heeneman S, Gijbels MM, de Winther MP, Frederik P, van der Made I, Daugherty A, Sijbers AM, Fisher A, Long CJ, Saftig P, Black D, Daemen MJ, Cleutjens KB. Disruption of the cathepsin K gene reduces atherosclerosis progression and induces plaque fibrosis but accelerates macrophage foam cell formation. Circulation. Jan 3 2006;113(1):98-107.

15. Lutgens S, Kisters N, Lutgens E, van Haaften R, Evelo C, de Winther M, Saftig P, Daemen M, Heeneman S, Cleutjens K. Gene profiling of cathepsin K deficiency in atherogenesis: profibrotic but lipogenic. J Pathol. Nov 2006;210(3):334-343.

16. Kanters E, Pasparakis M, Gijbels MJ, Vergouwe MN, Partouns-Hendriks I, Fijneman RJ, Clausen BE, Forster I, Kockx MM, Rajewsky K, Kraal G, Hofker MH, de Winther MP. Inhibition of NF-kappaB activation in macrophages increases atherosclerosis in LDL receptor-deficient mice. J Clin Invest. Oct 2003;112(8):1176-1185. 
17. Claveau D, Riendeau D, Mancini JA. Expression, maturation, and rhodamine-based fluorescence assay of human cathepsin K expressed in CHO cells. Biochem Pharmacol. Sep 15 2000;60(6):759-769.

18. Guay J, Riendeau D, Mancini JA. Cloning and expression of rhesus monkey cathepsin K. Bone. Aug 1999;25(2):205-209.

19. Jessup W, Gelissen IC, Gaus K, Kritharides L. Roles of ATP binding cassette transporters A1 and G1, scavenger receptor BI and membrane lipid domains in cholesterol export from macrophages. Curr Opin Lipidol. Jun 2006;17(3):247-257.

20. Chen GC, Lau K, Hamilton RL, Kane JP. Differences in local conformation in human apolipoprotein B-100 of plasma low density and very low density lipoproteins as identified by cathepsin D. J Biol Chem. Jul 5 1991;266(19):12581-12587.

21. Lindstedt L, Lee M, Oorni K, Bromme D, Kovanen PT. Cathepsins F and S block HDL3-induced cholesterol efflux from macrophage foam cells. Biochem Biophys Res Commun. Dec 26 2003;312(4):1019-1024.

22. Punturieri A, Filippov S, Allen E, Caras I, Murray R, Reddy V, Weiss SJ. Regulation of elastinolytic cysteine proteinase activity in normal and cathepsin K-deficient human macrophages. J Exp Med. Sep 18 2000;192(6):789-799. 


\section{Chapter 6 \\ Cathepsin K gene disruption does not affect murine aneurysm formation}

Suzanne P.M. Lutgens ${ }^{1}$, Ewald A.W.J. Dumont ${ }^{2}$, Linda Beckers ${ }^{1}$, Mat J.A.P. Daemen ${ }^{1}$, Kitty B.J.M. Cleutjens ${ }^{1}$, Sylvia Heeneman ${ }^{1}$

Departments of Pathology ${ }^{1}$ and Plastic and Reconstructive Surgery ${ }^{2}$, Cardiovascular Research Institute Maastricht (CARIM), University of Maastricht, P. Debyelaan 25, Maastricht, The Netherlands.

In preparation 


\section{2

\section{ABSTRACT}

Although disruption of cathepsin $\mathrm{K}$ has been shown to reduce atherosclerosis and induce plaque stability, its role in aneurysm formation still needs to be elucidated. Since cathepsin K shows strong collagenolytic and elastolytic activity, we hypothesized that cathepsin $\mathrm{K}$ deficiency reduces aneurysm formation. To test this hypothesis we investigated the role of cathepsin K in a mouse model of angiotensin II induced aneurysm formation.

Aneurysm formation was induced by chronic subcutaneous angiotensin II infusion in male apoE-/- and catK-/-/apoE-/- mice ( $\mathrm{N}=9$ per group). Macroscopic visible aneurysms were present in $56 \%$ of mice, with 3 thoracic and 3 abdominal aneurysms in both genotypes. Lumen area of the abdominal aneurysms $(126,031$ $\pm 43,317 \mu \mathrm{m}^{2}$ in apoE-/ - mice versus $117,985 \pm 59,303 \mu \mathrm{m}^{2}$ in catK-/-/apoE-/mice), abdominal aneurysm area $\left(906,956 \pm 119,330 \mu \mathrm{m}^{2}\right.$ versus $1,006,572 \pm$ $\left.165,874 \mu \mathrm{m}^{2}\right)$, and abdominal total vessel area $\left(1,302,392 \pm 156,146 \mu \mathrm{m}^{2}\right.$ versus $\left.1,386,556 \pm 89,619 \mu \mathrm{m}^{2}\right)$ were not different between both groups. Also the medial collagen content of the abdominal aneurysms ( $42 \pm 2 \%$ versus $47 \pm 18 \%$ ) was not different between both groups. Histological analysis revealed two types of adventitial response in the non-aneurysmatic, characterized by either a concentric and thickened adventitial layer consisting of cell rich, fibrotic tissue or focal adventitial thickening in response to medial elastin breaks, which we both interpreted as early indicators of aneurysm formation.

In conclusion, although cathepsin $\mathrm{K}$ deficient mice lack an important protease with potent collagenolytic and elastolytic activity, cathepsin K deficiency does not lead to a decrease in angiotensin II infusion induced aneurysm formation. 


\section{INTRODUCTION}

Abdominal aortic aneurysm (AAA) is a potentially lethal disorder. In general, the prevalence of abdominal aneurysms with a diameter of 2.9 to $4.9 \mathrm{~cm}$ ranges from $1.3 \%$ for men aged 45 to 54 years to $12.5 \%$ for men aged 75 to 84 years. For women these figures are $0 \%$ and $5.2 \%$ respectively ${ }^{1}$. Although a history of atherosclerotic disease is essential for aneurysm formation, several other factors are involved, including genetic predisposition, hemodynamic factors and structural remodeling of the extracellular matrix (ECM). Matrix metalloproteinases (MMPs) and their inhibitors, the tissue inhibitors of metalloproteinases (TIMPs), regulate the degradation of the ECM components elastin and collagen ${ }^{2-4}$. Doxycycline, a broad spectrum MMP inhibitor, was shown to prevent angiotensin II induced aneurysm formation in hyperlipidemic LDL receptor deficient mice ${ }^{5}$. Also other proteinases, like serine elastases and proteases (plasmin and plasminogen activators) and cathepsins (cysteine proteases) take part in ECM degradation ${ }^{3}$. Gacko and colleagues found elevated activity levels of cathepsin D and cathepsin $\mathrm{L}$ in the human aortic aneurysm wall ${ }^{6}$. Protein levels of cathepsins $\mathrm{K}$, L, and $\mathrm{S}$ were also found to be elevated in the human aortic aneurysm wall when compared with the normal artery wall, whereas the levels of the cysteine protease inhibitor cystatin $\mathrm{C}$ were decreased ${ }^{7,8}$.

Currently several mouse models, either genetically or chemically induced, are available to study aneurysm formation. The chemically induced models include intraluminal infusion of elastase, periaortic incubations of calcium chloride and subcutaneous infusion of angiotensin II $^{9}$. Important characteristics of angiotensin II induced aneurysm formation include its hemodynamic stability, the suprarenal localization of aneurysms and the requirement of hyperlipidemia, since the incidence of aneurysms in C57BL/6 mice is much lower than in apoE-/- mice ${ }^{9,10}$.

In chapter 3, we showed that deficiency of cathepsin $\mathrm{K}$ in apoE-/- mice reduced plaque progression and atherosclerotic plaque area and increased collagen content and macrophage size ${ }^{11}$. Furthermore, the number of elastin breaks in the media underlying the atherosclerotic plaque was decreased in advanced lesions of cathepsin $\mathrm{K}$ deficient mice, compared with apoE-/- mice ${ }^{11}$. Together with the previously reported increased cathepsin $\mathrm{K}$ protein expression in aneurysm samples, these data suggest an important role for cathepsin $\mathrm{K}$ in aneurysm formation. We hypothesized that cathepsin $\mathrm{K}$ deficiency would protect against aneurysm formation and studied the effect of cathepsin K deficiency in an angiotensin II infusion induced apoE-/- mouse model of aneurysm formation. 


\section{METHODS}

Animals and surgery

Male apoE-/- mice on a C57B16 background ( $n=9)$ were obtained from Iffa Credo (Lyon, France) and were backcrossed at least 9 times to catK-/- mice on a C57B16 background $(n=9)^{12}$. Animal experiments were approved by the regulatory authority of the University of Maastricht and were performed in compliance with the Dutch government guidelines. Mice were fed a normal chow diet throughout the experiment.

\section{Infusion of angiotensin II}

Alzet mini-osmotic pumps (model 2004; ALZA Scientific products, Mountain View, California, USA) were implanted into apoE-/- and catK-/-/apoE-/mice at 10 weeks of age. Pumps were filled with angiotensin II (Sigma Chemical Co., St. Louis, Missouri, USA) dissolved in PBS, which delivered subcutaneously $1 \mu \mathrm{g} / \mathrm{min} . \mathrm{kg}$ of angiotensin II for 28 days. Pumps were placed into the subcutaneous space in the neck of $2.5 \%$ isofluorane anesthetized mice through a small incision that was closed using a silk suture (5-0).

\section{Tissue harvesting and histological analysis}

After an 8-hour fast at the age of 14 weeks, mice were sacrificed and the arterial tree was perfused through a catheter inserted into the left cardiac ventricle with PBS containing $0.1 \mathrm{mg} / \mathrm{ml}$ nitroprusside (Sigma) and subsequently with $1 \%$ paraformaldehyde. Aortic tissue of both sacrificed mice and mice which died preliminary was removed from the ascending aorta to the aortic bifurcation, fixed overnight in $1 \%$ paraformaldehyde and embedded in paraffin. Ten cross-sections ( $4 \mu \mathrm{m}$ thick) were cut at $200 \mu \mathrm{m}$ intervals throughout the thoracic and/or abdominal aorta starting at the middle of the aneurysm. From each level, a cross-section was stained with Elastica von Gieson (EvG), hematoxylin and eosin (HE) and sirius red (SR). Elastica von Gieson stained cross-sections were used for morphometric analysis of total vessel area and elastin band ruptures. Sirius red stained cross-sections were used to measure medial collagen content. Morphometric analysis was performed by one blinded investigator (SL, intra-observer variability was $<10 \%$ ).

\section{Statistical analysis}

Values are expressed as mean \pm SEM and a Mann-Whitney non-parametrical test was used to compare individual groups of animals. Probability values of $<0.05$ were considered significant. 


\section{RESULTS}

\section{Cathepsin K deficiency does not protect against angiotensin II infusion induced aneurysm formation.}

During removal of the aortas, aneurysms were visible in the thoracic and/or abdominal area of the aorta in $56 \%$ (5 out of 9 ) of apoE-/ - mice and $56 \%$ (5 out of 9) of catK-/-/apoE-/- mice. Two out of nine apoE-/- mice showed a thoracic aortic aneurysm (TAA), two mice showed an abdominal aortic aneurysm (AAA), and one mouse showed both a TAA and AAA. Of these five mice, one died preliminary at day 24 due to rupture of a TAA. CatK-/-/apoE-/- mice showed similar morbidity rates but an increased mortality rate since three out of five mice with an aneurysm died preliminary. Unfortunately, two thoracic aortas were lost to follow up and were excluded for further analysis. Figure 1 shows the survival curve of mice with an aneurysm, indicating that more catK-/-/apoE-/- mice $(\mathrm{N}=3)$ died due to rupture of an aneurysm than apoE-/- mice $(\mathrm{N}=1)$. All six abdominal aneurysms and four out of six thoracic aneurysms could be analyzed morphometrically. Two thoracic aneurysms (one apoE-/- and one catK-/-/apoE-/-) were completely disintegrated upon rupture. There was no difference between apoE-/- and catK-/-/apoE-/- mice concerning abdominal lumen area $\left(126,031 \pm 43,317 \mu \mathrm{m}^{2}\right.$ versus 117,985 \pm 59,303 $\left.\mu^{2}\right)$, abdominal aneurysm area $\left(906,956 \pm 119,330 \mu \mathrm{m}^{2}\right.$ versus $\left.1,006,572 \pm 165,874 \mu \mathrm{m}^{2}\right)$, or abdominal total vessel area $\left(1,302,392 \pm 156,146 \mu \mathrm{m}^{2}\right.$ versus $1,386,556 \pm 89,619$ $\mu \mathrm{m}^{2}$ ), as shown in figure $2 \mathrm{~A}$. There was also no difference in lumen area of the thoracic aneurysms, thoracic aneurysm area, and thoracic total vessel area, as shown in figure $2 \mathrm{~B}$. Note that the number of mice per group ( 3 mice per genotype for abdominal and 2 mice per genotype for thoracic aneurysms) is very small. No difference in medial collagen content was observed between apoE-/- and catK-/-/apoE-/- mice for abdominal aortas (29 $\pm 4 \%$ versus $37 \pm 8 \%$ ) nor for thoracic aortas, neither was there a difference in medial collagen content between both groups for abdominal ( $42 \pm 2 \%$ versus $47 \pm 18 \%$ ) nor thoracic aneurysms.

\section{Histological analysis revealed early features of aneurysm formation in both} genotypes

Histological analysis of ten cross-sections of the abdominal and thoracic aorta of non-responders (mice without macroscopic signs of an aneurysm) revealed two types of adventitial response. One type of adventitial reaction is represented by a concentric and fairly symmetric (Figure 3C and D) or asymmetric concentric (Figure $3 \mathrm{E}$ and $\mathrm{F}$ ) thickened inner adventitia consisting of cell rich, fibrotic tissue characterized by the presence of inflammatory cells, macrophages, and iron depositions. The other form is characterized by focal adventitial thickening in areas of 


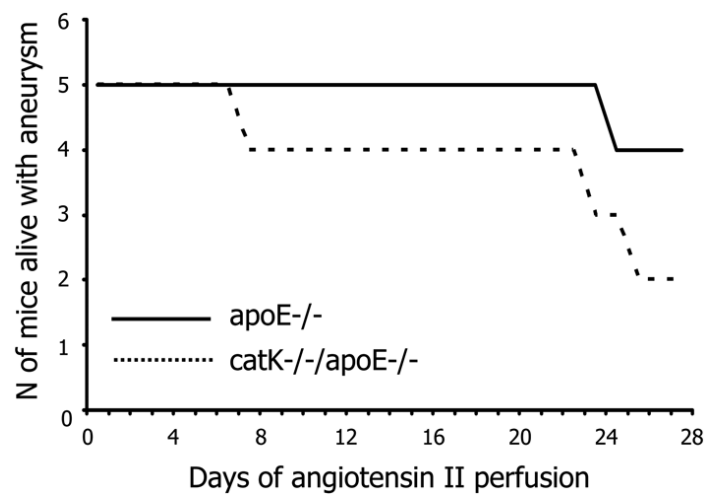

Figure 1. Survival curve of mice with a microscopically confirmed aneurysm. Death of mice is caused by rupture of a TAA or AAA.
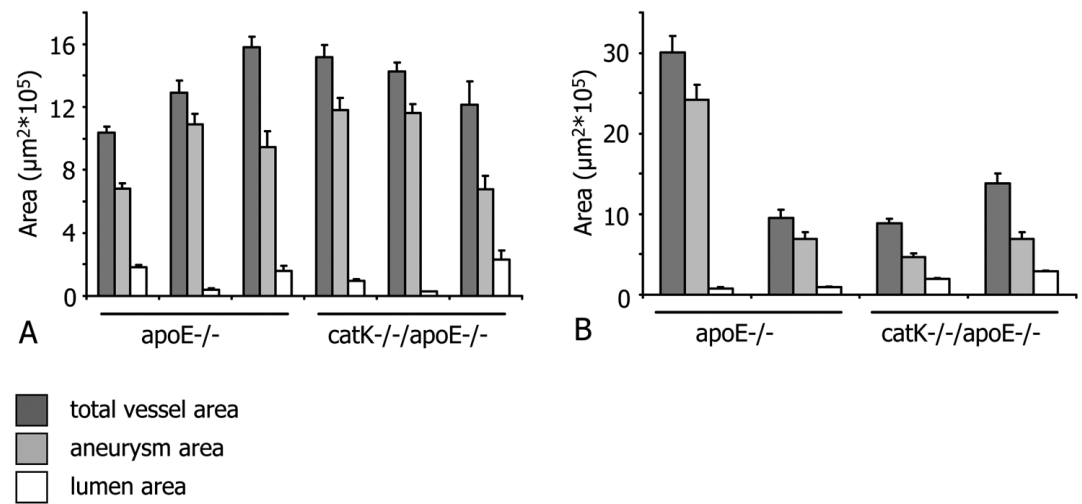

Figure 2. Morphometric analysis of lumen area, aneurysm area and total vessel area of individual abdominal (A) and thoracic (B) aneurysms. No difference between catK-/-/apoE-/- and apoE-/- mice was observed concerning lumen area, aneurysm area, or total vessel area. Only 4 out of 6 TAAs are shown, since 2 TAA segments were completely disintegrated upon rupture and could not be measured.

medial elastin breaks (Figure 3G and $\mathrm{H}$ ). In figure 3I and $\mathrm{J}$ an aneurysm in the adventitia with an intact artery is shown, while in figure $3 \mathrm{~K}$ and $\mathrm{L}$ an aneurysm with a complete medial break and dilation of the lumen is shown. Out of 10 analyzed microscopic cross-sections per artery, the thoracic or abdominal aortas were classified according to the most "advanced" feature (asymmetric, symmetric, focal) of aneurysm formation found. Table I gives an overview of the distribution of either thoracic or abdominal arteries in the mentioned categories and shows that cathepsin K deficiency did not alter the severity of early features of aneurysm formation. 

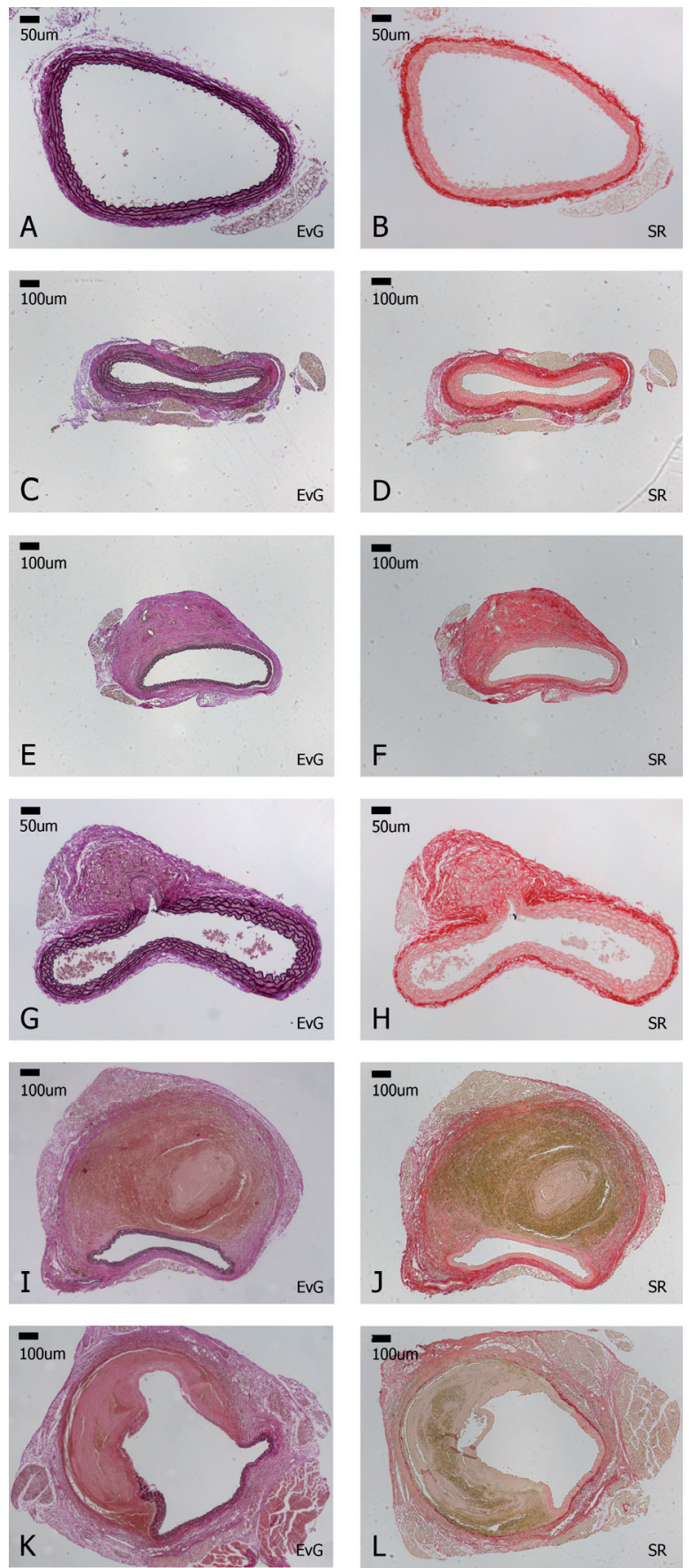

Figure 3. Histological analysis (EvG and SR) of aortas. Figure $3 \mathrm{~A}$ and $\mathrm{B}$ show normal aorta morphology. Figure 3C-F shows symmetrical (C and D) or asymmetrical (E and F) hypertrophied inner adventitial layer consisting of cell rich, fibrotic tissue. In figure $3 \mathrm{G}$ and $\mathrm{H}$ local adventitial hypertrophy in response to medial elastin breaks is shown. Figure 3I-L shows an aneurysm in the adventitia with an intact artery ( $\mathrm{I}$ and $\mathrm{J}$ ) and an aneurysm with a complete medial break and dilation of the lumen ( $\mathrm{K}$ and L). 
Table I. Overview of the distribution of either thoracic or abdominal arteries in the following categories: I: normal, no obvious alterations, II: (a)symmetrical hypertrophied inner adventitial layer consisting of cell rich, fibrotic tissue, III: adventitial hypertrophy in response to medial elastin breaks, IV: aneurysm in the adventitial space with an intact artery or aneurysm with a complete medial break and dilation of the lumen.

\begin{tabular}{lllll}
\hline & I & II & III & IV \\
\hline AAA apoE-/- $(\mathrm{N}=9)$ & 3 & 1 & 2 & 3 \\
AAA catK-/-/apoE-/- $(\mathrm{N}=9)$ & 3 & - & 3 & 3 \\
TAA apoE-/- (N=9) & 4 & 1 & 1 & 3 \\
TAA catK-/-/apoE-/- $(\mathrm{N}=7)$ & 2 & 1 & 1 & 3 \\
\hline
\end{tabular}

AAA indicates abdominal aortic aneurysm and TAA indicates thoracic aortic aneurysm.

\section{DISCUSSION}

Abdominal aortic aneurysms are life-threatening conditions characterized by chronic inflammation, degradation of the ECM, and increased expression of proteases, like MMPs and cathepsins ${ }^{3,13}$. Two groups studied the effect of deficiency of the cathepsin cysteine protease inhibitor cystatin C in hyperlipidemic mice and found opposite effects on aneurysm formation ${ }^{14,15}$. Bengtsson and colleagues found no effect of cystatin C deficiency on aortic arch circumference and aortic length in apoE-/- mice ${ }^{14}$, while Sukhova and colleagues found an increase in both aortic circumference and length in apoE- $/-$ mice $^{15}$. These differences can be attributed to differences in length of high-fat diet (25 versus 12 weeks) and gender of the mice (female versus male).

Since cathepsin K exerts important elastolytic ${ }^{16,17}$ and collagenolytic ${ }^{18}$ functions, we hypothesized that deficiency of this cysteine protease would decrease aneurysm formation in angiotensin II infused apoE-/- mice. Unexpectedly, we had to reject our hypothesis, since cathepsin $\mathrm{K}$ deficiency did not reduce aneurysm formation nor reduce the severity of early features of aneurysm formation. In contrast, there may even be a stimulating role for cathepsin $\mathrm{K}$ deficiency in aneurysm formation, since slightly more animals in the apoE-/-/catK-/- group than in the apoE-/- group died due to aneurysm rupture (3 versus 1 animal).

There are several possible explanations for the lack of effect of cathepsin K disruption on aneurysm formation. Firstly, Eagleton and colleagues showed that angiotensin II induces an increase in aortic MMP-2 and MMP-9 activity, peaking at 28 days ${ }^{19}$. This increase in angiotensin II induced MMP activity may overrule the protective effect of cathepsin $\mathrm{K}$ deficiency in aneurysm formation. Also in other mouse models of aneurysm formation (periaortic incubation of calcium chloride) compensatory mechanisms of MMP activity have been shown. For example, disruption of MMP-9 is accompanied by an increase in MMP-2 activity 
compared with wild-type mice, though this increase is not sufficient to overrule MMP-9 deficiency induced reduction in aneurysm formation ${ }^{20}$. On the contrary, deficiency of MMP-12 is not compensated by an increase in MMP-2 or MMP-9 activity $^{21}$. However, additional zymography experiments are needed to define the exact role of MMP-2 and -9 activity on aneurysm formation when cathepsin $\mathrm{K}$ is deficient. Secondly, Tham and colleagues showed that subcutaneous infusion of angiotensin II during 30 days causes arterial stiffening by increasing collagen content and decreasing elastin conten $\mathrm{t}^{22}$. This may lead to higher wall stress, which induces aortic dilatation and aneurysm formation. Assuming similar effects of angiotensin II in our study, angiotensin II may overrule the collagenolytic activity of cathepsin $\mathrm{K}$ in apoE-/- mice, thereby equalizing the collagen content in apoE-/- and catK-/-/apoE-/- aortas. Alternatively, angiotensin II may further increase the collagen content in cathepsin $\mathrm{K}$ deficient aortas, thereby increasing arterial stiffening. Since we did not observe a difference in medial collagen content between both genotypes, the latter explanation is less likely.

As already mentioned, collagen content increased in arteries of angiotensin II infused apoE-/- mice, which is partly caused by increased collagen content in the adventitia $^{22}$. Other researchers also suggested involvement of the adventitia in aneurysm formation. Daugherty et al. found that aneurismal regions were resistant to dissection of adventitial tissue in angiotensin II infused mice, while adventitial tissue in vehicle infused mice was easily removed ${ }^{10}$. Furthermore, angiotensin II infusion leads to adventitial thickening and to an accumulation of macrophages in the adventitia of the thoracic and abdominal aorta ${ }^{10,23-25}$. These data point to an important role for the adventitia in angiotensin II induced aneurysm formation. Given our observations of an adventitial response preceding the actual aneurysm formation, the adventitia may even play a causative role in aneurysm formation in angiotensin II infused mice. We suggest that arterial stiffening caused by angiotensin II induced collagen deposition in the adventitia (as described by Tham et al.) may cause ruptures in medial elastic laminae, an early characteristic of aneurysm formation. However, the current number of mice in each group and the current experimental set-up are not sufficient to give a definite answer on the question whether the adventitial response is a causal event in aneurysm formation. The recent developments in the field of ultrasound biomicroscopy ${ }^{26}$ may help us to non-invasively follow lesion development in mice over time in vivo.

In conclusion, deficiency of the collagenolytic protease cathepsin $\mathrm{K}$ in angiotensin II infused apoE-/- mice does not seem to reduce aneurysm formation, which may be due to an increase in activity of other proteases, like MMP's, in absence of cathepsin K. Alternatively, angiotensin II may overrule the 
collagenolytic activity of cathepsin $\mathrm{K}$ in apoE-/- mice, thereby equalizing the collagen content in apoE-/- and catK-/-/apoE-/- aortas.

\section{REFERENCES}

1. Hirsch AT, Haskal ZJ, Hertzer NR, Bakal CW, Creager MA, Halperin JL, Hiratzka LF, Murphy WR, Olin JW, Puschett JB, Rosenfield KA, Sacks D, Stanley JC, Taylor LM, Jr., White CJ, White J, White RA, Antman EM, Smith SC, Jr., Adams CD, Anderson JL, Faxon DP, Fuster V, Gibbons RJ, Hunt SA, Jacobs AK, Nishimura R, Ornato JP, Page RL, Riegel B. ACC/AHA 2005 Practice Guidelines for the management of patients with peripheral arterial disease (lower extremity, renal, mesenteric, and abdominal aortic): a collaborative report from the American Association for Vascular Surgery/Society for Vascular Surgery, Society for Cardiovascular Angiography and Interventions, Society for Vascular Medicine and Biology, Society of Interventional Radiology, and the ACC/AHA Task Force on Practice Guidelines (Writing Committee to Develop Guidelines for the Management of Patients With Peripheral Arterial Disease): endorsed by the American Association of Cardiovascular and Pulmonary Rehabilitation; National Heart, Lung, and Blood Institute; Society for Vascular Nursing; TransAtlantic Inter-Society Consensus; and Vascular Disease Foundation. Circulation. Mar 21 2006;113(11):e463-654.

2. Thompson RW, Parks WC. Role of matrix metalloproteinases in abdominal aortic aneurysms. Ann N Y Acad Sci. Nov 18 1996;800:157-174.

3. Thompson RW, Geraghty PJ, Lee JK. Abdominal aortic aneurysms: basic mechanisms and clinical implications. Curr Probl Surg. Feb 2002;39(2):110-230.

4. Kadoglou NP, Liapis CD. Matrix metalloproteinases: contribution to pathogenesis, diagnosis, surveillance and treatment of abdominal aortic aneurysms. Curr Med Res Opin. Apr 2004;20(4):419-432.

5. Manning MW, Cassis LA, Daugherty A. Differential effects of doxycycline, a broad-spectrum matrix metalloproteinase inhibitor, on angiotensin II-induced atherosclerosis and abdominal aortic aneurysms. Arterioscler Thromb Vasc Biol. Mar 1 2003;23(3):483-488.

6. Gacko M, Glowinski S. Cathepsin D and cathepsin L activities in aortic aneurysm wall and parietal thrombus. Clin Chem Lab Med. Jun 1998;36(7):449-452.

7. Shi GP, Sukhova GK, Grubb A, Ducharme A, Rhode LH, Lee RT, Ridker PM, Libby $\mathrm{P}$, Chapman HA. Cystatin C deficiency in human atherosclerosis and aortic aneurysms.J Clin Invest. Nov 1999;104(9):1191-1197.

8. Liu J, Sukhova GK, YangJT, Sun J, Ma L, Ren A, Xu WH, Fu H, Dolganov GM, Hu C, Libby P, Shi GP. Cathepsin L expression and regulation in human abdominal aortic aneurysm, atherosclerosis, and vascular cells. Atherosclerosis. Feb 2006;184(2):302-311.

9. Daugherty A, Cassis LA. Mouse models of abdominal aortic aneurysms. Arterioscler Thromb Vasc Biol. Mar 2004;24(3):429-434.

10. Daugherty A, Manning MW, Cassis LA. Angiotensin II promotes atherosclerotic lesions and aneurysms in apolipoprotein E-deficient mice. J Clin Invest. Jun 2000;105(11): 1605-1612. 
11. Lutgens E, Lutgens SP, Faber BC, Heeneman S, Gijbels MM, de Winther MP, Frederik P, van der Made I, Daugherty A, Sijbers AM, Fisher A, Long CJ, Saftig P, Black D, Daemen MJ, Cleutjens KB. Disruption of the cathepsin K gene reduces atherosclerosis progression and induces plaque fibrosis but accelerates macrophage foam cell formation. Circulation. Jan 3 2006;113(1):98-107.

12. Saftig P, Hunziker E, Wehmeyer O, Jones S, Boyde A, Rommerskirch W, Moritz JD, Schu P, von Figura K. Impaired osteoclastic bone resorption leads to osteopetrosis in cathepsin-K-deficient mice. Proc Natl Acad Sci U S A. Nov 10 1998;95(23):1345313458.

13. Shimizu K, Mitchell RN, Libby P. Inflammation and cellular immune responses in abdominal aortic aneurysms. Arterioscler Thromb Vasc Biol. May 2006;26(5):987-994.

14. Bengtsson E, To F, Hakansson K, Grubb A, Branen L, Nilsson J, Jovinge S. Lack of the cysteine protease inhibitor cystatin C promotes atherosclerosis in apolipoprotein E-deficient mice. Arterioscler Thromb Vasc Biol. Oct 2005;25(10):2151-2156.

15. Sukhova GK, Wang B, Libby P, Pan JH, Zhang Y, Grubb A, Fang K, Chapman HA, Shi GP. Cystatin C deficiency increases elastic lamina degradation and aortic dilatation in apolipoprotein E-null mice. Circ Res. Feb 18 2005;96(3):368-375.

16. Punturieri A, Filippov S, Allen E, Caras I, Murray R, Reddy V, Weiss SJ. Regulation of elastinolytic cysteine proteinase activity in normal and cathepsin K-deficient human macrophages. J Exp Med. Sep 18 2000;192(6):789-799.

17. Yasuda Y, Li Z, Greenbaum D, Bogyo M, Weber E, Bromme D. Cathepsin V, a novel and potent elastolytic activity expressed in activated macrophages. J Biol Chem. Aug 27 2004;279(35):36761-36770.

18. Garnero P, Borel O, Byrjalsen I, Ferreras M, Drake FH, McQueney MS, Foged NT, Delmas PD, Delaisse JM. The collagenolytic activity of cathepsin K is unique among mammalian proteinases. J Biol Chem. Nov 27 1998;273(48):32347-32352.

19. Eagleton MJ, Ballard N, Lynch E, Srivastava SD, Upchurch GR, Jr., Stanley JC. Early increased MT1-MMP expression and late MMP-2 and MMP-9 activity during Angiotensin II induced aneurysm formation. J Surg Res. Oct 2006;135(2):345-351.

20. Ikonomidis JS, Barbour JR, Amani Z, Stroud RE, Herron AR, McClister DM, Jr., Camens SE, Lindsey ML, Mukherjee R, Spinale FG. Effects of deletion of the matrix metalloproteinase 9 gene on development of murine thoracic aortic aneurysms. Circulation. Aug 30 2005;112(9 Suppl):I242-248.

21. Longo GM, Buda SJ, Fiotta N, Xiong W, Griener T, Shapiro S, Baxter BT. MMP-12 has a role in abdominal aortic aneurysms in mice. Surgery. Apr 2005;137(4):457-462.

22. Tham DM, Martin-McNulty B, Wang YX, Da Cunha V, Wilson DW, Athanassious $\mathrm{CN}$, Powers AF, Sullivan ME, Rutledge JC. Angiotensin II injures the arterial wall causing increased aortic stiffening in apolipoprotein E-deficient mice. Am J Physiol Regul Integr Comp Physiol. Dec 2002;283(6):R1442-1449.

23. Bush E, Maeda N, Kuziel WA, Dawson TC, Wilcox JN, DeLeon H, Taylor WR. CC chemokine receptor 2 is required for macrophage infiltration and vascular hypertrophy in angiotensin II-induced hypertension. Hypertension. Sep 2000;36(3):360-363.

24. Saraff K, Babamusta F, Cassis LA, Daugherty A. Aortic dissection precedes formation of aneurysms and atherosclerosis in angiotensin II-infused, apolipoprotein E-deficient mice. Arterioscler Thromb Vasc Biol. Sep 1 2003;23(9):1621-1626. 
25. Manning MW, Cassi LA, Huang J, Szilvassy SJ, Daugherty A. Abdominal aortic aneurysms: fresh insights from a novel animal model of the disease. Vasc Med. Feb 2002; $7(1): 45-54$.

26. Gan LM, Gronros J, Hagg U, Wikstrom J, Theodoropoulos C, Friberg P, Fritsche-Danielson R. Non-invasive real-time imaging of atherosclerosis in mice using ultrasound biomicroscopy. Atherosclerosis. Feb 2007;190(2):313-320. 


\section{Chapter 7 \\ A new functional genomics approach to identify soluble mediators of atherosclerotic plaque stabilization}

Suzanne P.M. Lutgens ${ }^{1} \star$, Sylvia Heeneman ${ }^{1} \star$, Mat J. Rousch ${ }^{1}$, Esther Lutgens ${ }^{1}$, Andrea van Elsas $^{2}$, Anneke M. Sijbers ${ }^{3}$, Tilman M. Hackeng ${ }^{4}$, Mat J.A.P. Daemen ${ }^{1}$, Kitty B.J.M. Cleutjens ${ }^{1} \star$ Both authors have contributed equally

Departments of Pathology ${ }^{1}$ and Biochemistry ${ }^{4}$, University of Maastricht, CARIM, The Netherlands, Departments Target Discovery ${ }^{2}$ and Molecular Design and Informatics ${ }^{3}$, NV Organon, Oss, The Netherlands. 


\section{CHAPTER 7}

\section{ABSTRACT}

Since little is known about the mechanisms underlying the transition of stable to ruptured atherosclerotic plaques we recently used suppression subtractive hybridization ( $\mathrm{SSH}$ ) to identify genes differentially expressed between these conditions. However, a disadvantage of large scale gene expression studies is the lack of functional information. Therefore we developed a new high-throughput functional genomics approach to identify soluble mediators of inflammation, a key process in atherosclerosis.

To identify soluble mediators of plaque stability, the stable plaque SSH cDNA library was recloned in mammalian expression vectors, cDNAs were chemically transfected into HEK293 cells and their conditioned media were subsequently transferred to PMA differentiated THP-1 cells, after which cytokine production was assessed by ELISA.

Here we show the feasibility of our new functional genomics approach since an initial screen resulted in the identification of several candidates inducing IL-6 production, including 70G7, encoding a unique 10AA peptide. Synthetic 70G7 peptide dose dependently induced IL- 6 and IL-10 production by PMA differentiated THP-1 cells, while transfection of full length cathepsin K and S resulted in increased IL-6 production.

In conclusion, we have shown proof of concept of our new functional genomics approach to identify soluble mediators of inflammation, facilitating high-throughput screening of large expression libraries. 


\section{INTRODUCTION}

In Western society, cardiovascular diseases lead to high morbidity and mortality rates. Most of the clinical symptoms are initiated by rupture of a so-called vulnerable lesion, resulting in major organ complications such as myocardial infarction and stroke (reviewed $\mathrm{in}^{1-3}$ ). Although the morphological differences between stable and ruptured atherosclerotic plaques are well described ${ }^{4}$, relatively little is known about the molecular mechanisms underlying this transition. Also insight into the pathways that alter the phenotype of a stable atherosclerotic plaque to a vulnerable plaque is sparse.

The balance between inflammation and fibrosis is considered to be a major factor for the maintenance of a stable plaque phenotype $\mathrm{e}^{1-3}$. We and others have shown that regulators of extracellular matrix turnover and inflammation such as transforming growth factor $\beta 1$ (TGF- $\beta 1$ ), cathepsins, CD40L, IL-6 and - 10 are able to modulate plaque fibrosis and inflammation ${ }^{5-12}$. Although many cytokines can have both pro- and anti-atherogenic properties, the cytokines IL-6 and CD40L are generally considered to exert pro-atherogenic functions while the cytokines IL-10 and TGF- $\beta 1$ are considered to exert anti-atherogenic functions.

Large scale gene expression profiling may contribute to elucidate the molecular mechanisms underlying the transition of stable to vulnerable and eventually ruptured atherosclerotic plaques. Several studies compared gene expression profiles of human non-diseased arteries versus human atherosclerotic arteries using representational difference analysis (RDA) or microarray analysis ${ }^{13-15}$. Using suppression subtractive hybridization ( $\mathrm{SSH}$ ) we have generated a large library of genes containing 2,000 clones upregulated in human advanced but stable atherosclerotic plaques and 3,000 clones upregulated in ruptured human atherosclerotic plaques ${ }^{16}$. However, one of the drawbacks and potential pitfalls of the use of large scale gene expression approaches such as SSH and microarray analysis is the lack of functional assays early in the selection of potential candidates. To overcome this pitfall, we developed a high throughput functional screening procedure to select for cDNAs involved in inflammation, a key process in atherosclerosis. Although the principle of functional screening of expressed cDNA libraries has been applied successfully in the field of cancer and immunology research ${ }^{17-19}$, we are the first to present a functional screening for soluble mediators of inflammation, a key process in atherosclerotic plaque stabilization. In addition, this study is the first to apply functional screening on differentially expressed (SSH) cDNA clones, which makes it not a random quest, but a rational search for functional candidates from a pre-selected library of genes upregulated in stable atherosclerotic plaques. In this chapter, we show proof of concept of our new 
functional genomics approach and the identification of several potential and novel soluble mediators that can induce inflammatory cytokine production.

\section{METHODS}

Generation of mammalian stable plaque enriched cDNA expression library

For construction of a mammalian stable plaque enriched expression library we amplified the inserts of a suppression subtractive hybridization ( $\mathrm{SSH}$ ) library containing >2000 cDNA clones upregulated in human advanced but stable atherosclerotic plaques compared with plaques containing a thrombus, previously generated in our laboratory ${ }^{16}$, using primers containing EcoRI recognition sites (sense: 5'-TCGAGCGGAATTCCGGGCAGGT antisense: 5' AGCGT GGTCGAATTCGAGGTAC). After digestion, PCR-products were gel-purified (divided in fragments $<1000$ and $>1000 \mathrm{bp}$ ) and ligated into the mammalian expression vectors pTarge $^{\mathrm{TM}}$ (Promega) and pcDNA4/HisMax $^{\circ} \mathrm{A}, \mathrm{B}$, and C (Invitrogen), also digested with EcoRI. Ligation mixtures were used to transform Escherichia coli TG1 cells by electroporation and to obtain cDNA expression libraries representing all possible internal ORFs and fusion proteins.

To assess the number of colonies with insert, insert length, and insert diversity, single colonies were subjected to PCR amplification. The Amplitaq ${ }^{\circledR}$ DNA Polymerase kit (Applied Biosystems) was used to amplify inserts of the plasmid colonies. PCR amplification of inserts in pTargeT (M13 forward, 5'-CGCC AGGGTTTTCCCAGTCACGGAC-3'; M13 reverse, 5'TTTCACACAGG AAACAGCTATGA-3') or pcDNA4/HisMax (pcDNA4 forward, 5'TAT GGCTAGCATGACTGGT-3'; pcDNA4 reverse, 5'-TAGAAGGCACAGT CGAGG-3') was performed using standard conditions. The restriction enzyme MBO1 (New England Biolabs ${ }^{\circledR}$ ) was used to fingerprint the resulting PCR product.

\section{Plasmid isolation}

For growth in 96-wells bacterial culture plates, single colonies were picked, inoculated in LB or 2xTY medium supplemented with ampicillin and cultured overnight at $37^{\circ} \mathrm{C}$ shaking at $250 \mathrm{rpm}$. After 24 hours of culture, colonies were stored at $-80^{\circ} \mathrm{C}$ as $15 \%$ glycerol stock. Afterwards, plasmids from glycerol stocks were cultured in $1.3 \mathrm{ml}$ medium for 48 hours and isolated using the R.E.A.L. ${ }^{\circledR}$ Prep 96 plasmid kit (Qiagen). Plasmid DNA concentrations were measured using a Nanodrop spectrophotometer (NanoDrop Technologies) and stored at $-20^{\circ} \mathrm{C}$ until further analysis. Full length cathepsin $\mathrm{K}$ and $\mathrm{S}$ expression constructs were kindly provided by Organon NV (Oss, The Netherlands). 


\section{Cell culture}

HEK293 cells (human embryonic kidney cells (epithelial cells), ATCC CRL1573) were cultured in Dulbecco's modified Eagle's medium (DMEM), supplemented with 10\% fetal bovine serum, Glutamax-1 and $100 \mathrm{IU} / \mathrm{ml}$ penicillin/streptomycin (Gibco). THP-1 cells (human monocyte cell line, ATCC TIB-202) were cultured in phenol red free RPMI 1640 medium supplemented with $25 \mathrm{mM}$ HEPES, L-glutamine (Gibco), 10\% fetal clone III (Hyclone), and $100 \mathrm{IU} / \mathrm{ml}$ penicillin/streptomycin (Gibco). During functional assays THP-1 cells were grown in X-Vivo 15 medium (Cambrex) supplemented with 10\% fetal clone III and $100 \mathrm{IU} / \mathrm{ml}$ penicillin/streptomycin.

\section{Transfection}

On day $0,6.0 \star 10^{5}$ HEK293 cells were seeded in 6-wells format. Transfections were performed on day 2 using Metafectene ${ }^{\mathrm{TM}}$ (Biontex). For transfection of HEK293 cells, $2 \mu \mathrm{g}$ cDNA of either a pool containing eight individual plasmids or an individual plasmid was dissolved in $100 \mu \mathrm{l}$ DMEM without supplements. Subsequently, $16 \mu \mathrm{l}$ Metafectene dissolved in $100 \mu \mathrm{l}$ DMEM without supplements was added. After 30 minutes incubation at room temperature allowing complex formation, the solution was added to the HEK293 cells. Transfection efficiency was confirmed by transfection of pcDNA4/HisMax $/ \mathrm{LacZ}$ followed by X-gal staining on day 4 , resulting in efficiencies of $70-90 \%$.

\section{Functional assay}

A schematic drawing of the functional screening is shown in figure 1 . On day 0 , $1 \star 10^{5}$ THP-1 cells were seeded in 96-wells format and differentiated into macrophages by addition of PMA (phorbol 12-myristate 13-acetate, final concentration $120 \mathrm{ng} / \mathrm{ml}$ ). On day 3 , the medium was replaced by fresh medium without PMA. On day 4, the conditioned medium of transfected HEK293 cells was harvested. Subsequently, PMA differentiated THP-1 cells were incubated with HEK293 conditioned medium and standard X-vivo 15 medium in a 1:1 ratio. After 8.5 hours, media and cell lysates were collected and stored at $-20^{\circ} \mathrm{C}$

until analysis of cytokine production. Cytokine production in media was measured by IL-6, IL-8, and Il-10 ELISA (Sanquin) according to the manufacturer's protocol. Elastase and gelatinase activity in media and cell lysates were measured by EnzChek ${ }^{\circledR}$ elastase and gelatinase assay kits (Molecular Probes).

\section{Assay controls}

Lipopolysaccharide (LPS) and $\beta$-amyloid (Biosource) and TGF- $\beta 1$ proteins (Promega) served as positive controls for cytokine production by PMA differentiated THP-1 cells ${ }^{20,21}$. Both $\beta$-amyloid and TGF- $\beta 1$ plasmids were constructed 


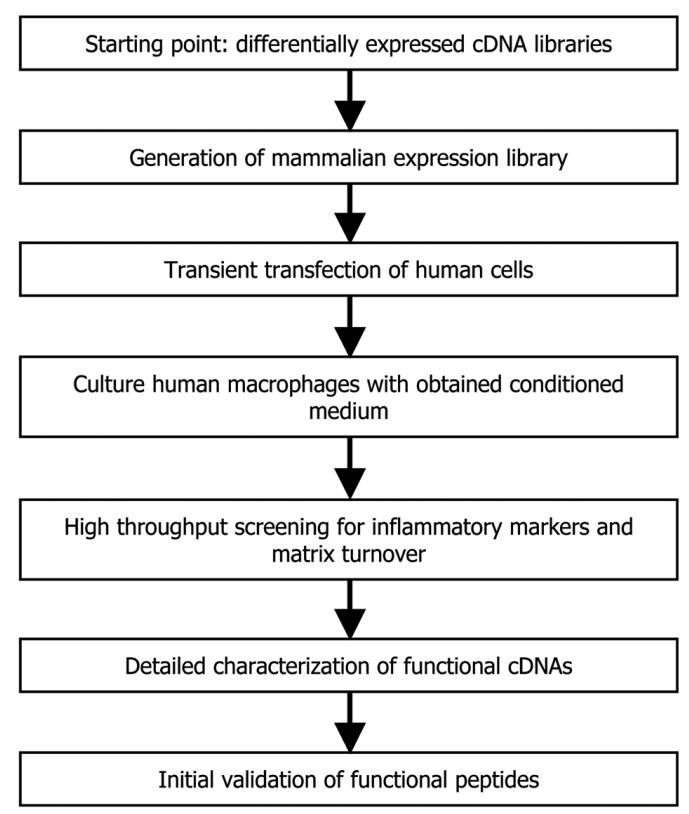

Figure 1. Overview of functional screening procedure.

to serve as positive assay control for the functional assay. For $\beta$-amyloid(1-42), amygdala (brain) from a human patient with Alzheimer's disease (PCR Ready First Strand cDNA, BioChain) was amplified using the Amplitaq DNA Polymerase kit (sense, 5'-GCCGCCACCATGGATGCAGAGTTCCGACATGA CTCAGG-3, plus antisense, 5'-GATCACTCACGCTATGACAACACCGC CCACC-3) and was performed using standard conditions. For TGF- $\beta 1$, RNA was isolated from cultured vascular smooth muscle cells using RNAzol/chloroform/isopropanol. CDNA was synthesized using SMART PCR cDNA Synthesis kit (Clontech), amplified using the Amplitaq DNA Polymerase kit (sense, 5'-GTTCGCGCTCTCGGCAGTGCC-3, plus antisense, 5'-GCGGG ACCTCAGCTGCACTTG-3) and performed using standard conditions. Amplified cDNAs were purified and ligated into $\mathrm{pTarge}^{\mathrm{TM}}$ (see earlier in this section) and inserts were completely sequenced. After transfection of the constructs into HEK293 cells, production of $\beta$-amyloid and TGF- $\beta 1$ was verified by ELISA (Biosource and Promega respectively), which was performed according to the manufacturer's protocol. Anti-sense $\beta$-amyloid construct and empty vector (TGF- $\beta 1$ ) served as negative assay controls. 


\section{Sequencing}

Cells were transfected in pools of 8 individual candidates. Positive pools were forwarded to a second screening round to test the individual clones of the positive pool. Individual positive candidates were sequenced using the BigDye ${ }^{\circledR}$ Terminator v3.1 Cycle Sequencing Kit on a ABI Prism ${ }^{\circledR} 3100$ Genetic Analyzer with the use of T7 (5'-TAATACGACTCACTATAGGG-3') or M13 forward (5'-CGCCAGGGTTTTCCCAGTCACGGAC-3') primer under standard conditions. Homology searches were performed by use of the advanced Blast Program on the combined GenBank/EMBL nonredundant expressed sequence tag (dEST), mouse EST, human EST, rat EST, Swiss protein, and human tagged genomic sequence (htgs) databases (National Center for Biotechnology Information, www.ncbi.nlm.nih.gov/).

\section{Peptide synthesis}

70 G7 peptide (Ac-GSSVVEFEVLRIFKISQ-NH ${ }_{2}$ ) and 70G7 scrambled peptide (Ac-FQSFISVESVKLGRIEV-NH $\mathrm{NH}_{2}$ were prepared by manual solid phase peptide synthesis (SPPS) on a $0.3 \mathrm{mmol}$ scale using the in situ neutralization/ HBTU activation procedure for Boc chemistry essentially as previously described $^{22}$. Peptides were purified on reversed-phase C18 HPLC using a semi-preparative column $(2.5 \times 25 \mathrm{~cm})$. Bound peptides were eluted with linear gradients of $90 \%$ acetonitril/water/0.1\% TFA in water/0.1\% TFA. Purified peptides were lyophilized and stored at $-20^{\circ} \mathrm{C}$ until use.

\section{Statistical analysis}

Values are expressed as mean \pm SEM and a Mann-Whitney non-parametrical test was used to compare groups. Probability values of $<0.05$ were considered significant.

\section{RESULTS}

cDNA library construction and quality control

To generate the mammalian stable plaque enriched cDNA expression libraries, a stable plaque $\mathrm{SSH}$ library was re-cloned into the mammalian expression vectors p Targe $^{\mathrm{TM}}$ and $\mathrm{pcDNA} 4 / \mathrm{HisMax}^{\circ} \mathrm{A}, \mathrm{B}$, and C. Using these vectors, the SSH cDNA fragments are expressed starting from an internal ATG (pTargeT) or as a fusion protein (pcDNA4/HisMax). Each of the resulting 8 libraries (4 different vectors containing either fragments $<1000$ or $>1000 \mathrm{bp}$ ) consisted of 60,000 to 120,000 individual clones. PCR amplification showed insert sizes ranging from 150 to over 1,500 base pairs. More than $98 \%$ of plasmids contained an insert, 


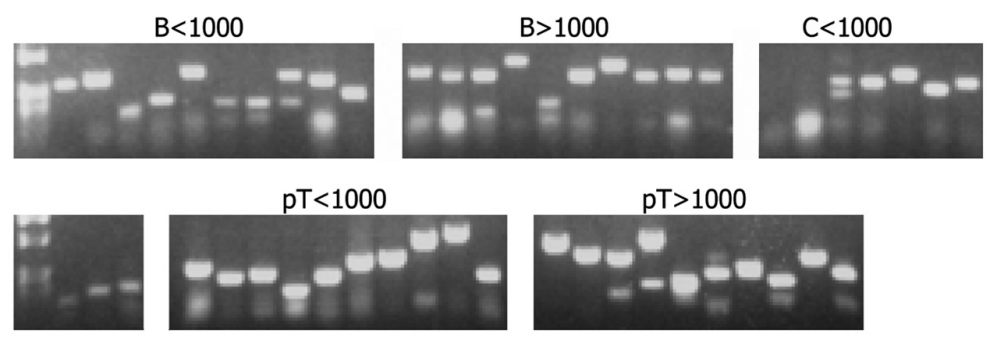

Figure 2. Fingerprinting (MBO1 digestion) of PCR amplification products, showing high diversity of fragments. $\mathrm{B}=\mathrm{pcDNA} \operatorname{HisMax}^{\mathcal{O}} \mathrm{B}, \mathrm{C}=\mathrm{pcDNA} \mathrm{HisMax}^{\mathcal{O}} \mathrm{C}$ and $\mathrm{pT}=$ pTarget $^{\mathrm{TM}}$.

while fingerprinting by MBO1 digestion of the amplified inserts showed high diversity (Figure 2).

Optimization functional read-out of PMA differentiated THP-1 cells

To study the optimal conditions for a reliable read-out of THP-1 macrophage induced cytokine production, we examined LPS induced IL-6, IL-8, and IL-10 cytokine production in PMA stimulated THP-1 cells. LPS was used at concentrations of 1, 10,100, and $1000 \mathrm{ng} / \mathrm{ml}$ and showed a dose dependent increase in the production of all three cytokines. As shown in figure 3A, IL-6 cytokine production by unstimulated THP-1 macrophages was low on day 1 to 6 ranging from 10 to $60 \mathrm{pg} / \mathrm{ml}$. Cytokine production significantly increased after addition of 1 $\mathrm{ng} / \mathrm{ml} \mathrm{LPS}$ to 350 and $700 \mathrm{pg} / \mathrm{ml}$ on day 4 and 6 . On the contrary, IL-8 cytokine production by unstimulated THP-1 macrophages was high on day 1 to 4 , ranging from 1,800 to $2,300 \mathrm{pg} / \mathrm{ml}$, but decreased significantly on day 5 and 6 . Addition of $1 \mathrm{ng} / \mathrm{ml}$ LPS on day 4 and 6 significantly increased IL-8 cytokine production again to $2,300 \mathrm{pg} / \mathrm{ml}$ (Figure 3B). IL-10 cytokine production by THP-1 cells was low on day 1 to 6 ranging from 0 to $3 \mathrm{pg} / \mathrm{ml}$. Cytokine production slightly, but significantly, increased after addition of $1 \mathrm{ng} / \mathrm{ml}$ LPS to $6 \mathrm{pg} / \mathrm{ml}$ on day 4 and increased even more to $100 \mathrm{pg} / \mathrm{ml}$ on day 6 (Figure 3C).

\section{Proof of concept of our functional screening protocol}

$\beta$-amyloid and TGF- $\beta 1$ proteins have been described to induce cytokine production $^{20,21}$. First, we confirmed that both $\beta$-amyloid and TGF- $\beta 1$ recombinant protein were able to induce IL-6 cytokine production in THP-1 macrophages (data not shown). Subsequently, both $\beta$-amyloid and TGF- $\beta 1$ plasmids were constructed. Transfection of either of the constructs in HEK293 cells resulted in quantifiable production of the encoding protein (data not shown). Subsequent addition of transfected HEK293 cells conditioned medium 

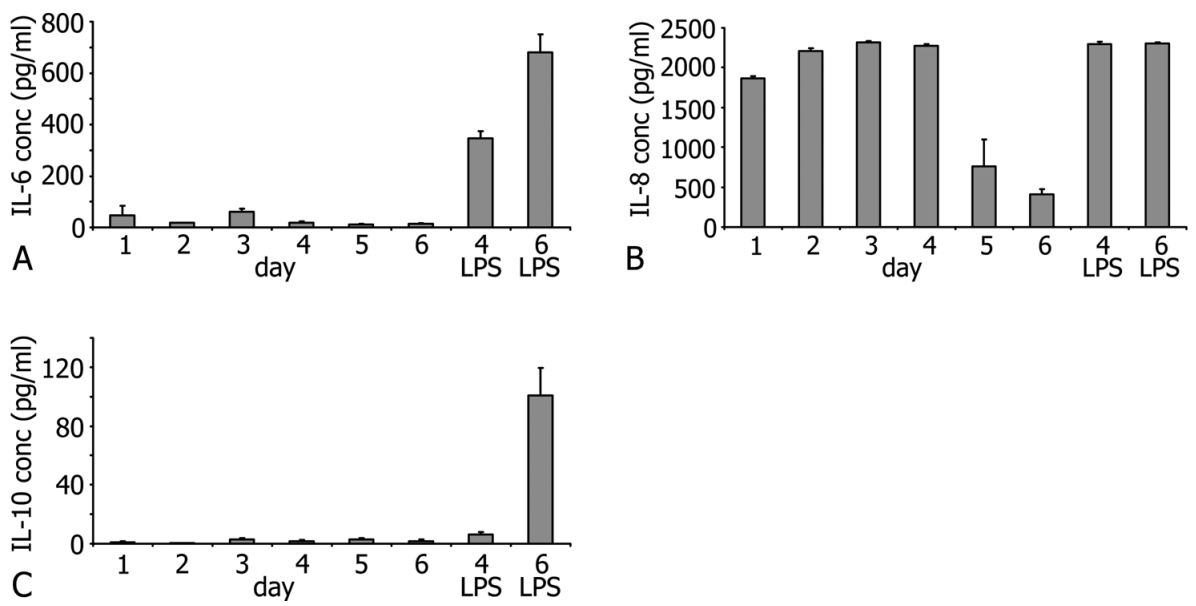

Figure 3. IL-6, -8, and -10 cytokine production by unstimulated or LPS stimulated (1ng/ml) PMA differentiated THP-1 cells. Data are represented as mean \pm SEM.

to THP-1 macrophages resulted in a significant increase in IL-6 cytokine production by these macrophages (Figure 4A). Transfection of the $\beta$-amyloid expression plasmid led to IL-6 cytokine levels of $92.2 \pm 3.2 \mathrm{pg} / \mathrm{ml}$ compared with $15.3 \pm 3.9$ $\mathrm{pg} / \mathrm{ml}$ for the antisense $\beta$-amyloid construct. Transfection of the TGF- $\beta 1$ expression plasmid resulted in IL-6 cytokine levels of $91.6 \pm 6.6 \mathrm{pg} / \mathrm{ml}$ compared with $19.7 \pm 6.8 \mathrm{pg} / \mathrm{ml}$ for the empty $\mathrm{pTarge}^{\mathrm{TM}}$ vector. During the functional screening of candidates, both $\beta$-amyloid and TGF- $\beta 1$ constructs served as positive assay controls for IL- 6 cytokine production, while TGF- $\beta 1$ construct served as positive assay control for IL-10 cytokine production. Transfection of the TGF- $\beta 1$ expression plasmid resulted in low, but significant, IL-10 cytokine production of $6.2 \pm 1.0 \mathrm{pg} / \mathrm{ml}$ compared with $0.1 \pm 0.03 \mathrm{pg} / \mathrm{ml}$ for the empty p Targe $^{\mathrm{TM}}$ vector (Figure $4 \mathrm{~B}$ ). These data showed proof of concept of our screening strategy since transfected HEK293 cells produced soluble mediators which induced inflammatory cytokine production by human macrophages.

\section{Candidate screening}

Figure 5 shows representative results of a functional screening on IL-6 cytokine production. In figure $5 \mathrm{~A}$, the functional screening of 36 pools, containing 288 clones, is shown. This screen resulted in the identification of several highly positive pools, indicated by the black bars. Figure 5B shows the screening of the individual clones from the four highest positive pools from figure $5 \mathrm{~A}$. This resulted in the identification of several highly positive individual candidates, again indicated by the black bars. In total we screened approximately 1,200 clones for IL-6 

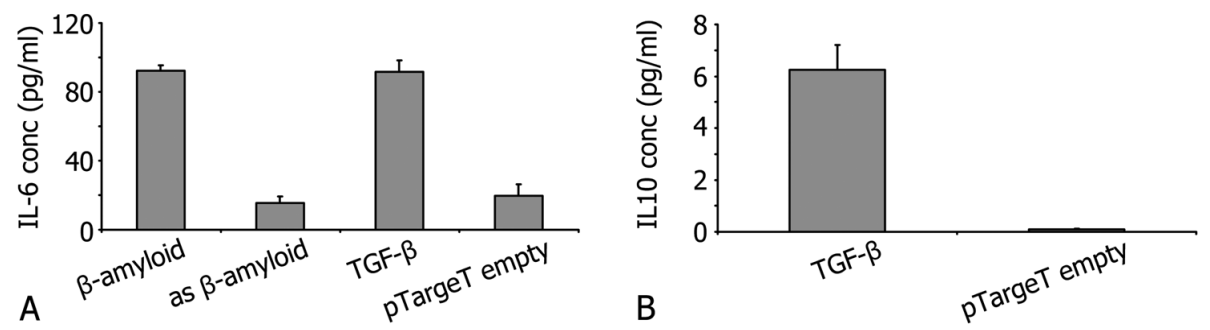

Figure 4. Proof of concept of functional screening: $\beta$-amyloid and/or TGF- $\beta$ plasmid tranfection in HEK293 cells and subsequent addition of conditioned medium to PMA differentiated THP-1 cells resulted in increased IL-6 (Figure 4A) and IL-10 (Figure 4B) cytokine production compared with the negative controls (antisense $\beta$-amyloid and/or empty $\mathrm{p}^{\text {Targe }} \mathrm{T}^{\mathrm{TM}}$ vector). Data are represented as mean \pm SEM.
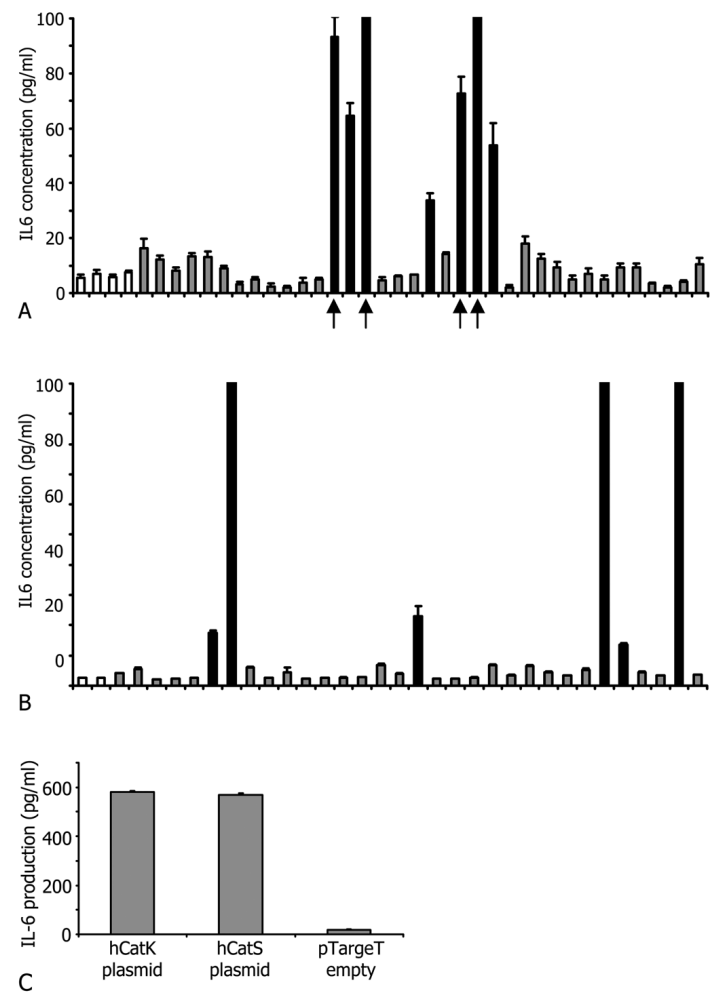

Figure 5. Figure 5A shows the screening on IL-6 cytokine production of 3 different 96 -wells plates, which resulted in several highly positive pools, indicated in black. Figure 5B shows the screening of the individual clones from the highly positive pools, indicated with arrows in figure $5 \mathrm{~A}$. This resulted in the identification of several highly positive candidates, again indicated in black. White bars represent negative controls. Full length cathepsin K and S expression plasmids were tranfected into HEK293 cells and the subsequent addition of conditioned medium to PMA differentiated THP-1 cells resulted in increased IL-6 (Figure 5C) cytokine production compared with the negative controls (empty $\mathrm{p}^{\text {Targe }} \mathrm{T}^{\mathrm{TM}}$ vector). Data are represented as mean $\pm \mathrm{SEM}$. 
cytokine production, resulting in the identification of 21 highly positive candidates $(2 \%)$. 'Highly positive' are those pools or individual candidates that stimulate the cytokine production more than 5-fold compared with the negative controls (Figure 5A and B). Table I shows the sequencing results and corresponding annotation of IL-6 inducing candidates. We also screened approximately 600 clones for IL-10 cytokine production, but no highly positive IL-10 inducing pools and clones were identified.

Since both cathepsin K and S cDNA fragments were also present in the stable plaque SSH library ${ }^{16}$ and both enzymes were shown to play an important role in atherosclerotic plaque stabilization ${ }^{7,23}$, we also tested whether full length cathepsin $\mathrm{K}$ and $\mathrm{S}$ constructs had an effect on IL-6 cytokine production. Transfection of the cathepsin K expression plasmid resulted in IL-6 cytokine levels of 580.2 \pm 5.4 $\mathrm{pg} / \mathrm{ml}$ compared with $19.9 \pm 2.2 \mathrm{pg} / \mathrm{ml}$ for the empty pTarge $^{\mathbf{T M}}$ vector, while transfection of the cathepsin S expression plasmid resulted in IL-6 cytokine levels of $568.3 \pm 8.0 \mathrm{pg} / \mathrm{ml}$ (Figure 5C).

\section{Validation of candidate $70 \mathrm{G} 7$}

Sequence analysis of candidate 70 G7 (candidate 1 in Table IA) revealed almost $100 \%$ homology to fibronectin-1 on the nucleotide level. Individual transfection of the 70 G7 plasmid DNA in HEK293 cells and subsequent addition of the conditioned medium of these transfected cells to THP-1 macrophages resulted in IL-6 cytokine production of $69.2 \pm 4.5 \mathrm{pg} / \mathrm{ml}$ by THP-1 macrophages (Figure 6A). Bioinformatic analysis revealed a 10 AA ORF (EVLRIFKISQ) which was in another reading frame than the fibronectin protein, showing homology (80\%) to arylamine acetylase 2. For further validation both synthetic $70 \mathrm{G} 7$ peptide (Ac-GSSVVEFEVLRIFKISQ- $\mathrm{NH}_{2}$, including 5 amino acids derived from the pcDNA4/HisMax C vector (GSSVV) and 2 amino acids (EF) from the modulated EcoR 1 site) and the corresponding scrambled peptide were directly added to PMA differentiated THP-1 cells. Addition of synthetic 70G7 to PMA differentiated THP-1 cells, resulted in dose dependent IL-6 cytokine production (Figure 6B), indicating a direct effect of 70 G7 on PMA differentiated THP-1 cells, while the scrambled peptide had no effect on IL-6 production. Additional experiments also revealed dose dependent IL-10 cytokine production (Figure 6C) induced by the $70 \mathrm{G} 7$ peptide, while again the scrambled peptide had no effect on IL-10 production. Furthermore, the $70 \mathrm{G} 7$ peptide did not induce gelatinolytic or elastolytic activity by PMA differentiated THP-1 cells (not in media neither in cell lysate, data not shown). 


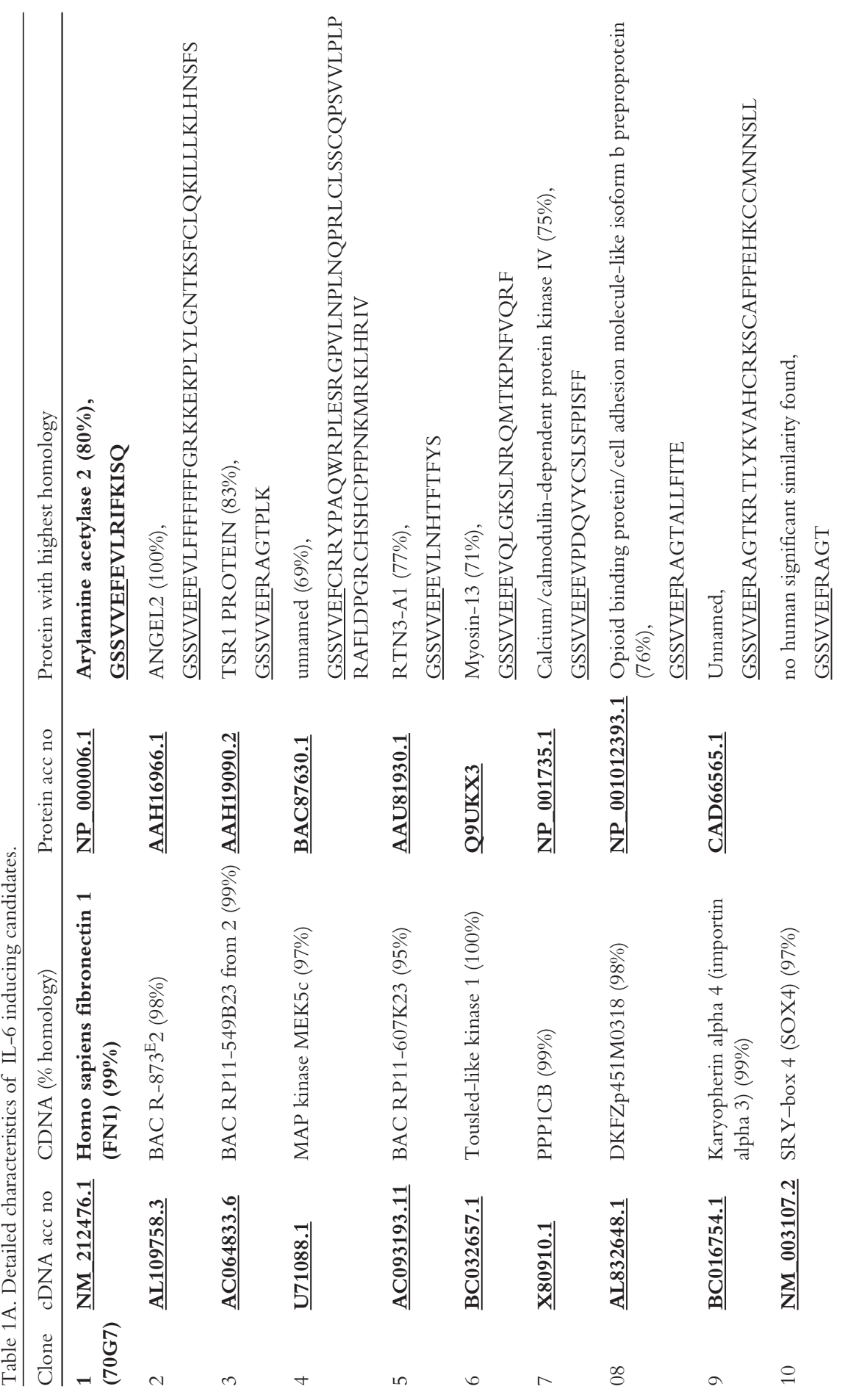




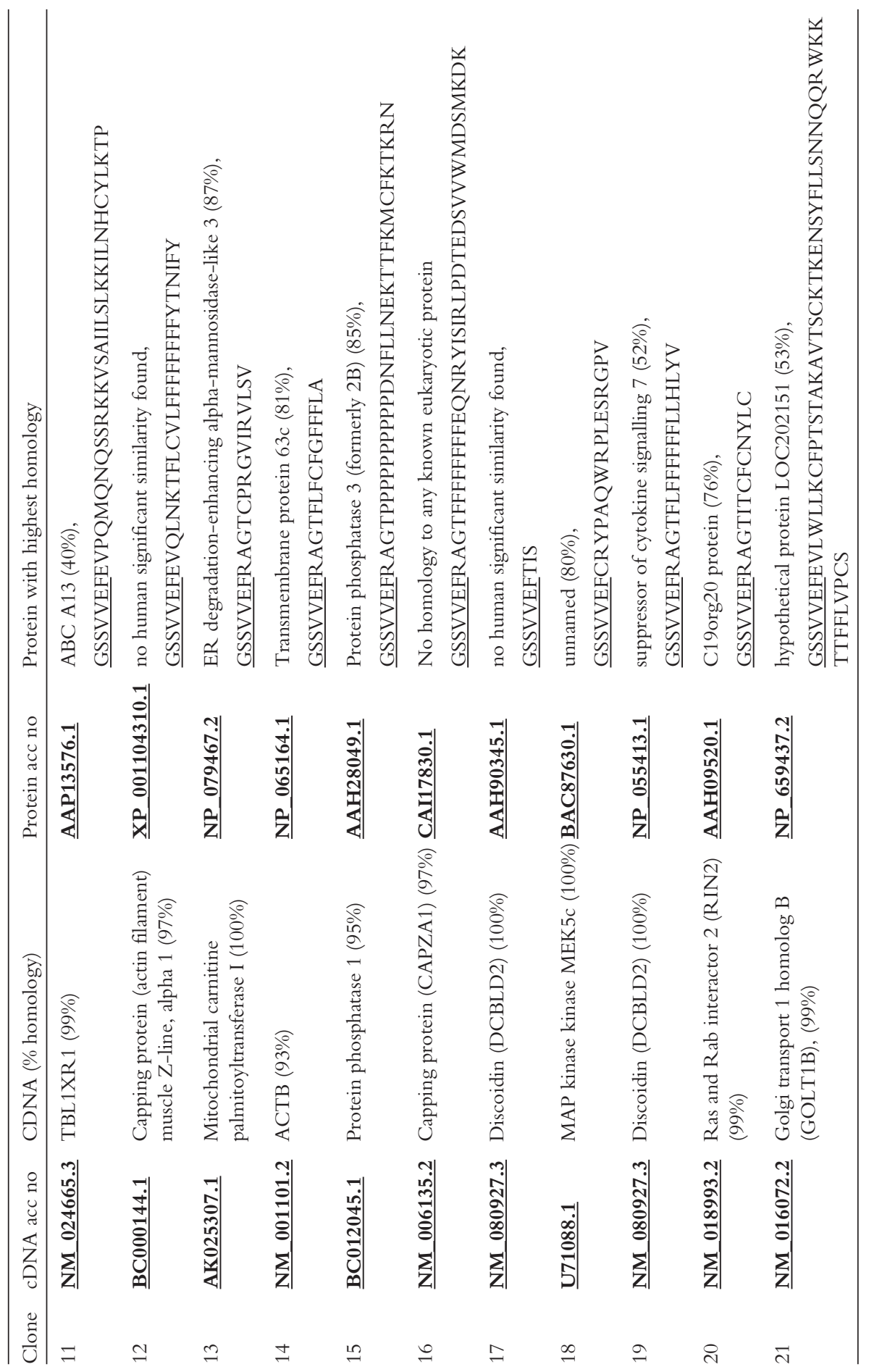



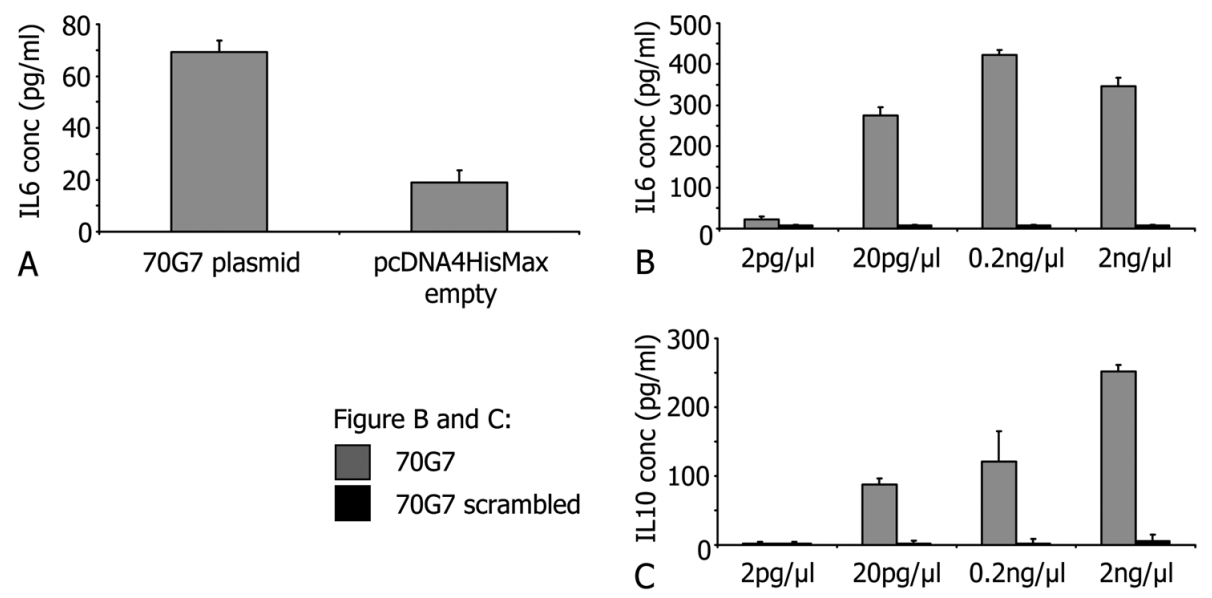

Figure 6. Individual transfection of the 70G7 plasmid in HEK293 cells and subsequent addition of the conditioned medium of these transfected cells to PMA differentiated THP-1 cells resulted in increased IL-6 cytokine production by THP-1 cells compared with the empty pcDNA4/HisMax C vector (Figure 6A, 1 representative assay out of 3 comparable assays is shown). Addition of the $70 \mathrm{G} 7$ synthetic peptide directly to PMA differentiated THP-1 cells, revealed dose dependent IL-6 cytokine production (Figure 6B, 1 representative assay out of 3 comparable assays is shown). Addition of the $70 \mathrm{G} 7$ synthetic peptide directly to PMA differentiated THP-1 cells, revealed dose dependent IL-10 cytokine production (Figure 6C, 1 representative assay out of 2 comparable assays is shown). Data are represented as mean \pm SEM.

Table 1B. 70 G7 shows homology to several proteins.

\begin{tabular}{ll}
\hline Protein acc no & Protein \\
\hline NP_000006.1 & $\begin{array}{l}\text { Arylamine acetylase 2 (identities 8/10=80\%), } \\
\text { EVLKNIFKIS }\end{array}$ \\
\hline NP_055178.2 & $\begin{array}{l}\text { Sacsin (identities 8/11 = 72\%), } \\
\text { EVLSRIFKNSE }\end{array}$ \\
$\underline{\text { NP_473447.1 }}$ & $\begin{array}{l}\text { olfactory receptor, family 5, subfamily AC, member 2 (identities 6/9 }=66 \% \text { ), } \\
\text { EILQLFKIS }\end{array}$ \\
\hline NP_005550.2 & $\begin{array}{l}\text { laminin, alpha 1 precursor (identities 6/7 }=85 \%), \\
\text { RIFKESQ }\end{array}$
\end{tabular}




\section{DISCUSSION}

In this study we developed a new functional genomics approach to screen large expression libraries and to identify soluble mediators that induce inflammatory cytokine production. This functional genomics approach is based on a SSH library of genes containing 2,000 clones upregulated in stable human atherosclerotic plaques. Several other research groups also compared gene expression in healthy versus diseased cultured cells or whole-mount tissue, using differential display, serial analysis of gene expression (SAGE), RDA or microarray analysis ${ }^{13-15,24,25}$. These large scale gene expression studies proved to be very useful in the field of cardiovascular research ${ }^{26}$. Differentially expressed genes can be categorized in three groups concerning their function. The first category of genes or proteins contains those that were previously linked to atherosclerosis. The second category contains known genes or proteins with known function but unknown for their role in atherosclerosis. The third category contains unknown genes or proteins with unknown functions. Especially this latter category reveals one of the disadvantages of large scale gene expression studies which is the lack of functional assays early in the selection of candidates, especially in the case of unknown genes or ESTs without significant homology to known proteins. To circumvent the problem of validating non-functional candidates we developed a new functional genomics approach in which differential gene expression is combined with early functional screening. Consequently, only those genes with a specified function will be identified and selected for further validation.

The principle of functional screening has been applied before in the field of cancer research. Li et al. used mouse fibroblasts (NIH 3T3) transduced with a hairpin ribozyme gene library to select for functional ribozymes that promote cell transformation. They identified the transforming ribozyme Rz007 with mTERT (telomerase reverse transcriptase) as a potential gene target ${ }^{17}$. Whitehead et al. used retroviral transfer of cDNA libraries to select for cDNAs which induce oncogenic transformation (loss of contact inhibition of proliferation) of mouse fibroblasts (NIH 3T3) and found several known oncogenes, known genes not previously known for their transforming activities, and unknown cDNAs with transforming activities ${ }^{18}$. Nonetheless, our study is the first to present a functional screen for soluble mediators of atherosclerotic plaque stabilization based on differentially expressed (SSH) cDNA clones, which makes it a non-random functional screen, and is the first applied in the field of atherosclerosis research.

In the current study we effectively re-cloned a stable plaque cDNA library in mammalian expression vectors, representing all possible reading frames and resulting in high diversity of inserts. Subsequent transfection of mammalian cells showed high and consistent transfection efficiencies. To facilitate the 
high-throughput process of our functional screening we decided to screen pools before refining our screen to individual candidates. This effort accelerated our functional screening since we were able to detect one single positive candidate in a pool containing eight individual plasmids, although there may be a risk of loosing a positive candidate in the noise of the pool. In this study, we showed that transfection of human cells with cDNA expression constructs, that are known for their ability to induce cytokine production ( $\beta$-amyloid and TGF- $\beta 1^{20,21}$ ), resulted in the production and secretion of these known soluble mediators. These soluble mediators were subsequently able to induce human macrophages to produce inflammatory cytokines, making them appropriate positive controls. Furthermore, we showed that also cathepsins $\mathrm{K}$ and $\mathrm{S}$ induced inflammatory cytokines production by human macrophages. Cathepsin $\mathrm{K}$ is one of the genes that was found to be differentially expressed in our SSH experiment comparing expression profiles of advanced but stable lesions and lesions containing a thrombus ${ }^{16}$. Expression profiling experiments suggested that deficiency of cathepsin K leads to a more stable plaque phenotype not only by decreasing proteolytic activity, but also by stimulating TGF- $\beta$ signaling ${ }^{27}$. However, cathepsin $\mathrm{K}$ deficiency also resulted in increased macrophage foam cell formation due to increased lipid uptake mediated by CD36 and caveolins ${ }^{27}$ (chapter 4). The present study shows that cathepsin $\mathrm{K}$ and $\mathrm{S}$ also have an effect on cytokine production by PMA differentiated THP-1 cells. Moreover, by applying this method to unknown expression constructs that are known to be upregulated in stable human atherosclerotic plaques, we were able to identify several new candidate soluble mediators such as 70G7. Transfection of the 70 G7 plasmid resulted in IL-6 cytokine production. Addition of synthetic 70 G7 directly to PMA stimulated THP-1 cells dose dependently induced IL-6 and IL-10 cytokine production while the scrambled peptide had no effect. Thus the present data show that this new high-throughput functional genomics approach is a reproducible and easy to use method to identify soluble mediators of inflammation, a key process in atherosclerosis.

The observation that a peptide, such as 70G7 peptide in our case, induces both pro-inflammatory (IL-6) and anti-inflammatory (IL-10) cytokine production seems contradictory, but has been described before. For example, prostaglandin E2 upregulates the levels of both IL-6 and IL-10 by activated murine macrophages, although via different pathways ${ }^{28}$. Furthermore, we showed that LPS and TGF- $\beta 1$ construct induce the production of both IL-6 and IL-10 cytokines by human macrophages. De Waal Malefyt et al. already showed that LPS induces IL-10 cytokine production by human monocytes peaking after 24-48 hours and that this IL-10 production may even inhibit the production of earlier produced pro-inflammatory cytokines, such as IL- $6^{29}$. 
Although we succeeded in the identification of several functional peptides, one of the pitfalls of our study is that none of the identified functional peptides was homologous to the proteins naturally encoded by the inserted cDNA fragments. An explanation for this pitfall is given by the fact that cDNAs can be ligated into the pcDNA4/HisMax vector in 3 different reading frames and in 2 directions, resulting in 6 possible fusion proteins from one single cDNA. Only 1 of these 6 possibilities represents the correct reading frame, while the other 5 possibilities represent alternative reading frames which may result in functional but non-physiologic proteins. Thus, although the identified proteins were functional (positive in functional assays), we have no information on differential expression of the resulting functional peptide, since an alternative reading frame was used. The phenomenon of peptide mimetics might explain why these proteins are functional without being in frame with the natural protein transcribed from the inserted cDNA. A peptide mimetic is a peptide that biologically mimics active determinants on hormones, cytokines, enzyme substrates, viruses or other bio-molecules, and may antagonize, stimulate, or otherwise modulate the physiological activity of the natural ligands. Thus the $70 \mathrm{G} 7$ peptide might be a peptide mimetic of a protein that induces human macrophages to produce IL-6 cytokine (for example $\beta$-amyloid). Arylamine acetylase 2 ( $\mathrm{N}$-acetyl tranferase 2 ), the protein to which 70 G7 showed $80 \%$ homology, plays a role in detoxification and activation of numerous therapeutic drugs and carcinogens ${ }^{30}$. Polymorphisms of the two N-acetyl transferase (NAT) enzymes, NAT1 and NAT2, result in rapid or slow acetylator phenotypes, which are associated with increased risk of developing urinary bladder, colorectal, breast, head and neck, lung and non-Hodgkin lymphoma ${ }^{31,32}$. NAT2 slow acetylator genotypes are associated with increased risk of bladder cancer $^{33,34}$, while NAT2 rapid acetylator genotypes are associated with colorectal cancer ${ }^{35}$. However, to our knowledge, this protein has not been related to inflammation or atherosclerosis before. At present, however, it is impossible to predict whether or not 70G7 is a peptide mimetic of arylamine acetylase 2 as for both peptides key amino acids are not yet identified. Moreover, 70 G7 also shows relatively high homology to several other proteins (Table IB). Noteworthy, as indicated in table I, each protein sequence starts with GSSVVEF ( 5 amino acids of the pcDNA4/HisMax C vector (GSSVV) and 2 amino acids (EF) from the modulated EcoR 1 site). This may suggest that this short sequence is responsible for IL-6 cytokine production. However, this is not likely since many other clones starting with the same deduced amino acid sequence did not induce IL-6 nor IL-10 cytokine production.

Although initially regarded as a strength, starting off our functional screening with an expression library enriched for differentially expressed cDNAs might even have become a drawback of our study. One explanation for the identification of 
peptide mimetics might be the use of the relatively short SSH derived differentially expressed cDNA fragments (150 to $1500 \mathrm{bp}$, mean length $500 \mathrm{bp}$ ) as starting material. As an alternative, a full length cDNA library could be subjected to functional screening. However, even when using full length cDNAs there may be a selection for smaller cDNAs. This is encountered by the findings of Fiscella et al who transfected full length cDNAs (identified by a bioinformatics tool) into cells and added the conditioned media to $\mathrm{T}$-cells ${ }^{19}$. A positive clone encoding a membrane-anchored protein of at least 612 amino acids was found, which also showed no homology to any known protein.

In conclusion, we have shown proof of concept of our new functional genomics approach since known soluble mediators ( $\beta$-amyloid and TGF- $\beta 1$ ) produced by HEK293 cells induced inflammatory cytokine production by human macrophages. Furthermore, the combination of differential gene expression and functional genomics is a potent and effective screening approach to identify novel and functional soluble mediators (including cathepsin K and S, and 70G7) that induce inflammatory cytokine production by human macrophages. This approach could facilitate high-throughput functional screening of large expression libraries.

\section{REFERENCES}

1. Glass CK, Witztum JL. Atherosclerosis. the road ahead. Cell. Feb 23 2001;104(4): 503-516.

2. Lusis AJ. Atherosclerosis. Nature. Sep 14 2000;407(6801):233-241.

3. Ross R. Atherosclerosis-an inflammatory disease. N Engl J Med. Jan 14 1999;340(2): 115-126.

4. Virmani R, Kolodgie FD, Burke AP, Farb A, Schwartz SM. Lessons from sudden coronary death: a comprehensive morphological classification scheme for atherosclerotic lesions. Arterioscler Thromb Vasc Biol. May 2000;20(5):1262-1275.

5. Lutgens E, Cleutjens KB, Heeneman S, Koteliansky VE, Burkly LC, Daemen MJ. Both early and delayed anti-CD40L antibody treatment induces a stable plaque phenotype. Proc Natl Acad Sci U S A. Jun 20 2000;97(13):7464-7469.

6. Lutgens E, Daemen MJ. Transforming growth factor-beta: a local or systemic mediator of plaque stability? Circ Res. Nov 9 2001;89(10):853-855.

7. Lutgens E, Lutgens SP, Faber BC, Heeneman S, Gijbels MM, de Winther MP, Frederik P, van der Made I, Daugherty A, Sijbers AM, Fisher A, Long CJ, Saftig P, Black D, Daemen MJ, Cleutjens KB. Disruption of the cathepsin K gene reduces atherosclerosis progression and induces plaque fibrosis but accelerates macrophage foam cell formation. Circulation. Jan 3 2006;113(1):98-107. 
8. Mallat Z, Gojova A, Marchiol-Fournigault C, Esposito B, Kamate C, Merval R, Fradelizi D, Tedgui A. Inhibition of transforming growth factor-beta signaling accelerates atherosclerosis and induces an unstable plaque phenotype in mice. Circ Res. Nov 9 2001;89(10):930-934.

9. Schonbeck U, Sukhova GK, Shimizu K, Mach F, Libby P. Inhibition of CD40 signaling limits evolution of established atherosclerosis in mice. Proc Natl Acad Sci U S A. Jun 20 2000;97(13):7458-7463.

10. Tedgui A, Mallat Z. Cytokines in atherosclerosis: pathogenic and regulatory pathways. Physiol Rev. Apr 2006;86(2):515-581.

11. Young JL, Libby P, Schonbeck U. Cytokines in the pathogenesis of atherosclerosis. Thromb Haemost. Oct 2002;88(4):554-567.

12. Schieffer B, Selle T, Hilfiker A, Hilfiker-Kleiner D, Grote K, Tietge UJ, Trautwein C, Luchtefeld M, Schmittkamp C, Heeneman S, Daemen MJ, Drexler H. Impact of interleukin-6 on plaque development and morphology in experimental atherosclerosis. Circulation. Nov 30 2004;110(22):3493-3500.

13. Archacki SR, Angheloiu G, Tian XL, Tan FL, DiPaola N, Shen GQ, Moravec C, Ellis S, Topol EJ, Wang Q. Identification of new genes differentially expressed in coronary artery disease by expression profiling. Physiol Genomics. Sep 29 2003;15(1):65-74.

14. Tyson KL, Weissberg PL, Shanahan CM. Heterogeneity of gene expression in human atheroma unmasked using cDNA representational difference analysis. Physiol Genomics. 2002;9(2):121-130.

15. Hiltunen MO, Tuomisto TT, Niemi M, Brasen JH, Rissanen TT, Toronen P, Vajanto I, Yla-Herttuala S. Changes in gene expression in atherosclerotic plaques analyzed using DNA array. Atherosclerosis. Nov 2002;165(1):23-32.

16. Faber BC, Cleutjens KB, Niessen RL, Aarts PL, Boon W, Greenberg AS, Kitslaar PJ, Tordoir JH, Daemen MJ. Identification of genes potentially involved in rupture of human atherosclerotic plaques. Circ Res. Sep 14 2001;89(6):547-554.

17. Li QX, Robbins JM, Welch PJ, Wong-Staal F, Barber JR. A novel functional genomics approach identifies mTERT as a suppressor of fibroblast transformation. Nucleic Acids Res. Jul 1 2000;28(13):2605-2612.

18. Whitehead I, Kirk H, Kay R. Expression cloning of oncogenes by retroviral transfer of cDNA libraries. Mol Cell Biol. Feb 1995;15(2):704-710.

19. Fiscella M, Perry JW, Teng B, Bloom M, Zhang C, Leung K, Pukac L, Florence K, Concepcion A, Liu B, Meng Y, Chen C, Elgin EC, Kanakaraj P, Kaufmann TE, Porter J, Cibotti R, Mei Y, Zhou J, Chen G, Roschke V, Komatsoulis G, Mansfield B, Ruben S, Sanyal I, Migone TS. TIP, a T-cell factor identified using high-throughput screening increases survival in a graft-versus-host disease model. Nat Biotechnol. Mar 2003;21(3): 302-307.

20. Kitani A, Fuss I, Nakamura K, Kumaki F, Usui T, Strober W. Transforming growth factor (TGF)-beta1-producing regulatory $\mathrm{T}$ cells induce Smad-mediated interleukin 10 secretion that facilitates coordinated immunoregulatory activity and amelioration of TGF-beta1-mediated fibrosis. J Exp Med. Oct 20 2003;198(8):1179-1188.

21. Szczepanik AM, Rampe D, Ringheim GE. Amyloid-beta peptide fragments p3 and p4 induce pro-inflammatory cytokine and chemokine production in vitro and in vivo. $J$ Neurochem. Apr 2001;77(1):304-317. 
22. Schnolzer M, Alewood P, Jones A, Alewood D, Kent SB. In situ neutralization in Boc-chemistry solid phase peptide synthesis. Rapid, high yield assembly of difficult sequences. Int J Pept Protein Res. Sep-Oct 1992;40(3-4):180-193.

23. Sukhova GK, Zhang Y, Pan JH, Wada Y, Yamamoto T, Naito M, Kodama T, Tsimikas S, Witztum JL, Lu ML, Sakara Y, Chin MT, Libby P, Shi GP. Deficiency of cathepsin S reduces atherosclerosis in LDL receptor-deficient mice. J Clin Invest. Mar 2003;111(6): 897-906.

24. Yamamoto M, Wakatsuki T, Hada A, Ryo A. Use of serial analysis of gene expression (SAGE) technology. J Immunol Methods. Apr 2001;250(1-2):45-66.

25. de Vries CJ, van Achterberg TA, Horrevoets AJ, ten Cate JW, Pannekoek H. Differential display identification of 40 genes with altered expression in activated human smooth muscle cells. Local expression in atherosclerotic lesions of smags, smooth muscle activation-specific genes. J Biol Chem. Aug 4 2000;275(31):23939-23947.

26. Bijnens AP, Lutgens E, Ayoubi T, Kuiper J, Horrevoets AJ, Daemen MJ. Genome-wide expression studies of atherosclerosis: critical issues in methodology, analysis, interpretation of transcriptomics data. Arterioscler Thromb Vasc Biol. Jun 2006;26(6):1226-1235.

27. Lutgens SP, Kisters N, Lutgens E, van Haaften RI, Evelo CT, de Winther MP, Saftig P, Daemen MJ, Heeneman S, Cleutjens KB. Gene profiling of cathepsin K deficiency in atherogenesis: profibrotic but lipogenic. J Pathol. Nov 2006;210(3):334-343.

28. Williams JA, Pontzer CH, Shacter E. Regulation of macrophage interleukin-6 (IL-6) and IL-10 expression by prostaglandin E2: the role of p38 mitogen-activated protein kinase. J Interferon Cytokine Res. Mar 2000;20(3):291-298.

29. de Waal Malefyt R, Abrams J, Bennett B, Figdor CG, de Vries JE. Interleukin 10(IL-10) inhibits cytokine synthesis by human monocytes: an autoregulatory role of IL-10 produced by monocytes. J Exp Med. Nov 1 1991;174(5):1209-1220.

30. Dupret JM, Rodrigues-Lima F. Structure and regulation of the drug-metabolizing enzymes arylamine N-acetyltransferases. Curr Med Chem. 2005;12(3):311-318.

31. Morton LM, Schenk M, Hein DW, Davis S, Zahm SH, Cozen W, Cerhan JR, Hartge P, Welch R, Chanock SJ, Rothman N, Wang SS. Genetic variation in N-acetyltransferase 1 (NAT1) and 2 (NAT2) and risk of non-Hodgkin lymphoma. Pharmacogenet Genomics. Aug 2006;16(8):537-545.

32. Hein DW, Doll MA, Fretland AJ, Leff MA, Webb SJ, Xiao GH, Devanaboyina US, Nangju NA, Feng Y. Molecular genetics and epidemiology of the NAT1 and NAT2 acetylation polymorphisms. Cancer Epidemiol Biomarkers Prev. Jan 2000;9(1):29-42.

33. Gu J, Liang D, Wang Y, Lu C, Wu X. Effects of N-acetyl transferase 1 and 2 polymorphisms on bladder cancer risk in Caucasians. Mutat Res. Mar 7 2005;581(1-2): 97-104.

34. Garcia-Closas M, Malats N, Silverman D, Dosemeci M, Kogevinas M, Hein DW, Tardon A, Serra C, Carrato A, Garcia-Closas R, Lloreta J, Castano-Vinyals G, Yeager M, Welch R, Chanock S, Chatterjee N, Wacholder S, Samanic C, Tora M, Fernandez F, Real FX, Rothman N. NAT2 slow acetylation, GSTM1 null genotype, and risk of bladder cancer: results from the Spanish Bladder Cancer Study and meta-analyses. Lancet. Aug 20-26 2005;366(9486):649-659.

35. Lilla C, Verla-Tebit E, Risch A, Jager B, Hoffmeister M, Brenner H, Chang-Claude J. Effect of NAT1 and NAT2 genetic polymorphisms on colorectal cancer risk associated with exposure to tobacco smoke and meat consumption. Cancer Epidemiol Biomarkers Prev. Jan 2006;15(1):99-107. 


\section{Chapter 8 \\ General discussion}


Although the morphological differences between stable and ruptured atherosclerotic plaques are well described ${ }^{1}$, relatively little is known about the molecular mechanisms underlying this transition. The balance between inflammation and ECM deposition is considered to be a major factor for the maintenance of a stable plaque phenotype $\mathrm{e}^{2-4}$. By in vivo interventions in atherosclerotic mouse models, we and others have shown that individual extracellular matrix turnover and inflammator regulators such as TGF- $\beta 1$, cathepsin S, CD40L, IL-6 and -10 are able to modulate plaque fibrosis and inflammation status ${ }^{5-12}$. These in vivo intervention studies are examples of the single gene approach, in which the role of a candidate gene in the disease of interest is studied. An alternative for this candidate approach is the pathway approach which can provide insight into the molecular regulations underlying plaque progression. Figure 1 gives a schematic overview of several approaches to study plaque stabilization, including the candidate gene approach, candidate pathway approach, and the functional genomics approach.

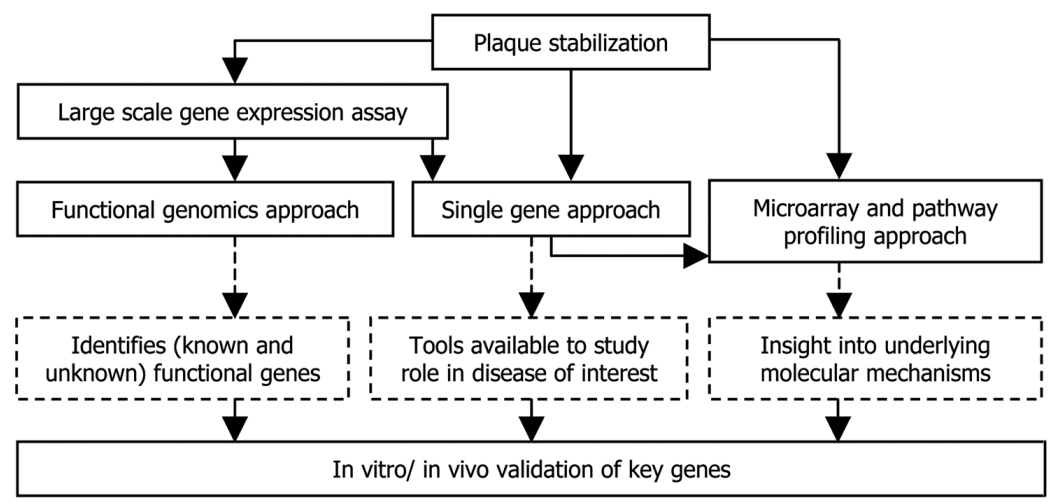

Figure 1. Schematic overview of several approaches to study plaque stabilization, including the most important advantages of these approaches.

\section{Candidate gene approach}

The decision to study a specific candidate gene for its role in atherosclerosis can be based on (1) the gene's involvement in other physiological or pathological processes, (2) the role of a family member of the concerning gene in either atherosclerosis or related physiological or pathological processes, or (3) the selection of this gene in a screening assay such as suppression subtractive hybridization (SSH) or microarray analysis. Our interest in cathepsin K originated from a large scale gene profiling study, in which cathepsin $\mathrm{K}$ was found to be highly upregulated in human advanced but stable atherosclerotic lesions when compared with lesions containing a thrombus ${ }^{13}$. Once a specific gene has been selected, several tools are 
available to study its role in the disease of interest, including (1) mRNA and protein expression studies in various organs, disease stages and species, (2) in vitro (intervention) studies using RNA interference, inhibiting antibodies, (ant)agonists, and knock-in and knock-out strategies, and (3) in vivo intervention studies using inhibitors, blocking antibodies, (ant)agonists, and transgenic, knock-in and knock-out animal models.

As illustrated in chapter 4 , a second round of microarray analysis in combination with pathway profiling was very useful to gain more insight into the molecular mechanisms by which the gene of interest, cathepsin $\mathrm{K}$, exerted its function. Microarray analysis of cathepsin K deficient atherosclerotic lesions showed differential expression of several genes and pathways, among which the anticipated identification of genes and pathways involved in the induction of fibrosis and aggravation of foam cell formation. In addition, differential expression of a set of genes related to cell death and apoptosis was identified (bcl2, bid, casp3, etc., chapter 4). This observation was in close agreement with earlier observations by Chen et al. who showed that cathepsin K deficient osteoclasts of mice on a $129 / \mathrm{Sv}$ background, but not on a C57Bl6 background, lacked normal apoptosis and senescence ${ }^{14}$. On a 129/Sv background, cathepsin K deficiency caused osteoclasts to re-enter the cell cycle, whereas forced expression of cathepsin $\mathrm{K}$ resulted in senescence.

In early atherosclerotic lesions, efficient phagocytic clearance of apoptotic cells by macrophages appears to be protective against atherosclerosis progression. In advanced (late) atherosclerotic lesions however, phagocytic clearance of apoptotic macrophages is defective, leading to secondary necrosis and a proinflammatory response, and contributing to plaque destabilization ${ }^{15}$. Assuming similar effects of cathepsin K deficiency in plaque macrophages as in osteoclasts and given the observation that cathepsin $\mathrm{K}$ levels are higher in advanced lesions, cathepsin $\mathrm{K}$ deficiency may reduce apoptosis and thereby promote plaque stability. Unfortunately, no data on a possible role of cathepsin $\mathrm{K}$ in phagocytic clearance are currently available.

Normally, cathepsins are located in the lysosomes. However, upon stimulation or cell damage, both cathepsin B and L were shown to be released to the cytoplasm leading to subsequent apoptosis ${ }^{16-18}$. Furthermore, inhibition of cathepsin L resulted in decreased caspase-3 activation ${ }^{19}$, while inhibition or deficiency of cathepsin S led to a decrease in interferon- $\gamma$ induced DNA injury and apoptosis in a murine pulmonary emphysema model ${ }^{20}$. Also these data show that cathepsin cysteine proteases, including cathepsin $\mathrm{K}$, may promote apoptosis, thereby reducing plaque stability. 


\section{Candidate pathway approach}

Microarray analysis and pathway profiling can be used to gain more insight into the molecular mechanisms by which a certain gene/pathway exerts its function. In addition, these techniques can also be used to find 'novel' pathways involved in atherogenesis. Bijnens et al. recently made an overview of gene expression profiling studies in both murine and human atherosclerosis ${ }^{21}$. The next paragraph briefly summarizes some of these studies.

Lutgens et al. used microarray analysis to study gene expression during atherosclerotic plaque progression in whole mount aortic arches of apoE-/mice $^{22}$. Time-related expression clustering and functional grouping of differentially expressed genes revealed upregulation of genes involved in inflammation and matrix degradation, generally considered as major factors for the maintenance of a stable plaque phenotype. King et al. used microarray analysis to study gene expression during atherosclerotic plaque progression in whole mount human lesions ${ }^{23}$. They found that early disease was characterized by increased expression of genes involved in smooth muscle cell (SMC) differentiation, regulation or activation, suggesting that loss of differentiated SMC gene expression is the primary expression signature of disease progression in atherosclerosis. In another set of experiments, cell-type specific gene expression profiles were compared. Dai et al. ${ }^{24}$ used microarray analysis to study specific gene expression of human endothelial cells (ECs) subjected to 'athero-prone' or 'athero-protective' shear-stress in vitro. ECs exposed to athero-prone shear-stress acquired a proinflammatory phenotype, expressing several important chemokine/chemokine receptors and elicited a dysregulation of the expression and organization of cytoskeletal and junctional proteins. Alternatively, the use of laser capture microdissection (LCM) enabled researchers to study gene expression of specific cell types during different stages of atherogenesis in vivo ${ }^{25}$. For example, using the LCM technique we found that the oxidative phosphorylation pathway was differentially regulated between macrophages derived from early lesions and advanced lesions ${ }^{26}$. Next to studying gene expression profiles of individual cells in different atherosclerotic plaque stages, gene expression profiling of subpopulations of a specific cell type can give insight into the phenotype of that cell type during plaque progression. To prevent variations in expression profiles between patients, Papaspyridonos et al. compared the gene expression profiles of stable (intact fibrous cap) and unstable (defined as a disrupted fibrous cap or surface thrombus or hemorrhage) segments of human carotid plaques in a single patient ${ }^{27}$. Matrix metalloproteinase 9 (MMP-9), cathepsin B, and legumain, a potent activator of MMPs and cathepsins, were found to be associated with plaque instability. Finally, using a comparable experimental set-up, gene expression profiles of atherosclerotic lesions located in different vascular beds may be compared. Such intra-patients 
comparisons may result in an enormous increase in statistical power. Thus, microarray analysis can be used to study atherogenesis from several perspectives, comparing whole mount, cell-type-specific, plaque component-specific, patient-specific and site-specific gene expression profiles. The use of microarray analysis to study cell-type-specific and site-specific gene expression profiles in atherosclerosis will be described and discussed in more detail in an upcoming thesis by colleague Kisters, entitled 'Heterogeneity in human atherosclerotic gene expression profiles: from man to macrophages'.

In conclusion, microarray analysis has been widely used to study the underlying mechanisms of atherosclerosis (reviewed $i^{21}$ ). A major advantage of the microarray analysis and subsequent pathway profiling approach is the fact that hundreds of differential expressed genes can be studied at once. Pathway profiling programs are available to convert these multiple data points into comprehensible information, providing insight into the molecular mechanisms of the disease of interest.

\section{Functional genomics approach}

As already mentioned in the preceding two paragraphs, the molecular mechanism underlying the transition of a stable atherosclerotic plaque to an unstable atherosclerotic plaque can be studied as a 'candidate gene approach' or as a 'candidate pathway approach'. In this thesis, the role of cathepsin $\mathrm{K}$ in atherosclerosis was studied in a candidate gene validation approach (chapter 3 ) and pathway analysis was used to further unravel the underlying regulatory mechanisms by which cathepsin Kled to the observed phenotypic changes (chapter 4). An alternative is a functional genomics approach in which differentially expressed genes between stable lesions and lesions containing a thrombus are subjected to a functional screen. The feasibility of such a functional screening approach was illustrated in chapter 7. Cathepsin K expression was shown to be highly upregulated in stable lesions when compared with lesions containing a thrombus and cathepsin $\mathrm{K}$ was shown to have a function in atherosclerotic plaque progression $\left({ }^{13}\right.$ and this thesis). Transfection of a full length cathepsin $\mathrm{K}$ expression plasmid into human cells stimulated these cells to produce soluble mediators in the supernatant which subsequently induced human macrophages to produce inflammatory cytokines. Also cathepsin S, which was also known to be an important regulator of plaque progression ${ }^{8,10,28}$, was able to evoke inflammatory cytokine production.

Several variations are applicable on the functional genomics approach as presented in chapter 7 . Firstly, a dysregulation of inflammation and matrix turnover is considered to be essential for the progression to a vulnerable plaque phenotype $^{2-4}$. In the functional screening assay presented in chapter 7 , we evaluated the effect of soluble mediators on inflammatory cytokine production by 


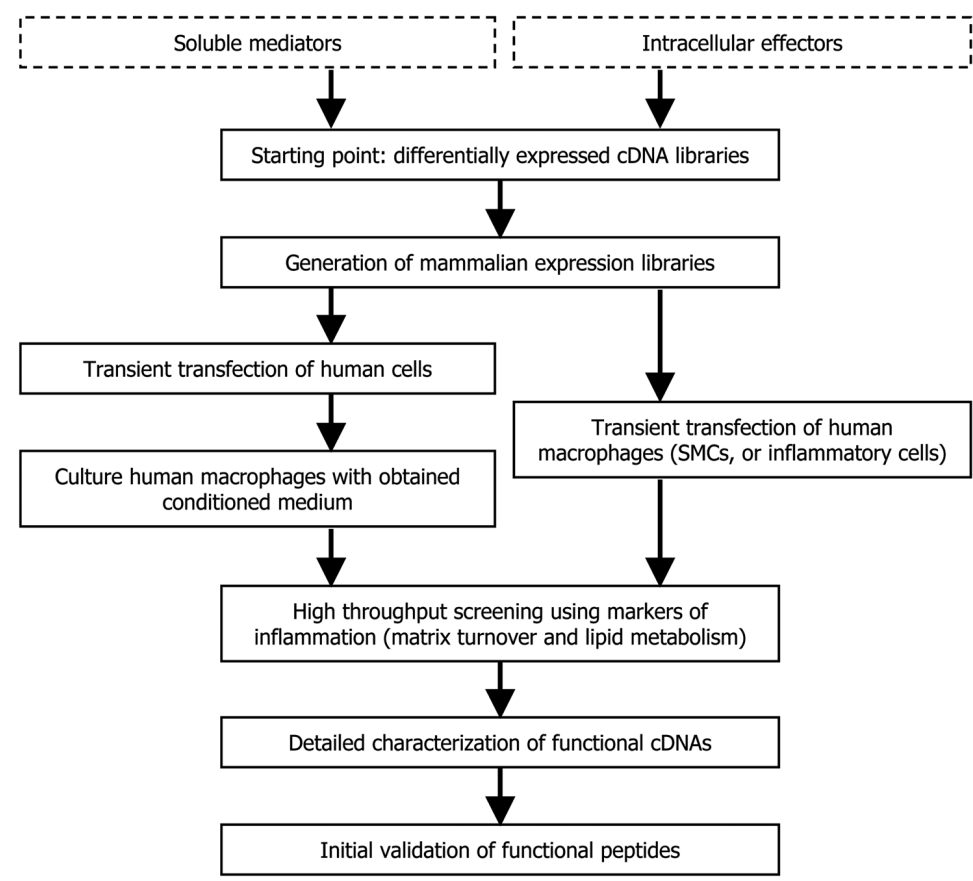

Figure 2. Functional genomics. On the left, the screening procedure for extracellular soluble mediators as performed in chapter 7 is depicted. On the right, the replacing steps of the screening procedure for intracellular effectors are shown.

human macrophages. Alternatively, these extracellular soluble mediators may also be evaluated for their effect on matrix degradation (gelatinase, collagenase, and elastase activity) and lipid metabolism. Secondly, although macrophages are considered to be an important cell type in plaque progression, other cell types, such as SMCs and inflammatory cells, can also be used to investigate the effect of soluble mediators on inflammation, matrix turnover, and lipid metabolism in atherosclerosis. Thirdly, in the functional screening approach as presented in this thesis. we studied the effect of extracellular soluble mediators on inflammatory cytokine production by human macrophages. Alternatively, the effect of intracellular effectors on inflammation and matrix turnover can be evaluated, by direct transfection of effector cells, such as macrophages, SMCs, and inflammatory cells (Figure 2). However, we were unsuccessful in transfecting human macrophages, since both primary macrophages and macrophage cell lines showed low transfection efficiencies and low cell viability when using non-viral transfection methods. Similar difficulties were reported by other laboratories ${ }^{29}$. 


\section{Cathepsin $(K)$ in relation to other protease activities}

Cathepsin K was first cloned from a rabbit osteoclast cDNA library and called $\mathrm{OC}-2^{30}$. Later the human equivalent was cloned and designated cathepsin $\mathrm{K}^{31}$. Deficiency of the human cathepsin $\mathrm{K}$ protein resulted in pycnodysostosis, an autosomal recessive osteochondrodysplasia characterized by osteosclerosis and short stature $^{32}$. Cathepsin K deficient mice showed an osteopetrotic phenotype with excessive trabeculation of the bone marrow space ${ }^{33}$, indicating that cathepsin $\mathrm{K}$ plays a major role in osteoclastic bone resorption. However, cathepsin K deficient mice continued to grow, suggesting that other proteases, such as MMPs, compensated for the loss of cathepsin $\mathrm{K}_{\text {activity }}{ }^{34}$. It was suggested that osteoclasts lower the $\mathrm{pH}$ in the resorption area after which the bone matrix was first digested by cysteine proteases. Secondly, digestion by MMPs followed at higher $\mathrm{pH}$ levels ${ }^{35}$. Site-specificity existed in relation to digestion of the bone matrix by osteoclasts, since osteoclastic resorption of calvarial bone (intramembranous bone) was dependent on both cysteine proteases and MMP activity, while long bone (endochondral bone) resorption was only dependent on cysteine protease activity $^{36}$. Others suggested that resorption of scapular bone (intramembranous bone) was more dependent on MMPs than cysteine proteases while resorption of long bone (endochondral bone) was more dependent on cysteine proteases than $\mathrm{MMPs}^{37}$. Recently, it was shown that calvarial osteoclasts use other cysteine proteases in addition to cathepsin $\mathrm{K}$ and that long bone osteoclasts use MMPs in the absence of cathepsin $\mathrm{K}^{38}$.

In atherosclerosis, or other cardiovascular diseases, neither a relation between the ECM degrading activity of cysteine proteases and MMPs nor a site-specificity has been described. Microarray analysis of cathepsin K deficient atherosclerotic lesions (chapter 4) did not show differences in expression of MMPs. Only TIMP-2 and ADAM-17 (a desintegrin and metalloproteinase) were found to be differentially expressed between apoE-/-/catK-/- and apoE-/- aortic arches. Thus, the relative contribution of cysteine proteases and MMPs to ECM degradation in atherosclerosis still remains to be elucidated.

\section{Diagnostic potential of cathepsin $K$}

In both oncology and atherosclerosis research, molecular and cellular imaging aims to visualize biological properties of the disease in vivo ${ }^{39-41}$. Visualization of the atherosclerotic plaque may help to detect high-risk plaques and could also attribute to evaluation of effectiveness of therapy ${ }^{41}$. Near infrared (NIR) smart probes are a class of imaging probes that change their physical properties after specific molecular interaction. These probes are optically silent in their quenched state and become highly fluorescent after enzyme-mediated release of fluorochromes, resulting in signal amplification. Interestingly, cathepsin B has 
been used as NIR smart probe. Several in vivo studies have shown the feasibility of the use of a smart probe of this protease in near infrared fluorescence (NIRF) imaging, such as in breast carcinoma ${ }^{42,43}$, lymph nodes ${ }^{44}$, (osteo-) $\operatorname{arthritis~}^{45,46}$, and lung carcinoma ${ }^{47}$. Recently, it was also shown that murine osteoclast activity could be measured in vivo using a cathepsin $\mathrm{K}$ activated near infrared imaging probe $^{48}$. Furthermore, using a cathepsin K-activatable NIRF imaging agent it was shown that cathepsin $\mathrm{K}$ enzyme activity could be imaged in ex vivo human (endarterectomy specimens) and in vivo apoE-/- atherosclerotic lesions ${ }^{49}$. The NIRF signal correlated with macrophages and SMCs expressing immunoreactive cathepsin $\mathrm{K}$. Based on these data, cathepsin $\mathrm{K}$ may be a promising imaging tool in atherosclerosis research.

Besides the use of a gene/protein with a potential role in atherosclerosis as an imaging tool, such genes/proteins may also have value as (circulating) biomarkers. During the past years several authors provided evidence for the diagnostic value of circulating biomarkers, including C-reactive protein (CRP), IL-6, oxidized low density lipoprotein, type II secretory phospholipase A2, MMPs and soluble CD40 ligand ${ }^{50}$. Although the levels of several of the above mentioned circulating markers were elevated in patients with unstable cardiovascular disease, they were at best moderate (odds ratio at max 4.2) predictors for future cardiovascular disease in individual patients and none could be recommended to physicians for routine clinical use. Even a set of 10 contemporary biomarkers (the multimarker approach), added only moderately to standard risk factors in assessing risk in individual persons ${ }^{51}$. These data indicated the limitations of the use of biomarkers as prognostic tool for the individual patient ${ }^{52}$, and the importance of evaluating new biomarkers to complement the existing ones. Cathepsins L and S were both found to be increased in serum of patients with significant stenosis in at least one of the coronary arteries when compared with patients without coronary stenosis ${ }^{53,54}$. These data indicate that cathepsins L and S may serve as useful serum biomarkers in the diagnosis of atherosclerosis. Although cathepsin $\mathrm{K}$ serum levels have been shown to serve as a marker for nontraumatic fractures and bone-mineral density ${ }^{55}$, there are no data available about cathepsin $\mathrm{K}$ serum levels in relation to cardiovascular disease.

\section{Therapeutic potential of cathepsin $K$}

Knowing the important role of cathepsin $\mathrm{K}$ in bone resorption, cathepsin inhibitors are considered promising therapeutic agents for the treatment of osteoporosis and arthritis and possibly atherosclerosis. The use of cathepsin $\mathrm{K}$ inhibitors should however be evaluated with care since genetic disruption of cathepsin K showed dual effects on matrix turnover and lipid metabolism. Although our data are still preliminary and the molecular mechanism are unclear, it seems to be possible to 
develop an inhibitor that only affects the fibrotic and not the lipogenic effects of cathepsin K. To date, two cathepsin K inhibiting compounds have enrolled clinical trials to study their effect on osteoporosis and/or osteoarthritis ${ }^{56,57}$. A phase II study of the cathepsin K inhibitor AAE581 for the treatment of osteoporosis was reported in 2003. Preliminary results suggested that the compound was well tolerated, inhibited bone resorption and improved bone formation. The chemical structure of the compound was not disclosed. In 2002, a phase I trial of SB-462795 (relacatib) for the treatment of postmenopausal osteoporosis and osteoarthritis was reported. Recently, it was shown that relacatib inhibited bone resorption in monkeys ${ }^{58,59}$. However until now, no data are available on the effect of either AAE581, SB-462795 (relacatib) or other cathepsin K inhibitors in animal or human atherosclerosis.

\section{Limitations of the study}

In chapter 3 we described differential gene expression levels of cathepsin $\mathrm{K}$ in human atherosclerosis and the effect of genetic disruption of cathepsin $\mathrm{K}$ on lesion development in apoE deficient mice. In chapter 4 we studied the underlying mechanisms by which cathepsin $\mathrm{K}$ deficiency led to the observed phenotypic changes. We found that deficiency of cathepsin $\mathrm{K}$ alters plaque phenotype not only by decreasing proteolytic activity, but also by stimulating TGF- $\beta$ signaling. Besides this profibrotic effect, cathepsin $\mathrm{K}$ deficiency has a lipogenic effect owing to increased lipid uptake mediated by CD36 and caveolins. In chapter 5, we assessed the role of a new cathepsin $\mathrm{K}$ inhibitor on ECM turnover and lipid metabolism and found that it was possible to isolate profibrotic effects of cathepsin $\mathrm{K}$ inhibition. However, a limitation of this chapter was that we could not evaluate the effect of this cathepsin $\mathrm{K}$ inhibitor in vivo, since this inhibitor had low biological availability due to immediate clearance by the kidneys.

The role of cathepsin K deficiency in aneurysm formation was assessed in chapter 6. Unexpectedly, deficiency of the collagenolytic protease cathepsin K in angiotensin II infused apoE-/ - mice did not reduce aneurysm formation This finding raised several hypotheses, which pointed to a central role for angiotensin II. Firstly, we hypothesized that angiotensin II induces MMP activity, which may overrule the protective effect of cathepsin K deficiency in aneurysm formation. Secondly, we hypothesized that angiotensin II may overrule the collagenolytic activity of cathepsin $\mathrm{K}$ in apoE-/- mice, thereby equalizing the collagen content in apoE-/- and catK-/-/apoE-/- aortas. Thirdly, angiotensin II may further increase the collagen content in cathepsin $\mathrm{K}$ deficient aortas, thereby increasing arterial stiffening. These hypotheses may imply that the angiotensin II infusion model is not the most appropriate model to study aneurysm formation in 


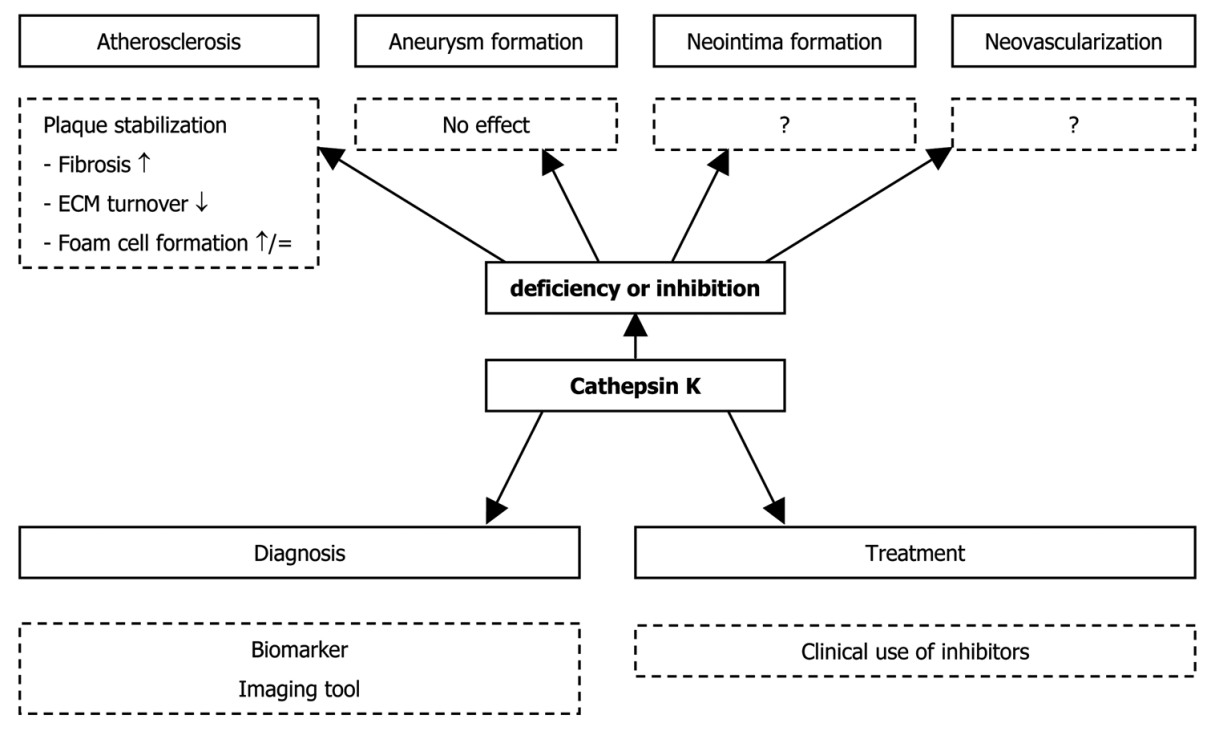

Figure 3. Summary of the effects (upper dashed boxes) of cathepsin K deficiency or inhibition on various cardiovascular diseases (upper closed boxes). The lower part represents future perspectives concerning cathepsin $\mathrm{K}$.

cathepsin $\mathrm{K}$ deficient mice. However, the current data and number of animals are insufficient to test these hypotheses. Using zymography experiments, the exact role of angiotensin II induced MMP activity in cathepsin $\mathrm{K}$ deficient mice can be defined. Additionally, to circumvent the possible effect of angiotensin II induced collagen synthesis, other chemically induced models are available to study aneurysm formation, including intraluminal infusion of elastase and periaortic incubations of calcium chloride ${ }^{60}$.

In chapter 7 , we showed proof of concept of our new functional genomics approach. Both known ( $\beta$-amyloid and TGF- $\beta 1$ ) and unknown (70G7) soluble mediators produced by HEK293 cells induced inflammatory cytokine production by human macrophages. A limitation of this high-throughput functional genomics screening procedure was the fact that none of the identified peptides was in frame with the natural protein transcribed from the corresponding cDNA insert. Expanding the functional screen, either with the current SSH library or a full length cDNA library, may lead to the identification of additional candidates with a role in inflammation and extracellular matrix turnover. This may eventually lead to the identification of candidates which can be examined for their clinical relevance as imaging-tool or biomarker. 


\section{Concluding remarks and future perspectives}

This thesis provided important insights into the role of cathepsin $\mathrm{K}$ in cardiovascular diseases, including atherosclerosis and aneurysm formation and further revealed a new functional genomics approach to identify novel and soluble regulators of inflammation, a key process in atherosclerosis. However, the role of cathepsin $\mathrm{K}$ in other cardiovascular diseases like neointima formation and neovascularization still needs to be determined. As described in chapter 2, increased expression patterns of cathepsins $\mathrm{K}$ and $\mathrm{S}$ during neointima formation in animal models and the increased ECM degrading potential of cathepsin S suggest that these proteases are involved in neointima formation ${ }^{61,62}$. However, we can only speculate on their exact role since in vivo studies are still lacking. Based on the sequence and functional homology between cathepsin K and S, we hypothesize that deficiency of cathepsin K reduces degradation of the ECM, thereby decreasing the migration and invasion of SMCs and macrophages which prevents arterial remodeling and subsequent neointima formation and restenosis. In chapter 3 and 4 we evaluated the effect of cathepsin K deficiency in an in vivo atherosclerotic mouse model and showed a role for cathepsin $\mathrm{K}$ in fibrosis and lipid metabolism. In chapter 5, the effect of pharmacologic cathepsin K inhibition was evaluated on ECM turnover and lipid metabolism. We found that it is possible to isolate profibrotic effects of cathepsin K inhibition. From these 3 chapters we concluded that cathepsin $\mathrm{K}$ inhibitors may also be useful for treatment of atherosclerosis. However, before entering clinical trials these cathepsin K inhibitors need to be tested in animal models for their effectiveness and safety in the treatment of atherosclerosis. As mentioned earlier in this chapter, two cathepsin $\mathrm{K}$ inhibiting compounds have already entered clinical trials for evaluation in the treatment of osteoporosis and osteoarthritis, but not in atherosclerosis related diseases.

In conclusion, as summarized in figure 3, this thesis provides interesting new insights in the role of cathepsin $\mathrm{K}$ in atherosclerosis. Genetic disruption of cathepsin $\mathrm{K}$ reduces lesion progression, induces plaque fibrosis, but aggravates macrophage foam cell formation. Detailed expression profiling suggested that cathepsin K deficiency alters plaque phenotype not only by decresing proteolytic activity but also by stimulating TGF- $\beta$ signaling. Cathepsin $\mathrm{K}$ deficiency also has a lipogenic effect due to increased lipid uptake mediated by CD36 and caveolins. Furthermore, it was shown that the profibrotic and lipogenic effects of cathepsin $\mathrm{K}$ inhibition are two different entities and that it is possible to specifically target one of these functions. However, further research is needed to address if cathepsins, including cathepsin $\mathrm{K}$, may function as possible biomarkers or imaging tools. A potent biomarker should not only be able to predict plaque 
destabilization, rupture and clinical complications in longitudinal studies, but also has to be able to predict risks for the individual patient.

\section{REFERENCES}

1. Virmani R, Kolodgie FD, Burke AP, Farb A, Schwartz SM. Lessons from sudden coronary death: a comprehensive morphological classification scheme for atherosclerotic lesions. Arterioscler Thromb Vasc Biol. May 2000;20(5):1262-1275.

2. Glass CK, Witztum JL. Atherosclerosis. the road ahead. Cell. Feb 23 2001;104(4):503516.

3. Lusis AJ. Atherosclerosis. Nature. Sep 14 2000;407(6801):233-241.

4. Ross R. Atherosclerosis-an inflammatory disease. N Engl J Med. Jan 14 1999;340(2): 115-126.

5. Lutgens E, Cleutjens KB, Heeneman S, Koteliansky VE, Burkly LC, Daemen MJ. Both early and delayed anti-CD40L antibody treatment induces a stable plaque phenotype. Proc Natl Acad Sci U S A. Jun 20 2000;97(13):7464-7469.

6. Lutgens E, Daemen MJ. Transforming growth factor-beta: a local or systemic mediator of plaque stability? Circ Res. Nov 9 2001;89(10):853-855.

7. Mallat Z, Gojova A, Marchiol-Fournigault C, Esposito B, Kamate C, Merval R, Fradelizi D, Tedgui A. Inhibition of transforming growth factor-beta signaling accelerates atherosclerosis and induces an unstable plaque phenotype in mice. Circ Res. Nov 9 2001;89(10):930-934.

8. Rodgers KJ, Watkins DJ, Miller AL, Chan PY, Karanam S, Brissette WH, Long CJ, Jackson CL. Destabilizing role of cathepsin $\mathrm{S}$ in murine atherosclerotic plaques. Arterioscler Thromb Vasc Biol. Apr 2006;26(4):851-856.

9. Schonbeck U, Sukhova GK, Shimizu K, Mach F, Libby P. Inhibition of CD40 signaling limits evolution of established atherosclerosis in mice. Proc Natl Acad Sci U S A. Jun 20 2000;97(13):7458-7463.

10. Sukhova GK, Zhang Y, Pan JH, Wada Y, Yamamoto T, Naito M, Kodama T, Tsimikas S, Witztum JL, Lu ML, Sakara Y, Chin MT, Libby P, Shi GP. Deficiency of cathepsin S reduces atherosclerosis in LDL receptor-deficient mice. J Clin Invest. Mar 2003;111(6): 897-906.

11. Tedgui A, Mallat Z. Cytokines in atherosclerosis: pathogenic and regulatory pathways. Physiol Rev. Apr 2006;86(2):515-581.

12. Young JL, Libby P, Schonbeck U. Cytokines in the pathogenesis of atherosclerosis. Thromb Haemost. Oct 2002;88(4):554-567.

13. Faber BC, Cleutjens KB, Niessen RL, Aarts PL, Boon W, Greenberg AS, Kitslaar PJ, Tordoir JH, Daemen MJ. Identification of genes potentially involved in rupture of human atherosclerotic plaques. Circ Res. Sep 14 2001;89(6):547-554.

14. Chen W, Yang S, Abe Y, Li M, Wang Y, Shao J, Li E, Li YP. Novel pycnodysostosis mouse model uncovers cathepsin $\mathrm{K}$ function as a potential regulator of osteoclast apoptosis and senescence. Hum Mol Genet. Jan 82007.

15. Tabas I. Consequences and therapeutic implications of macrophage apoptosis in atherosclerosis: the importance of lesion stage and phagocytic efficiency. Arterioscler Thromb Vasc Biol. Nov 2005;25(11):2255-2264. 
16. Chwieralski CE, Welte T, Buhling F. Cathepsin-regulated apoptosis. Apoptosis. Feb 2006;11(2):143-149.

17. Li W, Dalen H, Eaton JW, Yuan XM. Apoptotic death of inflammatory cells in human atheroma. Arterioscler Thromb Vasc Biol. Jul 2001;21(7):1124-1130.

18. Li W, Yuan XM. Increased expression and translocation of lysosomal cathepsins contribute to macrophage apoptosis in atherogenesis. Ann N Y Acad Sci. Dec 2004;1030: 427-433.

19. Ishisaka R, Utsumi T, Kanno T, Arita K, Katunuma N, Akiyama J, Utsumi K. Participation of a cathepsin L-type protease in the activation of caspase-3. Cell Struct Funct. Dec 1999;24(6):465-470.

20. Zheng T, Kang MJ, Crothers K, Zhu Z, Liu W, Lee CG, Rabach LA, Chapman HA, Homer RJ, Aldous D, De Sanctis GT, Underwood S, Graupe M, Flavell RA, Schmidt JA, Elias JA. Role of cathepsin S-dependent epithelial cell apoptosis in IFN-gamma-induced alveolar remodeling and pulmonary emphysema. J Immunol. Jun 15 2005;174(12):8106-8115.

21. Bijnens AP, Lutgens E, Ayoubi T, KuiperJ, Horrevoets AJ, Daemen MJ. Genome-wide expression studies of atherosclerosis: critical issues in methodology, analysis, interpretation of transcriptomics data. Arterioscler Thromb Vasc Biol. Jun 2006;26(6):1226-1235.

22. Lutgens E, Faber B, Schapira K, Evelo CT, van Haaften R, Heeneman S, Cleutjens KB, Bijnens AP, Beckers L, Porter JG, Mackay CR, Rennert P, Bailly V, Jarpe M, Dolinski B, Koteliansky V, de Fougerolles T, Daemen MJ. Gene profiling in atherosclerosis reveals a key role for small inducible cytokines: validation using a novel monocyte chemoattractant protein monoclonal antibody. Circulation. Jun 28 2005;111(25):34433452.

23. King JY, Ferrara R, Tabibiazar R, Spin JM, Chen MM, Kuchinsky A, Vailaya A, Kincaid R, Tsalenko A, Deng DX, Connolly A, Zhang P, Yang E, Watt C, Yakhini Z, Ben-Dor A, Adler A, Bruhn L, Tsao P, Quertermous T, Ashley EA. Pathway analysis of coronary atherosclerosis. Physiol Genomics. Sep 21 2005;23(1):103-118.

24. Dai G, Kaazempur-Mofrad MR, Natarajan S, Zhang Y, Vaughn S, Blackman BR, Kamm RD, Garcia-Cardena G, Gimbrone MA, Jr. Distinct endothelial phenotypes evoked by arterial waveforms derived from atherosclerosis-susceptible and -resistant regions of human vasculature. Proc Natl Acad Sci U S A. Oct 12 2004;101(41):1487114876.

25. Trogan E, Choudhury RP, Dansky HM, RongJX, Breslow JL, Fisher EA. Laser capture microdissection analysis of gene expression in macrophages from atherosclerotic lesions of apolipoprotein E-deficient mice. Proc Natl Acad Sci U S A. Feb 19 2002;99(4):22342239.

26. Kisters N, Faessen M, Fledderus JO, Volger OL, Cleutjens KBJM, Daemen MJAP, Bijnens APJJ. The oxidative phosphorylation pathway is differentially regulated between macrophages microdissected from early and advanced lesions. Supplement to Journal of Vascular Research. September 2005 2005;42(S2).

27. Papaspyridonos M, Smith A, Burnand KG, Taylor P, Padayachee S, Suckling KE, James $\mathrm{CH}$, Greaves DR, Patel L. Novel candidate genes in unstable areas of human atherosclerotic plaques. Arterioscler Thromb Vasc Biol. Aug 2006;26(8):1837-1844.

28. Sukhova GK, Shi GP, Simon DI, Chapman HA, Libby P. Expression of the elastolytic cathepsins $\mathrm{S}$ and $\mathrm{K}$ in human atheroma and regulation of their production in smooth muscle cells. J Clin Invest. Aug 1 1998;102(3):576-583. 
29. Heider H, Verca SB, Rusconi S, Asmis R. Comparison oflipid-mediated and adenoviral gene transfer in human monocyte-derived macrophages and COS-7 cells. Biotechniques. Feb 2000;28(2):260-265, 268-270.

30. Tezuka K, Tezuka Y, Maejima A, Sato T, Nemoto K, Kamioka H, Hakeda Y, Kumegawa M. Molecular cloning of a possible cysteine proteinase predominantly expressed in osteoclasts. J Biol Chem. Jan 14 1994;269(2):1106-1109.

31. Inaoka $\mathrm{T}$, Bilbe $\mathrm{G}$, Ishibashi $\mathrm{O}$, Tezuka K, Kumegawa M, Kokubo T. Molecular cloning of human cDNA for cathepsin K: novel cysteine proteinase predominantly expressed in bone. Biochem Biophys Res Commun. Jan 5 1995;206(1):89-96.

32. Gelb BD, Shi GP, Chapman HA, Desnick RJ. Pycnodysostosis, a lysosomal disease caused by cathepsin K deficiency. Science. Aug 30 1996;273(5279):1236-1238.

33. Saftig P, Hunziker E, Wehmeyer O, Jones S, Boyde A, Rommerskirch W, Moritz JD, Schu P, von Figura K. Impaired osteoclastic bone resorption leads to osteopetrosis in cathepsin-K-deficient mice. Proc Natl Acad Sci U S A. Nov 10 1998;95(23):1345313458

34. Okaji M, Sakai H, Sakai E, Shibata M, Hashimoto F, Kobayashi Y, Yoshida N, Okamoto $\mathrm{K}$, Yamamoto K, Kato Y. The regulation of bone resorption in tooth formation and eruption processes in mouse alveolar crest devoid of cathepsin k. J Pharmacol Sci. Apr 2003;91(4):285-294.

35. Everts V, Delaisse JM, Korper W, Beertsen W. Cysteine proteinases and matrix metalloproteinases play distinct roles in the subosteoclastic resorption zone.J Bone Miner Res. Sep 1998;13(9):1420-1430.

36. Everts V, Korper W, Jansen DC, Steinfort J, Lammerse I, Heera S, Docherty AJ, Beertsen W. Functional heterogeneity of osteoclasts: matrix metalloproteinases participate in osteoclastic resorption of calvarial bone but not in resorption of long bone. FasebJ. Jul 1999;13(10):1219-1230.

37. Shorey S, Heersche JN, Manolson MF. The relative contribution of cysteine proteinases and matrix metalloproteinases to the resorption process in osteoclasts derived from long bone and scapula. Bone. Oct 2004;35(4):909-917.

38. Everts V, Korper W, Hoeben KA, Jansen ID, Bromme D, Cleutjens KB, Heeneman S, Peters C, Reinheckel T, Saftig P, Beertsen W. Osteoclastic bone degradation and the role of different cysteine proteinases and matrix metalloproteinases: differences between calvaria and long bone. J Bone Miner Res. Sep 2006;21(9):1399-1408.

39. Mahmood U, Weissleder R. Near-infrared optical imaging of proteases in cancer. Mol Cancer Ther. May 2003;2(5):489-496.

40. Weissleder R. Molecular imaging in cancer. Science. May 26 2006;312(5777):11681171

41. Jaffer FA, Libby P, Weissleder R. Molecular and cellular imaging of atherosclerosis: emerging applications. J Am Coll Cardiol. Apr 4 2006;47(7):1328-1338.

42. Bremer C, Tung CH, Bogdanov A, Jr., Weissleder R. Imaging of differential protease expression in breast cancers for detection of aggressive tumor phenotypes. Radiology. Mar 2002;222(3):814-818.

43. Mahmood U, Tung CH, Bogdanov A, Jr., Weissleder R. Near-infrared optical imaging of protease activity for tumor detection. Radiology. Dec 1999;213(3):866-870.

44. Wunderbaldinger P, Turetschek K, Bremer C. Near-infrared fluorescence imaging of lymph nodes using a new enzyme sensing activatable macromolecular optical probe. Eur Radiol. Sep 2003;13(9):2206-2211. 
45. Lai WF, Chang CH, Tang Y, Bronson R, Tung CH. Early diagnosis of osteoarthritis using cathepsin B sensitive near-infrared fluorescent probes. Osteoarthritis Cartilage. Mar 2004;12(3):239-244.

46. Wunder A, Tung CH, Muller-Ladner U, Weissleder R, Mahmood U. In vivo imaging of protease activity in arthritis: a novel approach for monitoring treatment response. Arthritis Rheum. Aug 2004;50(8):2459-2465.

47. Figueiredo JL, Alencar H, Weissleder R, Mahmood U. Near infrared thoracoscopy of tumoral protease activity for improved detection of peripheral lung cancer. Int J Cancer. Jun 1 2006;118(11):2672-2677.

48. Kozloff KM, Quinti L, Tung C, Weissleder R, Mahmood U. Non-invasive imaging of osteoclast activity via near-infrared cathepsin-K activatable optical probe. J Musculoskelet Neuronal Interact. Oct-Dec 2006;6(4):353.

49. Kim D, Jaffer FA, Quinti L, Tung CH, Aikawa E, Libby P, Weissleder R. Imaging of cathepsin $\mathrm{K}$ activity in atherosclerosis using a protease-activatable near infrared fluorescence agent. Supplement to Circulation. October 252005 2005;112(17):II-206.

50. Koenig W, Khuseyinova N. Biomarkers of atherosclerotic plaque instability and rupture. Arterioscler Thromb Vasc Biol. Jan 2007;27(1):15-26.

51. Wang TJ, Gona P, Larson MG, Tofler GH, Levy D, Newton-Cheh C, Jacques PF, Rifai N, Selhub J, Robins SJ, Benjamin EJ, D’Agostino RB, Vasan RS. Multiple biomarkers for the prediction of first major cardiovascular events and death. N Engl J Med. Dec 21 2006;355(25):2631-2639.

52. Ware JH. The limitations of risk factors as prognostic tools. N Engl J Med. Dec 21 2006;355(25):2615-2617.

53. Liu J, Ma L, YangJ, Ren A, Sun Z, Yan G, Sun J, Fu H, Xu W, Hu C, Shi GP. Increased serum cathepsin $\mathrm{S}$ in patients with atherosclerosis and diabetes. Atherosclerosis. Jun 2006;186(2):411-419.

54. Liu J, Sukhova GK, YangJT, Sun J, Ma L, Ren A, Xu WH, Fu H, Dolganov GM, Hu C, Libby P, Shi GP. Cathepsin L expression and regulation in human abdominal aortic aneurysm, atherosclerosis, and vascular cells. Atherosclerosis. Feb 2006;184(2):302-311.

55. Holzer G, Noske H, Lang T, Holzer L, Willinger U. Soluble cathepsin K: a novel marker for the prediction of nontraumatic fractures? J Lab Clin Med. Jul 2005;146(1):13-17.

56. Abbenante G, Fairlie DP. Protease inhibitors in the clinic. Med Chem. Jan 2005;1(1): 71-104.

57. Yasuda Y, Kaleta J, Bromme D. The role of cathepsins in osteoporosis and arthritis: rationale for the design of new therapeutics. Adv Drug Deliv Rev. May 25 2005;57(7):973993.

58. Kumar S, Dare L, Vasko-Moser JA, James IE, Blake SM, Rickard DJ, Hwang SM, Tomaszek T, Yamashita DS, Marquis RW, Oh H, JeongJU, Veber DF, Gowen M, Lark MW, Stroup G. A highly potent inhibitor of cathepsin K (relacatib) reduces biomarkers of bone resorption both in vitro and in an acute model of elevated bone turnover in vivo in monkeys. Bone. Jan 2007;40(1):122-131.

59. Yamashita DS, Marquis RW, Xie R, Nidamarthy SD, Oh HJ, Jeong JU, Erhard KF, Ward KW, Roethke TJ, Smith BR, Cheng HY, Geng X, Lin F, Offen PH, Wang B, Nevins N, Head MS, Haltiwanger RC, Narducci Sarjeant AA, Liable-Sands LM, Zhao B, Smith WW, Janson CA, Gao E, Tomaszek T, McQueney M, James IE, Gress CJ, Zembryki DL, Lark MW, Veber DF. Structure activity relationships of 5-, 6-, and 
7-methyl-substituted azepan-3-one cathepsin K inhibitors. J Med Chem. Mar 9 2006;49(5):1597-1612.

60. Daugherty A, Cassis LA. Mouse models of abdominal aortic aneurysms. Arterioscler Thromb Vasc Biol. Mar 2004;24(3):429-434.

61. Burns-Kurtis CL, Olzinski AR, Needle S, Fox JH, Capper EA, Kelly FM, McQueney MS, Romanic AM. Cathepsin S expression is up-regulated following balloon angioplasty in the hypercholesterolemic rabbit. Cardiovasc Res. Jun 1 2004;62(3):610620.

62. Cheng XW, Kuzuya M, Sasaki T, Arakawa K, Kanda S, Sumi D, Koike T, Maeda K, Tamaya-Mori N, Shi GP, Saito N, Iguchi A. Increased expression of elastolytic cysteine proteases, cathepsins $\mathrm{S}$ and $\mathrm{K}$, in the neointima of balloon-injured rat carotid arteries. $\mathrm{Am}$ J Pathol. Jan 2004;164(1):243-251. 


\section{Summary}

In Western society, cardiovascular diseases, such as myocardial infarction, stroke, and peripheral artery disease, are the principal cause of death. The underlying cause of these cardiovascular diseases is atherosclerosis. The early stages of atherosclerotic lesions, which do not cause clinical problems, usually arise during the first decennia of life. More advanced, but stable lesions, may cause clinical manifestations, such as angina pectoris. Most serious life-threatening complications arise when a stable lesion becomes unstable and ruptures. Exposure of lesion components to the blood causes thrombus formation, which may completely occlude the blood stream. Occlusion of the coronary arteries may result in myocardial infarction and occlusion of cerebral arteries may result in stroke. The exact mechanisms by which a stable plaque becomes unstable and ruptures are largely unknown. However, extracellular matrix remodeling is known to play a role in plaque stabilization and is affected by several proteases, including cathepsins.

In this thesis, we showed that the cysteine protease cathepsin $\mathrm{K}$ is differentially expressed between stable lesions and lesions containing a thrombus. Furthermore, by genetic deficiency and inhibiton, we investigated the role of cathepsin $\mathrm{K}$ in two cardiovascular diseases, atherosclerosis and aneurysm formation. In addition, we used a functional genomics approach to identify new genes/peptides that play a role in atherosclerotic plaque (de)stabilization.

The role of various cysteine proteases (cathepsins) in cardiovascular diseases has been summarized in chapter 2 . Although the in vivo role of both cathepsins $\mathrm{K}$ and $\mathrm{S}$ in atherosclerosis has been extensively described, little is known about the in vivo role of other cathepsins of the cysteine protease family. Until now, no data are available about the in vivo role of cathepsins in aneurysm and neointima formation. However, given the expression patterns of cathepsins in diseased arteries, cathepsins may also play an important role in aneurysm and neointima formation. Cathepsins also play a role in the lipid metabolism, for example by degradation of lipids.

The effect of cathepsin K (deficiency) on atherosclerosis has been described in chapters 3 and 4 . In vivo, deficiency of cathepsin $\mathrm{K}$ led to a reduction in the number of atherosclerotic lesions, a reduction in lesion size, more collagen and 
less elastin breaks, all characteristics of plaque stabilization. However, deficiency of cathepsin $\mathrm{K}$ also resulted in increased macrophage size in the atherosclerotic lesion. In vitro experiments showed that this increased macrophage size resulted from increased lipid uptake and increased cholesterol ester storage in cathepsin $\mathrm{K}$ deficient macrophages, leading to macrophage foam cell formation (chapter 3). To further unravel the molecular mechanisms underlying the observed phenotypic changes evoked by cathepsin K deficiency, we performed gene expression profiling of aortic arches of catK-/-/apoE-/- and apoE-/- mice on a mouse oligo microarray. Microarray analysis suggested a role for CD36 and caveolins in the lipid metabolism. In vitro validation experiments confirmed that both CD36 and caveolins contributed to foam cell formation in cathepsin K deficient macrophages. Furthermore, the microarray analysis suggested that cathepsin $\mathrm{K}$ deficiency not only alters plaque phenotype by reducing proteolytic activity, but also by increasing TGF- $\beta$ signaling (chapter 4 ).

There is increasing interest of pharmaceutical industries for the use of cathepsin $\mathrm{K}$ inhibitors for the treatment of osteoporosis and osteoarthritis. These cathepsin $\mathrm{K}$ inhibitors may also be useful in the treatment of atherosclerosis. In chapter 5 we studied the in vitro effect of a cathepsin $\mathrm{K}$ inhibitor on both extracellular matrix degradation and lipid metabolism in murine and human macrophages. The cathepsin $\mathrm{K}$ inhibitor reduced degradation of the extracellular matrix components collagen I and IV and elastin by recombinant murine and human cathepsin $\mathrm{K}$ and in cell lysates of murine macrophages. Pharmacological inhibition of cathepsin $\mathrm{K}$ had no effect on lipid metabolism, including lipid uptake and cholesterol efflux in murine macrophages. However, absence of cathepsin $\mathrm{K}$ led to increased lipid uptake (chapter 3) and reduced cholesterol efflux (chapter 5) in murine macrophages. Thus, the profibrotic and lipogenic effects of cathepsin $\mathrm{K}$ inhibition can be separated.

In chapter 6, we described the in vivo effect of cathepsin K deficiency on angiotensin II-induced aneurysm formation. Despite the absence of a protease with strong collagenolytic and elastolytic activity, deficiency of cathepsin K did not result in an increase in angiotensin II-induced aneurysm formation. Additional research to clarify why cathepsin $\mathrm{K}$ deficiency did not reduce aneurysm formation in this in vivo model is needed.

An important characteristic of the current techniques to study differentially expressed genes, is the lack of a functional assay early in the selection of candidates. In chapter 7 , we introduced a new functional genomics approach to identify genes that are involved in inflammation, one of the key factors in plaque stabiliza- 
tion. This screening approach led to the identification of several candidates which were further validated in vitro, including 70G7. This approach showed that combining differential gene expression and functional genomics is a potent and effective screening approach to identify novel and functional soluble mediators that induce inflammatory cytokine production by human macrophages. This approach could facilitate high-throughput functional screening of large expression libraries.

In chapter 8 the findings of the five experimental chapters are discussed. Various approaches to study differential gene expression between stable and ruptured atherosclerotic plaques are placed into perspective: the candidate gene approach, the candidate pathway approach, and the functional genomics approach. Besides, the role of cathepsins is compared with the role of MMPs concerning their protease activity. Finally, the use of cathepsins as a therapeutic target and as a diagnostic tool is discussed.

From the studies described in this thesis, we concluded that deficiency of cathepsin $\mathrm{K}$ induced atherosclerotic plaque stabilization, but also contributed to plaque destabilization by inducing foam cell formation. It was possible to reduce collagenolytic and elastolytic activity of macrophages by pharmacological inhibition of cathepsin K, without affecting the lipid metabolism. Furthermore, we showed that cathepsin $\mathrm{K}$ deficiency did not lead to an increase in angiotensin II-induced aneurysm formation. Finally, we introduced a new approach to facilitate high throughput functional screening of large expression libraries. 


\section{Samenvatting}

In de Westerse wereld zijn hart- en vaatziekten (cardiovasculaire aandoeningen), zoals hartinfarct, herseninfarct en perifeer arterieel vaatlijden, de belangrijkste oorzaak van overlijden. De onderliggende oorzaak van deze hart- en vaatziekten is atherosclerose. De vroege stadia van atherosclerotische laesies (plaques), die overigens geen klinische verschijnselen veroorzaken, ontstaan gewoonlijk gedurende de eerste decennia van het leven. De meer gevorderde (stabiele) laesies kunnen wel klachten zoals pijn op de borst veroorzaken. Het merendeel van de klinische complicaties ontstaat echter als een laesie onstabiel wordt en openscheurt (ruptuur). Door blootstelling van de inhoud van een opengescheurde laesie aan het bloed, ontstaat een bloedprop (trombus) die een bloedvat volledig kan afsluiten. Afsluiting van een kransslagader kan leiden tot een hartinfarct, terwijl afsluiting van een bloedvat in de hersenen kan leiden tot een herseninfarct. De precieze mechanismen die ertoe leiden dat een stabiele laesie onstabiel wordt zijn grotendeels onbekend. Echter, de betrokkenheid van verscheidene proteases, inclusief cathepsines, in de afbraak van extracellulaire matrix componenten is uitgebreid beschreven.

In dit proefschrift hebben we laten zien dat het cysteine protease cathepsine $\mathrm{K}$ differentieel tot expressie komt tussen stabiele laesies en laesies met een thrombus. Ook hebben we, door middel van genetische deficiëntie en inhibitie, de rol van cathepsine $\mathrm{K}$ in twee cardiovasculaire andoeningen, atherosclerose en aneurysma vorming, onderzocht. Daarnaast hebben we een functionele screeningsmethode gebruikt om nieuwe genen/peptiden, die mogelijk een rol spelen in atherosclerotische plaque (de)stabilisatie, te identificeren.

De rol van verschillende cysteine proteases (cathepsines) in cardiovasculaire aandoeningen is beschreven in hoofdstuk 2 . Hoewel de in vivo rol van cathepsine $\mathrm{K} \mathrm{en} \mathrm{S} \mathrm{in} \mathrm{atherosclerose} \mathrm{uitgebreid} \mathrm{is} \mathrm{beschreven,} \mathrm{is} \mathrm{er} \mathrm{nog} \mathrm{weinig} \mathrm{bekend} \mathrm{over} \mathrm{de}$ in vivo rol van de overige cathepsines van de cysteine protease familie. Ook over de mogelijke betrokkenheid van cathepsines in aneurysma en neointima vorming zijn geen in vivo data bekend. Maar gezien hun expressie patronen in de aangedane vaten zouden cathepsines ook in deze aandoeningen een rol kunnen spelen. Naast een rol in extracellulaire matrix degradatie, spelen cathepsines ook een rol in het vetmetabolisme, onder andere door degradatie van lipiden. 
In de hoofdstukken 3 en 4 is het effect bestudeerd van cathepsine $\mathrm{K}$ deficiëntie op atherosclerose. In vivo heeft deficiëntie van cathepsine $\mathrm{K}$ enerzijds geleid tot een kleiner aantal atherosclerotische laesies, kleinere laesies, meer collageen en minder elastine breuken, allen kenmerken van plaque stabilisatie. Anderzijds heeft cathepsine $\mathrm{K}$ deficiëntie tot grotere macrofagen in de atherosclerotische laesies geleid. In vitro experimenten hebben laten zien dat deze toegenomen macrofaag grootte het gevolg is van toegenomen vetopname en toegenomen cholesterol ester opslag in cathepsine $\mathrm{K}$ deficiënte macrofagen (hoofdstuk 3). Om de onderliggende mechanismen verder te bestuderen, hebben we de gen expressie profielen van aortabogen van catK-/-/apoE-/- en apoE-/- muizen vergeleken met behulp van een microarray analyse. De gevonden expressie profielen onthulden een mogelijke rol voor CD36 en caveolines. In vitro validatie experimenten hebben vervolgens de bijdrage van CD36 en caveolines aan schuimcel vorming in cathepsine $\mathrm{K}$ deficiënte macrofagen bevestigd. Daarnaast suggereerden de expressie profielen dat cathepsine $\mathrm{K}$ deficiëntie niet alleen via een vermindering van de aanwezige proteolytische activiteit, maar ook als gevolg van stimulering van TGF- $\beta$ signaal transductie tot een stabiel plaque fenotype zou kunnen leiden (hoofdstuk 4).

In de farmaceutische industrie is er een toenemende interesse voor het gebruik van cathepsine K remmers voor de behandeling van osteoporose en osteoartritis. Deze cathepsine K remmers kunnen mogelijk ook gebruikt kunnen worden voor de behandeling van atherosclerose. In hoofdstuk 5 hebben we het in vitro effect van een cathepsine K remmer op extracellulaire matrix degradatie en het vetmetabolisme in muizen beenmerg macrofagen en humane macrofagen bestudeerd. Toevoeging van deze cathepsine $\mathrm{K}$ remmer resulteerde in verlaagde afbraak van de extracellulaire matrix componenten collageen I, IV en elastine door recombinant muis en humaan cathepsine $\mathrm{K}$ en in cellulaire lysaten van muizen macrofagen. Farmacologische inhibitie van cathepsine $\mathrm{K}$ had echter geen effect op het vetmetabolisme voor zover dat vetopname en cholesterol efflux in muizen macrofagen betrof. Deficiëntie van cathepsine K heeft wel geleid tot meer vetopname (hoofdstuk 3) en minder cholesterol efflux (hoofdstuk 5) in muizen macrofagen. De effecten van cathepsine $\mathrm{K}$ op de extracellulaire matrix en het vetmetabolisme kunnen dus losgekoppeld worden.

In hoofdstuk 6 hebben we het in vivo effect van cathepsine K deficiëntie op angiotensine II geïnduceerde aneurysma vorming beschreven. Ondanks de afwezigheid van een protease met sterke collagenase en elastase activiteit, heeft cathepsine $\mathrm{K}$ deficiëntie niet tot een toename in angiotensine II geïnduceerde aneurysma vorming geleid. Verder onderzoek is nodig om aan te tonen waarom deficiëntie 
van cathepsine $\mathrm{K}$ niet leidt tot verminderde aneurysma vorming in dit in vivo model.

Een belangrijk kenmerk van de huidige technieken om differentiële genen te bestuderen, is het gebrek aan een vroege screening naar de functie van de betreffende genen. In hoofdstuk 7 hebben we een methode beschreven waarbij differentiële genen, gedefinieerd als genen die verhoogd tot expressie komen in de stabiele laesie, al in een vroege fase op functie geselecteerd kunnen worden. De differentiële genen zijn gescreend op een functie in inflammatie (ontsteking), een belangrijke factor in plaque stabilisatie. Deze nieuwe screeningsmethode heeft geleid tot de identificatie en in vitro validatie van enkele kandidaten, waaronder peptide 70G7. Onze proefopzet heeft dan ook laten zien dat het combineren van een differentiële gen expressie studie en het onderzoek naar de functie van genen een effectieve manier is om nieuwe en functionele genen, die humane macrofagen aanzetten tot de productie van inflammatoire cytokines, te identificeren. Deze benadering kan de functionale screening van grote expressiebanken vergemakkelijken.

In hoofdstuk 8 hebben we de bevindingen uit de vijf experimentele hoofdstukken in een breder perspectief geplaatst. De verschillende methodes om genen die differentieel tot expressie komen tussen stabiele laesies en laesies met een thrombus nader te bestuderen zijn hier bediscussieerd: de kandidaat gen benadering, de kandidaat genexpressie benadering, en de benadering waarin onderzoek gedaan wordt naar de functie van genen. Daarnaast hebben we in dit hoofdstuk de rol van de cathepsines met betrekking tot hun protease activiteit vergeleken met de rol van MMP's. Tenslotte is hier ook het gebruik van cathepsines voor therapeutische doeleinden en als diagnostische marker geëvalueerd.

De studies zoals beschreven in dit proefschrift hebben aangetoond dat deficiëntie van cathepsine $\mathrm{K}$ enerzijds bijdraagt aan atherosclerotische plaque stabilisatie door middel van toegenomen fibrose, maar anderzijds ook leidt tot plaque destabilisatie als gevolg van toegenomen macrofaag grootte. Verder blijkt het mogelijke om, door middel van farmacologische inhibitie van cathepsine $\mathrm{K}$, collageen en elastine afbraak door macrofagen te remmen, zonder daarbij het vetmetabolisme te beïnvloeden. Daarnaast hebben we aangetoond dat cathepsine K deficiëntie niet leidt tot een toename in angiotensine II geïnduceerde aneurysma vorming. Tot slot hebben we een nieuwe methode geïntroduceerd om grote differentiële expressie banken op een snelle manier functioneel te screenen. 


\section{Dankwoord}

Promotor, Mat Daemen. Mat, dat 'schizofrene plannetje' om geneeskunde met onderzoek te combineren, heeft dus toch zijn vruchten afgeworpen. Tijdens het combineren van geneeskunde en onderzoek heeft $u$ me ervan overtuigd dat ik geneeskunde prioriteit kon geven boven het onderzoek in tijd van nood. Ik heb dat als een prettige geruststelling ervaren. De meest plezierige werkbesprekingen vond ik die van het laatste jaar. Grote knopen zijn doorgehakt en het proefschrift is met rappe schreden afgerond! Ook zal ik uw bijdrage aan het verkrijgen van de opleidingsplaats aan de overzijde van het ziekenhuis niet vergeten.

Co-promotoren, Kitty Cleutjens en Sylvia Heeneman. Graag wil ik jullie bedanken voor jullie grote bijdrage aan dit proefschrift. Kitty, vanaf het begin van het onderzoek is je enthousiasme aanstekelijk geweest voor menigeen en zeker voor mij! Dat enthousiasme gecombineerd met jouw doorzettingsvermogen en kennis maakt van jou een geweldige co-promotor. Sylvia, al staat het hele lab op zijn kop, jij bent de rots in de branding! Daar waar ik struikelde over ideeën, proeven en artikelen, wist jij mij weer met beide benen terug op de grond te zetten. Jij als evenwichtige factor maakt het promotieteam compleet. Kitty en Sylvia, bedankt dat ik altijd bij jullie terecht kon.

Analist en rechterhand, Mat Rousch. Mat, toen ik begon heb je me wegwijs gemaakt op het lab, tijdens de afgelopen jaren hebben we veel proeven samen gedaan, en op het laatst van het proefschrift is je bijdrage nog steeds onmisbaar, bedankt! Ik heb je gevraagd om paranimf te zijn tijdens mijn promotie en ik weet zeker dat je ook die taak vol overgave en enthousiasme zult vervullen.

Collega-AIO's, de cardio-kippen, Linda, Marjo, Natasja, Judith en Kitty. Linda, bij jou kan ik altijd terecht. Bedankt voor je uitgebreide hulp bij de muizenexperimenten! Marjo, na je promotie in 2005 hebben we nog even van je mogen leren als postdoc. Ik heb je boekje regelmatig als naslagwerk gebruikt. Een aantal jaren geleden zijn we ongeveer tegelijk als AIO begonnen: Natasja, Judith, Kitty en ik. Hoewel we zelf wel eens gedacht hebben dat ons AIO-leven niet altijd over rozen is gegaan, mag het eindresultaat er zeker wezen. Natasja, je bent bijna klaar, je zit nu als postdoc in Brussel en spreekt al bijna vloeiend Frans. Judith, ook bijna klaar 
en al een postdoc functie in een vooraanstaand atherosclerose lab in New York in het vooruitzicht. Kitty, jij hebt gewoon niet te veel gezeurd en je gaat van ons vieren dan ook als eerste promoveren in september. Dames, heel veel succes met jullie verdere carrières en bedankt voor de leuke tijd. De nieuwe lichting AIO's, Lili, Dirk en Wouter zijn inmiddels volop met hun onderzoek bezig, veel succes verder.

Pathologie: Anique, Ine, Coby, Petra A, Anouk, Erwin, Ruben, Barry, Moniek, Wendy, Monique, Jeffrey en Chantal, bedankt voor jullie hulp op het lab: het vele snijwerk, jullie technische ondersteuning en de prettige samenwerking. Anique, bedankt dat een extra kleuring of extra snijwerk nooit te veel was. Barry, bedankt voor je hulp op het lab met de Western blots en de efflux experimenten en natuurlijk voor je geduld met betrekking tot het 'eigenwijze' karakter van de computers. Birgit, Cherida, Esther, Ann-Pascale, Wanwisa, Veronica en Petra E, bedankt voor jullie antwoorden op vele vragen. Birgit, mijn proefschrift is een vervolg op dat van jou. Ik heb jouw proefschrift dankbaar als leidraad gebruikt. Esther, fantastisch wat jij allemaal presteert. Ik ben trots dat ik van je heb kunnen leren en met je heb kunnen samenwerken. Elly en Cor, bedankt voor de administratieve en financiële ondersteuning. Ik voel me altijd welkom als ik weer eens voor het een of ander bij jullie binnenstorm. Jack, bedankt voor je hulp bij het 'quantimetten'. Edith, bedankt voor je hulp in de celkweek. Robert-Jan bedankt voor al je gezwets in de wandelgangen en je begeleiding bij de keuzestage van geneeskunde. Els, Freek, Jolanda en Andrea, jullie hebben me tijdens mijn afstudeerstage van gezondheidswetenschappen wegwijs gemaakt op het lab, bedankt.

Moleculaire genetica: Menno, Inge en Mathijs, bedankt voor jullie hulp bij de beenmerg macrofaag experimenten. Marion, bedankt voor je kritische blik op de muizencoupes. Populatiegenetica: Rob, bedankt dat ik van je faciliteiten gebruik heb mogen maken. Vooral de nanodrop heeft me een hoop werk bespaard. Cardiologie: Nicole, bedankt dat je altijd voor me klaar stond om te helpen met de muizen. Je hebt veel geduld met me gehad. Farmacologie: Ben en Jacques: bedankt dat ik van jullie muizenlab faciliteit gebruik heb mogen maken. Biochemie: Tilman, bedankt voor de synthese van de peptiden. Marc, Wim (Biochemie) en Jos (Moleculaire celbiologie), hoewel de 2-photon en confocale microscopie experimenten niet in dit proefschrift opgenomen zijn, wil ik jullie graag voor jullie hulp bedanken. Electronenmicroscopie: Peter Frederik en Hans, bedankt voor jullie hulp bij de elektronenmicroscopie experimenten. Bioinformatica: Rachel en Chris, bedankt voor jullie hulp bij het analyseren van de array. Het is een mooi artikel geworden. Radiologie: Marc en Robbert-Jan, veel succes met jullie proefschriften. Centrale proefdiervoorziening (CPV): Paulien, Allard, Nadine en Rik, bedankt voor de uitstekende verzorging van 
mijn dieren! Medische microbiologie: Prof. Bruggeman en dr. van Tiel, bedankt dat jullie mij de mogelijkheid gegeven hebben om het proefschrift tijdens de opleiding af te ronden.

Organon: Anneke Sijbers, Dianne Delsing, Paul Vink en Andrea van Elsas, bedankt voor de prettige samenwerking. Met jullie hulp hebben we de THP-1 kweek en de cholesterol efflux proef op de rails kunnen zetten.

Vriendinnen van geneeskunde ('G.G. De Geraniums'), ofwel Reggy, Quirine, Lieke, Esther, Marieke, Ewka, Annelieke en Linda, bedankt voor jullie hulp bij geneeskunde en interesse in mijn onderzoek. Ik wens jullie heel veel succes met jullie carrières, jullie worden een paar geweldige medisch specialisten! Reggy, zonder jouw hulp zou het afronden van geneeskunde toch echt een stukje zwaarder zijn geweest. Ook jou heb ik gevraagd om paranimf te zijn. Ik weet zeker dat met jou erbij alles tot in de puntjes geregeld zal zijn. Vriendinnen die naast het onderzoek en de opleiding ook belangrijk voor me zijn, zijn Judith, Mirjam, Debby en Roos. Nu kunnen jullie lezen waarmee ik me de laatste jaren bezig heb gehouden. Ouders van Ewald, en Richard en Tamara, bedankt voor jullie interesse en luisterend oor.

Frank, wat jij kunt, kan ik ook ... zo ongeveer dan. Papa en mama, bedankt voor jullie steun en stimulans tijdens mijn opleidingen. Ik vind het prettig om met jullie te praten over mijn onderzoek, mijn opleiding en mijn wensen voor de toekomst. Ook de komende jaren zal ik vaak terug naar huis komen om daar met jullie over te kletsen of om gewoon lekker te kunnen klooien en ontspannen. Tot slot, waar die AIO-cursussen al niet goed voor zijn . . . Ewald, als het even tegen zit, vrolijk je me op. Als het goed gaat, geniet je met me mee. We hebben het héérlijk samen, dankjewel! 



\section{Curriculum Vitae}

\section{SUZANNE LUTGENS}

27 December 1979 Born in Sittard, the Netherlands

\section{Education}

$1992-1998$

$1998-1999$

$1999-2002$

$2000-2001$

$2001-2004$

$2004-2006$

2006 - present
VWO (Gymnasium), College Sittard, the Netherlands Propaedeuse Health Sciences, University of Maastricht, the Netherlands

Doctoral phase (MSc) Health Sciences, University of Maastricht, the Netherlands, Cum Laude Propaedeuse Medicine, University of Maastricht, the Netherlands Doctoral phase (MSc) Medicine, University of Maastricht, the Netherlands, Cum Laude Internships (MD), University of Maastricht, the Netherlands, Cum Laude Specialization Medical Microbiology, Department of Medical Microbiology, Academic Hospital Maastricht, the Netherlands

\section{Research}

$2002-2006$
PhD student, Department of Pathology (CARIM), University of Maastricht, the Netherlands

\section{Full articles}

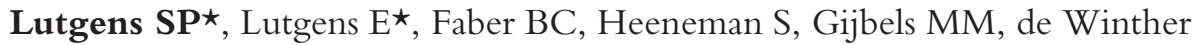
MP, Frederik P, van der Made I, Daugherty A, Sijbers AM, Fisher A, Long CJ, Saftig P, Black D, Daemen MJ, Cleutjens KB. Disruption of the cathepsin K gene reduces atherosclerosis progression and induces plaque fibrosis but accelerates 
macrophage foam cell formation. Circulation. 2006 Jan 3;113(1):98-107. * Both authors have contributed equally.

Lutgens SPM, Kisters N, Lutgens E, van Haaften RIM, Evelo CTA, de Winther MPJ, Saftig P, Daemen MJAP, Heeneman S, Cleutjens KBJM. Gene profiling of cathepsin $\mathrm{K}$ deficiency in atherogenesis: profibrotic but lipogenic. J Pathol. Nov 2006; 210(3):334-343.

Lutgens SPM, Cleutjens KBJM, Daemen MJAP, Heeneman S. Cathepsin cysteine proteases in cardiovascular disease. Faseb J. May 232007.

Lutgens SPM, Heeneman S, Rousch MJ, Lutgens E, van Elsas A, Sijbers AM, Hackeng TM, Daemen MJAP, Cleutjens KBJM. A new functional genomics approach to identify soluble mediators of atherosclerotic plaque stabilization (Submitted).

Lutgens SPM, Dumont EAWJ, Beckers L, Daemen MJAP, Cleutjens KBJM, Heeneman S. Cathepsin K gene disruption does not affect murine aneurysm formation (In preparation).

Lutgens SPM, Rousch MJ, Jutten B, Delsing DJ, Long CJ, Fisher A, Black D, Saftig P, Daemen MJAP, Heeneman S, Cleutjens KBJM. Pharmacologic inhibition of cathepsin K: extracellular matrix degrading effects do not coincide with lipogenic effects (In preparation).

\section{Awards}

Merit Award for Young Investigators. American Heart Association Council on Arteriosclerosis, Thrombosis, and Vascular Biology. AHA Scientific Sessions 2005.

Scientific Sessions Poster Competition: Basic Science Award. "The Two Faces of Cathepsin K Deficiency in Atherogenesis: Profibrotic, but Lipogenic." AHA Scientific Sessions 2005. 